\title{
Exploring Worker Consciousness in China
}

\author{
Elly Leung \\ B.A. Sociology (Honours) \\ B.A. Internet Studies (Politics and Cultures)
}

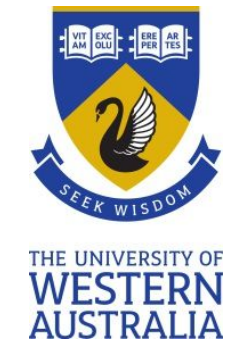

This thesis is presented for the degree of Doctor of Philosophy of The University of Western Australia

Management and Organisation Division, Business School

Employment Relations

2018 


\section{THESIS DECLARATION}

I, Elly Leung, certify that:

This thesis has been substantially accomplished during enrolment in the degree.

This thesis does not contain material which has been accepted for the award of any other degree or diploma in my name, in any university or other tertiary institution.

No part of this work will, in the future, be used in a submission in my name, for any other degree or diploma in any university or other tertiary institution without the prior approval of The University of Western Australia and where applicable, any partner institution responsible for the joint-award of this degree.

This thesis does not contain any material previously published or written by another person, except where due reference has been made in the text.

The work(s) are not in any way a violation or infringement of any copyright, trademark, patent, or other rights whatsoever of any person.

The research involving human data reported in this thesis was assessed and approved by The University of Western Australia Human Research Ethics Committee. Approval \#: RA/4/1/4952

The research involving animal data reported in this thesis was assessed and approved by The University of Western Australia Animal Ethics Committee. Approval \#: N/A

The following approvals were obtained prior to commencing the relevant work described in this thesis: Approval \#: RA/4/1/4952

This thesis contains published work and/or work prepared for publication, some of which has been co-authored.

Signature:

Date: 23 May, 2018 


\section{Abstract}

The aim of this thesis is to explore how the lived experiences of everyday Chinese workers influence their struggle to improve their working conditions. Using a narrative methodology, the thesis draws upon original interviews combined with participant-observation of workers who have engaged in worker actions $(n=21)$ such as work stoppages, as well as those that have not engaged in such actions $(n=53)$. The interview data were gathered through fieldwork conducted in multiple locations in China: Shenzhen City, Haizhu, Foshan, and Panyu Districts (Guangzhou Province), Hefei City (Anhui Province), and Hangzhou City (Zhejiang Province). Drawing on Foucault's power-knowledge framework, the thesis argues that because the consciousness of everyday Chinese workers remains at an embryonic level, their ability to campaign and change their working conditions remains constrained. The focus adopted in this thesis is justified by the explosion of China into a 'world factory', and a world export leader, following the open market reforms of 1978 (Leung \& Pun 2009), and the subsequent conversion of millions of Chinese peasants into urban industrial and service workers in order to support this transformation (Leung \& Pun 2009; Pun, Chan \& Chan 2009; Pun \& Lu 2010; Pun \& Lu 2010b; Schucher 2011). The thesis makes the following contributions: first, by applying Foucault's genealogical method to examine how worker consciousness has been shaped by power-knowledge relations in China, the thesis provides a unique interpretation of the significance of key historical events in shaping worker consciousness; second, the thesis uses an ethnographic-narrative research method that draws on original interviews with ordinary workers in different industries to unmask how these industries have affected their lives and opportunities; third, the thesis assesses the potential for organised labour movement among Chinese workers, and considers the significance of this for the future of Chinese society. In generating a greater appreciation of the diversity and dynamism of Chinese workers, the thesis subsequently offers a different perspective for considering the substance of worker consciousness and identity formation, and the potential of the working class of developing themselves into an organised labour movement in China. 


\section{Contents}

Chapter One: Introduction

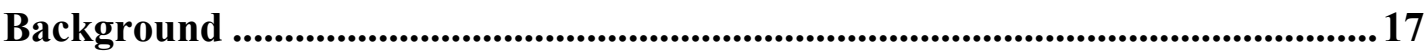

Research Focus............................................................................................................. 17

Research Questions .....................................................................................................................2 21

The Marxian Theories on Worker Consciousness and Organised Labour Movement 21

Understanding the Chinese Working Class and Activist Culture in China .......24

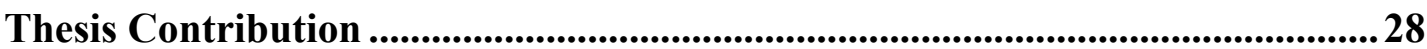

Research Propositions .........................................................................................30

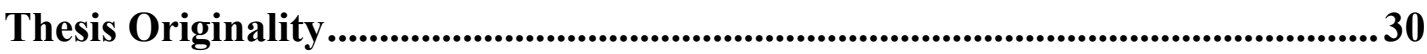

Thesis Overview ..............................................................................................................31

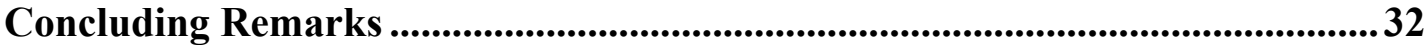

Chapter Two: Working with Foucault: Governmentality and the Government of Self

Foucault, Power-Knowledge and Governmentality..............................................36

'Problematization' .............................................................................................................38

Problematizing the Historical objects of Thought .................................................39

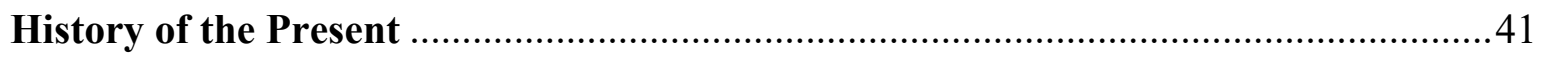

Genealogy: The History of the Present ........................................................................... 42

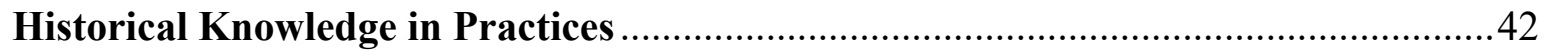

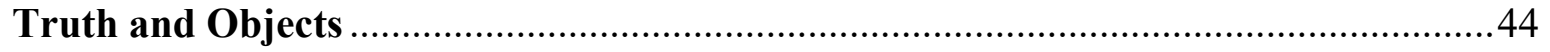

Power, Knowledge and Truth ......................................................................................44

'Normalisation' and Examination ........................................................................................4 47

Subjectivation and Re-subjectivation .................................................................49

Concluding Remarks ....................................................................................55

Chapter Three: Docile Bodies and Minds: A Genealogy of Chinese Workers in China

Li Rules and Confucianism ............................................................................57

The Confucian 'Mandate of Heaven' ..........................................................................60

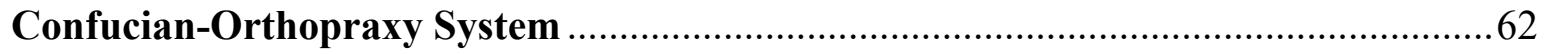


The "Demise" of Confucianism after 1949 .....................................................63

Thought Control and Revolution under Mao Zedong ........................................65

Living and Working under Post-Mao Leadership...................................................... 72

Chinese Legal System and Social Stability .............................................................78

The Discourse of weiwen 維穩, xiaokang 小康 and hexie shehui 和諧社會 .........80

Thought Work in Post-Mao Period......................................................................83

Chinese Habits of Making Docile Bodies and Minds within Social Hierarchy .. 85

The Destiny (ming 命) of Low-Quality (or Low-educated) Workers in the Chinese Occupational Hierarchy ....................................................................................................91

Concluding Remarks ...............................................................................................93

Chapter Four: Debates on Class and Class Consciousness Development in China SOE Worker Protests in Early Reformed China................................................97

Maintenance of Social Stability (weiwen) through the Weak enforcement of Laws and Weak Positions of Workers' Organisations .99

The Continual Rise in SOE Worker Protests under Legal Rights Protection (Weiquan) Discourse 102

Dagong 打工 Experiences among Peasant Workers in FIEs 107

Open Protests by Peasant Workers 109

Accumulated Dagong Experiences and the 'Forming' of a Class-for-itself.... .110

Problems with Class Analysis in China 113

Concluding Remarks 120

Chapter Five: Ethnonarratives of Workers in China

Foucault and Ethnographic Practice 123

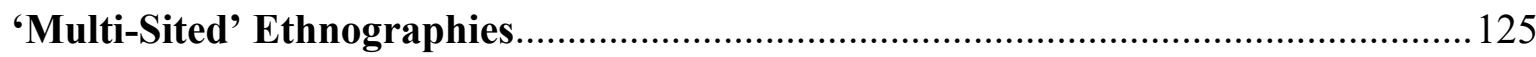

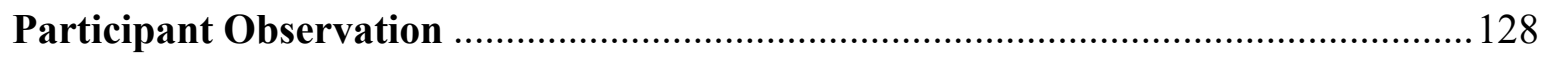

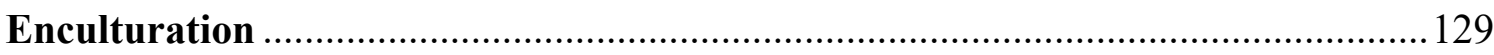

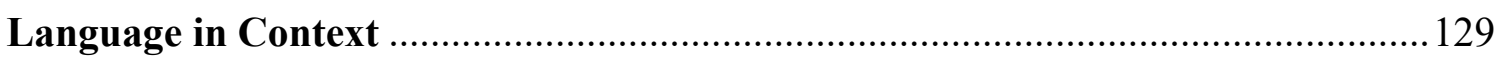

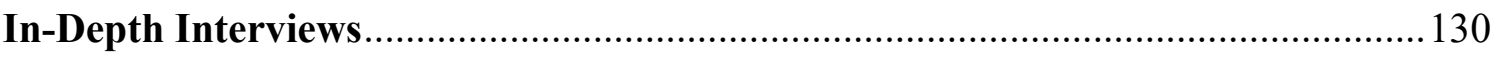

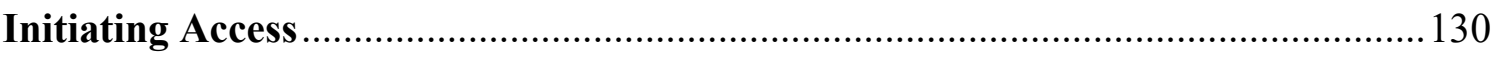

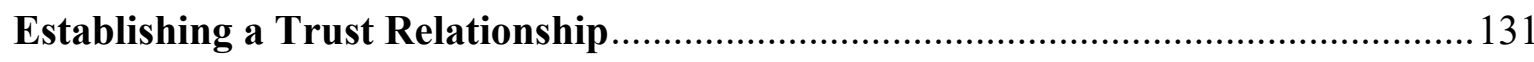


Constraining Access

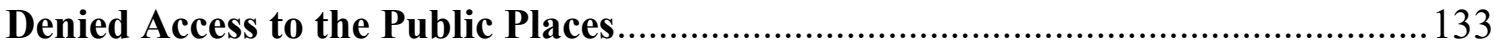

Life on the Street: 'Guerrilla Street Interview' Technique ................................... 135

Research Processes in Hefei ...........................................................................137

Research Process in Hangzhou .................................................................................. 140

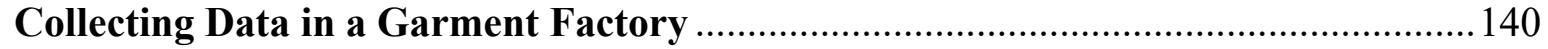

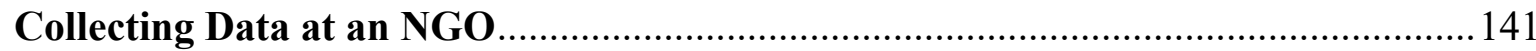

Research Sample ....................................................................................................................... 142

Documenting and Transcribing Data ................................................................. 143

Different Ways of Seeing: Narrative and Discourse Analysis ...........................144

Reliability and Validity.................................................................................................... 147

Ethical Considerations....................................................................................................... 149

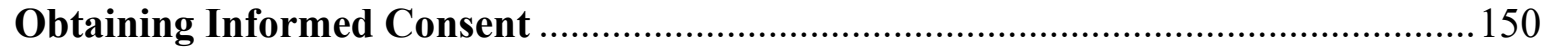

An Alternative Method: Verbal Consent and Practical Issues ...............................151

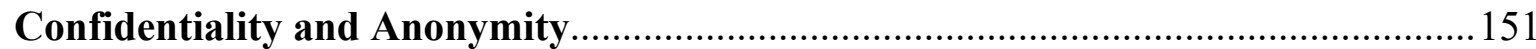

Concluding Remarks .............................................................................................. 152

Chapter Six: Automatic Docility in Market Socialism

The Desire to Escape Poverty (tuopin 脫貧) ...........................................................154

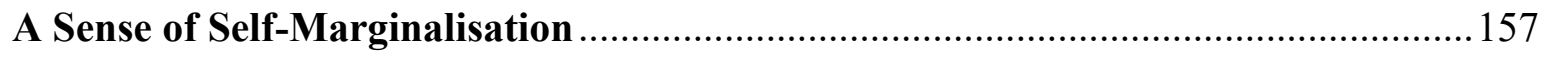

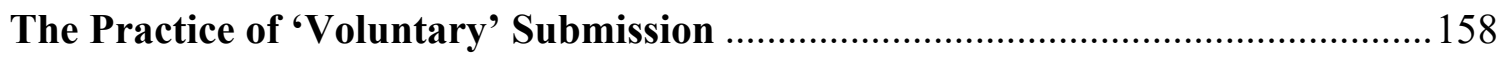

The Destiny of 'Low-Quality' Workers ...................................................................... 160

'Positive' Punishments and Doctrine of Similarity ....................................................... 163

The Disciplinary Techniques of Normalisation ..................................................... 164

'Normalising' the 'True-Selves'..............................................................................166

The 'Selves' and the Everyday 'Carceral Network' ............................................169

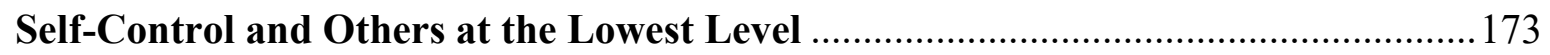

The Other as Self-Responsibility ....................................................................175

Concluding Remarks .....................................................................................177 
Chapter Seven: 'Beyond' the Selves and Reflective Docility

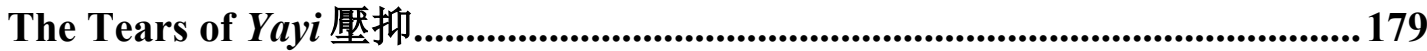

Cultural Activities and Yayi-based Solidarity ...............................................187

Nationalistic Sentiments and the 'Truth' of Yayi Lives....................................... 189

Counter-Hegemonic Discourse and Alternative 'Truth' .......................................... 190

'Automatic' Self-Devaluation ....................................................................................... 191

The Struggle for a United 'Voice'............................................................................. 192

The Attacks on Workers' ......................................................................................195

Externalising the Worker Struggle in the 'Carceral Network' ............................ 197

Strengthening Worker Passivity....................................................................199

Self-Value and the Norm-based Moralities .........................................................202

Concluding Remarks ..............................................................................................................204

Chapter Eight: Conclusions

Making and Remaking a Chinese Working Class over the Past Decades......... 206

Studies on Labour Activism in China ....................................................................208

Discussing Research Propositions .............................................................................209

Discussing Research Questions ..............................................................................2213

Worker Activism and Governmentality in China's Thought Management System

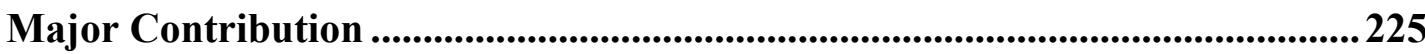

Limitations .................................................................................................................. 225

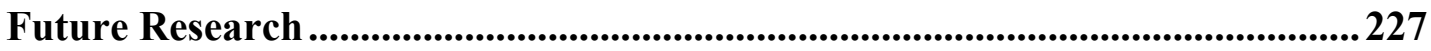

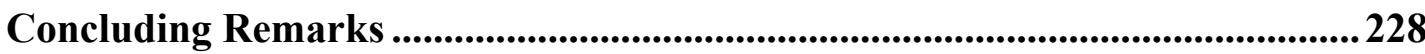

Appendix

Appendix 1: Labour Law (1995) and The Labour Contract Law (2008).........229

Appendix 2: Interview Schedule....................................................................230

Appendix 3: Respondents' Profile ..............................................................................2232

Appendix 4: Exception from Requiring Signed Consent Form from the Research Participants...................................................................................................2236

Appendix 5: Translated Consent Sheet ..................................................................237 
Appendix 6: Original Consent Sheet..........................................................2239

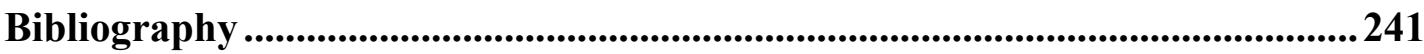




\section{Dedication}

This thesis is dedicated to my parents who passed away during my $\mathrm{PhD}$ journey

\section{Ernie $\mathrm{Su}$}

$\&$

Paul Y.C. Leung 


\section{Acknowledgements}

This research was supported by an Australian Government Research Training Program (RTP) scholarship and UWA Safety-Net Top-Up Scholarship. The completion of this thesis would not have been possible without this financial support as well as the encouragement of many people. I would like to take this opportunity to express my gratitude to those who have assisted me in a myriad of ways.

I am indebted to my lovable supervisor, Dr Donella Caspersz, - the most patient, supportive and considerate supervisor I could have asked for. There was million times I had reached the crossroads and she was there listening to my troubles and made me feel as if my work mattered. I appreciate the time, invaluable knowledge, feedback and recommendations that she gave me to make this a better research, and to make me a better person. It is with her encouragement and supervision that this work came into existence.

Within the University I have also had the support from my retired supervisor Winthrop Professor Rob Lambert, thank you for his helpful advice. Special thanks go to Dr Michael Azariadis for proofreading and providing critical comments on some of my work. Thanks also go to Dr Catherine Leighton, Elvira Plosko-Kurejsepi, Mei Han and Robyn Oliver for their friendship.

Warm thanks go to my fellow students Renata Casado, Marisa Duong, Jue Wang, Huang Ying, Faye Qin, Tom Barrett, Sandra Martain, Nicole Celestine, Natalie Kaiko, Xiaolin Tang, Terence Chia, Shukrullah Fassehi and Hafizah Hsbollah who at opportune times offered me their wise counsel.

I am thankful to Apo Leung and Sally Choi at the Asia Monitor Resource Centre (AMRC); Ping Kwan at the Labour Action China (LAC); Xiaoyi, Xiaobo, Qing, Jinyu among others (whose names cannot be disclosed) across several China's labour NGOs; Professor Li Kungang at Anhui University; Dr Jenny Chan at the University of Oxford and Professor Pun Ngai at Hong Kong Polytechnic University for their assistance in this research work. 
I am deeply thankful to my interviewees. Their names cannot be disclosed but I want to acknowledge and appreciate their help and transparency at the interviews. Their information has helped me to complete this thesis.

Thank you to my wonderful friends Stuart Hawkins, Leslie Howarth, Aleysha Howarth, Leanne Howarth-Gairen, Nonie Howarth, Ann Teh, Beverly Clark, Cathy Li, Zoe Yuen, Zoe Ip, Penny Wong, Daphne Wong, Caron Lim, Ian Tan, Clara Choi and John Lee for looking out for me.

Finally, I would like to thank my family to whom I owe a great deal. To my sister Jessica N.T. Leung: thank you for always being there for me with unconditional love. Left to the last, but the most important of all, my thanks to my late parents Ernie Su and Paul Y.C. Leung. No longer can I say thank you to my mom and dad in person, but I thank them for instilling in me from a very early age the value of possessing good manners, courtesy and compassion for others when in need, with the willingness too, to offer a helping hand. 
This thesis contains work that has been [published and/or prepared for publication].

Details of the work:

Leung, E \& Caspersz, D, 2016 'Exploring worker consciousness in China', Labour \& Industry: A Journal of The Social And Economic Relations of Work vol. 26, no. 3, pp. 237-250.

Location in thesis:

Introduction, Chapters Two, Three, Four, Five, Six, Seven and Eight

Student contribution to work:

First Author and Corresponding Author

Co-author signatures and dates:

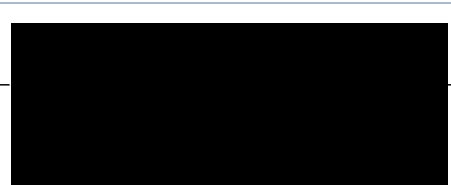

23 May, 2018

Student signature:

Date: 23 May, 2018

I, Donella Caspersz, certify that the student statements regarding their contribution to each of the works listed above are correct

Coordinating supervisor signature:

Date: 23 May, 2018

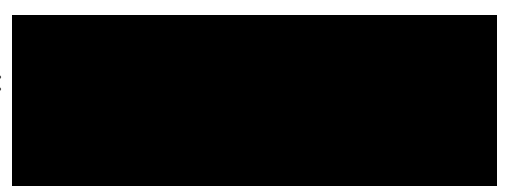


This thesis contains the following sole-authored work that has been [published and/or prepared for publication].

Details of the work:

Leung, E 2016, 'Docile Bodies and Minds: A Genealogy of Chinese Workers in China', in TASA 2016

Conference, ed. M Chou, The Australian Catholic University, Fitzroy, Melbourne, pp. 215-221.

Location in thesis:

Chapters Three, Four, Five, Six, and Seven

Details of the work:

Leung, E 2017, 'Ethical Dilemmas of Fieldwork in China', Newsletter of the Australian Sociological Association (NEXUS), vol. 29, no. 3. Available from:

https://nexus.tasa.org.au/ethical-dilemmas-of-fieldwork-in-china/.

Location in thesis:

Chapter Five

Signature:

Date: $23 \mathrm{Ma}$ 


\section{Abbreviations}

\begin{tabular}{|c|c|}
\hline ACFTU & All-China Federation of Trade Unions \\
\hline AMRC & Asia Monitor Resource Centre \\
\hline $\mathrm{CCP}$ & Chinese Communist Party \\
\hline FDI & Foreign Direct Investment \\
\hline FIE & Foreign Direct Investment \\
\hline GDP & Gross Domestic Product \\
\hline GNP & Gross National Product \\
\hline ILO & International Labour Organisation \\
\hline I.T. & Information Technology \\
\hline LAC & Labour Actions China \\
\hline NGO & Non-government Organisation \\
\hline OHS & Occupational Health and Safety \\
\hline SEZ & Special Economic Zone \\
\hline SM & Sadomasochism \\
\hline SOE & State-owned Enterprise \\
\hline TVE & Township and Village Enterprise \\
\hline U.K. & United Kingdom \\
\hline U.S. & United States \\
\hline UWA & University of Western Australia \\
\hline USSR & Union of Soviet Socialist Republics \\
\hline WTO & World Trade Organisation \\
\hline
\end{tabular}




\section{List of Illustrations}

\section{Figures}

$1 \quad$ Workers' Protests in China 19

2 Interior View of the Panopticon 93

3 Death by a Thousand Cuts (Lingchi) 106

4 China's Share of Global GDP and Merchandise Exports 119

5 Orthopraxy System 132

$6 \quad$ Multiple Field Locations in China 134

$7 \quad$ First Phase of Data Collection in China 136

$8 \quad$ Second Phase of Data Collection in China 138

$9 \quad$ 'Community Area' 144

$10 \quad$ Talent Markets 147

11 Labour Bureau Official 150

12 Garment Factory Workers 152

13 Everyday Workers in China 167

14 State-employed Street Cleaners 189

15 Small Group Discussions at the NGO 194

\section{Tables}

1 Rising Trend of Worker Protests in China 18

2 Examples of Three Types of Fees in Beijing in $2000 \quad 126$

3 Respondents' Details 153

$4 \quad$ Interview Groupings 154

$5 \quad$ Example of Speech Practices 155

$6 \quad$ Example of Coding 'On Work' from Interview Transcripts 157 
7 Example of the Main Narrative Themes 


\section{Chapter One: Introduction}

\section{Background}

The term "rising consciousness" (yishi shangsheng 意諳上升) (C. Chan 2010b; Chan \& Hui 2016; Chan \& Selden 2016; Chan \& Pun 2009) has been progressively used to describe the increased number of worker protest cases in the belief that these incidents exhibit workers' awareness of their class-based interests (or common economic interests) throughout their brutal working experiences in China. These experiences are perceived by mainstream scholars in Chinese labour studies (C. Chan 2010b; Chan \& Hui 2016; Chan \& Selden 2016; Chan \& Pun 2009) as a fundamental element that has raised workers' consciousness up to a class level, and so that they have formed themselves into a Chinese working class to take collective actions in advancing the work rights and benefits to improve the overall working conditions for themselves and others. These actions are considered confrontational and thus they often faced with strong and prevalent suppression both by the Chinese State ${ }^{1}$ and entrepreneurs (Qi 2010), while there is no independent workers' unions and organisations supporting these struggles (Hess 2013; Pringle \& Clarke 2011). Given these unfavourable conditions, mainstream scholars in Chinese labour studies conclude that it is the work-based experiences that heightened workers' class consciousness, and it is this consciousness that has become a powerful source for them to organise a collective labour movement that can challenge against not only business operations, but also the policies - and ultimately - the authority of the Chinese State (C. Chan 2010b; Chan \& Hui 2016; Chan \& Selden 2016; Chan \& Pun 2009).

\section{Research Focus}

The aim of this study is to understand how the lived experiences of everyday Chinese workers have influenced their struggle to improve their working conditions to explore the potential of worker activism in China to develop into an organised labour movement. Ever since the departure of the socialist legacies of the first generation of Chinese Communist Party (CCP) Chairman Mao Zedong, the political leader from 1949 to 1976 (Teiwes 1997), China has experienced the fastest sustained expansion of a major economy in history. This is due to

\footnotetext{
${ }^{1}$ A Chinese State is defined as a politically organised community living under the rules of different political leaders in history. The CCP is the political leader to rule China since 1949.
} 
successive "Open Door"2 economic reform programmes, which were first introduced by postMao CCP leader Deng Xiaoping ${ }^{3}$ in 1978 (Chen 1997; Harvey 2005). With an average growth rate of nearly ten percent in gross domestic product (GDP) since the reforms, China has become a world's factory and export leader with the world's largest workforce, containing a minimum of 769 million workers by 2013, to become the largest contributor to world growth since the global financial crisis of 2008 (The World Bank 2017).

While the post-Mao reform programmes claim to have lifted out over 800 million Chinese people from poverty through their labour, much has noted that China's export-oriented industrialisation is developed through its prolonged capacity in subjecting Chinese workers to one of the most exploitative labour regimes in modern history (Chan 2001; Fan 2003; 2004; Hurst \& O'Brien 2002; Leung \& Pun 2009; Li \& O'Brien 1996; O'Brien 1996; Pun 2007; Pun, Chan \& Chan 2009; Pun \& Lu 2010; Pun \& Lu 2010b). Although the All-China Federation of Trade Unions (ACFTU) ${ }^{4}$ - the only legal trade union in China - supposedly functioned as an independent worker organisation to protect the rights and interests of workers by setting up branches at the enterprise and local levels, its priority was to ensure the State policies reached down to the workplaces to boost production while occasionally settling disputes between individual workers and enterprise managers since the 1950s (Chan 1993; Cooney, Biddulph \& Zhu 2013; Gallagher 2007; Pringle 2011). This scenario was disrupted in 1966 as the ACFTU

\footnotetext{
2 The 'Open Door' policy relates to a series of economic modernisation programmes that altered China's development strategy from one based on self-sufficiency in the Maoist state to one that actively participates in the world market. See Huan, G 1986, 'China's Open Door Policy, 1978-1984', China in Transition, vol. 39, no. 2, pp. $1-18$.

${ }^{3}$ Deng Xiaoping was the second generation of the CCP leader. See Dillon, M 2015, Deng Xiaoping: The Man who Made Modern China, I.B. Tauris \& Co. Ltd, London.

${ }^{4}$ The All-China Federation of Trade Unions (ACFTU) was founded by the Chinese Communist Party (CCP) in 1925 and was legitimised by the Maoist State (1949-1976) under the Trade Union Law (1950) to provide a twoway conduit (or 'transmission-belt) for supporting the State policy (top-down transmission) and for protecting the rights and interests of workers (bottom-up transmission) in the State-owned enterprises (SOEs). The term 'transmission-belt' is used to describe the role of trade unions as tools for ensuring that the will (or wishes) of the central planners was fulfilled at the enterprise level under the State domination within a communist society. See Chan, A 1993, 'Revolution or Corporatism? Workers and Trade Unions in Post-Mao China', Chicago Journals, vol. 29, pp. 31-36, Cooney, S, Biddulph, S \& Zhu, Y 2013, Law and Fair Work in China, Routledge, New York, Ding, D, Goodall, K \& Warner, M 2002, 'The Impact of Eocnomic Reform on the Role of Trade Unions in Chinese Enterprises', The International Journal of Human Resource Management, vol. 13, no. 3, pp. 431-449, Zhu, Y, Warner, M \& Feng, T 2011, 'Employment Relations "with Chinese Characteristics": The Role of Trade Unions in China', International Labour Review, vol. 150, no. 1-2, pp. 127-143, Lenin, V 1918/1992, The State and Revolution, trans. R Service, Penguin Books, London.
} 
shut down in the face of violence during the Cultural Revolution (Ding, Goodall \& Warner 2002; Zhu, Warner \& Feng 2011). It was not until the onset of economic reforms of 1978 that the ACFTU returned to its former position to restore production by continuing its former role to supervise workers with management at the enterprise and local levels to achieve economic goals (Warner 1991, pp. 210-212). By becoming subordinate to the CCP and the enterprise management, the ACFTU was thus incapable to function as an independent worker organisation to protect workers' rights and interests (Cooney, Biddulph \& Zhu 2013). As a result of this, ongoing labour violations and abuses ranging from excessive forced overtime work to unpaid wages and physical assaults such as kneeling, slapping, and being locked up in dog cages are well documented in academic accounts (Chan 2001; Pun 2005). Recent literature reveals that workers' experiences of the ongoing deterioration in workplace conditions (Chan 2001) associated with the lack of genuine worker organisations (Howell 2008) have sparked a rising trend of worker protests (see Table 1) in China:

Table 1: Rising Trend of Worker Protests in China

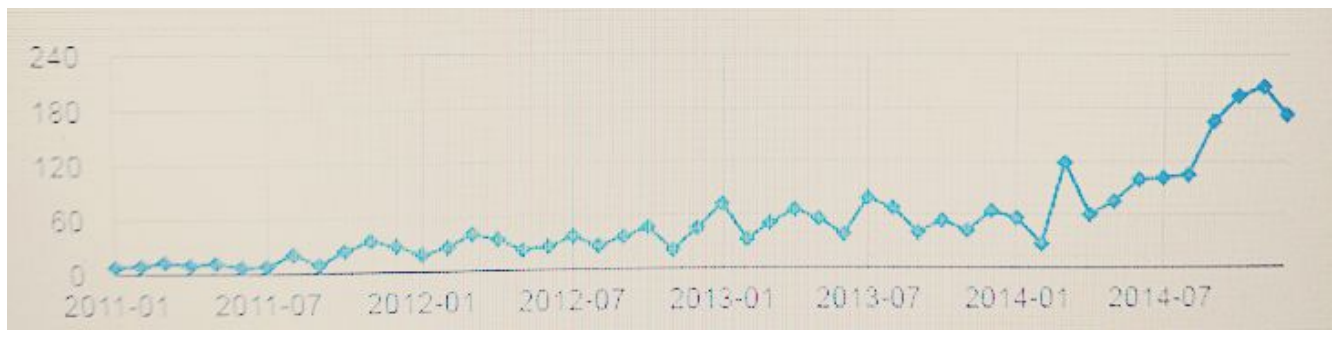

Source: China Labour Bulletin (2017)

Despite official figures of labour incidents have been made unavailable to the public by the post-Mao CCP leaders, non-government labour-rights organisations (NGOs) such as China Labour Bulletin (2017) that is based in Hong Kong has reported that the number of worker protest actions have continued to from 185 incidents in 2011 to 1,379 in 2014 (see Figure 1) across China: 
Figure 1: Workers' Protests (numbers as indicated in each circle) in China

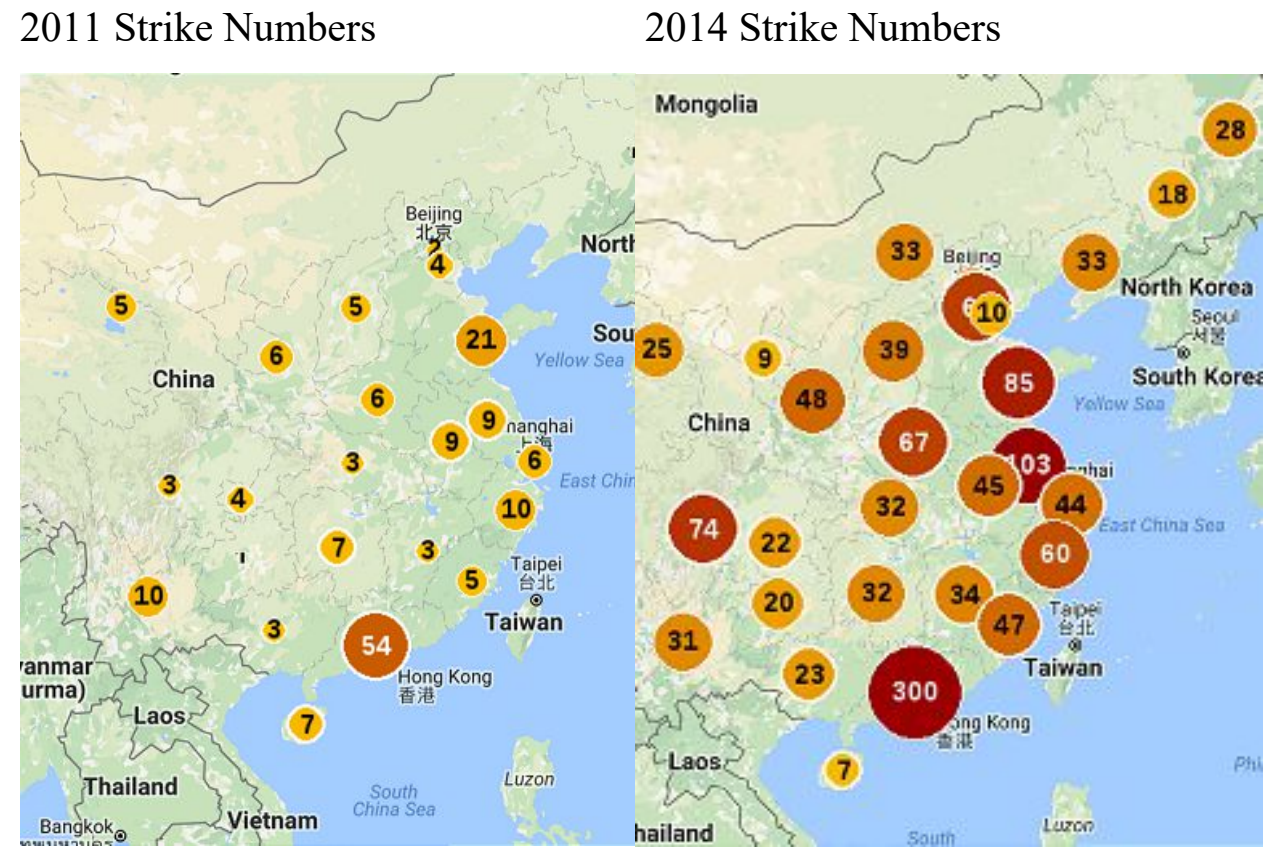

Source: China Labour Bulletin (2017)

Combining the NGOs' findings with the oft-quoted number that 'mass incidents', including environmental protests and work stoppages (Friedman \& Lee 2010) have consistently increased from 74,000 in 2004 to 87,000 in 2005 (Estlund 2017; Leung \& Pun 2009, p. 553), mainstream scholars in Chinese labour studies (Chan \& Hui 2016; Chan \& Pun 2009; Pun \& Lu 2010; 2010b) subsequently claim that the prevalence of protest activities herald a "rising class consciousness" that is generated from the experiences of workers as being a class of workers in post-Mao China. Mainstream scholars from this standpoint (Chan \& Hui 2016; Chan \& Pun 2009; Pun \& Lu 2010; 2010b) claim that the work-based experiences have been the main ingredient to raise millions of workers' collective consciousness to the extent to which they have become aware of their class position both in their workplaces and society. Exponents (Chan \& Hui 2016; Chan \& Pun 2009; Pun \& Lu 2010; 2010b) of this view optimistically conclude that it is this awareness that has fostered a Chinese working class to struggle against the prolonged abusive and exploitative working conditions - and it will ultimately - mount a massive upheaval for social change in China. 


\section{Research Questions}

The assumption presented in mainstream literatures has thus guided this study for an exploration of the following research questions:

1. How has worker consciousness been shaped in China?

2. How does the shaping of worker consciousness affect labour activism by Chinese workers?

3. How does the shaping of worker consciousness affect their ability to develop themselves into an organised labour movement to improve living and working conditions for themselves and others?

\section{The Marxian Theories on Worker Consciousness and Organised Labour Movement}

The research question sets together with the ongoing discourses on a "rising class consciousness" to explore the workers' potential to mobilise organised labour movement for themselves in China have brought us to Karl Marx's (1844/2007) distinction between class-initself and class-for-itself of industrial workers. Organised labour movement, as originally theorised as a class-for-itself by Marx (1844/2007), is constituted by workers' practices in relation to their material (or economic) conditions. Marx (1894/1992) perceived material conditions to be created predominantly by the interdependent relationship between the two main classes ${ }^{5}$, that is, the employers (capitalists or bourgeoisies) and wage workers (labourers or proletariats), which triggered conflicts of interest between the two classes under the capitalist wage system. Marx noted that the class relations of wage labourers existed as a system of exploitation because workers were paid less than the value of the commodities they produced in order to maximise profits for their employers in an unequal production structure (1844/2007). For Marx, workers' awareness of their economic and social positions within this exploitative structure of the relations of production is the main determinant progressing their consciousness as a class (or group) of workers, which is the basis of their power, leading them to continuously organise themselves from single factory to then unite across factories in pursuing its own

\footnotetext{
${ }^{5}$ In Marxist theory, a capitalist society only consisted of a capitalist and a proletarian class in the material production structure. The former is also referred to as the bourgeoisie who are the owners of the means of production and employers of wage labour while the latter is a class of wage labourers who have no means of production of their own and are compelled to sell their labour power in exchange for a wage to live. See Marx, K \& Engels, F 1848/2010, The Communist Manifesto, Penguin Books, London.
} 
interests (1894/1992). This phenomenon is referred to as a class-for-itself that occurs when worker consciousness is matured (Marx 1894/1992). Marx from this context envisaged that the maturation of worker consciousness is key for the ongoing mobilisation of workers' struggles against capitalist tendencies aiming to create a classless, socialist (or communist) ${ }^{6}$ society in revolution (1844/2007).

Since the $20^{\text {th }}$ century, exponents of Marx's class-for-itself theory have strived to develop strategies and resources to shape workers' consciousness into one that facilitates cooperation and commitment to liberate the working class by achieving socialism (or communism). The Russian revolutionary leader Vladimir Lenin (1918/1992), for example, argued that the opportunities to transform a working class from a class-in-itself to a class-for-itself were rooted in the Socialist Revolutionary Party's ${ }^{7}$ decisive role and actions to raise workers' consciousness. Lenin in this context divided workers' consciousness into three levels, that is, individual consciousness; trade union consciousness and revolutionary consciousness (1918/1992). He insisted that workers' consciousness could be raised, from individual level that focused upon wage maintenance for the selves; to trade union level where workers united across factories to counter the strength of their employers, and to the revolutionary level that they advocated political changes for themselves, only by intellectual vanguard, that is, the Socialist Revolutionary Party (1918/1992). Thus, Lenin perceived that the consciousness maturation among workers relied on the Party's action in providing them with a 'proper revolutionary education' that drew on party propaganda such as "The Revolutionist [...] no private interests [...] property [...] of his own. His entire being is devoured by one purpose, one thought, one passion - the revolution" (Shepley 2013, p. 101) to engage workers in political struggles (Harding 2009). It is in this context that Lenin asserted that only the dictatorship of a single socialist party could effectively advance worker consciousness to eliminate their exploitation by the capitalist class (1918/1992). Contrary to Lenin, Karl Korschi (1938/2016) and Louis Althusser (1965/2005) noted that workers' consciousness was not merely a reflection of their

\footnotetext{
${ }^{6}$ The similarities between socialism and communism have been the emphasis on the egalitarian ideals of society and the role given to workers although the latter also used forms of oppression, control and lack of freedom in governing workers, as in the case of China. See Szalay, L \& Mir-Djalali, E, 'Image of the Enemy: Critical Parameters, Cultural Variations', in The Psychology of War and Peace: The Image of the Enemy, ed. R Rieber, Plenum Press, New York, pp. 213-250.

${ }^{7}$ The Socialist Revolutionary Party was a faction of the Marxist Russian Social Democratic Party (RSDLP). The Party was founded by Vladimir Lenin and Alexander Bogdanov in 1905 which consisted of workers. See Shepley, N 2013, Russia's Struggle With Modernity 1815-1929, Andrews UK Limited, Bedfordshire.
} 
economic conditions, but also of the production of a political ideology in a capitalist society. They argued that it is only when workers developed a higher level of consciousness that they understood how dominant political ideology had marginalised and ruled them as the workers that they could begin to form themselves into a class-for-itself to struggle against their conditions. Thus, Antonio Gramsci (1988/2000) placed the role of political ideology at the centre of his analysis by arguing that the formation of a class-for-itself required intellectual-led (or 'organic intellectuals') political organisations to shape workers' consciousness through a contestation over hegemony (or domination). Georg Lukács (1968) maintained that workers' awareness about their marginal position vis-à-vis the capitalist class was generated by their thoughts and feelings about their class experiences in the production process. For Lukács (1968), class experiences were fundamental to shaping workers' consciousness, whereby the formation of a class-for-itself and its significant actions were determined by such a class consciousness. By extending Lukács' debate around the relations between class experiences and consciousness, E.P. Thompson (1966) emphasised the role of workers' culture and social relationships in the making of a class-for-itself through their lived experiences within and outside the production process:

People find themselves in a society structured in determined ways [...] [particularly] in productive relations, they experience exploitation [...] they identify points of antagonistic interest, they commence to struggle around these issues and in the process of struggling they discover themselves as classes, they come to know this discovery as class consciousness.

(Thompson 1978, p. 149)

Thompson (1966) insisted that class consciousness emerged only when through their lived experiences, workers articulated and understood the differences between themselves and the 'other' (ruling) class that was antagonistic to their interests. He argued that such experiences exerted pressure upon workers' consciousness, which fostered workers' agency and the subsequent activity of making a class in the process of shaping desires and actions for itself:

[...] class is defined by men as they live their own history, and, in the end, this is its only definition. 


\section{Understanding the Chinese Working Class and Activist Culture in China}

Influenced by Thompson (1966), mainstream scholars (Chan \& Hui 2016; Chan \& Pun 2009; Leung \& Pun 2009) in Chinese labour studies have thus increasingly employed Marxist class concept to understand workers' consciousness and hence activist culture in China. While these scholars have provided rich empirical narratives about the work conditions and protest actions, their writings tend to focus on the viewpoints of protest activists in one or two large-sized factories and even one individual worker (Pun \& Lu 2010) as evidence of "rising class consciousness" (see Chapter Four, pp. 106-112). The methodological limitations of past studies thus have been the over-reliance on data in those with experiences of protest activities in factories in order to fit the overall analysis within a Marxist class framework. The weak evidence proffered by these studies precluded a full appreciation of the significance of how the non-work experiences of Chinese workers that is grounded in their historical and cultural experiences have also influenced their consciousness and hence the development of a Chinese working class.

Perhaps one reason for this diffusion of how class emerges in China is that an analysis of events illustrates how a Chinese working class was born in the absence of many cultural and institutional factors that were identified as crucial facilitating elements for the formation of workers' class consciousness in Western historical experiences. During the early days of industrialisation in England, for example, labour struggles were led by artisans (or craftsmen) who considered themselves as skilled workers (Thompson 1966, pp. 234-240). Later, as the factory system arose throughout the Industrial Revolution in the $19^{\text {th }}$ century, factory workers inherited the tradition of class struggle from artisans through which their class identity and subsequent shared interests began to shape (Thompson 1966, pp. 243-268). Contrary to the English counterparts, artisans (gongren 宮人) ${ }^{8}$ in China occupied a very low societal status (Grasso, Corrin \& Kort 2009) as many were originally slaves to manufacture iron weapons, paper and textile products for Chinese Emperors in different Imperial periods (Zhang 2015, pp. 205-207). Without the historical and cultural evolution such as what the English working class had in which to form a class consciousness, generations of Chinese workers experienced proletarianisation by adapting to the conditions of the industrial system as atomized (or

\footnotetext{
${ }^{8}$ Government slaves were referred to as gongren 宮人 in Imperial China. See Wagner, D 1998, A Classical Chinese Reader: The Han Shu biography of Huo Guang, Routledge, New York.
} 
isolated) workers who endured social and political changes with their habits of hard work, small expectations, and a lack of positive sense of their identity as a Chinese working class (Wu 2016).

Thus, their experience of class and hence identity as Chinese workers was discursively articulated and constituted by 'others' namely the original Emperors and later the Socialist and Communist ideology. In contrast to the English working class, Chinese workers did not have the similar experiences to ground the development of their consciousness. As historian Joan Scott (1999) noted:

Experience is not seen as the objective circumstances that condition identity; identity is not an objectively determined sense of self defined by needs and interests; politics is not the collective coming to consciousness of similarly situated individual subjects. Rather, politics is the process by which plays of power and knowledge constitute identity and experience.

(Scott 1999, p. 5)

Similar to Scott (1999), French philosopher and historian Michel Foucault (1980a) considers individuals' consciousness is constituted by their identities and experiences which are all constructed for them through the creation of truths about events or even people (that is, the subject), that then become accepted as being "the truth" in a particular society. Whether one interpretation about an event or people becomes recognised as the truth is linked to what Foucault refers to as the power-knowledge relations (1980a). These relations, for Foucault, are inseparable as power produces reality and 'domains of objects and rituals of truth', that is, knowledge; and are reinforced within individuals through the work and non-work relations that they engage in, for example, relationship with work supervisors, co-workers, teachers and parents in their social relationships (1991a, p. 194). Thus, it is these human relationships with bodies of knowledge that have implicitly formed the basis of control and regulation for individuals within the power-knowledge regimes in a particular culture (Foucault 1980b).

Contrary to mainstream scholars (Marx 1894/1992; 1844/2007; Thompson 1966; 1971; 1978), who treat power as a commodity or as coupled with agency, Foucault (2014) uses the series of lectures on psychiatric power at the College de France from 1979 to 1980 to argue that power was invested in discourses that became truths because they became the forms of knowledge 
about events and people. Foucault's argument about how these truths became the knowledge by which people were categorised into societal positions, such as for instance parents and children, informs this thesis. Foucault would ask, how do we know a parent as a parent and a child as a child? And would respond that we know this because of the construction of a truth about what constituted a parent or child, and which was then circulated through discourse or speaking to become the dominant thought or knowledge about what constitutes a parent or child. When studying discourses, Foucault therefore focuses on how the truth affects individuals in their social relationships and the effects of that truth on their social world (1982). Foucault is especially interested in how the 'truth' about themselves affected an individual's notion of subjectivity, that is, how they behaved or acted in their world (1980b; 1982; 1997). Ideas about 'madness', for example, not only represents what we come to know as a mental illness, but also reflects the norms that wider society uses to judge what is normal and abnormal thinking and acting (Foucault 2001; 2006). It is the emergence of the form of normalising judgement (or examination) across different institutions, such as schools and hospitals, that has guided the individual to spontaneously conform to the norm of behaviour of their society (Smart 1985).

Given this general understanding of the relations between power-knowledge, discourses and subjectivity, Foucault (1988) develops the notion of governmentality to describe his work on rethinking the concept of governmentalisation. Defined as 'the conduct of conduct', Foucault's concept of governmentality is characterised as subtle forms of governmental strategies, using particular types of knowledge (or truths) to govern the population (1980a). Thus, 'governmentality' relates to the how of governing: how we govern, how we are governed, and the relation between the government of the state, the government of ourselves and others, with particular mentalities of government that have emerged in particular societies (Dean 2010, p. 2). These mentalities are forms of knowing and thus become the rationalities by which we come to know an event or even people as true, that is, these rationalities help us to make meaning of the world. But, Foucault argues that our rationalities are constituted by a multitude of government apparatuses, such as schools and families, and practices (Foucault 2001; Skålén, Fougère \& Fellesson 2008, p. 27). From this perspective, governmentality is thus a study of the collective and taken-for-granted discourses (truths or knowledge) regarding how we should behave in a particular social network or time (Dean 1994; 2010). Because these rationalities 
are embedded in our psyche or mentality, the truth of these rationalities in prescribing our behaviour or even our social status is rarely questioned or problematized (Downing 2008, pp. 17-18).

Foucault's concept of governmentality has been widely used by Western academics to explain the politics of the present (Dean 2010; 2012; Smart 1985; 1998). A series of works have dealt with the nature of governmental thinking and practices in Western democracies in the context of globalised capitalism; for example, Wendy Larner and William Walters's Globalization as Governmentality (2004); Ronnie Lipschutz and James Rowe's Globalization, Governmentality and Global Politics: Regulation for the Rest of Us (2005); Jonathan Joseph's Governmentality of What? Populations, States and International Organisations (2009); Rahel Kunz's The Political Economy of Global Remittances: Gender, Governmentality and Neoliberalism (2011); Mitchell Dean's Rethinking Neoliberalism (2012); and Jean-Sébastien Guy’s Beyond Global Modernity, Global Consciousness and Global Governmentality: The Symmetrical Anthropology of Globalization (2016). Furthermore, Foucault's theme and analysis of governmentality have also been applied to the examination of daily matters such as: education (Mitchell 2006); sexual and ethical politics (Penttinen 2008); the regulation of pregnancy and abortion (Barcelos 2013); and the government of everyday life (Dean 2010).

Scholars in Chinese studies have also extensively used the concept of governmentality to analyse contemporary Chinese politics and society. Beginning with Michael Dutton's pioneering work Policing and Punishment in China (1992), the field of Chinese studies has generated a collection of governmentality analyses of sex and prostitution controls (Jeffreys 2004), the socialist work unit (danwei 單位) system (Bray 2005), birth and population control policies (Greenhalgh 2010), consumer-citizens (Cartier 2016), new professionals (Sigley 2016) and the role of the Chinese media in enforcing ethical behaviours (Brady 2012a). Moreover, a growing number of Chinese scholars have used the notion of governmentality as a framing tool to discuss the relationships between the government and the daily management of citizenship (Bray 2009; Xu 2009), religion (Cooke 2009), and desires and identities (Woronov 2016) through an examination of Chinese politics in commercial advertisements and television programmes. 


\section{Thesis Contribution}

One aim of this thesis is to contribute to this body of research that draws on Foucault's work to understand Chinese society by using his methods and concepts to analyse the politics of Chinese labourist activist culture. This is by exploring how worker consciousness and activism are shaped by the governmental discourses and rationalities in post-Mao China. In so doing, this study not only draws on Foucault's ideas, but also his methodological approaches. This is by using the technique of genealogy to show how worker activism is influenced by the CCP's approach of thought management (sixiang guanli 思想管理). Given that mainstream scholars in Chinese labour studies (C. Chan 2010b; Chan \& Hui 2016; Chan \& Selden 2016; Chan \& Pun 2009) have as yet failed to make this connection, the thesis widens the resources to include data on those with experiences of protest activities and those without across the spectrum of different industries (hereafter: everyday workers ${ }^{9}$ ) to understand the relations between worker activism and Chinese politics, because the effect of thought management is:

[...an] activit[y] to control, guide, adjust, or develop the social or ideological relationships which influence the shaping (change or development) of people's thinking; to make their thinking conform to the dominant ideology, thereby standardizing people's behaviour in order to put in place a set of objectives.

(Brady 2012a, p. 2)

In the context of Chinese worker activism, thought management epitomises the CCP's penchant for combining Confucian methods of persuasion (Brady 2012b), such as the use of ideological campaigns (see Chapter Three, pp. 78-88), with new governmental discourses and rationalities to maintain its monopoly on political power, while at the same time creating an

\footnotetext{
${ }^{9}$ The term everyday workers refers to those who sell their labour in exchange for a living wage. The term is interchangeable with that of ordinary workers, see Munck, R 2004, 'Introduction: Globalisation and Labour Transnationalism', in Labour and Globalisation: Results and Prospects, ed. R Munck, Liverpool University Press, Liverpool, pp. 1-18. Ordinary workers refer to those skilled and unskilled wage labourers, male or female, across different occupations and industry types and sizes in the labour market. It is argued that the term everyday workers is more appropriate to this study because it emphasises the lived experiences of workers, that is, their everyday experiences within and outside the production process as being the workers, to understand both their work and the way workers live, see Thompson, EP 1966, The Making of the English Working Class, Vintage Books, New York. Thus, given that the focus for this study (see pp. 27-28, and Chapter One, p. 32) is to understand how living and working in post-Mao China has shaped the consciousness of Chinese workers, and how this consciousness affects their activism, as well as their ability to develop themselves into an organised labour movement to improve their living and working conditions for themselves and others, using the term everyday workers as explained is appropriate to pursuing this focus.
} 
abundance of cheap and docile workers to meet the labour market needs required for China's economic development. Despite the predictions that the brutal work-based experiences of workers would foster a class consciousness that would coalesce them into a class-for-itself to challenge entrepreneurs, the CCP and its continued rule in China; the CCP remains in charge of China and the workers' destiny (or ming 命) (see Chapter Three, p. 90). The thesis argues that China's stable polity is sustained through the CCP's ability to retain, update and incorporate many Confucian values into a contemporary form of thought management using social networks, such as families and schools, to continuously shaping workers' consciousness into one that maintains their docility (Brady 2012b, p. 62). Most significantly, Confucian ( $l i$ 禮) filial piety $\left(\text { xiao } \text { t }^{7}\right)^{10}$, which has been a part of traditional Chinese culture since the $13^{\text {th }}$ B.C.E. (Zhou dynasty) and which emphasises a "proper" attitude and conduct, such as respect for authority figures, has become a vital theme in this contemporary thought education (Pearce 2001). Thus, as in individuals' relationships with their parents, filial piety in China highlights that "proper conduct" at the workplace refers to those who have been categorised as having a lower status towards their immediate superiors and the nation's rulers and the maintenance of attitudes and conduct by them that perpetuates this lower status, much like as in the time of Imperial China (Whyte 1988a). By behaving in this way, workers have, together with the State, constituted a status consciousness (Koo 2001), that is, an 'older rule consciousness' which is influenced by the Confucian status ideologies (Perry 2009), for themselves to uphold an orthopraxy or proper conduct or behaviour that perpetuates the systems of inequality (Evasdottir 2004). The significance for workers to engage in an orthopraxy system to behave properly is that this militates against their ability to coalesce into an organised labour movement to improve their conditions for themselves and others because they rarely think that they should act outside of the rules that are linked to their social truth of their low social status to which centuries of thought management that are still being exercised even today, has assigned them to.

\footnotetext{
${ }^{10}$ Filial piety (xiao 孝) is one of the most important aspects of Confucian thought that concerns not only the individuals' relationship with their parents; but it has also been promoted by the CCP as a virtue of respect for their immediate superiors and the nation's rulers within the social hierarchical relationships in contemporary China. See Bell, D 2008, China's New Confucianism: Politics and Everyday Life in a Changing Society, Princeton University Press, New Jersey, Brady, A-M 2012b, 'State Confucianism, Chineseness, and tradition in CCP Propaganda', in China's Thought Management, ed. A-M Brady, Routledge, New York, pp. 57-75.
} 


\section{Research Propositions}

The latter body of debates lead to tentatively proposing that contrary to a view promoted by mainstream scholars in Chinese labour studies, workers' consciousness in China is affected by more than their experience of work. In light of this, the following propositions thus emerged to inform the research questions for this study:

1. Worker activism in China is influenced by a status consciousness (or 'older rules consciousness')

2. The 'older rules consciousness' has affected their willingness to engage in acts that are perceived as contradictory to their cultural (or social) practices in China

3. Workers' consciousness and their resistant activities are influenced by 'older rule consciousness', rather than work-based experiences alone

\section{Thesis Originality}

The originality of this research project resides in substantiating this scenario, which is supported by original interviews with everyday workers conducted across two phases of data collection in several locations in China. This focus is one that has however unfolded during the project. That is, this project began with the intention of undertaking fieldwork in order to better understand the basis upon which working class formation was developing in post-Mao China, and the opportunity this presents for resistance activity by workers to improve their living and working conditions. However, the research that was undertaken with everyday workers from across China, who had been either involved in worker protest action $(n=21)$ or not involved in worker protest action ( $n=53)$, exposed a counterfactual: that is, despite having the world's largest workforce(Fujita \& Hu 2001), the opportunity for Chinese workers to develop a level of individual consciousness that matures into a collective consciousness as a group (or a class) of workers who are prepared to willingly engage in struggles to collectively improve their living and working conditions remains limited. This is because, while experiences of exploitation of everyday workers might incite them to engage sporadically in collective actions, the findings suggest that workers' consciousness and actions remain highly influenced by the framework of thought management that rests on Confucian values that are embedded in their society. As a result, their capability to mobilise into organised labour movement to improve the conditions for themselves and for others remains limited. 
As already stated, the study draws on Foucault's themes and toolkits to provide this analysis. The study explores how Confucian ideology has become a dominant, subtle power that influences workers' consciousness (or thought) in their everyday lives. This theme will be examined in relation to key events in Chinese history. Further, Foucault's $(1987 ; 1997 ; 2001)$ genealogical method (or History of the Present) has been adopted to reveal how governmental discourses (or "knowledge") in China emerged and have become truths that are used today to regulate the ways of thinking and acting among workers in Chinese history. It will be demonstrated that these conditions have constituted a set of cultural norms and rules that have in turn constituted a set of practices' in today's Chinese social system. It will be argued that the internalisation of the "normal" and "abnormal" discourses within the mindsets (or mentalities) of Chinese workers have implicitly guided them to engage in a strict set of selfregulatory rules that they impose on themselves. These are grounded in their cultural understanding of proper behaviour, which they have in turn internalised to become their social truth about their prescribed routines of life and work. Not only this cultural compliance conducted by workers has worked to maintain their consciousness at an embryonic level, but it also worked to entrench a natural self-governance by workers, causing them to internally accept the legitimacy of oppressive and coercive labour practices and subsequently diminish the potential of organising collective action that is beyond individual needs in China.

\section{Thesis Overview}

Presenting an alternative view to understand workers' consciousness requires viewing the matter through different theoretical lens. The thesis thus begins with Chapter Two to discuss how Foucault (1980a; 1982; 1987; 1997; 2014) uses history as a tool to question and analyse the problems of the development of thought, and to explore the forces of control that were exercised externally and internally upon workers to guide their behaviour in the present day (or the History of the Present).

Chapter Three elaborates upon this by applying Foucault's genealogical method (or the History of the Present) to explore how worker consciousness has been shaped by the power-knowledge relations in successive historical periods in China. The chapter shows how the Chinese state fostered the production and reproduction of docile bodies and minds among workers by revitalising the existing Confucian-orthopraxy (standardisation or proper behaviour) system. 
Chapter Four is a review of the existing literature concerning labour activism in China. While these studies provide invaluable and insightful information about the work-related experiences of the Chinese working class, their implicit use of Thompson's (1966) agency-oriented class concept is at odds with the counterfactual that emerges through the fieldwork. The empirical evidence shows that the influence of the unique events in China's socio-cultural history had a prolonged effect in shaping the consciousness of Chinese workers.

Chapter Five contains a description of the research approach that was used to explore the power-knowledge relations that are embedded in the discourses and practices of everyday Chinese workers. In summary, the study has relied on a combined method of ethnographicnarrative (or ethnonarrative) (Hansen 2006). A detailed explanation of the research processes of ethnographic data collection across multiple locations in China is provided, as well as a description of the challenges encountered during this research. While the sample of this study was relatively small, the combination of research strategies adopted in the study empowered the research participants to tell stories about their unique experiences of their everyday lives.

Chapter Six engages Foucault's theoretical framework in discussing the two phases of original field data elicited from 53 everyday workers in Group One - who had never engaged in any protest activities - that were gathered in a wide range of industries and occupations in multiple locations of China between 2011 and 2014.

Chapter Seven presents and discusses for the two phases of empirical data elicited from 21 everyday workers in Group Two - who had engaged in protest activities - that was collected at multiple locations, mainly through contacts with non-governmental labour organisations (or labour NGOs) in Hong Kong and Guangzhou Province in China between 2011 and 2014.

Chapter Eight provides an overview of the study's findings and considers the broader implications for worker activism in China in the future. The discussion is followed by an acknowledgement of the limitations of this research and suggestions for future research.

\section{Concluding Remarks}

This chapter provided a brief discussion of how Chinese worker activism has been articulated as an effect of a rising class consciousness that is necessarily generated from their brutal workbased experiences by mainstream scholars in Chinese labour studies (Chan 2001; Hurst \& 
O'Brien 2002; Howell 2008; Leung \& Pun 2009; Li \& O'Brien 1996; Pun 2007; O'Brien 1996; Pun \& Lu 2010; Pun, Chan \& Chan 2009; Pun \& Lu 2010b). However, the thesis suggests that this perspective is generated from selectively focusing on workers' protest actions to argue that their work-based experience is the primary determining factor that has shaped their class consciousness and inspired them to mobilise class-based actions against their exploitative conditions in post-Mao China. While providing useful information about the work-based experiences of the Chinese working class, existing studies seem to present only the viewpoints of activists, which render these accounts incomplete. Their predictions of class movement in China, premised on a selective sample of those who had undertaken protest actions, have illustrated that most of these mainstream scholars have implicitly or explicitly rejected the significance of China's thought management system as an approach for understanding the politics of the Chinese labourist activist culture.

To address the gaps in current scholarship, this study will show how the CCP has incorporated the Confucian values into its contemporary thought management system through social networks to internalise moral knowledge within workers. The implications of thought management as a means of social control thus strengthen the CCP's power with little violence by retaining the traditional filial piety in Chinese culture. Hence, drawing on Foucault's governmentality thesis, this study will illustrate that the CCP retains historical knowledge as a tool to manipulate workers' mentalities and subsequently curtail the possibility of their forming a class-for-itself to act collectively to improve their conditions beyond their power-knowledge relations. Chapter Two presents the toolkits and themes that Foucault uses to trace the historical development of individuals' consciousness through their social (or cultural) practices in particular societies. The chapter shows how such consciousness development affected the ways individuals lived their lives and related to others (or governmentality) in their powerknowledge relations. While Foucault notes that all individuals are the historical products of power-knowledge relations, his views of a range of oppositional responses that produce a picture of what resistant activities might be like will be discussed in the next chapter. 


\section{Chapter Two: Working with Foucault: Governmentality and the Government of Self}

[...] the task of philosophy has been to make diagnoses, and its aim is no longer to proclaim a truth which would be valid for all and for all time. I seek to diagnose, to carry out a diagnosis of the present: to say what we are today and what it means, today, to what we do say [...] In trying to make a diagnosis of the present in which we live [...] I sought to [...] see how an object for knowledge had come to be constituted, and how a certain type of discourse had functioned [...] Man appeared as possible object of [...] the human sciences - and at the same time as the being [...] to any knowledge is possible. Man thus belonged to the field of knowledge as a possible object and [...] he was placed in a radical manner as the point of origin of every type of knowledge.

(Foucault 1999, pp. 91-92)

Foucault describes knowledge in his books, from History of Madness $(2001 ; 2006)$ to his final work The History of Sexuality $(1976 ; 1986 ; 1990)$ series, to illustrate how individuals' practices (or behaviours) are culturally constructed in a historical moment (Davidson 1994; Dean 1994; 2010; 2012; Downing 2008; Oksala 2005; Smart 1985). Foucault's analysis of madness (2001; 2006), medical knowledge (1989/2002; 2003), imprisonment (1977) and sexuality (1976) demonstrate that social practices at a specific historical moment resulted in the shaping of individuals in accordance with the cultural values and criteria that informed their experiences of their existence. On this basis, Foucault (1980a) notes that all histories contain thoughts from particular cultures that are inseparable from individuals' actions (practices or behaviours) and from their experiences of existence. In The History of Sexuality (1976; 1986; 1990), for example, Foucault analyses how the individuals' experiences were objectified and influenced by the medical knowledge (discourse or truth) of 'homosexuality' that had emerged since the $19^{\text {th }}$ century through the ways people acted and thought about themselves. Hence those 
categorised as 'homosexuals' were viewed according to that knowledge, which was circulated in Western societies. Foucault contends that these forms of knowledge created culturally specific views and practices that eventually came to constitute (or affirm certain practices as inimitable) the conditions that lead to the categorisation of people as - for instance 'homosexuals'. Foucault argues that our 'knowing' of how these conditions became linked to this categorisation cannot be solely revealed by studying the experience of a person or historical moment; but by analysing the power-knowledge relations in the relevant society (Foucault $1976 ; 1986 ; 1990)$. Foucault crafts the concept of power-knowledge to describe how we come to know the 'rules of right' or the pouvoir-savoir (discourse) that shape, form and hence constitute our social identities (Foucault 1991b). That is, an individuals' understanding of identity, for instance what makes someone a homosexual, emerges because of the relations of power that confirm this as 'knowledge' (or objectify) (Foucault 1991a; 2001).

The aim of this chapter is to present Foucault's theoretical approach, which was adopted for this study to explore the 'truths' that are in their historical and cultural context that influence everyday Chinese workers in contemporary China about how they think about themselves and accordingly act with a kind of self-knowledge that they believe to be true about themselves. The rationale for drawing on Foucault's approach to explore the research topic was prompted by the need to understand China's labourist activist culture beyond class theories. While useful, it is argued that previous Chinese labour studies have provided a limited understanding of this culture because of their approach in trying to analyse important features of case studies about Chinese worker activism into class theories. It is suggested that their project was motivated by an attempt to provide a coherent body of legitimate (or universal) knowledge to illustrate how exploitative experiences have necessitated that Chinese workers form into a class-for-itself to struggle against their given conditions. While the existing literature has provided insightful information about the relations between workers' experiences and their consciousness development through their increased protest actions, it is argued that by failing to address the complexity of historical and cultural (or social) norms and practices that have affected how Chinese workers come to view themselves, we are unable to fully appreciate the complexities of Chinese labourist activist culture and hence the effect of this culture on their consciousness and ability to develop into an organised labour movement to improve the working and hence living conditions for themselves. The study thereby proposes that it is the 
linkage between the past knowledge and the present cultural practices that have constituted Chinese workers as a specific kind of subjects (or people) that their ability to stage effective resistant activities to improve their conditions is situated within their power-knowledge relations. That is, worker activism in China is influenced by their status consciousness that is linked with their 'older rules consciousness' which is embedded in them since the Imperial period. This 'older rules consciousness' is arguably affected their willingness to engage in acts that are perceived as contradictory to their cultural (or social) practices in China, and that the development of class consciousness and class-for-itself among workers is restrained by 'older rules consciousness'. In exploring these propositions, Foucault's theoretical approach provides the opportunity to chart the historical development of social practices and self-knowledge among everyday Chinese workers that will give us a greater appreciation of how living and working in post-Mao China has shaped the consciousness of everyday Chinese workers, and how this consciousness affects their activism, as well as their ability to develop themselves into oirganised labour movement to improve their living and working conditions for themselves and others.

\section{Foucault, Power-Knowledge and Governmentality}

Michel Foucault (1926 - 1984) is well recognised for the significance, originality and productive nature of his work on power within governmentality (see Chapter One, p. 30) studies in social science disciplines (Dean 1994; 2010; Gordon 1991; Gutting 2003; Flynn 2005; Fillion 1998; Nadesan 2008; O'Farrell 2005; Oksala 2007). The continued proliferation of governmentality studies after the death of Foucault in 1984 demonstrates the relevance and overall importance of Foucault's theoretical approach, but criticism has also been levelled at this framework. Much of the disagreement with Foucault's work has been about the absence of a 'class point of view' in his theory to explain the determining role of the State in the history of the mode of production (or historical materialism) (Clegg 1989; Jessop 2012; Vouros 2013). This class-based analysis (Clegg 1989; Jessop 2012; Vouros 2013) focuses on conceptions of the exercise of power by the State and its apparatuses, and also by the agency of social classes to resist the exploitative structure of the relations of production in capitalism (Marx 1844/2007). The 'absence' of these foundations of power, which is associated with a neglect of the of the State's power in Foucault's work, is deemed by class theorists (Crowther \& Green 2004; 
Giddens \& Dallmayr 1982; Musto 2012; Noon, Blyton \& Morrell 2013) to constitute a logical impasse, limiting the basis and condition for the development of class relations and resistance (or opposition) to power in capitalist societies. This criticism does not take into account Foucault's clear rejection of a common conception of power and resistance that is necessarily grounded in a binary division along class lines (Smart 1985). In a reformulation of the powerresistance conception, Foucault documents a series of forms of resistance to power in Western societies that cannot be classified as a dynamic of class struggle, such as the power of men over women (1976), of parents over children (1980a), of psychiatry over mental illness (2006) and of administration of the way people live (1980b). Each of these non-class struggles highlights an important feature of modern societies and implies a historical subject of resistance to particular techniques and effects of power that are linked to the specific historico-cultural knowledge of the individuals. Knowledge, therefore, is the major concern of Foucault's theorisation of governmentality, which is firmly positioned within his broader thinking about power (1980a; 1980b; 1982; 1989/2002). Foucault drew on analyses of how we come to know what we know (that is, knowledge) to inform the analysis of the art of government (or how to govern), particularly with respect to guiding and shaping individuals' thoughts and practices in a desired direction that does not necessarily require coercion in a particular society (Ransom 1997b).

Regarding the question of 'how to govern' the thoughts and practices of individuals in certain ways, Foucault calls for the 'death of man' in his book The Order of Things (1966/2005) by introducing the concept of episteme to 'decentre' the subject. Referring to the German philosopher Immanuel Kant, Foucault (1966/2005) appropriates the Greek word episteme for knowledge and relates it to the 'historical a priori'. Like Kant, Foucault deploys the concept of 'a priori' to emphasise that knowledge and thought are constrained to, or emerge from, a given period of history (O'Farrell 1989; 2005). However, unlike Kant, who locates those constraints in the individual's epistemological realm in relation to fixed knowledge, Foucault seeks to understand the historical knowledge that created those constraints as a critique of the humanist conception of individuals (or subjects) as creatures that are ruled by reason and history (O'Brien 1988; O'Farrell 1989).

Going beyond Kantian and humanist philosophies, Foucault's (1999) approach to episteme requires us to look outside man's being to search for the thinkable possibilities of man on a 
historical basis. In Foucault's view, the 'conditions of possibility' (1966/2005, p. 265) for the existence of various forms of scientific and pre-scientific knowledge are subject to tacit or invisible rules (Downing 2008). These invisible rules are fundamental to governing, organising and regulating the epistemic system of individuals in a given historical moment (O'Farrell 2005). That is, knowledge (or what we view as truth), in opposition to the taken-for-granted status of neutral and verifiable truth, is historically constructed in conformity with certain rules that guide individuals to regulate themselves and others (or rather governmentality or the conduct of conduct) to think and behave in certain ways (Foucault 1980a). For example, Foucault demonstrates, in Discipline and Punish (1977), that criminals' behaviour could be altered, not by the absolute sovereign (or State) power to punish their bodies, but by enabling them to internalise disciplinary power (or microphysics of power) (Foucault 1977, p. 26), which corrects their minds and then alters their behaviour through knowledge. Knowledge and power are thus inseparable because power "produces reality (or knowledge); power produces domains of objects and rituals of truth" (or knowledge) that have historically comprised the set of rules to permit and delimit the types of thought among and within individuals (Foucault 1991a, p. 194).

\section{'Problematization'}

In analysing the possibilities and impossibilities for thinking, Foucault introduces the method of problematization to examine problems (O'Farrell 2005). Drawing on Brazilian philosopher Paulo Freire's (2016) work, Foucault carries over the term problematization from calling into question accepted 'truths' as ideological manipulation, to the inquiry into the accepted objects of thought, in other words how 'truths' become known as a problem (Bacchi 2012). Sharing a conviction that questions should be approached differently, Foucault adopts the term problematization as a form of inquiry by problematizing objects of thought as specific issues that are taken to be problematic (Bacchi 2012).

Foucault problematizes the objects of thought for two reasons: firstly, the term problematization is used to describe his method of analysis and, secondly, the term is used to refer to a historical process of producing objects of thought (Bacchi 2012). This particular method of analysis, which Foucault calls thinking problematically, is not used to seek a correct answer to a problem, but to investigate how that problem is being "questioned, analysed, 
classified and regulated" at particular times and under particular circumstances (Bacchi 2012, p. 1). The second aspect of problematization captures a twofold process in terms of "how and why certain things become a problem" and how these things are shaped as specific objects of 'official' knowledge or thought (Bacchi 2012, p. 1). Those objects, according to Foucault, are problematic because they become a fundamental problem in terms of constituting the conditions of individuals (Bacchi 2012).

\section{Problematizing the Historical objects of Thought}

To understand the problem of human thoughts, Foucault's problematization method is to search out the historical roots of how objects of thoughts were constructed and established in history (Bacchi 2012; Rabinow \& Rose 2003). In his book History of Sexuality, for example, Foucault questions how different modern epochs have problematized the accepted knowledge of sexuality, which have made sexuality a particular object of thought (O'Farrell 2005). The study of this particular kind of problem is marked by traces of historical approaches to sexuality since the $17^{\text {th }}$ century (Wilson 2003). By investigating the earlier history, particular attention was paid to the shaping influence of the body of knowledge (or truth) about sexuality and on the political and social structures, laws and regulations that determined what became known as sexual practices (Bacchi 2012; Foucault 1976). 'Sexuality', as Foucault notes, “does not exist as an object of thought" outside the relations shaped by particular knowledge and regulations (Bacchi 2012, p. 2). To understand how 'sexuality' becomes accepted and treated as a particular problem for individuals, one needs to search out the invisible forces that have come to constitute 'sexuality' as an object of thought in Western history (Bacchi 2012). This was Foucault's objective when he studied 'sexuality' as a problem.

Foucault considers similar objectives and thereby deploys the problematization method in his other book, History of Madness (2006), for example. In this book Foucault's primary concern is the 'scientific knowledge' of mental illness. Thus he questions how and why very different things were gathered together, characterised, treated and established as 'madness' between the $13^{\text {th }}$ and $19^{\text {th }}$ centuries in European history (Bacchi 2012; Foucault 2006; O'Farrell 2005). To answer this question, Foucault investigates elements, such as economic, institutional, medical, political and ethical practices, which were considered relevant to that problematization (Bacchi 2012; O'Farrell 2005). By examining these interventional 'elements', Foucault's objective is 
to underline the criteria for the establishment of the object of 'madness' on the one hand, and to query the 'true', 'universal', 'neutral' and 'fixed' scientific status of madness on the other (Bacchi 2012).

Rather than assuming that knowledge or episteme has a true status, Foucault's problematization method is underpinned by the idea of 'dismantling' objects, such as madness and sexuality, as 'universal', 'neutral' and 'fixed' essences (Bacchi 2012). Regarding the above examples, questioning and searching for how ideas about 'sexuality' and 'madness' have emerged in the historical process are an illustration of how problematization has called into question the presumed fixed knowledge status. In contesting 'true' knowledge, problematization opens up possibilities for one to analyse a flux of complex relations, such as connections, support and strategies, which result in the formation of objects of thought in Western history (Bacchi 2012).

Insofar as noted above, the critique of the problem of knowledge in Foucault's work is historical. Knowledge, according to Foucault, is a central component of power and domination (O'Farrell 2005). He considers history as a form of knowledge and at the same time a form of power (Poster 1982). To put it another way, history is a means of controlling and dominating the past in the form of knowing about it (Poster 1982). In Foucault's view, the knowing of history is an integral part of the essence of individuals, because this may be able to change the perceptions of individuals and the ways in which he or she may interact with the world (O'Farrell 2005; Roth 1981).

Historical knowledge is thereby seen as a thing that constitutes the 'truth' about how things are (Bacchi 2012; O'Farrell 2005). Importantly, historical knowledge about 'objects' such as 'sexuality' and 'madness', produce all sorts of effects on how an individual is governed and how s/he is to live their life (Bacchi 2012). Thus, because the historical objects of thoughts are internalised as norms, they can be co-opted as strategies that are used to govern the populations in a given society. Methodologically, Foucault calls for a disruption to the status (or our knowledge) of those objects as normal and true in order to make room for change (Bacchi 2012). Foucault goes on to argue that by configuring that problem as one that continues to influence governmentality in the present (or contemporary society), one can avoid being trapped in assigning this problem to being something of the past (O'Farrell 2005). 


\section{History of the Present}

Foucault's examination of the problems of the past shines a new beam of light onto contemporary problems, which are referred to as a History of the Present (or effective history) (O'Farrell 2005). History, by definition, is about the past. However, Foucault's historical analysis begins with his perception that something is problematic in the present (Gutting 2003). As discussed above, Foucault engages with the 'past' (or history) to demonstrate that certain problems of current social circumstances, such as 'madness', 'sexuality' and 'discipline', are linked to that past (Gutting 2003). For instance, Foucault was directly involved in political campaigns for the reformation of the prisons in France in his day (Bacchi 2012). To inquire about the status of French prisons, in his text Discipline and Punish (1977) he attempted to show how the punishment systems were problematized in the past and how the imprisonment practices of 'the present' were related to those previous problems. The characterisation of Discipline and Punish as a 'history of the present' considers the history of a problem in relation to how that problem is now seen in the present (Castel 1994).

One of the essential characteristics of Foucault's approach to a history of the present was his rejection of the notion of continuity that underpins much in traditional' historiography (Gutting 2003; O'Farrell 1989; O'Farrell 2005). As discussed previously, Foucault regards historical objects of thoughts as things that form the basis for modern episteme (or knowledge). Therefore, history itself is an unavoidable element of human thought in terms of forming the foundation of human knowledge, perceptions and ways of thinking (O'Farrell 1989). However, Foucault notes that traditional historiography aims to show a continuous status of the objects, such as 'sexuality' and 'madness', to reflect 'where we are' and 'who we are' are inevitably resulting from the progressive causes and effects (Gutting 2003; Hook 2005). His concern with the given condition of the historical continuous is how such overgeneralised or universal forms of narrative could explain specific and particular significations or problems across different historical contexts (Hook 2005).

In order to think through the problems of the limits facilitated by traditional historiography, Foucault calls for a suspension of the notion of continuous progression in order to focus upon the fragmentary nature of histories (Nicholls 2009). That is, Foucault conceptualises history as a set of fragmented and incoherent events, which are the consequence of man's diverse practices (or lived experience) (Thacker 1997). Hence, all forms of human activities, ideas and 
experiences are considered as events or series of events (O'Farrell 2005). This is unlike traditional historiography, in which events are neutralised as "the accidents or the minutiae of deviations". By contrast, Foucault deems events as human "errors [...] false appraisals and [...] faulty calculations" (Meadmore, Hatcher \& McWilliam 2000, p. 466). For this reason, the event at the centre of Foucault's analysis is the fragmentation of human activities, in which historical problems need re-examination. Such re-examination requires one to rethink an 'event' in a particular way as a means to search for the multiplicity of causes and conditions so that the objects, such as 'sexuality' and 'madness', can be analysed according to the multiple and complex processes that constitute this as an event or a problem (Hook 2005; Meadmore, Hatcher \& McWilliam 2000). This process is employed to illustrate that there is no ideal, natural and continuous progression, thus challenging the neutral and liminal region of episteme, which is produced by traditional historiography (Hook 2005; Meadmore, Hatcher \& McWilliam 2000).

\section{Genealogy: The History of the Present}

In examining the individuals' epistemological boundaries in the present, Foucault incorporates a notion of genealogy in developing an 'effective history', or a 'history of the present' (Thacker 1997). In his article Nietzsche, Genealogy, History, Foucault characterises genealogy as "grey, meticulous and patient documentary" (Oksala 2007, p. 47). This characterisation is illustrative of Foucault's opposition to the interpretation of histories as continuous and neutral, as produced by traditional history. Instead, Foucault's statement indicates that the use of genealogy in search of epistemological limitation involves a precise study of history and a detailed documentation of historical facts, as in the case of 'madness' and 'sexuality' (Oksala 2007). This unique method of historical analysis, as indicated above, is aimed at historicalising timeless 'events' in order to investigate the inevitable character of the 'problematic' forms of our everyday practices in the present.

\section{Historical Knowledge in Practices}

Genealogy, as a unique kind of historical analysis, underscores the link between our everyday practices and history (Jorgensen 2006). Through the use of history, Foucault's genealogical analysis is aimed at questioning the values in the forms of our present practices (Jorgensen 2006). In this regard, Foucault wishes to explore how the episteme of the past influences our 
daily practices, because he believes that the ways we think, act, judge and interact with the world are all products of our own history (Jorgensen 2006). In this sense, Foucault perceives practices in relation to 'what is said' and 'what is done' as interconnected with the given historical objects or reasons and the rules imposed in historical contexts (Bacchi 2012; Thacker 1997). These practices have created a 'judicative' component to establish norms and rules, wherein such practices have come to constitute a "veridicative' function of a practice" within the given status of true and false historical objects of knowledge (Flynn 2005, p. 32).

For example, in his book Discipline and Punish, Foucault notes that "the practice of legal punishment $[\ldots]$ entails a code that regulates ways of acting - how to discipline an inmate and the production of true discourse, which legitimates these ways of acting" (Flynn 2005, p. 31). Foucault's method of genealogical inquiry focuses on searching out how the rules that regulate the daily practices of human beings are tied to the objects within a matrix of power relations in society - such as how the production of objects regulates the ways of acting in the present (Flynn 2005; Oksala 2007).

By turning to practices, Foucault's genealogical analysis seeks to reveal how specific historical objects, such as 'madness', emerge as a thing to regulate the ways of acting (Bacchi 2012; emphasis added). Like 'sexuality', 'madness' is not a thing that exists as an object of thought until it is was produced through human practice (Bacchi 2012). In this context, the term practice can be considered an intelligible background for human actions, and hence practice and thought are weighed at the same level (Flynn 2005).

Taking this assumption further, Foucault postulates that practices are things that obey the "preconceptual, anonymous, socially-sanctioned body of rules" and, at the same time, such practices are things that govern one's thoughts in terms of "perceiving, judging, imagining, and acting" (Flynn 2005, p. 31). This statement indicates that practices are things that shape emergent individual men and relations to the extent to which men are constituted as specific kinds of subjects through practices (Bacchi 2012). Thus, practices, as part of the 'constitution' process, are deemed problematic. In summary, genealogy is a study of the emergence of historical objects of knowledge. For example, using Foucault's method requires studying 'madness', by investigating the practices that problematize, constitute, classify and regulate those designated as 'madmen' (Bacchi 2012). 


\section{Truth and Objects}

The focus of Foucault's genealogy is on those practices that produce objects of knowledge, and which in turn legitimate claims to truth (Bacchi 2012; See Chapter Four, 107-129). Truth, argues Foucault, "has had a history with history, from which we are barely emerging" (Foucault 1977, p.144 cited in Hook 2005, p. 15). The task of genealogy is to search beneath the 'surfaces of truth' for hidden meanings and interior consciousness (Hook 2005). This, in turn, requires one to yield to an inner consciousness to interpret a subjective truth, that is, how we come to know what we know as true, within one's objects and subjects of analysis (Hook 2005). This interpretative process demands that one listen to history and to diverse historical events (Hook 2005). Doing so allows us to discover something different beneath the events of the past, not simply a continuous, universal and essential truth (Hook 2005). Foucault's conclusion is that these so-called 'truths' have no essence, or simply that the essence is "fabricated in a piecemeal fashion from alien forms" (Foucault 1984, p.78 cited in Thacker 1997, p. 34). As we have seen in Foucault's historical work, the truth of 'sexuality' and 'madness' does not exist as a fixed essence; rather, the truth emerges and becomes real objects of thought in practice (Bacchi 2012).

Through an examination of the practices that are attached to historical objects, such as 'madness' and 'sexuality', the question asked in the genealogical approach is: how have objects emerged and become something true (Bacchi 2012)? Genealogy in fact searches for 'the true and the false', a goal that is reflected in Foucault's conceptualisation of 'games of truth' or truth (Bacchi 2012, p. 4). Foucault finds that 'telling the truth' is similar to 'playing a game', because neither 'a game' nor 'a truth' requires external criteria to judge its content (Bacchi 2012, p. 3). Rather, the content of 'a game' or 'the truth' is judged and shaped by internal rules (Bacchi 2012, p. 3). This implies that the emergence of 'real' objects is conditioned by the rules of 'production of truth', internally, within each particular historical context. The 'production of truth', Foucault argues, does not mean a "production of true statements", but rather, an internalisation of the realms to which the production of 'the true and the false' objects is regulated by the internal 'rules of a game' (Bacchi 2012, p. 4).

\section{Power, Knowledge and Truth}

To underscore the intervention of the 'production of the objects', Foucault's interest in genealogy concerns its articulation with respect to the effects of power upon individual bodies 
(Flynn 2005). For instance, Foucault begins Discipline and Punish (1977) with an account of the punishment that is imposed upon the body of "Damiens the regicide"11 (Smart 1985, p. 74). Following the narrative of Damiens' torturous public execution, Foucault focuses on a series of discussions on the nature of power as discipline (or control), which is contrasted with what he terms the 'traditional juridical notion of power' (Hutchings 1997, p. 105). The difference between the two notions of power is illustrated in the contrast between the public spectacle of physical punishment of Damiens and the treatment of prisoners within the panopticon (Hutchings 1997; Smart 1985). Unlike the juridical power exercised through sovereignty and law, the panoptic system exercises the power of discipline through "internalisation of a discreet, watchful gaze" for the efficient control of the behaviour of prisoners (Magill 1997; Oksala 2007, p. 57). This effect is achieved through prisoners' knowledge of being watched so that they are compelled to regulate their own behaviour (Magill 1997; Ransom 1997a) in the centralised observation system of the Panopticon (see Figure 2):

Figure 2: Interior View of the Panopticon

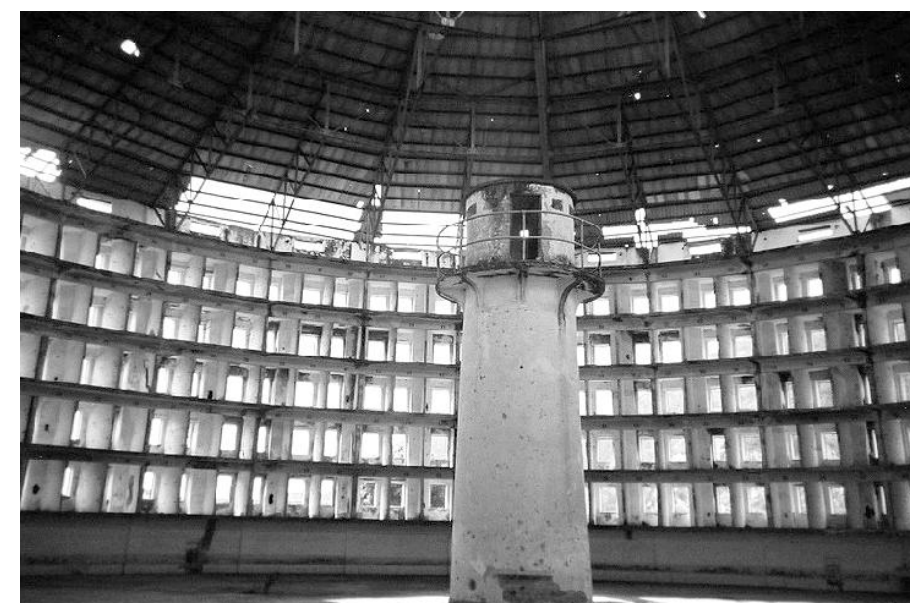

Source: 'Bentham's Prison: A Study of the Panopticon Penitentiary: A Study of the Panopticon Penitentiary' (Semple 2003)

\footnotetext{
${ }^{11}$ Robert Francois-Damien who attempted to assassinate (regicide) King Louis XV in 1757 was arrested and subjected to Paris execution which consisted of a number public tortures. Damien was first subject to a torture in which his legs were compressed by devices called boots. He was then tortured with red-hot pincers; the hand with which he held the knife to assassinate was burned using sulphur; molten wax and lead, and boiling oil. Finally, he was remanded to the executioner who harnessed horses to his legs and arms to be dismembered. See Foucault, M 1977, Discipline and Punish: The Birth of the Prison, trans. A Sheridan, Vintage Books, New York.
} 
The interior design of the Panopticon consists of a circular structure with an inspection house at the centre of the tower, while the individual cells have large windows that open to the centre, with smaller windows in the rear to enable backlighting to illuminate the cells from one end to another. The concept of the design of the Panopticon is to allow the criminals in the cells to be visible to the watchman without the criminals detecting the precise source of their surveillance, which compels them to self-regulate their behaviour (Magill 1997; Ransom 1997a). This creates a "new mode of obtaining power of mind over mind [or 'conduct of conduct' in Foucault's terminology], in a quantity..." (Bentham 1843, p. 39) and leads to an efficient control and reform of the criminals through the internalised gaze of a watchman (Magill 1997; Oksala 2007, p. 57). The truth of being watched under constant surveillance in the panoptic system facilitates the automatic functioning of a disciplinary power within the minds and bodies of the criminals without external authority being imposed (Ransom 1997a).

Using the metaphor of the Panopticon, Foucault (1977) notes that a disciplinary power is embedded in all levels of social relations in smaller elements, such as at hospitals, schools and factories, and in families, that individuals engage in. Together these social relations exercise a regime of a disciplinary power to produce behaviour by individuals within a norm (or rule), all the while ensuring that behaviour that departures from this norm are identified as needing to be corrected:

The workshop, the school, the army were subject to a whole micro-penalty of time (lateness, absences, interruptions of tasks), of activity (inattention, negligence, lack of zeal), of behaviour (impoliteness, disobedience), of speech (idle chatter, insolence), of the body (incorrect' attitudes, irregular gestures, lack of cleanliness), of sexuality (impurity, indecency).

(Foucault 1977, p. 178)

Foucault (1991a) subsequently conceptualises power as networks of relationships that are formed by webs of productive, individual relations that produce reality by constructing domains of rituals and objects of truth (or knowledge), such as 'criminals' and 'madness', to correct the minds of individuals and both determine as well as alter their behaviour in society. Knowledge and power are thus viewed by Foucault as inseparable relations that function together to enable a disciplinary power that reaches into the physical and cerebral areas, and 
exercises discipline over the bodies, soul, gestures, behaviours and practices of the individuals within the social network (1977).

Foucault's genealogical analysis reveals that both the soul and the body, as objects of discipline and control, are the "target for the exercise of power" in a disciplinary society (Smart 1985, p. 75; See Chapter Four, p. 103). To manipulate individuals' behaviour in certain ways, a particular conception of 'truth' emerges as a specific object (or reason) to govern the thoughts of individuals (Bacchi 2012). 'Truth', according to Foucault, is generated by the interplay of disciplines immersed in the bodies of scientific knowledge (Ransom 1997b). A certain set of truths emerge around the tasks the disciplines design as something 'natural' and 'normal' (Ransom 1997b). What counts as natural and normal depends on the kinds of things that science, or the disciplines, decides to measure, including specific economic, military and social needs. The disciplines, as a result, determine what is natural and normal in order to measure those who are abnormal (Ransom 1997b).

In Madness and Civilisation, for example, Foucault (2001) questions the truth of how and why notions of the abnormality of various conditions were gathered together, characterised, treated and labelled as 'madness' in the European historical context. In the classical age, Foucault (2001) notes, the houses of confinement were not inhabited only by the mad, but also by abnormal people, including lazy, poor and unemployed people. The abnormal were categorised as 'the mad' because their behaviour was conceptualised as a violation of the work ethics of their society (2001). Their morally deviant behaviour was considered to be 'unreason', 'dangerous' and 'idleness', which could not be constrained by the juridical laws (2001). The 'madmen' were subsequently chained in their cells in order to be segregated from the normal (Oksala 2007). In this narrative, Foucault wishes to illustrate that scientific truth, like madness, has no essence, because this essence is simply "fabricated in a piecemeal fashion from alien forms" (Foucault 1984, p.78 cited in Thacker 1997, p. 34). In Foucault's view, a truth emerges, as in a real object, to normalise the way people practice and judge in their societies (Bacchi 2012).

\section{'Normalisation' and Examination}

Normalisation, in terms of behaviours and judgments, thus spreads through the function of examination (or judgement) that operates throughout the entire social body, within the schools, 
the hospitals, the factories and families in their social relationships (Foucault 1980a). This resembles a carceral (or prison) system that creates a dominant class of managed, controlled and useful bodies that serve as supervisors of others (Schrift 2013). Christian schools, for example, constitute minute social 'observatories' and surveillance systems to train and correct children's behaviour - their piety and morals, for instance (Foucault 1977). This makes individuals become a society of judges and hence the judges of normality are present everywhere in society - the teacher-judge, the doctor-judge and the social worker-judge (Schrift 2013). Each individual is attached to an identity (the truth about oneself) and subjects their body, gestures, behaviour, aptitudes and achievements to the discourses of truth that are embedded in his or her society (Foucault 1980a; 1980b; 1991a). As a result of this, individuals are indeed the product of power-knowledge relations through which their behaviours exhibit the set of rules, practices and constraints that are established by the carceral network of their culture:

The carceral network constituted one of the armatures of this power-knowledge that has made the human sciences historically possible. Knowable man (soul, individuality, consciousness, conduct, whatever it is called) is the object-effect of this analytical investment, of this domination-observation.

(Foucault 1977, p. 305)

The extension of the panoptic system to various unofficial centres that operate forms of indirect supervision has made individuals exercise disciplinary power among themselves to ensure that everyone acts in accordance with the discourses of 'truth' (Smart 1985). It is in this context that Foucault (1980a; 1980b) argues that a disciplinary society emerges, not by the making of laws, but by the internalisation of norms that have conjoined the mind, body and movement of individuals. This effect is referred to as government of mentalities (governmentality or conduct of conduct) that guides the individuals to self-regulate their own (and others') behaviour, to achieve the status of truths (or norms) of their society, without engaging in critical thinking, within the carceral network (Foucault 1980b). 


\section{Subjectivation and Re-subjectivation}

Foucault (1982) notes that the intertwined relations of the discourses and governmentality are problematic to individuals in the processes of subjectivation ${ }^{12}$ (or the self) in the present. His work on, for example, 'madness' and 'criminals', illustrates the nature of selfhood within the forms of discourses that have worked to constitute individuals as specific kinds of subjects in self-governing and self-regulating their thoughts and behaviours in particular ways (Davidson 2003). It is in such a way that self-formation is repressed by truths from outside the self in its own history, that is, the force of a carceral system is to repress any other thought about how else we can think about what we come to know as being true. This argument is reinforced by Foucault's (1978) analysis of 'sexual conduct' and 'sexual repression' in Western societies. In The History of Sexuality (1978), Foucault's draws on a long history of Christian confession to analyse the Western discourses and values related to sex since the $17^{\text {th }}$ century. He notes that the discourse such as sex with boys was constructed as evil to tie individuals into that 'truth' and then into silent subjects (1978). Foucault (1980b) subsequently argues that self-formation is inseparable from the forms of discourses that are circulated within the carceral network of a particular society. In other words, the truths about the self are predominantly attained through a circumscription of a space of possibilities or limitations for the development of selfhood in the historical processes of subjectivation:

$[\ldots]$ the history of subjectivity: no longer, however, by way of the divisions between the mad and those who are not mad, the ill and those who are not ill, delinquents and those who are not delinquents; no longer by way speaking, working subject. But rather by the putting into place and the transformations, in our culture, of the "relations to oneself", with their technical armature and their effects of knowledge. And one could thus take up, under another aspect, the question of "governmentality": the government of the self by the self in its articulation with relations to others [...]

(Foucault 1989, pp. 135-136 cited from Davidson 1994, p. 127)

\footnotetext{
${ }^{12}$ Subjectivation is a process of self-formation in which individuals construct identities for themselves throughout the process. See Clifford, M 2001, Political Genealogy After Foucault: Savage Identities, Routledge, New York.
} 
Subjectivity, for Foucault (1987), thus emerged from the endless processes ${ }^{13}$ of the construction of the true identities which individuals 'attain' in the specific historical circumstances, such as the influence of Christianity. The formation of the self is thereby the processes of becoming that focus on who we are and so what we do (Ball \& Olmedo 2013, p. 87), and which is grounded in the 'moral majority' (Besley \& Peters 2007, p. 41) about what is regarded as 'truth' (Richardson \& Woolfolk 2013, p. 11) in their specific social relations (such as for instance, the truth that sex with boys is evil). It is within these relationships that the subject (or the self) becomes governed by others while at the same time becomes the governor of the self (or the government of the self) in the given power-knowledge networks (Dean 2010).

The government of the self is crucial in Foucault's (1987) elaboration of resistance that developed from his analysis of the power-resistance against the specific normalising disciplinary practices in particular cultures. For example, cultural representations of the body and its sex are constructed as natural for gender identification. This knowledge forces individuals into two opposite gender categories, which in turn have a normative effect that unquestionably conforms to codes of practices that are based on the social expectations of what it means to be heterosexual (Oksala 2005). Taking the homosexual (or gay) subcultures of San Francisco in the 1980s as an example, Foucault argues that those engaged in sadomasochistic (or SM) activities had organised themselves as alternative communities which escaped aping heterosexuality and culturally approved coupledom around their own principles of 'pleasures and bodies'(1997, pp. 152-169). The notion of 'bodies and pleasures' becomes an important element for resistance, for instance: performing gay SM sexual activities for bodily pleasures, such as binding the penis or trapping it between magnets, through sex-desires or fantasies, created different sexual identities and selves (Chaline 2010), role-play for example, and have challenged the normative queer idea that the gay identity must perform certain acts, such as being anally penetrated by a man with a strap-on (Downing 2008). Using the gay SM scenes as an example, Foucault wishes to show that the refusal of the gay SM to act in accordance with what sexuality and queer identification are habitually put is a form of reversal power that

\footnotetext{
${ }^{13}$ Foucault perceives subjectivication as endless processes because the exercise of power is always partial and contradictory in the power-knowledge relations. See Foucault, M 1982, 'The Subject and Power', in Michel Foucault: Beyond structuralism and hermeneutics, eds H Dreyfus \& P Rabinow, University of Chicago Press, Chicago, pp. 208-226.
} 
presents a possibility for subverting normalisation by the self through overcoming the normative practices in favour of a problematization of the 'truth' that lies in the fixed identity categories (Downing 2008).

Thus, while forms of subjectivity correspond to the historical tradition of thought, Foucault (1997) argues that re-subjectivation (or self-reformation) can be achieved through ethical practices (or aesthetics of existence). In The Ethics of the Concern for Self as a Practice of Freedom, an interview in 1984; Foucault (1997) emphasises that the discourse of truth is an ascetic practice of self-reformation. Ascetic, as Foucault defines it, is an "exercise of self upon the self by which one attempts to develop and transform oneself, and to attain a certain mode of being" (1997, p. 282). This task is focused on practices related to taking care of one's soul in order to make one's life into an art of existence:

When you take care of the body, you do not take care of the self. The self is not clothing, tools or possessions; it is to be found in the principle that uses these tools, a principle not of the body but of the soul. You have to worry about your soul - that is the principle activity of caring for yourself. The care of the self is the care of the activity and not the care of the soul-as-substance.

(Foucault 1997, p. 230)

Foucault (1997) perceives taking care of the self-as-soul as a form of knowing the self (gnothi seauton), which enables one to relate the self and its life, not as something simply given, but as a thing that can be transformed in the direction of freedom. Hence, while forms of subjectivation are normalised by codes of behaviour within the discourses in the system of one's culture, Foucault's genealogical study of his unfinished project of the Care of the Self (1986) illustrates how the Greek monastics adjusted the codes of sexual conduct for themselves within Christian discourses:

[...] each of the three great arts of self-conduct, the three major techniques of the self, that were developed in Greek thought - dietetics, economics and erotics - proposed, if not a particular sexual ethic, then at least a singular modulation of sexual conduct. In this elaboration of the demands of austerity, not only did the Greeks not seek to define 
a code of conduct binding everyone, neither did they seek to organize sexual behaviour as a domain governed in all its aspects by one and the same set of principles.

(Foucault 1990, p. 251)

Foucault's (1997) study of the Greeks and their corresponding conception of the self demonstrates that there is no true self that can be emancipated from the forms of discourses. He envisages that the practices of the self that are exercised upon the self by knowing the self enables one to shape one's life creatively. The example of Greeks demonstrates that even their sexual behaviour was still referenced to a code of conduct, because their modes of actions were guided by their own definitions of the use of pleasure for the self. From this perspective, Foucault points out that even though individuals are historically constituted within a regulatory framework, they are not simply constructed, but they themselves are able beings who partake in that construction to modify themselves through practices of the self (1990). Much like his discussion on gay SM, Foucault's study of the Greeks' sexual pleasure was continuously presented as an ethical substance that required a strong subject to achieve pleasure over domination of codes of conduct (1986). It is only by knowing the self that the individual is able to take control of shaping their ways of life and behaviours, that is freely adhering to their aesthetic criteria and ethics of existence for the self:

The emphasis is placed on the relationship to self, which means that one does not allow oneself to be swept away by appetites and pleasures; [one is] to keep mastery and superiority over them, to keep one's sense in a state of calmness, to remain free from any inner slavery to passion and to reach a mode of being which can be defined by the full enjoyment of oneself or the perfect sovereignty of self over self.

(Foucault, p. 38 cited in Smart 1985, p. 111)

Foucault's $(1982 ; 1986 ; 1987 ; 1997)$ idea of the alternative form of self-formation, namely the quest for freedom, characterises individuals not simply as docile bodies, but as selves who are able to actively refuse and alter their form of being, thus contesting the effects of normalising power in their social relationships. The Greeks' self-care practices, as a form of practising freedom, functioned as resistance to normalising practices by shaping the self and lifestyle 
through the exploration of opportunities for new ways of being and new fields of experiences, pleasures, and modes of living and thinking within their relationships with others in the Greek culture (Olssen 1999; Oksala 2007). The important legacy of Foucault's thought about resistance is that self-control is embodied in the nature of selfhood among other individuals to the extent that re-subjectivation is a process that liberates the self by opening up spaces of freedom that make a different way of life in the power-knowledge relations possible (1997). Foucault views self-care practices as ethical because they emphasise one's relationships and duties towards others, such as family members and other people in society:

Care for self is ethical in itself, but implies complex relations with others, in the measure that this ethos of freedom is also a way of caring for others [...] ethos implies also a relation with others to the extent that care for self renders one competent to occupy a place in the city, in the community or in interindividual relationships [...] And the care for self implies also a relationship to the other to the extent that, in order to really care for self, one must listen to the teachings of a master [...] the problem of relationship with others is present all along this development of care for self.

(Foucault 1987, p. 118)

By making reference to the close relationship between care of the self and care for others, Foucault's notion of individuals' self-care practices is bounded by a system of reciprocal obligations (Smart 1998). In other words, responsibility for others is fundamental to the care of the self and care for others, that is individuals exercise their cautious agency to control their own conduct in adjusting their thoughts and behaviour in the processes of re-subjectivation in their society. Henceforth, in the process of making something different in the self, one is obligated to control the self's conduct because the ethos (or action) of freedom is an ethical act that deals (and impacts upon) a surrounding community (of family, friends and others) (Oksala 2005). As a result, the self is never isolated from, but always linked to proper practice in society and relationship with others through and throughout power-knowledge relations.

In summary, resistance as characterised in Foucault's (1987) philosophy is developed from the notion of 'the art of life' that is associated with the principle of the 'caring for the self' to resist 
normalising practices. For Foucault, self-care practices are forms of knowing the self which enable one to adjust the codes for one's conduct and live differently as well as to question the subtle forms of domination that have constructed individuals as different types of subjects - as homosexuals, madmen, as normal and healthy, and as workers (1980a; 1997). Thus, Foucault's work on power-knowledge relations are never about total domination or manipulation, as they always present a possibility of resistance ${ }^{14}$ in irregular fashion.

When considering Foucault's account of resistance in relation to the topic of this thesis, this study seeks to understand how historical knowledge constitutes a thing that guides everyday workers to think and act in certain ways and how self-care practices by the workers empower them to live and act according to their own will of improving their living and working conditions for themselves as a class. To explore this aspect, the study applies Foucault's genealogical method to investigate how worker consciousness has been shaped by powerknowledge relations since Imperial China (13 ${ }^{\text {th }}$ B.C.E. $)$ through to the present day to address the research question and proposition (see pp. 13-14).

\section{Concluding Remarks}

In this chapter Foucault's theoretical framework and his toolkits have been described. To understand the epistemological limitation in the present, Foucault gives us a genealogical method as a means to produce a history of the present (or effective history). This method involves techniques to develop a precise study of history through detailed documentation of historical events and facts (as in the case of Foucault's studies of 'madness', 'criminals' and 'sexuality') to investigate the inevitable character of problematic forms of practices that are shaped by the historical knowledge (or discourse) within the power-knowledge relations.

Foucault subsequently maintains that historical knowledge is a thing that constitutes both the conditions of possibility for social beings to think and the conditions that enable or constrain the effects of action, and shape the practices of individuals within forms of discourses. Thus, social practices embody thoughts and reflect the ways that individuals are being governed in

\footnotetext{
${ }^{14}$ Foucault argues that "there are no power relations without resistances", for example: slavery is not a power relationship when men are in chains. See Foucault, M 1980a, Power/Knowledge: Selected Interviews and Other Writings 1972-1977, trans. C Gordon, L Marshall, J Mepham \& K Soper, Vintage Books, New York, Foucault, M 1982, 'The Subject and Power', in Michel Foucault: Beyond structuralism and hermeneutics, eds H Dreyfus \& P Rabinow, University of Chicago Press, Chicago, pp. 208-226.
} 
their social networks. In this context, Foucault argues that it is the internalisation of the sociocultural historical knowledge among individuals that shapes their consciousness in such a way that they are able to manage themselves, and therefore to live their lives and relate to themselves and to other people (governmentality or conduct of conduct) according to the norms within a given society of the present (1980a).

In the next chapter Foucault's genealogical method will be applied to the investigation of Chinese governmentality to explore the knowledge that has been produced and the kind of consciousness that has been continuously promoted. It is argued that the effect has been to create docile bodies and minds of Chinese workers. By writing a Chinese history of the present we are thus able to better analyse the possibilities for everyday workers to form into an organised labour movement to struggle against their given conditions. Thus, the study borrows the themes and toolkits from Foucault concerning the way power operated in China by analysing the specific historical events (see Chapter Three) that have continued to shape workers' consciousness and the way they live their lives (see Chapters Six and Seven) in today's China. Doing so enabled us to explore how worker activism in China is influenced by 'older rules consciousness', or status consciousness; how this consciousness affects their willingness to engage in acts that are perceived as contradictory to their cultural (or social) practices in China, and how the development of class consciousness and class-for-itself among workers is influenced by this 'older rules consciousness'. 


\section{Chapter Three: Docile Bodies and Minds: A Genealogy of Chinese Workers in China}

According to Nietzche, Blanchot and Bataille, experience [...] accomplishes the 'tearing' of the subject from itself, transforming it into something different from what it was, or completely other than itself, achieving its annulment, its disassociation, as a result. This enterprise of de-subjectification, the idea of a 'circumscribed experience', that tears the subject from itself, is the fundamental lesson that I have taken from these authors. The ways I do my books, I have always conceived them as direct experiences 'tearing me' from myself, to prevent me from always being the same.

(Foucault 1991c, pp. 31-32)

The aim of this chapter is to investigate the historical development of the Chinese governmentality that has shaped workers' consciousness by tracing the key events using Foucault's (1991a) historicalisation methods, which are grouped under the rubric of genealogy (see Chapter Two, p. 49). As noted in Chapter Three, Foucault's genealogical study of the effects of power relations in terms of conditioning individuals into a certain kind of thinking is contrasted to the traditional conceptualisation of a continuous, knowing consciousness (1991a, p. 95). In opposition to the notion of continuation and true (or universal) knowledge as the final point of human development (Foucault 1991a, p. 83), his analysis of the emergence of 'prison practices' (1977), the institutionalisation of 'madmen' $(1976$; 2006) and the construction of 'sexual conduct' (1978) has shown that individuals are the products of power relations (see Chapter Three, p. 87). Foucault's critique of knowledge (or episteme) (2002, pp. 30-54) is that traditional historians aim to write history in a way that maintains and reinforces a continuous narrative, with little or no critical explanation (Smart 1985). However, while recognising the deficiency in traditional, historical writing, Foucault does not advocate abandoning knowledge and investigation of the past (Thacker 1997). Rather, he suggests that the quest for a more authentic knowledge is to think and identify contingencies between historical events and to then reinterpret earlier interpretations of the intellectual works in order to make sense of the 
past (Thacker 1997). It is through our effort to discontinue the intellectual landscapes of necessary forms of thinking that we can produce a genealogical study to free our thought "from what it silently thinks, and enable it to think differently" in our present day (Foucault 1990, p. 9).

Using Foucault's historicalisation methods, the study seeks to explore how worker activism in China is influenced by 'older rules consciousness'; how this 'older rules consciousness' affects their willingness to engage in acts that are perceived as contradictory to their cultural (or social) practices in China, and how the development of class consciousness and class-for-itself among workers is restrained by 'older rule consciousness'. To understand how living and working in post-Mao China has continuously shaped an 'older rules consciousness' among workers which affects their activism and ability to form into a class-for-itself to improve their living and working conditions for themselves and others, this chapter examines the historical events that have arguably produced important - but hidden - Confucian ( $l i$ 禮) knowledge that has been internalised by Chinese workers to guide their perception of their existence since Imperial China. The chapter begins with an analysis of how $l i$ rules were used to regulate Chinese conduct from the Zhou period (13 ${ }^{\text {th }}$ B.C.E). The chapter then explores how Zhou $l i$ was modified by Confucius and his followers (or the Confucians) to regulate the thoughts and behaviours of the Chinese. The manner in which the Confucian rules were used to govern the souls of the Chinese to create proper conduct (or orthopraxy) from the Han dynasty (206 B.C. - 220 B.C.) and through to the Qing dynasty (1644 - 1911) - the last Imperial dynasty - and into Mao's period $(1949-1976)$ is then illustrated. The chapter concludes that the $l i$ rules with Confucian elements that created docile bodies and minds among the Chinese have had significant implications for governing workers' minds and behaviours (or governmentality) in today's China.

\section{Li Rules and Confucianism}

$L i^{15}$ 禮 (proprieties) rules are a major Confucian moral concept that equates proper conduct with the social status of the high and the low (Pearce 2001). Originating in the pre-Confucian

\footnotetext{
${ }^{15} \mathrm{Li}$ was originally referred to religious and sacrificial practices that took place in the temple, such as funerals; and hence the word $l i$ had marked the moral and rank distinctions between spiritual gods and human beings in ancient China. See Cheng, C-Y 1979, 'Human Rights in Chinese History and Chinese Philosophy', Comparative Civilisations Review, vol. 1, pp. 1-20.
} 
primitive society as early as 2070 B.C.E. ${ }^{16}$, $l i$ rules were predominately associated with the concepts of tian 天 (heaven) and $d i$ 地 (earth) to make it mandatory for the Chinese on earth (the low) to 'naturally' worship the spirits of the heaven (the high) (J. Zhang 2014). Based on this utmost filial practice towards the spirits, $l i$ rules were transformed into mandatory rules of conduct by various emperors to standardise Chinese thinking and behaviours to maintain the monarchical power of the rulers (Head \& Wang 2005). Zhou Gong (922 B.C.E. - 900 B.C.E.) (Melton 2014, p. 87), who was the sixth king of the Western Zhou dynasty (1040 B.C.E. -771 B.C.E. $)^{17}$, modified $l i$ rules to facilitate the making of a social hierarchy to differentiate the social ranks of the noble (the high) and the peasants (the low) in a feudalistic social system (Cheng 1979; Yang 1978). To fortify the dominant position of the royal ruling classes and maintain the status quo, $l i$ rules were subsequently linked to a code of capital punishment (or death penalties - sihsing 死刑) to forbid certain speech, thoughts and actions among the masses (Leung 2016) under the laws of the ancient Zhou:

Death to anyone who disturb[s] the government by initiating reforms; death to anyone who confuse[s] people by making lascivious noise, wearing barbaric clothes, exhibiting strange skills, and using strange utensils; death to anyone who confuse[s] people through adherence to wrong doings, arguing for sophistry, studying unorthodox thoughts, and rebelling against authority; death to anyone who confuse[s] people by practising witcheraft $[\ldots]$ and fortune telling.

(Lu 1998, p. 60)

The criminal code enacted by the Zhou dynasty exemplified li rules that focused on the true values of filial piety (xiao 孝), through which the violations of the stated prohibitions and

\footnotetext{
${ }^{16}$ Ancient Chinese history began with the 'Three Dynasties (san dai 三代)', namely the Xia (2070 B.C.E. -1600 B.C.E.), the Shang (1600 B.C.E. -1046 B.C.E.) and the Zhou (1040 B.C.E. -771 B.C.E.). The Xia dynasty had left a wealth of archaeological artifacts which showed its existence, while a documentable history only began with the Shang dynasty in the form of inscriptions craved on oracle bones wherein the Zhou dynasty was the most well documented of the three. See Littlejohn, R 2011, Confucianism: An Introduction, I.B. Tauris \& Co Ltd, New York, Shankman, S \& Durrant, SW 2000, The Siren and the Sage: Knowledge and Wisdom in Ancient Greece and China, Cassell, New York.

${ }^{17}$ The Zhou dynasty was founded by the Ji family nearby Xi'an, Western China. In 771 B.C.E. the capital was attacked by a nomadic tribe called the barbarian (manren 蠻人) and thus Zhou's capital had moved Henan province and resulted in what was known as Eastern Zhou (770 B.C.E. - 256 B.C.E.). The Eastern Zhou was characterised by political fragmentation with six other state units arouse and gained power in the neighbourhood. See Orser, C 2014, Encyclopedia of Historical Archaeology, Routledge, New York.
} 
restrictions were subject to forms of torturous capital punishments. Methods of torture and execution ranged from being boiled in oil or water to being stoned or crushed, or 'death by a thousand cuts' (or Lingchi 凌遲 in Qing criminal code) (see Figure 1) by slicing the body of a confessed criminal with a maximum of 3,600 cuts, in a public space (Brook, Bourgon \& Blue 2008; Miethe \& Lu 2005).

Figure 3: Death by a Thousand Cuts (Lingchi 凌遲)

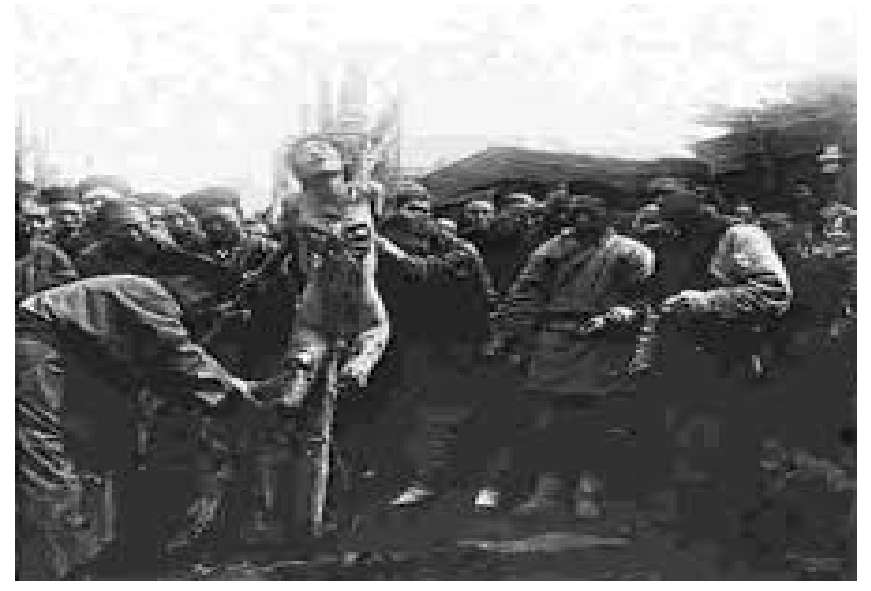

Source: 'Imperial Criminal Law' (Huangquan xinglu) (Wen \& Zhang 2014)

The punitive logic of public punishments was directed towards the protection of the 'truth' of the $l i$, that is the conduct of filial piety through a political ritual of judicial torture by producing pain in the body of a convicted criminal in order to demonstrate the sovereign's power for all to see (Lu 1998; Schrift 2013). In revealing the truth by exercising coercive power on bodies judges as deserving of this punishment because they had transgressed expectations of their behaviour; the mechanism of public torture and punishment was a visible form of truth-power relation to suppress the thoughts and actions of the masses and ensure the hegemony of the ruling class in the feudal society ( $\mathrm{Lu} \mathrm{1998).}$

With the decline of the Western Zhou dynasty after the invasion of the menren 蠻人 (or the Dog Barbarians) in the Spring and Autumn (772 B.C.E. - 481 B.C.E.) and the Warring States (480 B.C.E - 221 B.C.E.) period, the feudal system deteriorated (Dudbridge 2013; Fairbank \& Goldman 2006; Lu 1998; Yang 1978). During this period, private ownership of land increased and commercial progress accelerated when advanced agricultural technologies, such as iron tools, became more prevalent (Cheng 1979; Grasso, Corrin \& Kort 2009). More paid work 
became available as the production of agricultural equipment grew, while the domestic and foreign trade markets were also developing (Roberts 1999). These changes not only led to the demise of the feudal hierarchal structure, but also subverted the power underpinning the $l i$ rules of conduct (Yang 1978). Political crises precipitated a sense of moral decline among the peasants and workers (or masses) as the barbarian king lost the capacity to preserve the dynasty because of social disorder (Y. Zhang 2014). This caused social chaos and subsequently led to social and political upheavals, nomad invasions and chronic internecine war in the anarchical society of States (known as the Warring States) (J. Zhang 2014). The Warring States period ended with the unification of China by the ruler of the Qin dynasty (221 B.C.E. - 206 B.C.E.), who named himself Qin Shihuangdi ${ }^{18}$ 秦始皇 (259 B.C.E. - 210 B.C.E.), to rule his empire and solidify his power ${ }^{19}$. Stigmatised by his merciless pursuit of power, the Qin dynasty outlived Qin Shihuangdi himself by only four years as rebellion ensued after his death ${ }^{20}$.

\section{The Confucian 'Mandate of Heaven'}

In light of the ideal of Chinese unity and virtue fostered by the Zhou dynasty, Confucius (or Kongzi 孔子) (551 - 479 B.C.E.) (Mak \& So 2011, p. 38) sought to end the conflict and fragmentation of his time during the Warring States China through moral revival (Lovell 2007). Thus, the prescription of Confucius and his disciple Mencius (or Mengzi 孟子) (372 - 289 B.C.E) (Rainey 2010, p. 87) for a well-off (xiaokang 小康) harmonious (hexie 和諧) society remained informed by Zhou's $l i$ of proper conduct in a hierarchical order of superior (high) inferior (low) relationships (Lai 1995; Rojek 1989; Yang 1978). Using Zhou $l i$ as a template, Confucius sought to legitimise dynastic $l i$ rules by rectifying social ranks and names to establish an orderly set of social relations of the high and low positions, such as the father and the son, the older and the younger brother, and the husband and the wife, under a truth of the 'Mandate of Heaven' (tianming 天命) (Cheng 1979; Tan 2009). In the Confucian discourse, the 'Mandate of Heaven' articulated the individuals' true positions that then identified their life

\footnotetext{
${ }^{18}$ Shihuangdi 始皇 was referred to as first emperor of China. See Ching, F, Jarzombek, M \& Prakash, V 2007, A Global History of Architecture, John Wiley \& Sons, New Jersey.

${ }^{19}$ Qin Shihuangdi ruled the nation by codifying China's laws, standardising the Chinese writing system and language, raising taxes, suppressing those who opposed him, as well as completing the Great Wall to fend off the invaders which claimed countless Chinese lives. See ibid.

${ }^{20}$ The collapse of the Qin dynasty was a result of the establishment of the Han dynasty (206 B.C.E. -220 B.C.E.). See ibid.
} 
tasks and responsibilities in their ming 命 (fate or destiny). These were predetermined by tian 天 (or heaven) from birth (Pankenier 1995; Yao \& Zhao 2010):

The relation between superiors and inferiors is like that between the wind and the grass. When the wind blows across it, the grass must bend.

(Confucius 2010, p. 111)

The Confucian truth of the 'oneness of nature-human' (tianren tongxing 天人同行) ${ }^{21}$ order in the doctrine of the 'Mandate of Heaven' codes of $l i$ moral conduct, emphasised as paramount the need to accept and obey the 'natural' ruling order and the power of superiors imposed on ming by tian (Yuan \& Wen 2014). Superiors, such as the emperors were regarded by the Confucians as the 'Sons of Heaven' (tianzi 天子), with divine mandates to rule and control the lower classes (or inferiors) (Grasso, Corrin \& Kort 2009). A challenge to the 'Mandate of Heaven' of the ruling classes (or superiors) by inferiors was to disobey or deviate from the $l i$ codes of conduct (Guo 2013). These codes of proper conduct of filial piety and obedience to superiors were central to Confucian thought and regulated the social behaviour of the inferiors, such as son, wife and pupil, by reaffirming their given status imposed by their ming (Fouts \& Chan 1995).

By connecting the truth of ming with individuals' status (or positions), the followers of Confucius (or the Confucians) sought to inculcate a morality of obedience (or a mentality of respect for authority) into their mindsets in order to create an orderly society (Fouts \& Chan 1995; Rojek 1989). In this context, the Confucian $l i$ rules prioritised the moral teaching of proper conduct from the moment of birth (Fouts \& Chan 1995). One example was the teaching of filial piety to children (Rojek 1989), which contributed to influencing and correcting individuals' actions by their given status in broader contexts, such as community schools and extended family networks (Madsen 2008; Rojek 1989). By socialising an individual in the practices of education and culture, one's behaviour became observable to others (Fairbank \& Goldman 2006; Rojek 1989). In this way, individuals' behaviour became increasingly

\footnotetext{
${ }^{21}$ In Confucianism, the 'oneness' (or the sameness) of nature and humanity means that heaven and humans are morally the same. For example, human virtues such as humaneness (ren 仁), righteousness ( $y i$ 義), loyalty (zhong 忠) and faithfulness ( $x$ in 誠) are all bestowed from the heaven. Thus, the 'oneness' of the nature and human orders is a view of human participation in the universe where things are proceeded in a regular pattern. See Chen, $\mathrm{Y}$ 2016, The Chinese Christology of T. C. Chao, Brill Publishers, Netherlands.
} 
regulated by others on the basis of a collective moral judgement (of others) and the self (Fairbank \& Goldman 2006; Rojek 1989) under a doctrine of similarity to others (Evasdottir 2004).

\section{Confucian-Orthopraxy System}

The maintenance of social order in Confucianism relied upon conformity to commonlyaccepted correct actions, as characterised by orthopraxy (or standardisation of proper practice) (Watson 1988) as described in Chapter One (p. 28). In contrast to orthodoxy, orthopraxy was a system of correct 'orthodox practice' (or given belief) about the behavioural standards for individuals (Evasdottir 2004). Under a system of orthopraxy, correct messages were transmitted by superiors (or ruling classes) in order to create a higher level of "uniformity of [shared] beliefs, attitudes and conceptions" among the inferiors (lower classes or positions) as a means of ensuring a consistent set of correct forms of practices among them in their everyday social interactions (Brown 2007, p. 92; Sutton 2007, p. 4). Beliefs, thus, became less important as participants in orthopraxy shared the same standards that enabled them to interpret each other's actions in the same way (Evasdottir 2004). An example of this is the Chinese death ritual (or funeral $l i$ ) that illustrates a concern for proper behaviour according to $l i$ practice without specific meaning:

Funeral priests are choreographers of public ritual; they tell people where to stand, how to sit, when to wail, what to eat, who to greet, when to leave. [...] Older people often stand on the sidelines of funerals, watching like hawks to make certain proper form is followed. They do not hesitate to shout advice or dissent when they see what they perceive to be departure from standard ritual practice.

(Watson 1993, p. 100)

While there was minimal content (or meaning) in the routinised forms of actions of Confucian $l i$, these pre-programmed practices constituted a convenient setting for individuals to judge and correct the actions of the self and others in order to maintain the status of the given truth (Sigley 1996; Evasdottir 2004). The Confucian orthopraxy inner-control system thus enabled the ruling classes to define and redefine the ming of the docile minds and bodies to ensure they continued to serve their interests. This was the situation from the Han dynasty (206 B.C. - 220 B.C.) 
through to the Qing dynasty (1644 - 1911) - the last Imperial dynasty - under the culture of obedience in China (Grasso, Corrin \& Kort 2009; Rojek 1989).

Towards the final years of the Qing dynasty, Western moral values that challenged the Confucian tradition were introduced into China (Chen 2002; Dreyer 1993). The inability of the Qing emperors to stop the imposition of Western influences through foreign trade relations, diplomatic missions and ideas of democracy made it difficult for the Chinese State to exert the control they would have liked over people's lives (Whyte 1988a). Social conflicts, such as the Boxer Rebellion by peasants to oppose the European and Japanese power in 1900, and particularly after the fall of the Qing dynasty in 1911, became apparent as the nation came to be characterised by cultural diversity (Whyte 1988a). In the period after 1919 (the 'May Fourth Movement ${ }^{22}$ '), Chinese pro-Western intellectuals asserted that the 'backwardness' of Confucian culture was the cause of individual passivity and it accounted for the restriction of individual freedoms (Whyte 1988a). Subsequently, new Western cultural and political values, ranging from socialism to liberalism, were advocated as alternative moral frameworks to guide Chinese society (Whyte 1988a).

\section{The "Demise" of Confucianism after 1949}

In 1949, following the Second Sino-Japanese War (1937-1945) and the victory of the Chinese Communist Party (CCP) over the Kuomintang (KMT) party in the Chinese Civil War (19461949), Chairman Mao Zedong proclaimed the formal establishment of the People's Republic of China (PRC or China) (MacFarquhar 1997). The CCP's declaration of the founding of the PRC appeared to signal a 'defeat' of Confucianism and a victory for Western cultural values (Whyte 1988b). This is because the CCP itself was a product of the 'May Fourth Movement' between 1915 and 1922 (Grasso, Corrin \& Kort 2009). Thus, when the CCP came to power in 1949, Mao and other CCP founders deplored the 'intolerable elements' of Confucian values,

\footnotetext{
${ }^{22}$ The May Fourth Movement (1915-1922) was brought about by the complete rejection of Confucian values by advocating a substitution of Western values, such as democracy, egalitarianism, republicanism and Marxism. See Grasso, J, Corrin, J \& Kort, M 2009, Modernization and Revolution: From the Opium Wars to the Olympics, 4th edn, M.E. Sharpe, Inc, New York.
} 
exalting instead the socialist ideology (or Stalinism) ${ }^{23}$ of the Union of Soviet Socialist Republics (USSR or Soviet Union) ${ }^{24}$ (Leung 2016; Whyte 1988b).

By embracing Stalinism as a base, Mao subsequently developed Marxism-Leninism into the Thought of Mao Zedong (or Maoism) to impose revolutionary ideologies, that is, to destroy the system of private property ownership, for Chinese model of socialism (Chen 2002; Fu 1974). However, post-1949 Chinese society was characterised by a relatively small middle-class population dominating a much larger urban proletariat in the cities. Despite this, Chinese society was also characterised by a relatively small number of landowners dominating a greater number of peasants in rural areas (Chen 2013). Over eighty percent of the entire Chinese population resided in the rural areas, whilst less than twenty percent resided in the cities (Chen 2013). For this reason, Mao emphasised the important role of peasants, rather than the proletariat as identified by Marx and Lenin, in the success of the Chinese revolution ( $\mathrm{Lu} 2011)$. Mao contended that the virtues of the peasants, such as purity and simplicity, were the strengths of the Chinese people because they could be taught, educated, indoctrinated, and 'proletarianised' by the CCP to transform society (Lu 2011).

Hence, while denouncing a range of Confucian values, Mao initiated the Confucian-inspired thought reform programme zhengfeng 整風 (or 'Rectification Campaign') to impose his revolutionary ideologies on the Chinese masses in the already poor China ${ }^{25}$ (Chen 2002; Fu 1974). In contrast to the models of Marx and Lenin, who believed a revolutionary consciousness was derived from one's economic and class conditions, Mao insisted that

\footnotetext{
${ }^{23}$ Stalinism was implemented by Joseph Stalin to create a vanguard party in the Soviet Union. It is a set of socialist-related policies, including rapid industrialisation, a centralized state, the collectivisation of agriculture, and a cult of personality in leadership, that were based on the ideas of Marxism and Leninism (see Chapter One, pp. 20-22) in pursuit of socialism. See Teiwes, F 1997, 'The Establishment and Consolidation of the New Regime, 1949 - 57', in The Politics of China: The Eras of Mao and Deng, 2nd edn, ed. R MacFarquhar, Cambridge University Press, Cambridge, pp. 5-86.

${ }^{24}$ Following the establishment of the People's Republic of China, Mao aligned China with the Union of Soviet Socialist Republics (USSR or Soviet Union), drawing upon the Stalin-led USSR, not only for ideas about socialism, but also notions about economic policies and programmes, and, of course, aid, to assist in the reconstruction of China Mitter, R 2004, A Bitter Revolution: China's Struggle with the Modern World, Oxford University Press, New York.. It was in keeping with Stalin's approach to socialism (or Stalinism) ${ }^{24}$ when Mao and the CCP sought to liberate the proletariat, or in this case the peasants, by eliminating (or overthrowing) the bourgeoisie (the landlords), through a series of mini-revolutions, particularly in the countryside, where 80 percent of the Chinese population resided at the time Weatherley, R 2006, Politics in China since 1949: Legitimizing Authoritarian Rule, Routledge, New York.

${ }^{25}$ Post-1949 Chinese society consisted of over $80 \%$ of peasants, with less than $20 \%$ of landowners (or middleclass) after the wars. See Chen, J 2013, A Middle Class without Democracy: Economic Growth and the Prospects for Democratization in China, Oxford University Press, Oxford.
} 
reforming one's consciousness to alter norms and behaviour was a more effective way to accomplish a socialist society (Grasso, Corrin \& Kort 2009). To achieve this purpose, Mao sought to revolutionise the peasants to get them to adhere to the truth of Maoism (Guo 2013). In this context, the Confucian-orthopraxy inner-control technique was once again manipulated to define the destiny (ming) of the Chinese inferior masses by facilitating their internalisation of the correct Maoist truth (Rojek 1989; Pye 1999).

\section{Thought Control and Revolution under Mao Zedong}

Manipulating the Chinese ming was exercised through Confucian thought control methods by turning the masses into a total obedient instrument of Mao (Schram 1969; Pye 1986; Teiwes 2000; Landsberger 2002). To begin with, the CCP sought to align the correctness of Mao's ultimate truth and leadership with Marx and Lenin to legitimise his hierarchically superior position:

In our Party, there are no special privileges for individuals; any leadership which is not exercised in the name of the organization cannot be tolerated. We obey the Party, we obey the Central Committee, we obey the truth; we do not obey individuals. No individual merits our obedience. Marx, Lenin and Mao [Zedong] have done their work well; they represent the truth, and it is only for this reason that we obey them

(Schram 1969, p. 6)

The validity of the new 'mandate' of Mao's ruling legacy was further reinforced through all possible means of propaganda, including newspapers and public broadcasts, to transmit principles of obedience to his sole authority (Weatherley 2006). This Confucian-inspired thought control method was adopted to persuade prospective supporters to form the Red $\mathrm{Army}^{26}$ (or the People's Liberation Army) to combat the Nationalists in the civil war in the late 1920s (Lu 2004). While discrediting the Confucian culture, a large-scale thought reform programme, Rectification (zhengfeng) campaign commenced in the early 1940s to control the behaviour of the CCP members (Lu 2004; Perry 2002). This was extended further after 1949

\footnotetext{
${ }^{26}$ The Red Army was renamed the People's Liberation Army (PLA) after 1946. See Chapter Two, p. 61 and Grasso, J, Corrin, J \& Kort, M 2009, Modernization and Revolution: From the Opium Wars to the Olympics, 4th edn, M.E. Sharpe, Inc, New York.
} 
to control non-party members by eradicating negative thoughts about Maoism (Grasso, Corrin \& Kort 2009; Lu 2004). A more personalised method of compulsory study groups, conducted by CCP authority figures, was also used to inculcate correct thought into the masses (Weatherley 2006). Either willingly or under duress, the masses had to self-criticise and confess any incorrect personal thoughts that ran counter to Maoism (Grasso, Corrin \& Kort 2009; Lu 2004). Party cadres had to report the political thought of the masses to the CCP leaders (Dittmer 1973). These strategies enabled the CCP leaders to evaluate the thought of the masses and then implement the most appropriate techniques to continuously cultivate docile bodies and minds to Mao (Grasso, Corrin \& Kort 2009).

To demonstrate a high level of loyalty to Mao, the docile bodies had to translate their political ideas into revolutionary practice (Schram 1969; Barlow 1981). In the early 1950s, Mao launched nationwide land reform campaigns aimed at transferring land ownership from 'feudal' landlords (middle class or bourgeoisie) (Chen \& Goodman 2013) to the peasantry (Grasso, Corrin \& Kort 2009). Following Mao's order of 'criticising the seizure of land' in a series of 'mini-revolutions', peasants denounced their 'feudal' landlords under the slogan 'spitting bitter water' (tukushui 吐苦水) (Lu 2004). This provocative slogan aimed to raise the revolutionary consciousness of the peasantry such that they were reminded of the suffering caused by landlord exploitation over the centuries (Weatherley 2006). Many landlords were forced to publicly confess their own so-called crimes, while others were executed or stoned to death, as in the 'empire system' (Grasso, Corrin \& Kort 2009; Lu 2004). Exposing and publicly criticising other people's wrongdoings was thought to be a way to demonstrate loyalty to Mao and the CCP ( $\mathrm{Lu} 2004)$.

In proclaiming themselves the advocates of social justice, the CCP massacred approximately 15 million 'feudal exploiters' to dismantle the traditional hierarchical landlord-tenant relationship in the rural areas (Grasso, Corrin \& Kort 2009, p. 139; Lu 2004). Despite transferring land ownership to the peasantry, however, rural poverty continued and was exacerbated by a rapidly expanding population and a scarcity of farmland, which led to the next stage of agricultural development - the collectivisation of farmland (Liu 2011). 
The assault on the disobedient 'feudal exploiters' had subsequently 'voluntarily' engaged the rural masses in Mao's programme of collectivisation of farmland (Weatherley 2006). In this programme, Mao sought to re-shape public life through the creation of a collective economy by introducing work units (danwei 單位) ${ }^{27}$ in urban areas and the Chinese commune in rural areas within the State-owned enterprises (SOEs) (Ong \& Zhang 2008). The establishment of the latter was by forcing ${ }^{28}$ the rural masses to participate in agricultural cooperative planting and harvesting through the scheme of 'voluntary' agricultural producers cooperatives (APCs) (Dikotter 2010). Under this arrangement, approximately 20 to 40 peasant households (Lin, Cai \& Li 1996, p. 56) were formed into production teams by consolidating their farmland into collective agricultural units (Chen \& Goodman 2013; Chang 1951; Grasso, Corrin \& Kort 2009). To coerce peasant families to join APCs 'voluntarily', the CCP offered resources and equipment to peasant families (Weatherley 2006). The CCP also made it illegal to sell or purchase anything not produced through the APCs in the countryside (Grasso, Corrin \& Kort 2009). While unwilling, peasants who wanted to survive were forced to join the APCs in order to participate in agricultural development in the rural areas (Dikotter 2010).

While it was assumed that the APCs would enable the peasants to farm more efficiently by achieving economies of scale, the APC collectivisation experiment resulted in poor harvests in both 1953 and 1954 (Grasso, Corrin \& Kort 2009, p. 148). Food shortages occurred because of poor weather conditions and inadequate agricultural production outputs combined with stable consumption and a rapidly growing population (Breslin 2014). Yet rather than denouncing the collectivisation project, Mao attempted to reinvigorate the APC structures by transforming

\footnotetext{
27 The significance of the work units (danwei 單位) was that, beginning from 1951, all SOE workers were guaranteed pensions of approximately 80 to 90 percent of their salaries at the retirement age of 55 (women) and 60 (men) Hurst, W \& O'Brien, K 2002, 'China's Contentious Pensioners', The China Quarterly, vol. 170, pp. 345360.. This was followed in 1952 by the release of the important document 'Decisions on the Problems of Employment', the effect of which was to guarantee job security and welfare benefits, known as the iron rice bowl (tie fanwan 鐵飯碗), and which secured the livelihood of the Chinese people Fung, H-1 2001, 'The Making and Melting of the "Iron Rice Bowl" in China 1949 to 1995', Social Policy \& Administration, vol. 35, no. 3, pp. 258273.

${ }^{28}$ The entrance into the APCs was initially 'voluntary' although once the peasants entered were forbidden to leave. Later terror tactics such as food were deployed as a weapon to force families into the APCs. See Grasso, J, Corrin, J \& Kort, M 2009, Modernization and Revolution: From the Opium Wars to the Olympics, 4th edn, M.E. Sharpe, Inc, New York, Dikotter, F 2010, Mao's Great Famine: The History of China's Most Devasting Catastrophe, 1958 - 1962, Walker Publishing Company, New York.
} 
them into People's Communes ${ }^{29}$ (Weatherley 2006). This decision was part of a more farreaching programme called the Great Leap Forward (1958 - 1961) for China's industrialisation (Grasso, Corrin \& Kort 2009).

Despite food shortages, the deterioration of USSR-Sino-relations ${ }^{30}$ that was due to different interpretation of Marxism as well as the anti-communist movements ${ }^{31}$ arose around the world after 1956 was another element causing Mao to launch the Great Leap Forward programmes to generate self-sufficiency for Chinese socialism (Fung 2001; Oi 1995; Teiwes 1997). In 1958, Mao mobilised the masses to transform China into an industrialised, socialist country under the Great Leap slogan of 'overtaking Britain's steel production in less than 15 years' (Breslin 2014, p. 5). To accelerate industrial productivity, the masses were forced to labour in both the agricultural and industrial sectors on collective farms (Withington 2008). In this programme, Mao converted the APCs into large-scale labour armies by combining 750,000 collective farmlands, containing over 500 million people, into 26,000 small People's Communes (Ahn 1975, p. 632). Each 'small' commune contained small-scale manufacturing facilities (or backyard steel furnaces) and individuals were forced to labour day and night to achieve Mao's daily production quotas and targets to surpass Britain's steel industry (Breslin 2014; Grasso, Corrin \& Kort 2009). They were later forced to melt personal items such as cooking pots and pans to achieve Mao's objective of the Great Leap Forward (Li \& Yang 2005; Weatherley 2006). This policy led to the reduction of peasants harvesting the fields and caused the subsequent nationwide famine in 1959 and 1960 (Grasso, Corrin \& Kort 2009).

\footnotetext{
${ }^{29}$ Each commune was a combination of smaller collective farmlands for agriculture and steel productions. See Weatherley, R 2006, Politics in China since 1949: Legitimizing Authoritarian Rule, Routledge, New York.

${ }^{30}$ Stalin had by this time died, and his successor Kruschev denounced Stalin's regime, accusing Stalin of a 'grave abuse of power' in a secret speech at the $20^{\text {th }}$ Congress of the Soviet Union. See Teiwes, F 1997, 'The Establishment and Consolidation of the New Regime, 1949 - 57', in The Politics of China: The Eras of Mao and Deng, 2nd edn, ed. R MacFarquhar, Cambridge University Press, Cambridge, pp. 5-86. In the wake of the speech by Kruschev at the $20^{\text {th }}$ Congress of the Soviet Union, relations deteriorated between the USSR and PRC bureaucracies, before Kruschev finally withdrew aid from China in August 1960. See Mitter, R 2004, A Bitter Revolution: China's Struggle with the Modern World, Oxford University Press, New York.

${ }^{31}$ During the Cold War period in the mid-1950s, anti-communism arose among the major countries such as the United Kingdom (U.K.) and the United States (U.S.) to support political democracy and economic freedom. In 1957, the U.S. imposed trade embargos on China, North Korea and North Vietnam under the Trading with the Enemy Act of 1917. See Mitter, R 2004, A Bitter Revolution: China's Struggle with the Modern World, Oxford University Press, New York, Oi, J 1995, 'The Role of the Local State in China's Transitional Economy', The China Quarterly, no. 144, pp. 1132-1149, Weatherley, R 2006, Politics in China since 1949: Legitimizing Authoritarian Rule, Routledge, New York.
} 
During the great famine of 1959 and 1960, Mao further tightened the hukou 戶口(or household registration) system to restrict peasant mobility (Wu \& Treiman 2004). In 1955, the hukou system was introduced to register all households and categorise them as either agricultural or non-agricultural (Wu \& Treiman 2004). In the early period, Chinese people were guaranteed the right to move into and out of urban cities and throughout the countryside in China (Chan \& Li 1999). Between 1953 and 1957, millions of rural peasants sought employment in exchange for the guaranteed job security and welfare benefits of iron rice bowl (tie fanwan 鐵飯碗) within SOEs in the urban cities (Chan \& Li 1999). Yet in the aftermath of the Great Leap Forward, an influx of an additional 25 million rural workers into the cities in search of work (Fung 2001, p. 261). The demands that were placed on the State by this rapid shift triggered an 'overheating' of the iron rice bowl programme and economic disaster, as the Chinese State struggled to meet the demands of the populace (Fung 2001, p. 261).

The State's response was to force the return of thousands of former SOE danwei workers to their original rural villages with only minimal resources ${ }^{32}$ to help their survival. This confinement of the greater portion of population to the rural environment was reinforced by introducing the household registration or hukou system, which regulated rural-urban migration (Mallee 2000). Those who secured an urban hukou were entitled to food, housing, education, work and other social services, whereas those tied to a rural hukou had to fend for themselves (Cheung \& Selden 1994; Fan 2004). Through this system, Mao secured a permanent supply of low-cost agricultural products, because thousands of workers were confined to rural areas (Fan 2004), while State-enforced policies demanded that these rural cadres continue to supply grain to the State, even though they had minimal or no grain for their own consumption which caused 30 million Chinese died of starvation between 1958 and 1961 (Mitter 2004, pp. 3-6). Yet in the aftermath of the Great Leap Forward, the hukou system was further used to restrict rural-urban migration more stringently, and to effectively remove approximately 18 million peasant workers from the urban cities (Chan \& Li 1999). As a result, the restriction of peasant mobility in the wake of the famine conditions contributed to another 45 million deaths in the rural areas (Dikotter 2010).

\footnotetext{
32 The Chinese State provided only a small piece of land for each household and some basic equipment for their own survival production Fung, H-1 2001, 'The Making and Melting of the "Iron Rice Bowl" in China 1949 to 1995', Social Policy \& Administration, vol. 35, no. 3, pp. 258-273.
} 
Concern about the Maoist policies that had led to these effects triggered another revolutionary movement within the CCP itself. CCP State Chairman Liu Shaoqi ${ }^{33}$, who until then had been publicly acknowledged as Mao's successor and had supported the Great Leap Forward (Dittmer 1981), voiced concerns about the deleterious effects of Mao's policies, and along with others such as Deng Xiaoping ${ }^{34}$, who became the leader of the CCP following Mao's death in 1976, introduced a system of contract employment and other economic reforms to address the effects of the Great Leap Forward (Fung 2001). With Liu and Deng's post-Great Leap success, Mao was pushed to the CCP sidelines. In order to retain his mandate to rule the CCP and the country, Mao sought to regain political power by removing his CCP opponents, particularly Liu and Deng, through a programme of mass criticism (later the Cultural Revolution) to 'criticise bourgeois reactionary thinking' in 1965 (McCormick 2010, pp. 3-16; Tsou 1969b).

To gain support for the Cultural Revolution, Mao exploited the fear that he had created in the populace against those who became known as "capitalist roaders" (Dittmer 1981) by asserting that their initiatives would see the return of capitalism to China. In this context, Mao sought to legitimise his Cultural Revolution by mobilising the masses against, not only his CCP opponents, but also educators (or teachers), 'intellectuals' ${ }^{35}$ and Confucian sympathisers, who were "enthusiastic" in their support of capitalism (McCormick 2010; Tsou 1969b). Mao argued that Confucianism and its associated economic philosophy had historically been maintained in China through education, literature and the arts (Grasso, Corrin \& Kort 2009). He proclaimed that educators, intellectuals, writers and artists perpetuated the "Confucian standards" that inherently harboured the economic values of the dominant capitalist class that were established in traditional China (Weatherley 2006). Although the capitalist means of production had largely been removed, Mao contended that a dominant, proletarian culture of the peasantry was still unrealised in socialist China (Grasso, Corrin \& Kort 2009). He insisted that China's socialist revolution could be realised only if the feudalistic (or capitalistic) consciousness deeply rooted in Confucian culture was destroyed and replaced by his own idea of working class values to establish a proletarian culture in China (Grasso, Corrin \& Kort 2009). Mao thus sought to

\footnotetext{
${ }^{33}$ Liu Shaoqi was vice chairman of the CCP and President of the PRC from 1961 to 1968. See MacFarquhar, R \& Schoenhals, M 2006, Mao's Last Revolution, Harvard University Press, Cambridge.

${ }^{34}$ Deng Xiaoping was general secretary and vice-premier of the CCP and president of the PRC from 1977 to 1997. See Weatherley, R 2006, Politics in China since 1949: Legitimizing Authoritarian Rule, Routledge, New York. 35 'Intellectuals': Mao Zedong labelled anyone with a high school educational qualification or above an 'intellectual'. See McCormick, J 2010, Comparative Politics in Transition Cengage Learning, Boston.
} 
mobilise the masses through a Cultural Revolution, which he hoped would defeat his free market opponents (MacFarquhar \& Schoenhals 2006)

Immediately before the Cultural Revolution, Mao's followers (the Maoists) promoted knowledge of Mao's Thought to new heights (Tsou 1969b). From 1964, the Maoist Lin Biao, commander of the People's Liberation Army (PLA), promoted 'Mao Zedong Thought' by circulating the publication 'Quotations from Chairman Mao' ${ }^{36}$ to every Chinese citizen (Grasso, Corrin \& Kort 2009). Later, Lin turned 'Mao's Quotations' into PLA policy. He further politicised the PLA through the establishment of several compulsory political classes for soldiers (Weatherley 2006). In 1966, Lin publicly announced that:

Chairman Mao's experience in passing through many events is more profound than that of Marx, Engels and Lenin. No one can surpass Chairman Mao in his rich revolutionary experience.

(Tsou 1969b, p. 79)

The purpose of repositioning Mao as a 'supreme leader' was to enable him to gain a new sense of legitimacy and correctness. Through this newfound legitimacy, the disobedient CCP leaders, such as Deng and Liu, who turned against Mao, were subject to criticism (Tsou 1969b, p. 66).

To ensure that the inferior masses were thinking and feeling what he wanted them to think and feel, the apotheosis of Mao and his Cultural Revolution was promoted through art and literature in China's cultural sphere (Grasso, Corrin \& Kort 2009). Jiang Qing, Mao's wife and a former actress, and later a member of the Gang of Four ${ }^{37}$, was appointed to take charge of China's cultural and artistic affairs (Weatherley 2006). Subsequently, Jiang and her allies began to establish Mao's values about revolution and the working class in the Beijing opera (Grasso, Corrin \& Kort 2009; Weatherley 2006). In this context, traditional performances of 'Confucian-feudal style' plays, which featured characters such as emperors and princes, were outlawed (Grasso, Corrin \& Kort 2009). Writers, directors and performers were forced to write

\footnotetext{
36 'Quotations from Chairman Mao' was the so-called 'Little Red Book' that underlined the importance of proper ideas and revolutionary morality. See Grasso, J, Corrin, J \& Kort, M 2009, Modernization and Revolution: From the Opium Wars to the Olympics, 4th edn, M.E. Sharpe, Inc, New York.

${ }^{37}$ Gang of Four was coined by Mao to describe Jiang Qing and her allies Wang Hongwen, Zhang Chunqiao and Yao Wenyaun, who supported the Cultural Revolution. See Chapter One, p.42, ibid.
} 
and act scenes that portrayed the masses as destined to 'master the country' (Tsou 1969a; Lippit 1982). This revolutionary type of theatrical production was further extended to schools, factories and neighbourhoods to mobilise young people throughout the country to join the Red Guards (hongweibing 紅衛兵) ${ }^{38}$ in order to 'save China' (Grasso, Corrin \& Kort 2009). Bewitched by the Maoist propaganda that was pushed by PLA commander Lin and Jiang's committees, millions of Chinese joined the ranks to participate in the Cultural Revolution (Grasso, Corrin \& Kort 2009).

In 1966, the Red Guards and the PLA were ordered to repudiate the traditional Confucian culture of feudalism and capitalism under the slogan 'eliminate the Four Olds: old ideas, old culture, old customs and old habits' (Grasso, Corrin \& Kort 2009; Weatherley 2006). As well as destroying items of traditional Chinese culture, such as books and paintings, the masses were instructed to capture and seizure control of labour organisations, including the Ministry of Labour and All-China Federation of Trade Unions (ACFTU), as bases to promote the socialist vision of Mao (Bridgham 1968). This involved further brutal attacks on members of the Chinese populace. Approximately 142,000 teachers, 53,000 scientists and 2,600 writers and artists, who had been identified as "capitalist supporters", were assaulted and murdered while the disobedient CCP “capitalist roaders” Liu was repeatedly beaten by Mao's supporters, died in 1969; wherein Deng was imprisoned in solitary confinement (Dillon 2015; Grasso, Corrin \& Kort 2009; Weatherley 2006). The willing participation of the masses had once again demonstrated that worker consciousness was spiritually and bodily made docile according to the will of Mao as with those in the Imperial period to maintain a system of orthopraxy.

\section{Living and Working under Post-Mao Leadership}

These historical events had indelibly created the docile minds and bodies to the rulers that were fundamental to the success of the post-Mao leaders' goal of transforming China from a rural, agrarian economy into a modern, urbanised and industrialised economy following the death of Mao in the late 1970s (Gabriel 2006). This decision was spurred on by rising unemployment and a stagnating economy causing by the past events in Mao's period (Pringle 2011). Thus,

\footnotetext{
${ }^{38}$ In 1966, official Radio Broadcast defined the Red Guards (hongweibing 紅衛兵) as “an organisation set up by middle-school pupils from families of workers, poor and lower-middle peasants, revolutionary cadres and revolutionary soldiers". See ibid.
} 
post-Mao CCP leaders initiated economic modernisation programmes to raise productivity by revitalizing Chinese industrial sectors (Howell 1993, pp. 2-3; Harvey 2005, p. 121; Ong \& Zhang 2008, p. 6). In 1978, Deng consolidated his return to power by imprisoning Mao's allies - the Gang of Four - for life, and replaced the practice and ideology of Mao Zedong Thought with the Deng Xiaoping Theory of economic reforms and modernisation (Girdner 2004; Harvey 2005; Weatherley 2006). At the Third Plenum of the Eleventh Central Committee, for instance, Deng declared that China's economy ${ }^{39}$ had been destroyed by Mao's revolutionary practices and insisted that a practical approach to market-oriented modernisation was the correct path to attain 'socialism with Chinese characteristics' (or 'socialist market economy') (Li 2015). This is because Deng among the post-Mao CCP leaders proclaimed the Maoist economic programmes, such as socialist revolutions and the Great Leap Forward, as:

[being] too rigid and bureaucratic, constraining the flexibility of the economy, perpetuating poor labor production, and retarding technical changes. Changes were necessary [...] to increase the flexibility of movement of labor work-force, give management more power over their work-force labor, and to break the iron rice bowl of the state workers. Specifically [...] the degree of direct administrative control over urban labor has been excessive, rendering the economic actors themselves - both managers and workers - inert

(White 1989, p. 155)

To improve the economic performance of the Chinese socialist market system, an 'Open Door' policy (see Chapter One, p. 17) was adopted as an essential component of modernisation programmes to create a cheap and docile labour force for export-led industrialisation (Harvey 2005).

Post-Mao China's creation of a cheap and docile labour force began with cutting back social welfare and loosening regulations by opening Special Economic Zones (SEZs) in the coastal areas, such as Shenzhen, Zhuhai and Shantou cities, to attract foreign investment (Harvey 2005; Wei 2001). Flexible labour markets were also introduced, both by dismantling the SOEs

\footnotetext{
${ }^{39}$ China's GDP was recorded at 364.52 billion yuan, while the value of the GNP slumped from 12 percent in 1978 to 7 percent in 1979 and 5.5\% in 1980. See Dittmer, L 1981, 'China in 1980: Modernization and its Discontents', Asian Survey, vol. 21, no. 1, pp. 31-50.
} 
through the approach of 'releasing the small and grasping the large"40 (Harvey 2005, p. 129; Liew 2005, p. 336). The diversification of SOE ownership through corporatisation thus enabled foreign investors to exercise their own organisational practices to manage the SOE workers in order to maximise profits in the State sector (Yip 2006, p. 66). Under this arrangement, SOE managers were granted increased operational autonomy to restructure their workforces in accordance with production needs in order to improve profitability (Chen \& Goodman 2013; Wong \& Ding 2002). For instance, from 1982, SOE managers had introduced a bonus and wage system, which was attached to the performance of the workers (Walder 1991). SOE managers also introduced a labour contract system as a means of converting permanent SOE workers into contract workers in order to recruit temporary contract workers and to fire surplus workers, as well as those perceived as 'disobedient ${ }^{41}$ workers (Lee 1999b, p. 60; Leung 1988). The adoption of these flexible measures thus signalled a dismantling of the Maoist iron rice bowl lifetime employment system, under which all SOE workers were faced with fewer work benefits and lower incomes, as well as job insecurity in post-Mao period (Chen \& Goodman 2012; Yip 2006). It is reported that, between 1987 and 1999, about 8.05 million SOE workers were converted into contract workers, with about 7 million workers being laid off annually, while more than 50 million workers were made redundant by the State sector between 1987 and 2004 (Fung 2001, p. 113; Yueh 2011).

As well as massive job losses in the State sector, underemployment was also a crucial issue for rural peasants. This was due to the People's communes being either privatised or destroyed, while over 60 percent of private enterprises were established in the fast-growing regions in the coastal areas (Mallee 2000). The trend of coastal-inland (or urban-rural) inequality and the wide income gaps led to the relaxation of the hukou (or household registration) system that was established to restrict rural peasants from migrating to the cities in Mao's period (Bao et al. 2002; Walder 1991). Based on the Maoist urban-rural principle, the Chinese state introduced temporary residence permits to enable rural peasants (or peasant workers) only to work in the

\footnotetext{
${ }^{40}$ Under a policy described as 'releasing the small', small SOEs were either privatised or permitted to go bankrupt whereas the approach 'grasping the large' referred to the conversion of medium and large SOEs into shareholding enterprises. See Harvey, D 2005, A Brief History of Neoliberalism, Oxford University Press, New York, Liew, L 2005, 'China's Engagement with Neo-liberalism: Path Dependency, Geography and Party Self-Reinvention', The Journal of Development Studies, vol. 41, no. 2, pp. 331-352.

${ }^{41}$ The term 'disobedient workers' is used to describe those who fail to behave 'properly' in relation to their immediate superiors at work. See Chapters One, Six, and Seven.
} 
cities (Mallee 2000). The dream of better job opportunities and wages offered by the private enterprises had attracted a flood of peasants to relocate from the inland regions to the cities (Bao et al. 2002; Fan 2004). Thus local governments began to commodify the urban hukou system in the increasingly decentralised market (Fan 2003). Although selling urban hukou was forbidden by the Chinese state, central control of its commodification was gradually relaxed due to the increased demand for rural peasants in the cities (Fan 2004). By 1994, approximately three million urban hukou books had been sold to peasants across the nation (Chan \& Li 1999). The legalisation of this wholesale urban hukou had not only become an income source to raise revenue for the local authorities, but had also become one of the means to push peasants to engage in the labour force.

Competition between localities for foreign investments to sustain a profitable economic environment had further permitted private investors to establish their own organisational and labour practices to manage peasant workers. While China had adopted more than 160 regulations concerning wages, social insurance and welfare, as well as safety and hygiene among workers at their workplaces since 1979, none of the policies had been officially enforced by the central government (Ngok 2008). This gave the enterprises flexibility to adjust and recreate regulations in accordance with their interests to attract investments across localities (Orts 2001). From the 1980s onwards, employers in the private sector subsequently combined the idea of the hukou system with their factory policies by paying the cost of the temporary residence permits on behalf of the peasant workers and then deducting a sum from their monthly wages (Chan 2000). The effect was to force peasant workers to enter into a bonded relationship with the enterprises, because a portion of their wages was being withheld. Within this forced and bonded labour system, peasant workers faced abuses such as being paid irregularly, being forced to work long hours, having restricted toilet breaks, being limited to a certain number of times they could drink water and being physically punished by their employers (Chan 2001).

In the State-sector, similar conditions were also experienced by millions of workers under the new contract system. Moreover, the new system had created a sense of insecurity because workers could suddenly find themselves unemployed. Large-scale redundancies, for example, endangered the livelihoods of millions of laid-off SOE workers. To redress this situation, the off-duty (or xiagang 下崗) policy was endorsed in 1995 at the central level to provide basic 
livelihood protection for those being laid off (Fung 2001; Hurst \& O'Brien 2002). Under the xiagang scheme, those workers who had been made redundant and those who were considered inefficient, unnecessary or unaffordable were categorised as off-duty, that is, they had been taken out of the active SOE workforces but without being immediately dismissed from employment in the State sector (Hurst 2009, p. 67). Thus, while off-duty workers were no longer employed in the production process of SOEs and consequently were not entitled to wages and other benefits; they were still part of the work units and remained attached to the SOEs (So 2003). Within the xiagang policy framework, funding for off-duty workers was to be provided under a san-san 三三 (three-thirds or 3:3:3) arrangement, that is, one-third of the funding came from SOEs, one-third from local governments and one-third from the central government budget (Hurst 2009, p. 68). These funds were to provide off-duty workers with job training and job placement assistance, while the amounts of basic living allowances ${ }^{42}$ (jiben shenghuo fei 基本生活費), including housing and medical services, were provided by the work units of the SOEs as well as the local governments, for a maximum of three years (Hurst \& O'Brien 2002; So 2003).

Despite the CCP's intention to minimise economic grievances among those laid-off workers through the xiagang policy, it was reported that a large number of laid-off workers were either excluded from or received inappropriate xiagang-related assistance in their localities (Leung $\&$ Xu 2010, p. 52). A survey by the Chinese Federation of Labour Unions (Zhongguo zhigong zhangkuang diaocha (China personnel executive survey) 1996, p. 52) revealed that only 5 percent of the laid-off workers received the xiagang subsidies, and 11 million (this increased to 30 million in 1999) of dismissed SOE workers received inappropriate amounts or no financial support to maintain a subsistence lifestyle. This situation was caused directly by the shortage of the central (or CCP) budgetary funds allocated to local governments and hence local SOEs under the principle of the local 'State corporatism' (Oi 1995). In these circumstances, many SOEs found it difficult to provide their share of the xiagang subsides, given that they had to lay off workers due to their financial difficulties with paying wages in

\footnotetext{
${ }^{42}$ Given the differences in the cost of living in different cities, the CCP did not define an overall financial assistance guideline for the whole country. In general, the assistance line was set below the legal minimum wage and was adjusted by the local authorities based on the financial capacity of the local governments and SOEs. See Leung, J \& Xu, A 2010, 'The Emergence of Social Assistance in China: Challenges and Issues', in Social Policy and Poverty in East Asia: The Role of Social Security, eds J Midgley \& K-L Tang, Routledge, New York, pp. 4765.
} 
the first place (H.-Y. Lee 2000, p. 927). In light of the substantial increase in the number of laid-off workers, a number of SOEs declared bankruptcy to avoid paying their share of the financial burden (Lee 2007a). Delayed redundancy and pension payments that were officially reported by the laid-off workers mounted from 10,780 to 24,214 workers between 1995 and 1996 (Chen 2000), while many faced a decrease or even went without subsistence subsidies (Cai 2006, p. 26). In 1997, for example, a large number of laid-off workers were reportedly living in debt, while some died of illnesses because they could not afford medical care (Chen 2000). Given the inadequate xiagang subsidies, an estimate of 70 to 85 million laid-off workers had to compete with peasant migrants and other xiagong workers to find work in the private sector (Chan 2001).

Constructing poor living conditions is thus an essential prerequisite for pushing peasants and surplus laid-off (xiagang) SOE workers to participate in low-rate wages and a high-rate of capitalist exploitation $^{43}$ for their livelihood (Gabriel 2006). Despite poor labour and living conditions had led to their first major protest involvement in the 1989 Tiananmen movement (see Chapter Four, pp. 96-97) and had incited them to participate in other spontaneous worker protests, the need to sustain a livelihood had secured approximately 42.7 million SOE laid-off workers (Pringle 2011, p. 42) alongside 230 million peasant workers ${ }^{44}$ (Chan 2012b, p. 359) to continue working in appalling conditions, such as 12 hours a day or longer for 7 days a week, in private sector throughout the 2000s (Mah 2011, p. 30). The persistence of this particular labour practice by workers thus created a business-friendly climate that led to a subsequent coastal boom and accelerated the process of economic modernisation as the labour-intensive export-led manufacturing sector continued to grow (see Figure 4) in China (Xu 2009).

\footnotetext{
${ }^{43}$ In 1997, the legal minimum wage was set at 420 yuan (USD 63.27) a month with a 44-hour week for Shenzhen Special Economic Zone (SEZ) which was lower than any ASEAN (Association of Southeast Asian Nations) countries. Workers were reportedly worked 10 to 12 hours a day or longer and received less than 400 yuan (or USD 60) a month throughout the 1990s. See Chan, A 2001, China's Workers Under Assault: The Expoitation of Labour in a Globalizing Economy, An East Gate Book, New York. See Skeldon, R 1997, 'Hong Kong and Coastal China Growth Linkages', in Regionalization and Labour Market Interdependence in East and Southeast Asia, eds D Campbell, A Lateef, A Parisotto \& A Verma, MacMillan Press, London, pp. 151-173.

${ }^{44}$ The number of SOE laid-off workers employed by the private sector rose from 6.7 million in 1990 to 42.7 million in 2003. See Pringle, T 2011, Trade Unions in China: The Challenge of Labour Unrest, Routledge, New York. The number of peasant workers had soared from 120 million in 2000 to approximately 230 million in 2010 in the private sector. See Chan, C 2012b, 'Labour Policies under Hu-Wen's Regime: Transformation and Challenges', in China: A New Stage of Development for an Emerging Superpower, ed. J Cheng, City University of Hong Kong Press, Hong Kong, pp. 357-388.
} 
Figure 4: China's Share of Global GDP and Merchandise Exports

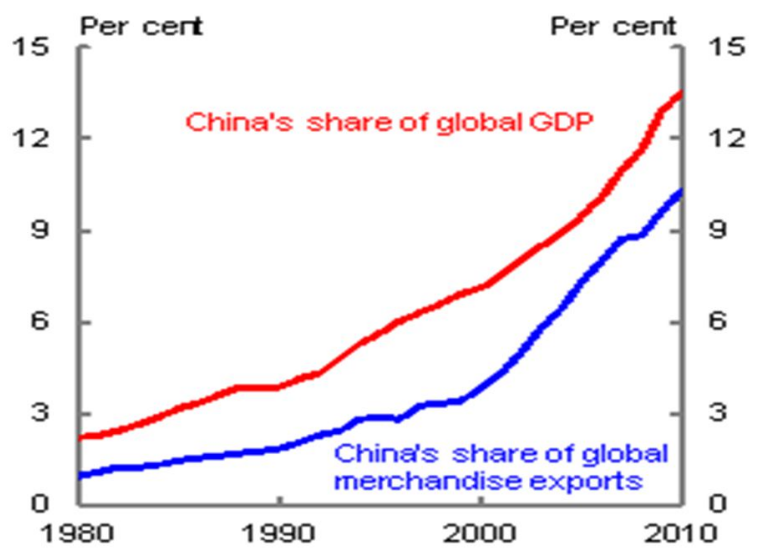

Source: World Development Indicators (The World Bank, 2017)

\section{Chinese Legal System and Social Stability}

During the 2000s, social stability had become the paramount goal of the CCP for maintaining the supply of disposable labour to support its export-led industrialisation (Benney 2016; Xu 2009). Since the 1980s, particularly after the crackdown of the Tiananmen movement, pressure from the International Labor Organisation (ILO) ${ }^{45}$ (Kent 2007; Kent 1999), and the need to safeguard China's external trade relations with countries such as the United States (U.S.) (Grasso, Corrin \& Kort 2009) had compelled the CCP to introduce over 160 labour legislations ${ }^{46}$ and enact the Labour Law (1995) followed by an updated version of the Labour Contract Law $(2008)^{47}$ (see Appendix 1) to regulate the Chinese employment system for social

\footnotetext{
${ }^{45}$ China has become a member of the ILO since 1919 Kent, A 1999, China, The United Nations, and Human Rights: The Limits of Compliance, University of Pennsylvania Press, Philadelphia.

${ }^{46}$ While a set of basic workers' rights such as work safety and hygiene had been outlined in the labour legislations in the 1980s, these regulations were not published or enforced by the State because the CCP leaders sought to enhance flexibility for the local governments and enterprises to implement their own set of labour policies to regulate the workers. See Orts, E 2001, 'The Rule of Law in China', Vanderbilt Journal of Transnational Law, vol. 34, no. 43, pp. 43-115, Ngok, K 2008, 'The Changes of Chinese Labor Policy and Labor Legislation in the Context of Market Transition', International Labor and Working-Class History, no. 73, pp. 45-64.

${ }^{47}$ Following the State workers' protest involvement in the 1989 Tiananmen movement, the CCP leaders enforced the labour standards provisions, including working hours, rest days, minimum wages and overtime penalty rates, to govern the rights and duties between employers and workers under the National Labour Law (1995). In 2008, the CCP enacted the Labour Contract Law (2008) to further regulate the use of employment contracts and also outlined the procedure for collective bargaining and labour dispute resolution. See ACFTU 1997, Labour Law of the People's Republic of China. Available from: $<$ http://www.acftu.org.cn/template/10002/file.jsp?cid=56\&aid=31>. [10 September 2012], Lehman 2008, Labour Contract Law of the People's Republic of China. Available from: $<$ http://www.lehmanlaw.com/fileadmin/lehmanlaw_com/laws_regulations/Labor_Contract_Law_of_the_PRC LLX_06292007_.pdf>. [12 October 2010], Su, Y \& He, X 2010, 'Street as Courtroom: State Accomodation

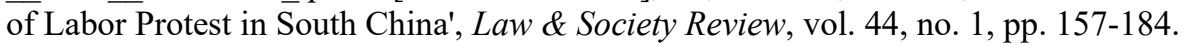


stability (Ngok 2008). While these laws covered employment issues, including labour contracts, reasonable working hours and rest days, overtime penalty rates, social insurance and labour disputes resolution and also encouraged the ACFTU to defend workers' rights, the capacity of the trade unions to protect workers was constrained by a set of other laws, including the Trade Union Laws (1992 \& 2001), Assembly Law (1989) and the Criminal Law (1987) ${ }^{48}$. The intention to restrain the ability of the trade unions as well as other worker representative organisations to provide the workers with direct assistance was indeed demonstrated in the CCP's refusal to ratify core ILO's labour standards ${ }^{49}$, that is, the Freedom of Association and assembly (1948, No.87) and the Right to Organise and Collective Bargaining (1949, No.98) conventions (Jantz 2010; ITUC 2010). Thus, rather than regulating the employment system, the CCP sought to utilise the legal systems to weaken workers' positions and the roles of worker organisations for social stability to sustain industrialisation. The failure of the CCP to eliminate the abuse of its labour force has thus incited to turn to non-legal methods, such as collective protests, to voice their dissatisfaction with their employment conditions (C. Chan 2010b). Mass incidents, including work-related protests, increased from 74,000 in 2004 to 87,000 in 2005 (Leung \& Pun 2009). Thomas Lum (2006, p. 2) reveals that in 2003 alone, "the PRC government reported more than 58,000 'major incidents of social unrest' involving an estimated 3 million to 10 million persons". The Institute for Global Labour and Human Rights

\footnotetext{
48 These laws were used during the 1989 Tiananmen protests to suppress workers' attempts to organise an independent labour movement under the twin doctrines of "no crime without a law" and "no punishment without a law" Keith, R \& Lin, Z 2003, 'The "Falun Gong Problem": Politics and the Struggle for the Rule of Law in China', The China Quarterly, vol. 175, pp. 623-642, Merchant, T 2004, 'Recognizing ILO Rights to Organize and Bargain Collectively; Grease in China's Transition to a Socialist Market Economy', Case Western Reserve Journal of International Law, vol. 36, no. 223, pp. 223-253, ITUC 2010, Internationally Recognised Core Labour Standards in the People's Republic of China: Report for teh WTO General Council Review of the Trade Policies of the People's Republic of China. Available from: <http://www.ituc-csi.org/IMG/pdf/Chinal_Final-2.pdf>. [2 November 2012].. The Criminal Law of 1987, for example, defined 'a criminal group' as a group of three or more people forming a criminal or an illegal organisation to carry out joint criminal activities to harm the society (Articles 14 and 26) UNHRC 1997, Criminal Law of the People's Republic of China, National Legislative Bodies. Available from: <http://www.unhcr.org/cgi-bin/texis/vtx/refworld/rwmain?docid=3ae6b5cd2\&page=search>. [31 October 2012].. In addition, while the new Labour Contract Law (2008) did not specify whether striking was a legal action Wang, T \& Cooke, F-L 2016, 'Striking the balance in industrial relations in China? An analysis of court decisions of 897 strike cases (2008-2015)', Journal of Industral Relations, vol. 59, no. 1, pp. 22-43., the regulations under the Assembly Law of 1989 stated that demonstrations or assembly activities must not "impair state, public or collective interests" (Article 4) UNHCR 1989, Law of the People's Republic of China on Assemblies, Processions and Demonstrations, National Legislative Bodies. Available from: $<$ http://www.unhcr.org/refworld/docid/3ae6b592e.html $>$. [22 October 2012]..

${ }^{49}$ China has ratified only four of the eight core ILO's labour standards, namely the Minimum Age (1973, No.138), Worst Forms of Child Labour (1999, No.182), Equal Remuneration (1951, No.100), Abolition of Forced Labour (1959, No.105) and anti-discrimination (1958, No.111) conventions.
} 
group reports that, in 2005, over 3,000 workers staged a protest at a sofa factory in Shenzhen, southern region, "after three colleagues were badly beaten by their Italian supervisors during a pay dispute" (Chinese Workers are Beaten and Hospitalized 2005). China Labour Bulletin's $(C L B)$ reporter P. Parameswaran (2008) comments that "at least one strike involving more than 1,000 workers occurs every day in China's manufacturing hub in the Pearl River area" in the southern coastal region. Labour disputes in the Shanghai and Guangdong provinces had been rising dramatically and it was reported that "the labour courts in Dongguan, Shenzhen and Guangzhou accepted more than 10,000 [dispute] cases during the first quarter of 2008 alone" (Wang et al. 2009, p. 492). A labour dispute case that had been left unresolved by the courts led 3,000 women workers to engage in a mass protest over unpaid wages at a garment factory that was wholly owned by German-Swiss lingerie giant Triumph International in Hainan, a southern region, in 2009 (China: Strike by 3,000 women workers 2009). In the same year, 10,000 workers were involved in a violent protest in Hubei, southern region, “after a man's suspicious death in a government-linked hotel, where the crowd clashed with police and did damage to police vehicles" (Hays 2012).

\section{The Discourse of weiwen 維穩, xiaokang 小康 and hexie shehui 和諧社會}

In the Eleventh Five-Year Plan for 2006 - 2010, the CCP deployed the discourse of maintenance of social stability (weiwen 維穩) to highlight its dual concern with the increased protest activities (see Chapters One, pp. 48-49 and Two, 51-65) and the need to secure the cheap labour force for China's economic growth (Benney 2016; Xu 2009). Weiwen, therefore, indicated not only the shift in emphasis away from coercive administrative measures and control of workers, but also a new strategy of the CCP to "connect to the global track" (Xu 2009, p. 38). "Connecting to the global track", according to Feng Xu (2009), was in part of both participating in the global supply chain production and conforming the administrative practices to international norms, including business and labour regulations. Aware that the rights of workers were often violated in the absence of a labour contract, the CCP promulgated the 2008 Labour Contract Law (see Appendix 1) to emphasise workers' responsibility of ensuring their employers signing a labour contract with them in order to protect their legal rights (Pringle 2011). Based on the 2009 Migrant Workers Survey in the Pearl River Delta of Guangdong Province and the 2010 China Urban Labour Survey, Mary Gallagher, John Giles, 
Albert Park and Meiyan Wang (2013, p. 15) reveal that workers' awareness of the Labour Contract Law had significantly increased the number of contracts signed. The actions of the workers in signing contracts indicated their acceptance of selling their labour in exchange for a wage based on their positions as being the workers under the logic of competition in the labour market (Xu 2009). Workers' engagement in this 'market transaction' was one of the elements guiding them to meet the demands of the labour market, and hence guiding them to reinforce the CCP's weiwen project for the development of a well-off (xiaokang 小康) and harmonious society (hexie shehui 和諧社會) (Brady 2012a, p. 2; Benney 2016, p. 390; Xu 2009, p. 38).

Another key component of building a xiaokang and harmonious society under weiwen discourse was linked with the CCP's “zero target” (Benney \& Marolt 2015, p. 94) project, aiming to eliminate visible forms of protest actions, through the horizontal coordination with government agencies and private entrepreneurs (Benney 2016; Chen 2015). During the last decade, private entrepreneurs were encouraged to become members of the People's Political Consultative Conference (PPCC) $)^{50}$ to participate in the governing activities at the national and local levels (Chen 2015, pp. 614-617). Minglu Chen (2015, pp. 616-617) notes that the PPCC, along with the CCP, the Chinese People's Government and the People's Congress, were referred to as 'the four sets of leadership' (si tao banzi四套班子), which constituted a "multiparty co-operation and political consultation" system. While the latter was the three political organs through which the CCP leaders exercised State power, the PPCC was the institution which brought together the non-CCP entrepreneurs to support the CCP's rules (Chen 2015).

Under the leadership of the CCP, the PPCC served as a channel for entrepreneur members to express opinions and thus influence State policies and regulations to protect their particular interests as a group (Chen 2015). For example, the concern with the protection of private property rights raised by the members at the PPCC annual meeting in 2001 was passed into the Property Law in 2007 (Chen 2015, p. 627). The privilege status of the PPCC membership

\footnotetext{
${ }^{50}$ The People's Political Consultative Conference (PPCC) is a political consultative body that worked with the People's Congress in the State system. PPCC members' businesses are registered with capital of a minimum of 500,000 yuan and each member is required to donate a certain amount of money in each PPCC activity. For example, on a visiting trip to poor urban households, each entrepreneur member was assigned to donate 50,000 yuan. See Chen, M 2015, 'From Economic Elites to Political Elites: Private Entrepreneurs in the People's Political Consultative Conference', Journal of Contemporary China, vol. 24, no. 94, pp. 613-627.
} 
further extended to prevent the entrepreneurs from legal responsibilities even their enterprises had violated the provincial laws and regulations (Chen 2015). By turning private entrepreneurs into the State's 'allies' by raising protection for the PPCC members beyond laws and regulations, it is suggested that the CCP leaders sought to 'buy stability' by marginalising the notions of laws and rights (Benney \& Marolt 2015).

'Buying stability' in the context of the 'retreat from law' was thus extended to China's social system to facilitate the work of weiwen (Benney \& Marolt 2015). The establishment of local 'stability maintenance offices' (weiwenban 維穩辦) which drew officials from the legal profession, the police, quasi-government organisations and local government had been the mechanism to prevent protest and acts of resistance from formalising (Benney 2013; Benney \& Marolt 2015). Despite exercising physical forces on occasional basis, weiwenban tended to use informal negotiation and re-negotiation associated with financial compensation or small 'coordination fees' to 'encourage' workers to discontinue their disputes (Benney 2013; Benney \& Marolt 2015, p. 94). As a result, protests by workers were reportedly easily defused by a couple of yuan as compensation (X. Chen 2016, p. 4). While shifting away from using military forces for social control, the ability of the CCP to exercise weiwen strategies to continue to manage and dominate workers through the ongoing historical cycles of 'coercive authoritarianism'(Benney 2013) was because workers' psyche had been embedded with a truth about their inferior status (or position) and those considered superior through these cycles.

The post-Mao's weiwen project was originally linked with Deng Xiaoping's stability project, which aimed to maintain political stability and economic growth after the 1989 Tiananmen crisis. Following the crackdown on the Tiananmen protesters, Maoist leftists within the CCP resented Deng's modernisation programmes on economic reforms because they posed threats to social stability (Dillon 2015; Dreyer 1993). Against the leftists, Deng used his 'supreme status' as 'core leader' of the $\mathrm{CCP}^{51}$ - a practice that was rooted in Mao's own struggle to

\footnotetext{
${ }^{51}$ While Deng had been imprisoned following his opposition against Mao's approaches of revolutionary programmes such as the Great Leap Forward and the Cultural Revolution, he continued Mao's habits and strategies to remove his opponents to legitimise his 'mandate' to rule the CCP and the country. See Dillon, M 2015, Deng Xiaoping: The Man who Made Modern China, I.B. Tauris \& Co. Ltd, London, Grasso, J, Corrin, J \& Kort, M 2009, Modernization and Revolution: From the Opium Wars to the Olympics, 4th edn, M.E. Sharpe, Inc, New York, MacFarquhar, R 1997, 'Introduction', in The Politics of China: The Eras of Mao and Deng, ed. R MacFarquhar, Cambridge University Press, Cambridge, pp. 1-4.
} 
legitimise the Cultural Revolution - to dismiss those who opposed economic reforms (Grasso, Corrin \& Kort 2009, p. 244).

Deng asserted that the strategy for China's socialism was grounded on the expansion and development of productive forces by guiding 'the Chinese', particularly the 'dissident groups', to engage in a market economy (Xu 2009). Drawing on Mao's thought control methods, the post-Mao 'core leaders' from Deng to Xi Jinping ${ }^{52}$ sought to revitalise the Confucian ideologies of filial piety and obey the superiors to continue their 'mandate' to rule under the control of the CCP (Dillon 2015). Already in 1982, the Confucian values of filial piety and obey the superiors were indicated in the 'Four Cardinal Principles', that is, Marxist-Leninism, Socialism, Party Leadership and People's Democratic Dictatorship, to demonstrate the CCP's commitment to Mao's idea of embracing absolute political control of the masses (Li 2015). This insistence was further announced in the 'Five Nos' (wugebugao 五個不搞) policy for the modernisation process:

We have made a solemn declaration that we will not employ a system of multiple parties holding office in rotation; diversify our guiding thought; separate executive, legislative and judicial powers; use a bicameral or federal system, or carry out privatisation. ${ }^{53}$

(B. Wu 2011, p. 9)

Combining with the 'Four Cardinal Principles', the 'Five Nos' policy which emphasised Deng's message on economic with limited political reform was circulated to legitimise his absolute power through the CCP's Central Propaganda Department ${ }^{54}$ (Weatherley 2006).

\section{Thought Work in Post-Mao Period}

As in the Maoist period, the manipulation and utilisation of the Propaganda Department had become an important tool to initiate post-Mao thought work for complementing and supporting

\footnotetext{
${ }^{52}$ Following previous generations led by Mao Zedong, Deng Xiaoping, Jiang Zemin and Hu Jintao, Xi Jingping is the fifth generation from 2012 to present day. See Kuhn, R 2011, How China's Leaders Think: The Inside Story of China's Past, Current and Future Leaders, John Wiley \& Sons, Singapore.

${ }^{53}$ The word 'privatisation' in China was replaced by numerous terms, such as reorganisation, cooperatives, incorporation, leasing contract, and shareholding cooperatives. See Guo, S 2013, Chinese Politics and Government: Power, Ideology and Organization, Routledge, New York.

${ }^{54}$ The CCP's Central Propaganda Department was given strong supervisory powers over the major government ministries, for example, the Ministries of Education and Publication, and over the entire nexus of mass media. See Weatherley, R 2006, Politics in China since 1949: Legitimizing Authoritarian Rule, Routledge, New York.
} 
the party policies (Brady 2012a; Benney 2013). With the new laws and legal system development since the 1980s, the CCP idea of using the 'law popularisation campaign' (pufa yundong 普法運動) or 'disseminating legal knowledge' (pufa changshi 普法常識) to herald new policies in activating the masses to engage in the State's defined "good socialist behaviours" (Gallagher 2005; 2006) began to take shape:

In the interest of developing socialist democracy and improving the socialist legal system, it is necessary to place the law in the hands of the masses of people so that they will know what the law is, abide by the law, acquire a sense of legality and learn to use the law as a weapon against all acts committed in violation of the Constitution and the law $[\ldots]$

(Thirteen Meeting of the Standing Committee of the Sixth National People's Congress, November 22, 1985)

Rather than focusing on legal resolution of grievances, the dissmination or pufa movement enacted in 1991 aimed at acquainting the masses with basic knowledge of the laws by inculcating them with a wide variety of State's propaganda or ideologies to shape their legal consciousness (Benney 2013). These legal educational campaigns were implemented by the CCP cadres through workplaces, mass media and educational systems (Gallagher 2005). For example, the 'thought emancipation movement' (1979-1981) was regularly used to transmit the truth about Deng Xiaoping Theory of economic reform and modernisation to cultivate them with correct thoughts and practices - filial piety and hard work - through the Chinese media (Jeffreys \& Su 2016). Other ideological campaigns 'anti-spiritual pollution' (1983-1984) and the 'socialist spiritual civilisation campaign' (1987-1998) were launched against the influx of Western democratic values and habits (Leung 2017). These campaigns were eventually a call for CCP members to promote Deng Xiaoping Theory of economic reform and modernisation in order to command support from the workers over whom they were to rule (Grasso, Corrin \& Kort 2009).

As the $p u f a$ campaign progressed, a wide range of compulsory re-education programmes of the 'party rectification campaigns' and 'theoretical study movements' (1989-2000) of MarxismLeninism, Mao Zedong Thought and Deng Xiaoping Theory, were implemented to penetrate the socialist ideologies and moralities (Li 2015) into the minds of workers. For instance, at the 
national conference on the 'party rectification campaigns' and 'theoretical study movements' in 1998, the philosophical absolutism of the CCP in command of the absolute 'truth' and correctness in building a 'socialist market economy' was emphasised:

Taking the socialist road is the inevitable outcome of Chinese history and the correct choice of the Chinese people [...] Any attempt to abandon socialism or take the capitalist road is completely wrong and fundamentally infeasible [...] Our reform is absolutely not to engage in capitalism, but is the self-perfection of the socialist system and the need of consolidating and developing socialism. Anything that might jeopardise socialism and the fundamental interest of our people must not be tolerated and must not be allowed to spread unchecked at any time and under any circumstances.

(Jiang Zemin cited in Guo 2013, p. 118)

The above message was further transmitted via the implementation of 'scientific development' and 'harmonious society' campaigns (2010) through the national education system, mass media, residential areas and workplaces to stress the important role of "patriotism as a unifying force" by emphasising “[...] China's [workers] is a matter of concern for China's destiny” (Brady 2008, p. 51) in order to mobilise "the whole party and the whole people of the nation" to work for economic modernisation (Guo 2013, p. 119). All of these political campaigns for economic modernisation had indicated that many of the Maoist mobilisation mechanisms and practices were retained by the post-Mao leaders to indoctrinate the general population daily with the 'correct' CCP ideology and the 'Four Cardinal Principles' to construct a 'socialist market economy' under the legal discourse(Guo 2013).

\section{Chinese Habits of Making Docile Bodies and Minds within Social Hierarchy} Henceforth, while dissociating from Mao's revolutionary orthodoxy, the Maoist past 'habits' of ideological indoctrination and techniques of propaganda were (and are) repeatedly employed by different generations of post-Mao leaders to shape workers' consciousness align with the vague ideas of the laws ( $p u f a$ ) in order to constitute them as docile bodies and minds for sustainable socioeconomic development (kechixuxing de shehui jingjin fazhan 可持續性的社會 經濟發展) (Jeffreys \& Su 2016). With rapid economic development associated with the growth of poverty, the third and the fourth generations of the CCP leaders Jiang Zemin and Hu Jintao 
sought to minimise social discontent and instability by upgrading the control methods $(\mathrm{Xu}$ 2009). From 2001 onwards, the $\mathrm{Hu}$ administration incorporated new discourses into the Confucian values to promote awareness of 'proper behaviour', such as respect for authorities, between the positions (or status) of workers and work superiors, to meet the needs of economic modernisation in a well-off (xiaokang) and harmonious society (hexie shehui) (Brady 2012b). The new set of values that were guiding the behaviour of workers began with the creation of numerous identities through the mass media through which the CCP aimed to change social images of both peasant migrant and SOE workers by referring to the latter as gongren 工人 55 (SOE workers) (Wagner 1998) and the former as nonmingong 農民工 (peasant workers), as well as mangliu 盲流 (blind floats), wailaigong 外來工 (outside workers) and dagong 打工 (working for bosses). Unlike their former status as 'masters of the state' (Warner \& Zhu 2010) under Mao's period, workers' new identities were now accorded a subservient status, which was programmed to be at a lower social position. This status degradation, according to Feng Xu (2009), was linked to the new discourse of 'low personal quality' (suzhi 素質 or human capital) which aimed at creating a self-value to serve as a rational justification among workers for accepting social inequalities in the market economy. This effort is an attempt to mould workers into 'low personal quality' subjects to become active participants in capitalist exploitation in the updated hierarchy of social relationships.

In making China's economy globally competitive, the value of education had become a priority to constitute 'low personal quality' workers to ensure the supply of a mass of cheap labour for production (Wang 2008). This objective was achieved through the rapid expansion of educational opportunities by popularising secondary and tertiary vocational-technical education that taught employment skills that would enable graduates to work in the cities (Postiglione 2011). The admission criterion was subject completion of the nine-year education programme under the Compulsory Education Law (Wang 2008). While the national population was 'guaranteed' nine years of compulsory schooling by law, access to education was determined by the hukou (or household) status the person held (Rong \& Shi 2001). The difference in the educational arrangements between rural and urban populations is that the latter was entitled to a set of social rights associated with the provision of medical care, housing,

\footnotetext{
${ }^{55}$ Government slaves were referred to as gongren 宮人 in imperial China. See Wagner, D 1998, A Classical Chinese Reader: The Han Shu biography of Huo Guang, Routledge, New York.
} 
childcare and access to local schools with very low fees (Wang 2008). These basic entitlements were denied to the rural peasants - which accounted for more than half of the national population - both in their village hometowns and the cities (X. Wu 2011).

Children of migrant peasants were thus either left behind (liushou ertong 留守兒童) with relatives in the villages or brought into the cities for education (Zhang, Li \& Xue 2015). In the former case, rural children began a two- to three-year education in the villages when they turned eight years old, because rural schools were far from home and the roads were generally unsafe for small children (Postiglione 2011). In the latter case, migrant children, formally referred to as jied $u$ 借讀 students (students from outside the community that borrowed a place to study), had to pay three types of fees (see Table 2) besides the regular fees that all students had to pay in public schools (Wang 2008, p. 694):

Table 2: Example of Three Types of Fees in Beijing in 2000

\begin{tabular}{|l|l|l|}
\hline Types of Fee & Fees Descriptions & Fees per term per head \\
\hline$j i e d u f e i$ & $\begin{array}{l}\text { Fee for non-local resident in a public } \\
\text { school }\end{array}$ & 480 yuan \\
\hline ze xiao fei & Fee for selecting the public school & 1000 yuan \\
\hline zan zhu fei & Fee for supporting the public school & $\begin{array}{l}\text { Average: } 1908 \text { yuan } \\
\text { Highest: } 20,000-30,000 \text { yuan }\end{array}$ \\
\hline
\end{tabular}

Source: The Marginality of Migrant Children in the Rural Chinese Educational System (Wang 2008, pp. 695-696)

Given that the monthly household income of most migrant parents was between 800 and 1500 yuan in the cities, which was around the local poverty line in most localities, a large proportion of the children of migrants were s either educated in migrant schools (minban xuexiao 民辦學 校) in the cities or in rural schools in the villages. Due to financial issues, these schools had low-quality teaching staff and poor facilities (Postiglione 2011; Wang 2008).

It is therefore argued that by creating this rural-urban divide - that was historically defined by birth - using the structure of the Chinese educational system provided a specific means of 
producing and reproducing 'low personal quality' workers for the CCP's modernisation plans of market socialism. Rather than focusing on ideas of 'Marxism' in the education provision, the making of a socialist market in the CCP's economic modernisation was concerned with the ability of the population to pay for a quality education that might gain them employment (Postiglione 2011). Compared to their urban counterparts, the majority of poor rural households were excluded from the mainstream norm of access to public schools that offered quality education, both in the cities and in their villages (Wang 2008). This deliberate exclusion of the rural groups from access to educational resources and opportunities beyond a limited circle of eligibilities thus led to high dropout rates from the low-quality, rural and migrant primary schools:

$[\ldots]$ dropout rates $[\ldots]$ were between $3.66 \%$ and $54.05 \%$ [...] beyond food and clothing, dropping out is caused by a lack of confidence and interest in continuing their education, difficult textbooks, a monotonous school life, tense relationships between students and teachers, poor food and lodging, inconvenient transportation and rising costs of school lodgings.

(Postiglione 2011, p. 90)

By confining rural and migrant populations to the category of low-quality education, the CCP leaders thus implicitly encouraged children to discontinue education, through which a minimum of 300 million illiterate and semi-illiterate ${ }^{56}$ people were created in China (Mao 2004). The intentional education inequality thus ensured that a large proportion of people could not get a higher education in order to produce and reproduce 'low personal quality' workers for the marketplace.

Further, images of 'low personal quality' workers were portrayed as a specific segment of the population that prevented China's progress towards civilisation (wenming 文明) (Gabriel 2006; $\mathrm{Xu}$ 2009). In an editorial comment in a prestigious Party newspaper, the 'low-quality'

\footnotetext{
${ }^{56}$ China defines illiterates and semi-illiterates as people who are twelve years of age or older who do not know characters, or know less than 1,500 characters, cannot read popular books and magazines, and cannot write simple words. See Miao, X 1992, 'China', in International Handbook of Reading Education, eds J Hladczuk \& W Eller, Greenwood Press, London, pp. 77-92.
} 
population was described as lacking discipline and modern civility because "they behav[e] like barbarians [...] forgetting [...] civility demands [...]" (China Daily 2014). As a result of widespread indoctrination, this official 'truth' became an everyday discourse that appeared in various cultural mechanisms, such as television and magazines. For example, in a national newspaper Nanfang Zhoumo 南方週末 (Southern Weekend) a reader complained to the editor that "the low-quality people are the reason for many things not getting done or not getting done well” (Xiaoyong 1999, p. 11). In his book, China's Two Pillars in the Twenty-First Century, Zhou Yi (2001, p. 748) suggests a more pessimistic view of the large numbers of so-called lowquality citizens by making the point that it is these people that "made it so difficult to advance our country $[\ldots]$ we must get rid of the illiterate people $[\ldots]$ particularly those illiterate young people". A Chinese reporter in Philippine World News commented that "[...] we have to admit that our quality is low [...] when compared to those in Western countries" (Xiaogang 2016).

Social recognition of the 'low-quality' population was applied predominantly to workers and was central to the production of 'new city people' (xin shimin 新市民) as the subjects of Chinese 'development' (Yan 2003; Xu 2009). This 'development' centred on the 'rectification' of population quality, in terms of which workers were identified by the CCP from the 1980s, as the major focus for 'improvement': "The national strength and the stamina of economic development was highly dependent on the quality of the labourers" (Zeng 1989, p. 165). Embedded in this invocation of 'quality improvement' (or development) was the CCP's interest to continue poverty by recoding such 'problem' as 'quality poverty relief'(suzhi fupin 素質扶 貧) and 'cultural poverty relief' (wenhua fupin 文化扶貧) in the labour market (Yan 2003). In this context, 'poverty-relief' discourses were functioned as a 'motivating force' to cultivate a desire within the 'low personal quality' workers' to escape from poverty (tuopin 脫貧) (Yan 2008). Thus, the introduction of this new discourse by the State marks a shift from projecting workers as being an object to becoming a subject for 'poverty-relief' actions (Yan 2003). The project of producing these desiring subjects is appositely a subtle task of producing 'new city people' for Chinese 'development' (or improvement).

It is argued that the production of the desiring subjects was conditioned by the production of a market consciousness among workers for 'development' through cultural processes (Yan 2008). 
In these processes, images of the outcomes of 'poverty-relief' that resulted from 'improvement', for example with the increased affordability of mobile phones and cars, were promoted in the Chinese media (Gabriel 2006). These commercial activities were used to promote the idea that "the future belongs to those who succeed in the capitalist labour power markets" to turn workers into customers (Gabriel 2006, p. 58). With a view to inculcating consumerism into the popular consciousness, instruments of mass media were again mobilised as a form of 'social education' (shehui jiaoyu 社會教育) to publicise the benefits of 'improvement' to inspire the subjects' 'intentionality' towards the 'development' of the labour market (Yan 2003, p. 504). This vision produced a positive demonstration of 'poverty-relief' being gifted through the opportunities afforded by 'development', because 'low quality' workers could "improve themselves by learning from their 'high quality' superiors at work in the cities" (Yan 2008; emphasis added).

By introducing a self-perception of workers as the subjects of 'development', the discourse of 'quality improvement' further constituted a 'status consciousness' (Koo 2001) or 'older rules consciousness' (Perry 2009) that was connected to an updated Confucian status ideology framework of a 'quality hierarchy' within social relationships (Chen \& Goodman 2012; Yan 2003). This 'hierarchal relationship' was defined in terms of the deterministic identities with which the 'lower-quality' workers were shaped and 'programmed' to see themselves as inferior to their 'higher-quality' superiors in the labour market (Gabriel 2006). The perception of a fundamental difference of 'quality' that comprised distinct 'races' of human beings was thereby notionally created:

[...] "white" workers gaining status as a consequence of racism. To the extent that certain workers gain status within the workplace as a consequence of racism, these workers may be willing to work for less material compensation. This is one way in which racism may reduce the value of labour power. It may also do so by creating selfdoubt, self-hatred and low self-esteem in those excluded from the transcendental race. The "black" [...] worker [...] for instance, believe[s] herself lucky to have any job and to be worthless $[\ldots]$

(Gabriel \& Todorova 2003, pp. 34-35) 
By substituting 'high-quality' for white and 'low-quality' for black, the racialized interactions of the perceived inferiority (the low) and the perceived superiority (the high) in China served to lower the value of workers in a quality hierarchy (Gabriel 2006; Yan 2008). Rather than a 'quality improvement', the discourse of 'development' hence imposed the notion of ming (destiny) on inferiority so that it would then function as a truth of the 'low personal quality' workers to think of themselves as low within their subjectivities with respect to their given positions in the current labour market system (Yan 2003). The CCP's strategies of keeping the 'low personal quality' workers to think and act within their prescribed ming by restricting their educational opportunities was the foundation of thought management established since the Zhou dynasty (13 ${ }^{\text {th }}$ B.C.E.) via $l i$ rules (later Confucian rules) (see this Chapter, pp. 103109) to maintain social status for producing and reproducing docile bodies and minds to meet the political, ideological and economic needs in different historical periods.

\section{The Destiny (ming 命) of Low-Quality (or Low-educated) Workers in the Chinese Occupational Hierarchy}

The intention of indoctrinating workers to accept their positions as their 'ming' and the discourse of 'quality development' was to subject the perceived 'inferiors' to continual readjustment and retraining (zhongsheng xuexi 終生學習) in order to integrate them into the market economy (Yan 2008). To achieve this goal, the workers were taught to 'love labour' and 'respect regulations' to behave 'properly' according to the everyday behavioural norms (richang xingweu judong 日常行為舉動) of the workplace in Jiang's period and after (Efthymiou-Egleton 2016). For example, they were taught to respect authority to ensure the maintenance of social order (Xu 2009). In this context, compliance with the social order was highlighted by the Chinese media as a way for workers to protect their rights. For example, even today the Chinese popular press publishes cautionary tales about workers' trying to find work in their own way outside the norms. These narratives typically end either with the victims being cheated by ‘black’ labour market brokers (hei zhongjie 黑中介) (Zhengzhou Wănbào 2016) or sold into prostitution (Ma 2013). To reduce social disruptions, services are provided to workers by the 'carceral network' (Foucault 1980a; see Chapter Three, pp. 94-95) of governmental and non-governmental organisations, such as job-seeking and educational training regarding laws and regulations in order to highlight the importance of signing labour 
contracts (Xu 2009). By exposing themselves to these forms of knowledge, the inferior subjects were supposedly guided to 'improve' their understanding of labour rights and conditions throughout the process of 'development'. While the 'low-quality' workers were offered new training opportunities for continuous 'self-improvement', these 'opportunities' are arguably designed to engage them as potential agents in their own governance (Jeffreys \& Sigley 2009).

This social management goal is embodied in the knowledge in which an array of CCP'sconceived standards of modernised behaviour is promoted by means of service activities (or programmes) (Cartier 2016). Cooperating with the CCP's interest in developing 'population quality' (renkou suzhi 人口素質) in the discourse of modernisation, social programmes run by the everyday 'carceral network' focus on the Chinese cultural economy and industry and standards for social conduct (National Civilised City Evaluation System 2011). These cultural standards are evident in large-format advertising slogans, including "Be a Civilized Person, Build a Civilized City (Zheng zuo wenming ren, gong chuang wenming cheng 爭做文明人共創文 明城)” and “Speak Civilly, Act Civilly” (Shuo wenming hua, ban wenming shi...說文明話辦文明 事) (Cartier 2016). These civilising perspectives are extensively reinforced by 'quality training' (suzhi peixun) and 'quality programmes' (suzhi jiemu 素質節目) throughout cultural institutions such as the mass media, within schools and on the streets (Cartier 2016), and were printed in the form of 'self-help' manuals to encourage workers to act according to sanctioned behavioural standards. In one 'self-help' manual (MDGIF 2011), for example, 'low quality' workers are encouraged to be satisfied with low-wage employment, relinquish excessive consumption behaviour, obey traffic lights, adopt good hygiene habits and exhibit 'proper' manners. Constructing these official and standardised 'civilised behaviours' (or cultural norms) highlights the CCP's desire to 'improve' self-constraint and self-control (or 'self-governance') of workers to ensure that they constitute appropriate subjects in the context of 'development' programmes.

In this manner, the discourse of 'development' confines the 'low-quality' population to a specific status. The discourse of 'development' is aimed at conditioning the self-attitude and conduct of the workers so that they will behave (Davidson 2003) in accordance with cultural norms and the 'quality-based' occupational hierarchy in China. The knowledge that has been 
facilitated by the everyday 'carceral network' to continuously inculcate forms of discourses of truth in the minds of workers is inherent to this normative Chinese cultural behaviour (Clifford 2001). This then enables the ongoing production and reproduction of docile minds and bodies by co-opting workers' thoughts, bodies and movements to serve the will of the CCP within the power-knowledge networks in China.

\section{Concluding Remarks}

To conclude, Foucault's genealogical method has been used to explore the development of workers' consciousness throughout the various historical periods of Chinese civilisation. The analysis illustrates how $l i$ (later Confucian) rules had been evolved from direct and brutal forms of physical punishment to internalised social norms to create the Chinese docile bodies and minds to uphold the orthopraxy (or proper behaviour) system (see Figure 5):

Figure 5: Orthopraxy System

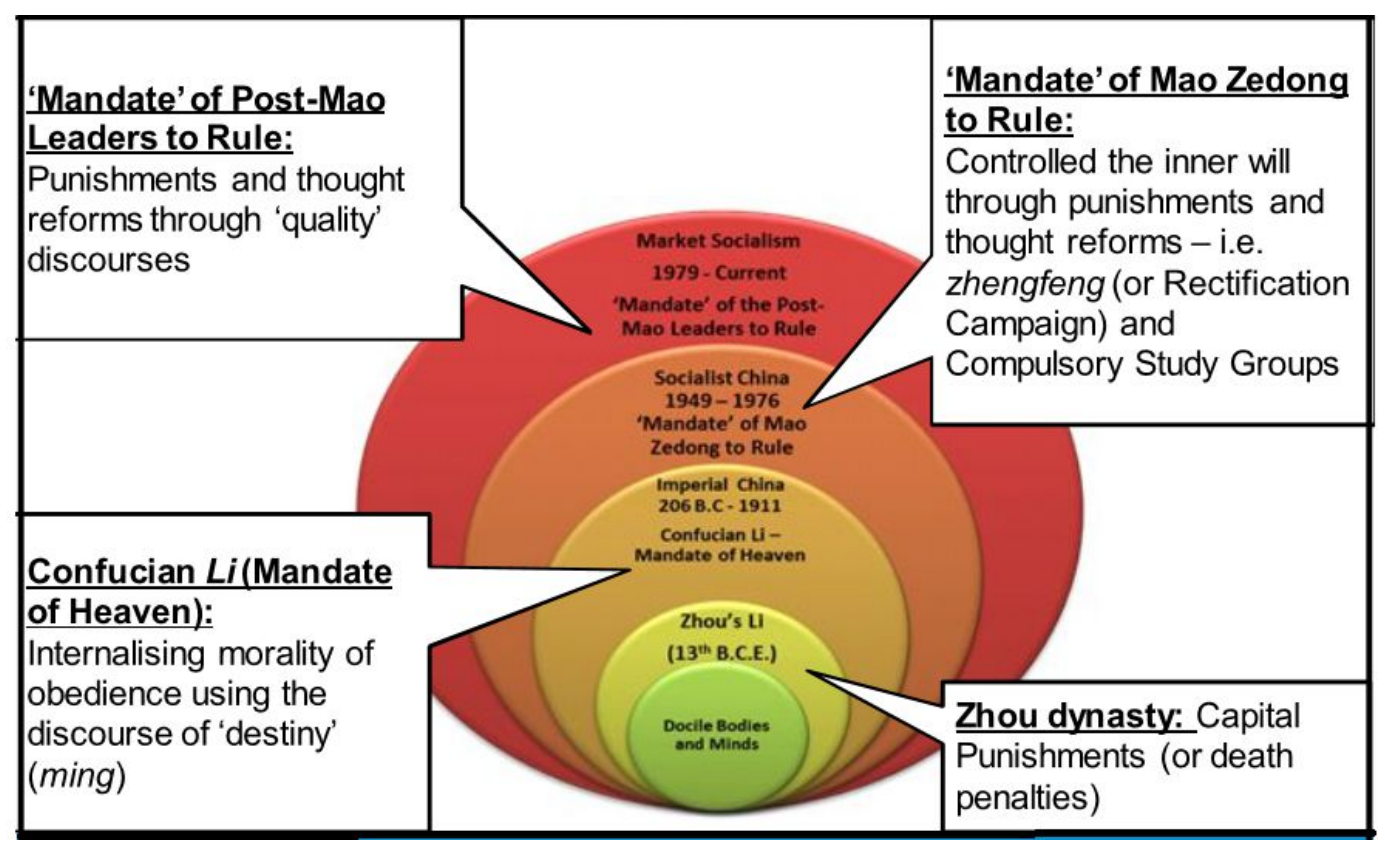

Figure 4 summarises the changing systems of rule that have been used to create the Chinese docile bodies and minds by rulers to maintain their dominance (or mandate to rule) in different historical periods since the Zhou dynasty (13 ${ }^{\text {th }}$ B.C.E.) through to Mao's period. Based on historical cycles, the post-Mao leaders consolidated their 'mandate' to rule by continuing the production and reproduction of docile bodies and minds among Chinese workers through the 
internalisation of the Confucian concept of social status. This status was further reinforced by the 'quality' discourse to guide the 'low personal quality' to think of themselves as destined for marginal positions (or governmentality) throughout their non-work lived experiences in China's thought management's programmes. Chapter Four illustrates how the work-based lived experiences are portrayed as key factors to stimulate the development of workers' class consciousness and hence increased incidence of labour activism in mainstream literature. While these writings provide invaluable information about the relations between work-based lived experiences, increased class consciousness and actions, the chapter reviews alternative thesis to show how the effectiveness of workers' resistant activities are hindered by their own embryonic consciousness that is maintained by their non-work lived experiences. 


\section{Chapter Four: Debates on Class and Class Consciousness Development in China}

Class is a social and cultural formation (often finding institutional expression) which cannot be defined abstractly, or in isolation, but only in terms of relationship with other classes; and, ultimately, the definition can only be made in the medium of time - that is, action and reaction, change and conflict. When we speak of a class we are thinking of a very loosely-defined body of people who share the same congeries of interests, social experiences, traditions, and value system, who have a disposition to behave as a class, to define themselves in their actions and in their consciousness in relation to other groups of people in class ways.

(Thompson 1966, p. 357)

In The Making of the English Working Class, E.P. Thompson (1966, p. 21) drew on Marx to theorise the term lived experience in describing the development of worker consciousness in the making of a class-for-itself (see Chapter One, pp. 22-23) to struggle against their poor working conditions during the turbulent years between 1790 and 1850 in England. The crucial contention of Thompson's (1966) analysis was that the emergence of worker consciousness and class actions was an outcome of the common experiences of workers at work as well as outside of work (see Chapter One, pp. 22-23). From this standpoint, Thompson's perception of class and consciousness gave primacy to worker agency, because a class was "made" by workers articulating their feelings and experiences, and coming to think and struggle in different times and places collectively (1966). He concluded that the way workers perceived and interpreted their material conditions and the way they struggled against these were influenced by cultural factors that were "embodied in tradition, value-systems, ideas, and institutional forms" in both work and non-work based experiences: that is, their lived experiences (1966, p. 10).

Inspired by Thompson's (1966) agency-oriented class concept, mainstream Chinese scholars have argued that the increased labour protest actions in China (see Chapter One, pp. 22-23) 
emerge from workers' "rising class consciousness" that has been shaped by their lived experience as workers over the past 30 years in post-Mao China. These studies argue that although economic reforms enabled the post-Mao China to generate high rates of gross domestic product (GDP) growth, these reforms eliminated the iron rice bowl (tie fanwan 鐵飯 碗) and produced growing economic insecurity associated with deteriorating employment conditions in both the State and private sectors. These experiences of workers have been articulated by labour scholars such as Chris Chan and Pun Ngai (2009) as the major source of labour disputes and the increased number of worker protests, despite the Chinese Communist Party (CCP) implementing policies and mechanisms to quell disturbances following the Tiananmen Massacre in 1989 (see Chapter Three, pp. 75-76). Labour scholars (Chan \& Pun 2009; C. Chan 2010b; Chan \& Hui 2012; 2016; Leung \& Pun 2009; Pringle 2011; Pun, Chan \& Chan 2009; Pun \& Lu 2010; 2010b; Pun et al. 2016; Smith \& Pun 2006) of the postTiananmen period have documented incidents of worker protest actions triggered by abuses and exploitations to claim that the prevalence of labour actions herald a "rising class consciousness" which is shaped by their work-based lived experiences. They subsequently extend this argument to predict that a new working class is coalescing into a class-for-itself to act against their continued exploitation and abuse under the market economy of post-Mao China.

The aim of this chapter is to review the studies about labour activism in China since the 1989 Tiananmen movement that posit the above arguments. This study argues that while the existing studies have provided insightful information about the work-related experiences of the Chinese working class, their evaluations are narrowly focused on activists' viewpoints of protest actions. It is suggested that their implicit use of Thompson's (1966) class concept of lived experience on the basis that increased protest actions signify a "rising consciousness" that is resulting in the making of a class-for-itself leaves us with an incomplete understanding of the politics of labourist activist culture in China. To support this argument, alternative perspectives are reviewed to illustrate how labour activism in East Asian societies is influenced by cultural factors, rather than class alone. The chapter concludes with the assertion that Chinese workers' experiences and consciousness have been shaped by unique events in China's sociocultural history that constrain their ability to form a class-for-itself to improve their conditions beyond their power-knowledge relations. 


\section{SOE Worker Protests in Early Reformed China}

Following the economic reforms of 1978, China's socioeconomic changes associated with the deteriorating prospects for Chinese workers had prompted a quantitative increase in protest activities. This assertion is reflected in the oft-quoted number of mass incidents that escalated steadily from 10,000 in 1994 to 87,000 in 2005 (Leung \& Pun 2009, p. 553). Ching Kwan Lee (2000a, p. 72), for example, notes that workers in State-owned enterprises (SOE) - who had once been the pride of a Maoist State, and who under this regime had attained great gains in their social status and enjoyed a high level of job security and welfare or iron rice bowl (tie fanwan 鐵飯碗) - suffered the greatest losses in post-Mao China. Matters such as reduced income and job losses were experienced by SOE workers as the post-Mao CCP leaders sanctioned a massive lay-off (off-duty or xiagang 下崗) program to restructure SOE workforces for efficiency and profitability (see Chapter Three, pp. 71-76). The declining SOEs and rising unemployment thus triggered waves of protests by SOE workers from 1988 (Chen 2000; Hurst \& O'Brien 2002; C.K. Lee 2000b; Walder 1991).

SOE protests were perceived as characterised by a high-level of class consciousness of the State workers to challenge against the CCP and its policies (Pringle \& Clarke 2011). Tim Pringle and Simon Clarke (2011, p. 59) note that despite large-scale SOE redundancies, privatisation and closure in the cities of the core industrial regions; SOE workers retained their awareness of that they were the traditionally created Chinese working class (gongren jieji 工人 階級), and supposedly constituted a leading class in Mao's China. Post-Mao's economic reforms and eventual closure or restructure of SOEs however threatened this position and undermined workers' traditional job and economic security. Pringle and Clarke (2011) argue that these events stimulated the class consciousness that was developed since the Maoist period to then foster an increased coalition among SOE workers and commitment to protecting the continuation of SOEs. Protests involving SOE workers were thus generally described as reflecting an anti-privatisation movement. Their coalition and focus for protest action was drawn upon to claim that SOE workers agitation about the effects of restructuring aroused their class consciousness which had become the seeds of the formation of a class-for-itself since their first major protest involvement in the 1989 Tiananmen movement (Chan \& Pun 2009; Pun, Chan \& Chan 2009). 
A rapid stage of class consciousness development among workers was depicted by scholars such as Jude Howell (1998) and Malcolm Warner (1991) in the wake of the 1989 student-led Tiananmen movement. Warner (1991), for example, notes that while workers in general were unwilling to voice their opinions or challenge the management and the government officials, their discontent over the poor labour protection and working conditions, their declining incomes and increasing financial burdens had incited them to form a number of independent workers' organisations for themselves to advance their rights and interests (Chan 1993; Lai 2010; Kent 2007; Walder 1991; Walder \& Gong 1993). The Beijing Worker Autonomous Federation (BWAF), for instance, had attracted 20,000 workers to engage in solidarity in 1989 (Goldman 2000, p. 122; C.K. Lee 2000a, p. 74; Potter 2001, p. 97). Similar organisations such as 'workers' support team', 'workers' picket team' and 'dare-to-die' corps ${ }^{57}$ (Walder 1991, p. 488) were also established to express grievances through demonstration (Lorimer 2004, p. 22). Not only these new workers' organisations formed in protest against the growing inequality and decline in working and living conditions, but also the All-China Federation of Trade Unions (ACFTU) (see Chapter One, pp. 17-18), which had become to be perceived as a puppet of the State (Hess 2013; Pringle \& Clarke 2011) to supervise and manage the workers, rather than siding with workers in defence of their rights and interests in the enterprises (see Chapter One, pp. 17-18). Workers in this context began to demand workplace rights such as the right to supervise the conduct of the management and the CCP cadres in SOEs independent of the ACFTU (Walder \& Gong 1993). Seung Wook Baek (2000) notes that the concern of the CCP with worker activists within these independent organisations was their ability to turn their protest into a politically-oriented class action. The CCP concern about the potential for unrest led to ordering the People's Liberation Army (PLA) ${ }^{58}$ to occupy the Tiananmen Square. In the resulting Massacre, hundreds of worker activists were either imprisoned or killed (Orts 2001).

\footnotetext{
57 The function of the 'workers' support team' was to mobilise workers to participate in demonstrations while the 'workers' picket team' aimed to protect the protesters. The 'dare-to-die' corps shared similar tasks with the 'picket team' but travelled anywhere to block the retaliatory action by the Chinese military, that is, the People's Liberation Army (PLA), against the protesters during the 1989 Tiananmen movement. See Walder, A 1991, 'Workers, Managers and the State: The Reform Era and the Political Crisis of 1989', The China Quarterly, vol. 127, pp. 467492.

58 The People's Liberation Army (PLA) was formerly called the Red Army prior to 1946. See Grasso, J, Corrin, J \& Kort, M 2009, Modernization and Revolution: From the Opium Wars to the Olympics, 4th edn, M.E. Sharpe, Inc, New York. The Army consisted of Chinese workers and peasants (the masses) which had engaged battles against the Japanese troops during the Second World War (1937-1945) and the Kuomintang (KWT) party in the Chinese Civil War (1946-1949). See Chapter One, p. 38 and Li, X 2012, China at War: An Encyclopedia, ABCCLIO, LLC, California.
} 
Further, following Tiananmen, the CCP enacted the Assembly Law (1989) and the National Law on Assemblies, Parades and Demonstration Law (1989) to weaken class solidarity by outlawing the right of workers to form independent organisations, demonstrate and protests under these legislative provisions (So 2006).

\section{Maintenance of Social Stability (weiwen) through the Weak enforcement of Laws and Weak Positions of Workers' Organisations}

Immediately after the Tiananmen movement, the CCP increased the wages for SOE workers, and temporarily halted reform of SOEs in order to maintain social stability (Pringle \& Clarke 2011). Maintenance of social order was also reinforced through the enactment of labour legislations as discussed in Chapter Three (pp. 77-81) While these laws and regulations were supposedly enacted to raise the material and social status of workers, they were rarely enforced with employers (see Chapter Three, pp. 71-76) (Friedman \& Lee 2010; Hess 2013). Thus, even the Trade Union Law (1992) was enacted to consolidate the rights of the ACFTU to exercise control over their affiliates ${ }^{59}$ and to represent the interests of the working class in SOEs (this was later extended to the private sector) (Cooney 2006-2007; Cooney, Biddulph \& Zhu 2013), there was no sign that the ACFTU was mobilising or protecting the interests of their workplace members by organising worker action against any employers or organisations (C. Chan 2010b). A major reason for this was that trade union officials at the enterprise level in China are largely appointed, rather than elected, by ACFTU-affiliated officials and the CCP cadres, who side with employers/management and the CCP government (F. Chen 2009; 2010; Howell 2008). Today, ACFTU still exists as an officially sanctioned organisation that acts as a transmission beltto implement directives from the $\mathrm{CCP}$, rather than being the representative of Chinese workers (Pringle 2011).

Given the weak enforcement of the Labour Laws (1995 \& 2008) associated with the weak position of the ACFTU, non-government labour organisations (or labour NGOs) began to emerge to provide assistance to the Chinese workers since 1995 (Chan 2012a). These labour NGOs were fundamentally sponsored by international funders, such as Oxfam Hong Kong,

\footnotetext{
${ }^{59}$ The number of ACFTU's enterprise affiliates increased sharply from 1,324,000 in 2006 to 1,845,000 in 2009 under the Trade Union Laws (1992 \& 2002) Chan, C 2010b, 'Class Struggle in China: Case Studies of Migrant Worker Strikes in the Pearl River Delta', South African Review of Sociology, vol. 41, no. 3, pp. 61-80, Cooney, S, Biddulph, S \& Zhu, Y 2013, Law and Fair Work in China, Routledge, New York.
} 
through the collaboration of labour projects with local governments in China's legal framework ( $\mathrm{Lu} 2009$ ). Hence, the operations of the labour NGOs or any social organisations were subject to their ability to obtain a 'business supervisory unit' from the authorised government organisations (Chan 2012a). In this context, NGOs had a diversity of legal statuses, from being registered as popular (minban 民辦 or organised by citizens) organisations to business enterprises or unregistered (illegal) organisations ( $\mathrm{Lu} 2009$ ). It was difficult for the NGOs to be registered as specific labour organisations, because China had banned the establishment of NGOs from membership-based funding or as an organisation to represent specific social groups, such as migrant workers or laid-off workers, as a means for prohibiting NGOs from growing bigger in order to prevent public outcry or collective protest against labour disputes (Biddulph 2015). Under this political culture, combining with the international support for law-oriented labour rights protection (weiquan 維權) programmes ${ }^{60}$, the scope of NGO activities was thus limited to defending workers’ legal rights (hefa quanyi 合法權益) (Benney 2013).

With both international funders and the CCP backing legalistic weiquan approaches in China, most labour NGOs engaged in legal training and advising on labour laws and regulations as well as policies relating to occupational health and safety (OHS) to increase workers' awareness of their labour rights (Chan \& Siu 2012). Chris Chan (2012a) notes that most labour NGOs were fundamentally functioned as service providers that they had established service centres to provide workers with free newspapers and educational classes to promote legal knowledge and awareness among workers. These labour NGO centres also offered free legal hotlines and consultation in providing workers with after-the-fact legal advice on resolving grievances through legal processes of mediation, arbitration and litigation (Friedman \& Lee 2010). Despite free services, Eli Friedman and Ching Kwan Lee (2010, p. 524) note many labour NGOs had turned into a business of "citizen's agents" (or legal agencies) to help workers, at a fee, with the preparation of legal documents to file complaints with the local

\footnotetext{
${ }^{60}$ Chinese discourse of rights protection is characterised by the acceptance of the laws as the standard by which the clauses such as working conditions and minimum wages have been set. See Benney, J 2013, Defending Rights in Contemporary China: Reserving the Right, Routledge, New York. See Chan, A \& Siu, K 2012, 'Chinese Migrant Workers: Factors Constraining the Emergence of Class Consciousness', in China's Peasants and Workers: Changing Class Identities, eds B Carrillo \& D Goodman, Edward Elgar Publishing Ltd, Massachusetts, pp. 79-101.
} 
labour bureaus ${ }^{61}$, as well as being their legal representatives in resolving disputes, such as backpay or workplaces injuries compensations, in courts. As a result, these legal-aid weiquan programmes were exercised only when workers' legal rights were violated, rather than proactively advancing their rights and interests that were beyond the legal standards (Benney 2013; Chan \& Siu 2012).

While relatively reactive, Mary Gallagher $(2005 ; 2006 ; 2007$; 2013) maintains that legal-aid weiquan services provided by the labour NGOs had been a critical instrument in raising legal rights consciousness (falu quanli yishi 法律權利意識) among workers. Although legal consciousness was profoundly shaped by the heavy hand of the State through pufa campaign (Benney 2013; see Chapter Three), Gallagher claims that the slogan "[...] use law as a weapon [...]" used in the National's People Congress and in the media's coverage (see Chapter Three, p.83) had provided workers with a strategic justification for legal action to sue their employers under the discourse of weiquan (2006). In her study at a labour NGO in Shanghai, Gallagher notes that the official propaganda and encouragement to use "legal weapons" had created workers' expectations which motivated them to use the laws to protect their rights even without substantive legal knowledge (2005; 2006, p. 799). Despite their sense of confusions over what the legal responsibilities of their employers were, their expectations associated with a sense of entitlement to "legal weapons" had been the most important elements that incited them to acquire knowledge in the realm of understanding the laws and regulations, legal procedures and the ways to collect and use relevant evidence through their participation in legal consultation offered by the labour NGO (Gallagher 2005; 2006). Gallagher concludes that workers' engagement in the legal consultation and discussion was both a learning and corrective process for developing a critical legal rights consciousness among the workers so that they could live up to the standards of the laws and defend the legal rights (weiquan) for themselves (2006).

As a consequence of the CCP's promotion of weiquan programmes through government and non-government organisations in its legal system (Benney 2013), the number of formal dispute

\footnotetext{
${ }^{61}$ Filing labour dispute arbitration with the local labour bureau is the prerequisite for filing civil lawsuits. See Friedman, E \& Lee, CK 2010, 'Remaking the World of Chinese Labour: A 30-Year Retrospective', British Journal of Industrial Relations, vol. 48, no. 3, pp. 507-533.
} 
cases over work related issues accepted by the Labour Arbitration Committees ${ }^{62}$ had been progressively increased since the 1990s (China Statistical Yearbook 2015). Eli Friedman and Ching Kwan Lee (2010, p. 517) note that thirty percent of the dispute cases was about unfair dismissal; whereas fifty percent of which was reflecting wage arrears, non-payment of xiagang benefits and social insurance that were mainly faced by SOE workers. Friedman and Lee further reveal that official disputes filed with the labour bureaus by SOE workers had accounted for thirty-four percent; while workers in foreign-invested and private enterprises, respectively, accounted for twenty-one percent and ten percent of the total of 48,121 cases, involving 189,120 workers, in 1995 alone (2010, p. 517). New cases continued to rise from 520,000 in 2008 (Friedman \& Lee 2010, p. 518) to 600,865 and to 715,163 by 2014 (China Statistical Yearbook 2015). Not only did the sharp increase in official labour disputes signify the overburdened labour bureaus were unable to efficiently resolve workers' grievances, but it also indicate that the labour law provisions associated with weiquan discourse were all rendered insignificant in the absence of any independent working-class organisation that can constitute its own union membership as a collective force (Friedman \& Lee 2010).

\section{The Continual Rise in SOE Worker Protests under Legal Rights Protection (Weiquan) Discourse}

The incapability of the legal channels in redressing workers' grievances had thereby fostered a continual rise in worker protest activities with increasing frequency and intensity under weiquan discourse from the mid-1990s in the State sector (Benney 2013; Chen 2003; Lee 2002a). Although the crackdown on the Tiananmen movement coupled with incentives such as a rise in wages that was offered to SOE workers caused a temporary halt to protest activity by State workers during the first half of the 1990s (Pringle \& Clarke 2011, p. 61); SOE worker protests began to escalate from the mid-1990s as reforms accelerated in a large number of SOEs (Cai 2002, p. 327; Lee 2007a, pp. 8-9). Suddenly subject to lay-offs, increased precariousness, reduced and unpaid wages and xiagang benefits (see Chapter Three, pp. 74-76) to maintain

\footnotetext{
${ }^{62}$ In accordance with Article 81 of the Labour Contract Law (2008), the Labour Arbitration Committee is established at the county, municipality and district levels. See Chen, K 2011, Labour Law in China, Kluwer Law International BV, The Netherlands. The Labour Arbitration Committee is composed of representatives of the local Labour Bureau (or labour administrative department) and the trade union as well as the government staff and lawyers as full-time or part-time arbitrators where the Committee is chaired by the responsible person in charge of the local labour administrative department. See Hunter, C, Lam, L \& Lin, K 2008, Employment Law in China, CCH Hong Kong Limited, Hong Kong.
} 
minimal living standards had been a major factor triggering a high volume of protest activities in the State sector (Friedman \& Lee 2010). Feng Chen's (2000) early study of worker protest activities in a medium-sized SOE in Henan province ${ }^{63}$, North China illustrates this. In this study, Chen reveals that wage and pension arrears as well as difficulties in livelihood provoked protests by laid-off workers. Chen in this context finds that workers within this enterprise were drawing on their own weiquan concept in defence their 'right to subsistence' (shengcun quan 生存權) (2000). Their anger and anxiety about how they were going to survive after being laid off for months or years and receiving no income at all during that period of time (2000). Thus, protests by laid-off workers were essentially spontaneous, leaderless and largely motivated by the subsistence crisis under which their demands were "no more than some subsistence aid from local authorities" (Chen 2003, p. 242). Given their limited demands, protests by SOE workers were therefore not repressed by the local authorities as their actions were "easily defused by a government promise of a couple of hundren yuan as compensation" (Chen 2006, p. 47). Chen thus argues that these SOE workers' actions remained passive and reactive as they appeared to submit themselves to the changes and conditions until they were not able to subsist (Chen 2000, p. 62). Their incapability to define interest beyond the 'right to subsistence' led Chen to conclude that the acts of SOE workers illustrated that the Chinese working class remained at the level of a class-in-itself ${ }^{64}$, rather than a class-for-itself (2000), that is, that their consciousness had not matured to a level capable of taking action for the 'wider good'. Their rather embryonic consciousness hence guided their action to remain focus on their own self at an individual level - in this case, their self-subsistence.

Lee (1999b) explains that SOE workers' values of a subsistence ethic was heavily influenced by the Chinese legislation of Labour Contract Reform policy (1986) in SOEs and the National Labour Law (1995). Her study reveals that the Labour Law (1995) provided enterprise

\footnotetext{
${ }^{63}$ Henan province was one of the top four provinces (next to the three other SOE concentrated locations of Liaoning, Heilongjiang and Jilin provinces) in terms of the number of SOE workers that faced with wage arrears. With 640,000 of 4.13 million SOE workers laid off, Henan's province's unemployment rate was reported as the third highest in the country, next to Liaoning and Heilongjiang. See Chen, F 2000, 'Subsistence Crises, Managerial Corruption and Labour Protests in China', The China Journal, vol. 44, pp. 41-63.

${ }^{64}$ Contrary to a class-for-itself, a class-in-itself is constituted by the production structure without becoming discursively aware (or conscious) of its own position (or identity) within the capitalist system. Thus, it is argued that a class-in-itself is formed without class identity and hence is incapable of engaging in class-based action to defend the rights and interests of workers. See Research Background, p. 23 and Haugaard, M 1997, The Constitution of Power: A Theoretical Analysis of Power, Knowledge and Structure, Manchester University Press, Manchester.
} 
management with a no-fault dismissal of SOE workers while labour contracts strengthened SOE managerial power to fire workers, particularly in less competitive and older industries (1999b). The legal enhancement of managerial autonomy within SOEs thus led to a steadily increased xiagang rate from 0.7 percent in 1988 to 10 percent in 1994 and skyrocketed to 35.8 percent in 1996 (Lee 1999b, pp. 55-56). In 1997, for example, the number of unemployed workers together with xiagang workers in Guangzhou province alone had mounted to approximately 103,000 (Lee 1999b, p. 56). Lee (1999) perceives that managerial power to make redundant or even dismiss workers had pressured those who were less competitive in the labour market such as the old and the sick, to become submissive or quiescent because they continued to receive xiagang benefits and were formally still attached to SOE work units' (danwei 單位) (1999b). Thus, the continuation of these arrangements and the provision of these subsidies weakened their capacity to act collectively and hence preventing their actions to become explosive even when their subsidies (or xiagang benefits) were inadequate or remained unpaid. In a sense, the series of labour laws and regulations were implemented not to strengthen workers' legal rights, but rather to construct a level of what Mary Gallagher (2005; 2006) refers to as legal consciousness among the workers that was aligned with a sense of individualised legal rights of what were necessarily collective issues. It is this consciousness within the workers that had continued to trigger only passive, spontaneous and sporadic protests rather than collective and organised protests by these SOE workers even though they were often desperate and had very little to lose (Lee 1999b, p. 68).

While protests by SOE workers were characterised by passive forms of resistance, Ching Kwan Lee $(2000 \mathrm{~b})$ envisages that their collective memories of Maoist socialism provided desperate xiagang workers with a strong sense of class solidarity to sustain these. In her research in Liaoning, a declining SOE industrial district in a northeastern province in China, Lee finds that workers' discourses were sprinkled with references to their past experiences of the socialist system during the protest actions, for example, 'Workers are masters of the state', 'Yes to socialism, No to capitalism' and 'Long live the working class' (2000b, p. 220). Lee notes that the sense of class, which workers developed in their socialist past was evident in their discourse when defending what they understood as their class interests: 
'We want to work', 'Our children want to go to school' [...], 'Not a yuan (Chinese dollar) in six months, we want to eat' [...]; 'Down with the newly emerging nobility', 'Eradicate the new bureaucratic bourgeoisie' [...]; 'Save the factory, save the people' $[\ldots]$

(C.K. Lee 2000b, pp. 219-220)

Drawing on protest slogans such as those noted above, Lee argues that class consciousness was increased through their direct experiences as workers working under market conditions, and their sense of their 'right to subsistence' was strongly related to the Maoist past and was embedded in their lifetime SOE employment and guaranteed welfare and pension (or iron rice bowl) (C.K. Lee 2000b). Lee argues (2000c; 20002a) that their loss of permanent jobs as a result of the SOE restructuring since the mid-1980s (see Chapter One, pp. 42-44), coupled with the failure of local government to implement central policies of xiagang benefits triggered months and years of collective actions by SOE workers to safeguard the Maoist ideal of their basic livelihood (or subsistence) for themselves and others as a working class. Lee suggests that workers' collective memories of Maoist socialism increased their class consciousness that stimulated their class sentiment and contention which led to their resistance to their material predicament from the mid-1990s onwards (2000b).

Building on Lee's perspective, Chen's later work on SOE protest activities describes that State workers' collective memories of the socialist past became the basis for their class solidarity in Chinese factories (2006). Drawing on case studies of three SOE factories that were merged with private enterprises in Liaoning, Chen notes that the workers from these factories had staged protests against these mergers, that is what became known as the SOE privatisation schemes (2006). Chen argues that in these workers minds, privatisation of SOEs reflected "class-conflict" (2006, p. 44) between themselves and capitalists. This mindset according to Chen, was cultivated among SOE workers through decades of indoctrination of socialist and anti-capitalist ideologies (or Maoism) during Mao's period (2006, p. 44). Contrary to Thompson's perspective ((Thompson 1966) that a class is formed through workers' experience with capitalism, Chen argues that a class of SOE workers was developed prior to their contact with capitalism during the period of Mao's socialism (2006). These memories inspired the use of class discourse by workers when discussing their struggle against the privatisation of SOEs: 
We are no longer the master of the factory. We are now an oppressed class. There are now a lot of incidents of oppressing workers [...] Our struggle [against privatisation] is a manifestation of class struggle $e^{65}$. Oppression and polarisation inevitably lead to class struggle.

(Chen 2006, p. 49)

Chen (2006) notes that the slogans used by SOE workers in their anti-privatisation movement were mixed with an anti-bourgeois (see Chapter One, p. 20) tone that promoted the Maoist doctrine about the superior status of the Chinese working class. This had been made popular during the Cultural Revolution (see Chapter Three, pp. 69-71). For Chen, workers' reappropriation of the old ideological rhetoric in describing the impact of privatisation on their lives reflected their proclivity for class-conscious action was largely a consequence of a collective class consciousness developed among SOE workers since Mao period (2006). Chen subsequently argues that the comprehension of the SOE privatisation in class terms by workers drawing on past experiences of socialism indicates a possibility to forge strong collective class movements in response to proletarianisation (Chen 2006). The success that the workers in these three factories had in halting the process of privatisation adds support to Chen's claim that workers were capable of taking effective class action. However, Chen's case studies stand in contrast to the overall effect of the CCP's privatisation agenda for SOEs, which decimated the potential for SOE workers to coalesce into a class-for-itself. That is, while the cultivation of class ideologies in workers in the Maoist past had presented the possibility for class consciousness development among SOE workers, the post-Maoist State acted decisively to quell any potential for this to mature further.

At the same time as initiating the lay-off of tens of millions of SOE workers during the 1990s who the State claimed were surplus to the labour needs of SOEs (see Chapter Three, pp. 7374); the State simultaneously recruited large numbers of new workers to work within the SOEs (Lin 2015). As Chapter One shows, these workers were mostly peasant workers who faced

${ }^{65}$ My italics 
more precarious labour conditions than did the earlier generation (Lin 2015). For instance, peasant workers were forced to work an additional 20 hours compulsory unpaid or underpaid overtime work each week in additional to their basic 40 hours work week in SOEs (Lin 2015, p. 75). However, as Chapter Three (pp. 71-74) further shows their dependency upon the new industrial work in SOEs to not only support themselves but also their extended family in their villages, was effective in quelling the potential for their protest activity. However, by substituting the older generation of working class SOE workers with a new class of peasant workers, the post Maoist State was able to effectively replace an entire generation of workers who had shown evidence of class-based interests with those who had little or no history of class, and whose very existence was even more precarious because of their working conditions. Therefore, it is no surprise that protest actions by SOE workers decreased dramatically from over 80 per cent of all 'mass incidents' (see Chapter One, p. 19) to 20 per cent between 2000 and 2010 (Lin 2015, pp. 81-82). As Lin (2015) notes following the period of privatisation and reconstruction of SOE workforces in the 1990s and working conditions, by the early 2000s, there was nothing left to defend. That is, through these actions, the CCP had effectively quelled the potential for the 'old' group of SOE workers who had been prominent in the Tiananmen movement to continue the development of class consciousness and action among workers in the State sector.

\section{Dagong 打工 Experiences among Peasant Workers in FIEs}

Although the conditions of peasant workers in the State sector differed from those of earlier generation of SOE workers, Lin reveals that SOE peasant workers perceived themselves as having better conditions than those in the export-oriented foreign-invested enterprises (FIEs) who had to work approximately 30 hours of overtime a week $(2015$, p. 75). Contrary to the decline in SOE protest actions, Yanqi Tong and Shaohua Lei (2010, p. 490), for example, note that protests by peasant workers in FIEs constituted 45 percent of mass incidents in China between 2003 and 2009. Studies (Bao et al. 2002; Chan \& Li 1999; Fan 2003; 2004; Mallee 2000) since the 1990s have noted that rural peasants who were pushed by rural poverty and pulled by the growing urban economy, migrated to the urban cities to find work in the 1980s (see Chapter Three, pp. 73-74). While their city earnings were higher than their rural incomes, Lee (2002b) comments that their wages were as little as only one-sixth that of Mexico and one- 
fortieth that of the U.S. The contradiction of the rapid growth of economy and cheap labour cost attracted criticism about China's role in driving a 'race to the bottom' (Li 2006; Silver \& Zhang 2009; Pringle 2011). Anita Chan (2001) and Pun Ngai (2005), for example, found that peasant workers experienced extreme exploitative employment conditions, including low wages and long working hours, in FIEs. These conditions were exacerbated by the household registration (hukou 戶口) system (see Chapter Three, pp. 73-74), which intentionally put peasant workers in a vulnerable position in exchange for subsistence wages in urban cities (Chan 2001). Pun (2005) reveals that peasant workers' status of semi-citizenshipin cities constituted by the hukou system enabled the management to facilitate class domination by using work rules, such as restrictions on toilet-going, to control the workers in FIEs.

Given their brutal work-based experiences, Pun (2005) predicts that a high-level of class consciousness would be developed among this newly emerged peasant working class and it would 'rise against' these exploitative conditions. Pun grounds this claim in a study during the mid-1990s in a FIE in Shenzhen, which identifies that the daily exploitative practices experienced by peasant women workers led to minor collective resistance in the workplace (2005). These included pretending to be ill, 'going-slow', deliberately making mistakes at work and gossiping about their work leaders who discriminated over their rural background through their own spaces of everyday resistance (Pun 2005, pp. 92-155). Pun argues that their class awareness of their position and identity as dagongmei 打工妹 $(2005$, p. 7) working in the factories motivated their everyday tactics of resistance. Imported from the Cantonese language from Hong Kong, the terms dagong 打工(working for the boss), dagongmei 打工妹 (working women) and dagongzai 打工仔 (working men) connote an idea of commodification of labour, that is, exchanging labour for a living wage (Pun 2005, p. 12). Contrasting with the term gongren 工人 (SOE workers) that signified a privileged class status with permanent employment (or iron rice bowl) in the State sector in Mao's period, dagong status in post-Mao China departed from the socialist employer and its value was determined by market forces and the ability of labour to contribute to the surplus value of the enterprise, thus maximising profits for entrepreneurs (Pun 2005, p. 12). Pun in this context perceives that there was a "minor genre of collective resistance" by dagongmei that formed through increased class consciousness that was shaped by workers' realisation of exploitation and alienation in their workplace (2005). 
Pun comments that although the everyday tactics of dagongmei were indirect, their resistance behaviours exhibited a collective confrontation and disruption of the dominant power to defend their autonomy, dignity and rights for themselves and others (2005).

\section{Open Protests by Peasant Workers}

Lacking effective workers' organisations to voice their grievances as with SOE workers, peasant workers also began to bypass the trade unions to mobilise protest actions to demonstrate their discontent after the mid-1990s (F. Chen 2009; 2010; Howell 2008). It was claimed that the number of labour disputes had increased dramatically from 120,191 cases in 1999 to 693,465 cases in 2008 while the number of protests had increased from 10,000 in 1994 to 87,000 in 2005 (Leung \& Pun 2009, p. 553). Although Smith and even Pun (2006) among others recognise the weakness of the resistance pattern among peasant workers and their class consciousness was not as matured as compared with SOE workers, they nonetheless argue that because peasant workers had networks of kinship, peers and even their original home-place was relatively nearby physically to the factory, their collective existence in the factory dormitory provided a platform for workers to begin to identify their common interests as a class.

In their study in Shenzhen, South China, Smith and Pun (2006) conceptualise the dormitory labour regime as a peculiar form of labour process that embedded both management control and workers' resistance. Their study reveals that the factory dormitory compound consisted of managers' and workers' ${ }^{66}$ accommodation wherein discipline and punishment were imposed to regulate the dormitory behaviour of the workers, such as sleeping, eating and bathing, in their private time (Smith \& Pun 2006, p. 1464). While the workers conformed to dormitory rules under strict control, management's decision to relocate its production lines and the dismissal of the first 600 workers without compensation (Smith \& Pun 2006, pp. 1465-1466). This incited the last 1000 workers who were to be dismissed to organise actions in the dormitory prior to the second wave of redundancy began in 2002 (Smith \& Pun 2006, pp. 14651466). Smith and Pun argue their everyday life in the dormitory and factory work life nurtured

\footnotetext{
${ }^{66}$ Each dormitory room housed 8 to 12 production workers in Pun and Smith's study. See Smith, C \& Pun, N 2006, 'The Dormitory Labour Regime in China as a Site for Control and Resistance', The International Journal of Human Resource Management, vol. 17, no. 8, pp. 1456-1470.
} 
a solidarity between these workers, which motivated them to act collectively to demand for the laid-off compensation for themselves through demonstrations (2006). As a result, Smith and Pun conceptualise that the close proximity of dormitories develop higher levels of class awareness and provide the bases of organised opposition and solidarity to support strong collective actions (2006).

Despite the opportunity that close proximity of living areas offered as spaces for peasant workers to form networks for class solidarity and organise actions, others (Cai, 2002; Leung \& Pun, 2009) argue that class actions in China was also formed through the coordination of crossenterprise action developed outside workers' living and working environments. Cai (2002), for example, suggests that cross-action was generated from a working class shared perception of enterprise-specific grievances. Pak Nang Leung and Pun Ngai (2009) argue that by sharing their bitter experiences and lessons with each other, workers supported each other in crossenterprise collective action. In their case study (2009) of the struggles of silicosis-afflicted gemstone workers, Leung and Pun find that workers' resistance developed from engaging in legal action to launch single- and cross-factory actions with other victimised workers across the gemstone industry, challenging their employers and government bodies. Collective actions, including road blockages and demonstrations at government buildings, were launched to demand economic compensation for other workers following their illness. Leung and Pun view this as class opposition that illustrates that a class consciousness was developing among these workers under which they shared a collective identity, both as peasant workers and as occupational diseases victims, that further transformed them from being "atomised workers in a single factory into a collective social force" (2009, p. 564).

\section{Accumulated Dagong Experiences and the 'Forming' of a Class-for-itself}

Thus, although peasant workers were not traditionally constituted as a working class in Mao's period, scholars such as Pun (2005) suggest that their class consciousness was emerged from their realisation of class identity and value through their work-based experiences in the cities: 
We are not treated as human beings. [...] We work like dogs and never stop. When the superior asks you to work, you have to work no matter when and where [...] Dagongzai is worth nothing. Dagongzai is only disposable stuff.

(Pun 2005, pp.23-24)

Pun (2005), for example, draws on the accumulated dagong experiences and feelings of the peasant workers to argue that self-understanding of specific class position and class relations as dagong was generated through their everyday dagong lives over decades, rather than being organised into a specific class (as was the case with the SOE workers) (C.K. Lee 2000b).

Recent studies by Pun and Hulin Lu (2010) and Kam Wing Chan (2010), and among others stress that the accumulated painful dagong experience of the first generation (born between the late 1960s and early 1970s) evolved into the anger and action of the second generation (born after the late 1970s and 1980s) peasant workers. Shared feelings and experiences between two generations was articulated as a particular element shaping consciousness of the younger generation; leading led them to change their perception and life expectation in the cities (K.W. Chan 2010; Pun \& Lu 2010). Kam Wing Chan (2010) notes that the younger workers were better educated and more rights-conscious, and therefore they were less tolerant of abuse and injustice than their elders. Pun and $\mathrm{Lu}$ (2010) explain that because the young workers move to dagong was not driven by economic needs, but by their 'dreams' of pursuing personal development and freedom in the urban consumer culture, they refused to tolerate their plight in silence. In their detailed study of the life struggles of one dagongzai in Shenzhen, Pun and Lu explain that the new generation of peasant workers realised that their semi-citizenship status had prevented them from pursuing material rewards and dreams in the cities (2010). For instance, the internalised anger and pain created by the unfulfilled expectations and the relentless frustration of the second generation in dagong life had driven five peasant workers to embark on a series of collective actions over the illegal operation of the factory (Pun \& Lu 2010). Pun and Lu argue that the dagong experience of anger, pain, and suffering that characterises the lives of the second generation of peasant workers was significant in nurturing a working class (2010). 
Similarly, numerous studies of the dagong life of student interns (or student workers), (Chan 2013; Chan, Pun \& Selden 2013; Pun \& Chan 2012; Pun, Chan \& Selden Forthcoming; Pun et al. 2016; Smith \& Chan 2015) indicate that anger and resentment further motivated the actions of the second generation of peasant workers to defend their dignity and rights (Wong 2011). These studies reveal that many peasant-student interns 'dispatched' by their vocational schools suffered from heightened feelings of desperation in one of China's biggest manufacturing FIEs - Hon Hai Precision Industry Company (commonly known as Foxconn) (Pun \& Chan 2012). In one analysis (Smith \& Chan 2015) student-internship is described as a form of forced labour that assigns students to jobs that are irrelevant to their educational qualifications or vocational training. Another study (Pun \& Chan 2012) reports that student workers maintained a student identity that disqualified them from labour protection because internship was not considered employment in China. Moreover, student workers were subjected to "super-exploitation" and tight control and discipline, both by their school teachers and work supervisors, who dominated their lives within a highly centralised and hierarchical production system (Pun \& Chan 2012, p. 392; Smith \& Chan 2015). Scholars comment that Foxconn's repressive and inhumane mode of management had pushed the student workers to their "physical and psychological limits", leading to daily resistance, such as slow-downs, stealing, and stoppages (Pun \& Chan 2012, p. 388). Some vented their frustration by smashing security offices and production facilities (Chan, Pun \& Selden 2013) and others threw fireballs at the dormitory (Smith \& Chan 2015). Moreover, multiple workers committed suicide (Chan 2013; Pun, Chan \& Selden Forthcoming). These suicide waves are described by scholars as an extreme expression of anger, anxiety, alienation and frustration due to the shattering of the hopes and dreams of the new generation of peasant workers by their desperate dagong experience in the cities.

Besides the extreme manifestation of suicide, Chris Chan and Elaine Hui (2012; 2016), and Kelvin Gray and Youngseok Jang (2015) find that workers' anger and frustration about their daily dagong experience contributed significantly to the growing level of class consciousness for large-scale, organised, interest-based action among the new generation of peasant workers. Thus, while protest actions by peasant workers were almost absent during the early 1990s (Lee 2002b), Chan and Hui's detailed study of the 2010 student workers' action at Honda's transmission and engine parts factory in Foshan, Guangdong Province, reveal their intolerance of unfair income distribution between foreign staff and student interns triggered 1,800 workers 
to engage in a 17 -day protest $(2012$, p. 656; 2016). Unlike the less-educated workers of other low-skilled exporting factories, Chan and Hui (2012; 2016) assert that the effective mobilisation of the Honda protest was grounded in the peer-network of the relatively welleducated workers formed previously at their vocational schools. Their organising was fostered through their familiarity with electronic communication technologies, such as mobile text messaging and the internet. Better organisation of this 'internet activism' was further fostered by a high level of interference and direct support from national and international intellectuals, as well as Hong Kong trade unions and NGOs (Xu 2013). The result (C. Chan 2010b; Chan \& Hui 2012; Chan \& Hui 2016; Gray \& Jang 2015) of the coordination between the NGOs and Honda workers was to force the company to close four assembly plants, which immediately crippled Honda's auto production in China. Honda's workers seized the opportunity to demand an 80 percent (or 800 yuan) 'big pay-rise' (Gray \& Jang 2015, p. 602), as well as a reform of the trade union and the establishment of collective consultation at the enterprise (Chan \& Hui 2012 ; 2016) to safeguard their workers' rights and interests as a working class. From this standpoint, it was argued that this collective and sustained nature of their actions was indicative of these workers gaining class consciousness to form themselves into a class-for-itself as a result of their accumulated dagong experiences and feelings over the decades of dagong lives in China (Chan \& Pun 2009; C. Chan 2010b; Chan \& Hui 2012; 2016; Leung \& Pun 2009; Pringle 2011; Pun, Chan \& Chan 2009; Pun \& Lu 2010; 2010b; Pun et al. 2016; Smith \& Pun 2006).

\section{Problems with Class Analysis in China}

Despite the view by some (Chan \& Hui 2012; 2016; Leung \& Pun 2009) that an increased volume of labour actions in China represents a new stage of class consciousness among workers, there are other scholars who argue that there is a problem in using a class analysis in China. For example, Ching Kwan Lee (1999b, pp. 45-68) argues that the resistance pattern of peasant workers was seemingly 'less progressive' and 'flexibly' adjusted to capitalism. Lee notes that "disorganised despotism" (or diverse market despotism) produced "labour subordination" and "collective inaction" through dismissal and recruitment of peasant workers from a fragmented, disposable labour market (1999b, pp. 45-68). Lee argues that protests by peasant workers occurred only when the arbitration procedure failed to protect their legal rights 
while their solidarity peaked only at the point of "collective exit from the factory, occasioned by plant closure or relocation" (2007a, p. 175). Because of this, peasant workers often diffused into different locations to work without necessarily contacting one another after the particular protests (Lee 2007a). Thus, peasant workers were unable to develop much "workplace or associational bargaining power" to then form themselves into a class-for-itself (2007b, p. 24). To substantiate this argument, Lee uses three insurgent identities of 'proletariat', 'citizen' and 'subaltern' to analyse the protests by laid-off SOE workers and peasant workers:

I have found that class identity is more muted and ambivalent among migrant workers than among rustbelt [northern SOE] workers, whereas claims made on the basis of equality before the law and of citizens' right to legal justice are impassioned and firm, as in the Sunbelt [South China]. Workers also identify themselves as the marginalised and the subordinate in society.

(Lee 2007b, p. 195)

Lee (2007b) privileges the full citizenship status of SOE workers over the semi-citizenship status of peasant workers to imply that laid-off workers had fostered a higher level of class consciousness compared to peasant workers. This idea is indicated in Lee's concept of the 'protest of desperation' by laid-off workers in relation to their unpaid pensions and xiagang payments as a specific protest behaviour, which was aligned with their sense of cultural and societal grievances related to their collective consumption and the commodification of their daily lives in post-Mao China (Lee 2007b). Lee emphasises the grievance and resistance patterns of SOE workers as characterised by the 'collective memories' of the 'socialist spirit' and contends that the consciousness of laid-off workers was generated by their shared feeling of being 'betrayed by the Chinese capitalist-State, which drove them to undertake action and cause a "disruption of social order" in the market economy (2007a, p. 71). This was in contrast to the peasant workers who lacked the past 'socialist spirit' as a Chinese working class and had to depend upon the firms' provision of survival needs in the competitive and fragmented labour market (Lee 2002b). It was in this context Lee maintains that the 'compromised' collective interests of peasant workers in sustaining their essential livelihood needs had constrained their capacity to act collectively in the fragmented market (2000a). 
Further, in specific reference to the Honda dispute, Anita Chan and Kaxton Siu (2012), note that protest action by Honda workers, as with those by their colleagues at other SOEs and export factories, still concentrated on serious and immediate economic grievances on an individual level, without achieving new coordination at a higher, cross-sectoral, cross-regional or national level to consolidate and achieve further victories:

[...] there have [been no] large-scale, coordinated and organised labour protests [...] nor have groups of workers from different factories made any collective demands on the local or central Chinese governments, nor have workers attempted to set up any independent trade unions at the workplace or multi-workplace level [... They] are cautious not to overstep the scope of their activities beyond economic rights-based demands.

(Chan \& Siu 2012, pp. 84-99)

In addition, while actions by Honda's workers, as well as other peasant and SOE workers, were viewed by many (C. Chan 2010b; Chan \& Hui 2012; Chan \& Hui 2016; Gray \& Jang 2015) as a class-based action, Chan and Siu (2012) and Steve Hess (2013) comment that the gains won by workers remained minimal. Honda's protest action, for example, was abandoned by groups of workers when they learned that they could receive individual wage increases as soon as they returned to work (Hess 2013). Workers' disunity consequently destabilised the strike action, although a wage increase of 24 to 32 percent was granted to the workers, which was far less than what they had initially demanded (Hess 2013, p. 97). This latter body of literature highlights that, despite the coordinated efforts among some workers, the acceptance of the smaller wage increased by other strike participants was grounded in their total lack of knowledge about trade unionism (Chan \& Siu 2012, p. 91) and their unwillingness to step forward to speak out for themselves and other participants (Hess 2013, p. 97) to sustain their protest actions further illustrated that workers' consciousness was fundamentally remained at individual level while occasionally sparked a level of "embryonic trade union consciousness" (Chan \& Siu 2012, p. 97): 
Once satisfied that their economic demands had been met, they did not press for the immediate election of a new trade union committee. Thus, when the provincial trade union took several months to organize the first round of elections for 30 trade union representatives, workers' enthusiasm and sense of solidarity dissipated, along with their willingness to struggle for genuine representation.

(Chan \& Siu 2012, p. 91)

In her comparative study of labour protests in East Asian countries (2011), Anita Chan evaluated the differences between workers' grievances and demands that triggered protest actions in Vietnam and China. Chan (2011) notes that while protest actions in both countries were spontaneous, unorganised, and had no orderly workers' representation to negotiate with management, the Vietnamese workers went on strike for better employment conditions, such as reducing work hours with better pay, while the Chinese workers did so to maintain their previous employment conditions, such as restoring their reduced overtime and previous wage level. According to Chan, protest actions by Chinese workers were generally restrained by their confused understanding of the integral relationship between wages and work hours and their lack of understanding of the kind of demands that needed to be made to improve their wages and overall employment conditions (2011, p. 35).

It is argued that various outbreaks of protest action in China were generally characterised by limited coordination and commitments between workers. Thus, their acts were rather isolated and were rooted in their aim of achieving specific personal gains in the collective actions. These led to the frequent waves of protest actions in China producing varying outcomes for the workers involved; some returned to work with better gains, others with partial gains, and others failed to redress their economic grievances at all (Hess 2013, p. 99). Chan and Siu (2012, p. 89) note that, contrary to those in Western capitalist societies, workers in China lacked the accumulated historical experience and tradition necessary to voice their collective interests or to press for changes or laws, such as legal minimum wages and maximum overtime, through class struggle. Collective actions occurred only when employers breached the legal standards set for them (Chan \& Siu 2012, p. 89) and threatened their 'right to subsistence' (Chen 2000, p. 44) within specific occupational sectors (Hess 2013, p. 83). Hence, while labour actions had spread to various workplaces, there was little evidence that their acts had evolved into sustained 
organised action or any attempts to improve their bargaining position by forming organisational linkages with other workers on a regional or national level (Hess 2013, pp. 88-99). This situation was maintained by the absence of reading materials on trade unions and labour movements, leading Chinese workers to have "little to inspire them to understand their own class position”, in the CCP's one-party authoritarian state (Chan \& Siu 2012, p. 99).

This alternative view of worker protests in China subsequently argues that their lack of understanding about their class position and class relations constrained their ability to sustain collective actions that could effectively improve the employment conditions for themselves and other workers. For example, Ivan Franceschini, Siu and Chan (2016, p. 440) note that the wages that workers' demands "are lower than the amount they are legally entitled to and for which they work more hours than the legal limits" in their protest activities. Yanhua Deng and Jonathan Benney (2017, pp. 92-99) describe this as 'misframing' demands where workers conformed to the 'rightful resistance' ${ }^{67}$ in order to align with the existing political structure in their protest actions. Deng and Benney note that these phenomena were contributed to by China's hierarchical political structure which consisted of different levels of government with contradictory policies in the social system (2017). For example, the central government valued the maintenance of social stability and harmony (hexie 和諧) (see Chapter Three, p. 80) wherein local governments were pressured to prevent "[...] all visible forms of protest (the so-called "zero target" model) [...]" (Benney \& Marolt 2015, p. 94) while focusing on the importance of regional economic development in different localities. Thus, local governments exercised threats of severe penalties, ranging from fines to criminal prosecution, to minimise protest actions (Benney 2016). Deng and Benney note that the current political situation had led to the issue of 'misframing' whereby 'protesters 'ask' for something that is not actually what they 'want'" in hope of achieving partial gains in protest activities (2017, p. 92). This suggests that workers were cautious to locate their protest demands within what they knew of hefa quanyi 合法權益 (legal rights) framework that was predefined for them. This indicates that their consciousness did not reach a critical level.

\footnotetext{
${ }^{67}$ The concept of 'rightful resistance' is original developed by Kelvin O'Brien to describe legal rights defense by Chinese protesters. See O'Brien, K 1996, 'Rightful Resistance', World Politics, vol. 49, pp. 31-55.
} 
Workers' 'misframing' demands thus further illustrates their hesitation to express their real grievances or concerns in protest actions. Fang Lee Cooke, Yuhua Xie and Huimin Duan (2016), for example, perceive that workers' negative emotions, including the fear of adverse consequences, was a major factor discouraging them from voicing their concerns or grievances. Their study across four manufacturing factories in Hunan, one of the less developed cities in inner province, identify that workers' experiences of remuneration, management style and work practices were the main sources of workplace grievances (2016, pp. 2124-2125). Cooke et al, nonetheless, find that workers' action of redressing their grievances was, far from speaking up for themselves and others, to maintain silence (2016). They note that workers' unwillingness to voice their grievances was fundamentally grounded in the imbalance of power distance between themselves and the management (2016). For example, grievance resolution methods adopted by factory managers were either aimed at diffusing tensions by re-educating the workers to seek their "compliance through coercion and enforcement" of financial penalties or by dismissing the disobedient workers who would not comply with management requests (Cooke, Xie \& Duan 2016, p. 2134). Cooke et al comment that these grievance resolution approaches underpinned not only the "generally poor leadership competence of Chinese managers", but also the Chinese traditional cultural values that influenced the ways workers were being managed. They argue that the traditional hierarchical social relationships in Chinese society were also significant in motivating workers to remain silent over their work-related grievances (2016, p. 2137).

Thus, there is a canon of alternative literature about worker protests in China that implies that there are non-work mechanisms and experiences shaping workers' consciousness to the extent that can militate against their willingness to take effective action that will improve their overall employment conditions in China. This literature presents an alternative view from those framing labour protests as necessarily emerging from workers' rising consciousness that is generated by their exploitative conditions as a working class. Lee (2007a, p. xii), for example, notes that the problem with the existing studies which emphasise work-based experiences as the source for resistance is the "tendency to make a leap of faith from the existence of exploitation to resistance". Elizabeth Perry (Perry 1996, p. 3) in this context comments that workers' collective actions in China and East Asian countries were "not fully explained by the familiar models of class consciousness inherited from the analysis of [Western...] capitalism". 
In contrast to their Western counterparts, who turned their localised protests into social movements, Perry notes that Chinese protests were generally limited in size, scale and scope, and that the "social composition, territorial reach, and endurance of individual protests have all been highly circumscribed" (2008, p. 206).

Other scholars offer further explanations. Dorothy Solinger (2002, p. 323) reveals that Chinese workers were generally dissuaded from participating in protest activities by their prevailing need to meet day-to-day survival needs and that they preferred to expend their energies by seeking employment elsewhere. From a Gramscian perspective (see Chapter One, pp. 21-22), Marc Blecher (2002, p. 288) argues that workers' absorption of the hegemonic values of the free market had directed them to believe their employment conditions were both acceptable and inevitable, deterring them from engaging in collective action. William Hurst (2008, pp. 7475) notes that the uneven opportunities in China's different regional political economies had been an outcome of inhibiting workers across regions from coordinating their protest actions. Peter Ho (2007, pp. 193-194) and Eli Friedman and Lee (2010, p. 523) have found that the CCP's careful alteration of its toleration and restriction of the labour NGOs' activities had also guided workers to engage in non-confrontational acts towards the State in their protest activities. John Hassard et al (2007) from this context conclude that it is the socio-cultural and institutional elements that had constrained class consciousness development among workers, leading them to confront their employers as individuals in the disorganised protest activities.

Thus, while commentators such as Pun and Lu (2010; 2010b), and Chan and Hui (2012; 2016) note the high number, intensity, and violence of worker protests, Perry maintains that workers' protest behaviour in China, as with those in other East Asian countries, underlines the importance of 'place' over 'class' (1993, p. 30). Although the definition of 'place' is wide ranging, Perry regards the cultural traditions within the 'native place' (or original place') as a major element inhibiting class and consciousness development in East Asia and in China. This view in particular refers to the role of state agents who have exercised a subtle power to influence the shaping of workers' behaviour by diluting their consciousness. As a result, Perry concludes that workers' actions in East Asia and China have exhibited non-class behaviour in attempting to better their status rather than their interests as a class in their cultural 'places' (1993, p. 3). 
Perry (2009, p. 20) continues that the consciousness of both protesters and non-protesters was strongly influenced by their cultural norms, characterised by “"orthopraxy' (or proper behaviour) over 'orthodoxy' (or proper belief)" (see Chapters One, pp. 29-30 and Three, pp. 61-62). This suggests that the acts and behaviours of Chinese workers were influenced by their sense of the rightness of moral action, which was predominantly informed by their cultural history. Further to this assertion, Perry explicates that Chinese workers' protests reflect an 'older rules consciousness' that was influencing their behaviour since the Imperial period (see Chapter Three). Thus, protesters tended to frame their grievances in officially approved language, such as using the terms 'rights to subsistence' (shengcun quan) (Chen 2000) and protecting legal rights (hefa weiquan) (Benney 2013; Chan \& Siu 2012), that is not beyond an individual economic needs in the Chinese state (2009). Similarly, Erika Evasdottir (2004, p. 16) suggests that the participation of Chinese workers in orthopraxy meant they behaved and acted the same, because they 'shared the same standards and interpreted each other's actions in the same way' under the doctrine of similarity. This similarity, as will illustrate in Chapters Six and Seven, is constituted by the updated Confucian values that underpin the social truths (discourses) about the proper behaviour and workers' destiny (ming) under the quality-based (suzhi) occupational hierarchy within China's thought management. It is these social truths that internalised by Chinese workers themselves that they have further constituted an embryonic and status-based consciousness for themselves to restrain their (and others) choices of actions in upholding the orthopraxy system throughout their social relationships.

\section{Concluding Remarks}

This chapter reviewed a growing body of literature discussing labour protests that claims a "rising class consciousness" among Chinese workers as a result have significantly advanced our understanding of the brutal work-based experiences of the Chinese working class over the past decades in post-Mao China. However, it is apparent that a great deal of this work is based on case studies of worker protests and activists' opinions. The alternative views that other scholars present in the literature is one that seeks to understand worker protests in the wider context of Chinese society. Their evaluation of protest behaviours has instead illustrated a 
degree of 'docility' among workers that they tended to subordinate their own interests to the workplace authorities and hence the Chinese State. This in turn suggested that the State had exercised a powerful influence on workers' consciousness that has further constrained their ability to develop into a class-for-itself as what the Marxist exponents have expected. When considering the latter body of literature, this thesis argues that current accounts have remained limited in their analysis for two reasons. The first is due to a reliance on a Marxist inspired framework of analysis and the second is that most studies ground their analysis in a sample of workers who have been engaged in protest activity, rather than used random sampling of workers that draws in those with an experience of protest activity as well as those without. The gap that this thesis thus seeks to respond to is to develop an understanding of how everyday workers or rather workers across the spectrum of work sites in China perceive protest action, and how their non-work life contributes to their willingness to form a class-for-itself in undertaking protest action. That is, how do workers in factories and outside of factories perceive protest action, and relatedly, aspects of class formation? And, how do these perceptions indicate the possibilities for Chinese workers to form a class-for-itself? These questions lead to tentatively proposing that contrary to a view promoted by some scholars, worker consciousness in China is affected by more than their experience of work. To explore how the work and non-work experiences had influenced the consciousness development of the Chinese workers, two phases of empirical work was undertaken with everyday Chinese workers between 2011 and 2014. Chapter Five discusses the methodology used to collect data in different locations in China while the findings will be reported in Chapters Six and Seven which show that workers' consciousness remained guided by an 'older rules consciousness' that affects their willingness to engage in acts that are perceived as contradictory to authority figures in China. 


\section{Chapter Five: Ethnonarratives of Workers in China}

If we accept that power and knowledge are inseparable $[\ldots]$ and if we accept we are simultaneously undergoing the effects of power and exercising power over others, then we will be unable to take a benign view of own practices. Nor will we be able to simply assume that our practices are primarily determined by our motives, or that we can avoid all participation in the field of power/knowledge through an examination of such personal motives.

(White \& Epston 1990, p. 29)

The aim of this chapter is to provide a description of the research instruments that were used to understand the power-knowledge embedded in the discourses and practices of the Chinese workers through the method of ethnographic-narrative (or ethnonarrative) (Hansen 2006) analysis to understand labourist activist culture in China. This research was conducted in multiple locations (see Figure 6) in China from 2011 to 2014.

The chapter begins with a justification of using ethnography and how it connects (or overlaps) with Foucault's ways of charting the sociocultural and historical milieus within which people live, think and act in given societies. This includes a detailed discussion of the processes of setting up and sustaining ethnographic research to conduct participant-observation and collect personal stories in China. The problems related to conducting field research associated with this study in China are also identified, before detailing the documentation and validity of the data, narrative and discourse analysis, and the ethical concerns. The chapter concludes with arguing that the ethnonarrative research tools and Foucault's approach enabled a distinct conceptualisation of text/context and the ways of working with data to understand hidden meanings and social practices attached to everyday workers. 
Figure 6: Multiple Field Locations in China

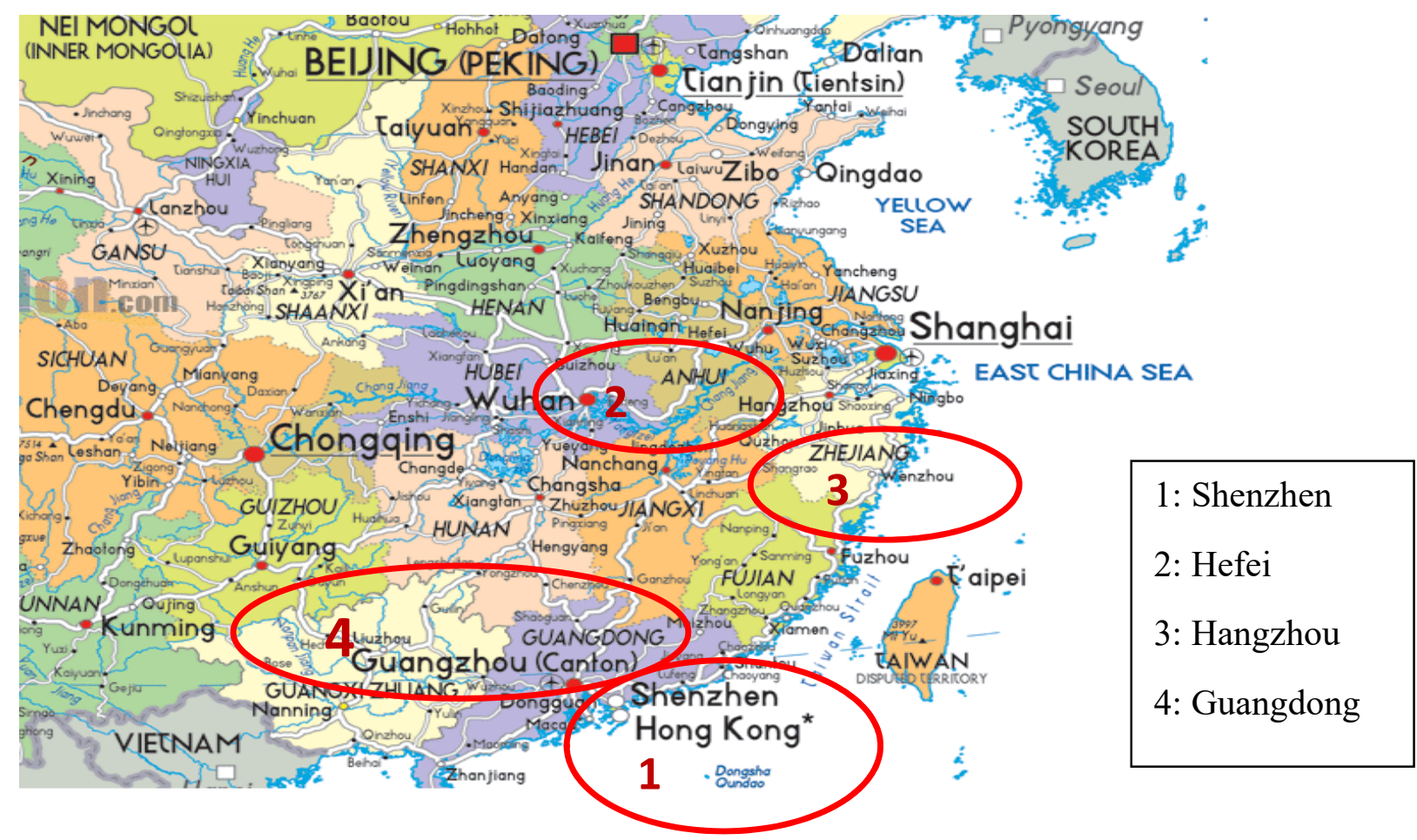

\section{Foucault and Ethnographic Practice}

In order to understand how living and working in post-Mao China has shaped the consciousness of everyday Chinese workers, and how this consciousness affects their activism, as well as their ability to form into a class-for-itself to improve their living and working conditions for themselves and others (see Chapter One, p. 20), this study draws on Foucault's ideas but primarily utilised an ethnographic approach ${ }^{68}$ in collecting the stories of workers for the study. The choice of adopting ethnographic methods for this study to explore the research focus rather than using close-ended ${ }^{69}$ quantitative methods such as ticking boxes on survey and questionnaire because these techniques tended to impose solely the researchers' ideas on a large group of research participants and also restrict the possible range of answers within questions (O'Reilly 2012). The restriction of the possible range of participants' responses and reflections on issues thus neglect each individual as a unique and complex case as well as an active agent of the self (Elliott 2005). Hence, in order to understand the worldview of Chinese

\footnotetext{
${ }^{68}$ Ethnographic method is a qualitative research approach and is the hallmark of cultural research to discover "another way of life from the native point of view". See Spradley, J 1980, Participant Observation, Harcourt Brace College Publishers, London.

${ }^{69}$ Example of close-ended question: 'Did you go to bed before nine or after'?
} 
workers, this study is primarily framed by ethnographic approach that has been extensively used by prominent Chinese labour scholars such as Anita Chan (2001), Ching Kwan Lee (2007a), Chris Chan (2012a) and Pun Ngai (2005) to explore the relations between work-based experiences and worker activism within particular occupations in China. However, unlike these scholars who focused on understanding worker protests and the viewpoints of activists in specific industrial sectors, the study has collected personal stories of everyday workers who had and had not engaged in protest activities across different industries and locations to examine how their lived experiences have influenced their willingness to improve their working and hence living conditions. The purposive inclusion of a wider group of workers in different age and gender groups with different work and non-work experiences across industries, including those working in the hotels, motels and factories (see Appendix 3), in China helped to yield insights and pertinent perspectives about the daily lives among workers in a wider social context. This in turn helped to untangle the research focus of how living and working experiences in post-Mao China has shaped their consciousness, and how this consciousness affects their activism, as well as their ability to form into a class-for-itself to improve their living and working conditions for themselves and others. This is because their experiences are shaped by their power-knowledge relations within the discourses of 'truths' that are embedded in the everyday realm of social and cultural life (Foucault 1980a; 1980b) in China. The ethnographic method was thus useful in exploring the micro-relations of power (Foucault 1977, p. 26) and knowledge of everyday workers.

By grasping the insider's point of view in a particular culture, the ethnographer seeks to understand the daily lives of people and to grasp their visions of their worlds (Dewalt \& Dewalt 2002). Thus, ethnographic fieldwork involves a study of "what the world is like to people who have learned to see" in their cultural contexts (Spradley 1980, p. 3). Ethnography is, therefore, a process of learning about people of other cultures. Its focus is on three aspects of human experience: "what people do, what people know and the things people make and use" (Creswell 2003, p. 10). In dealing with these aspects of human experience, ethnography is concerned with the discovery of hidden meanings (or regimes of truth) by which people are constituted through their exercise of power in their given societies. In other words, a large body of hidden, shared meanings that people use to engage in their everyday behaviours are embodied in their cultural knowledge (Spradley 1980). 
Shifting from observing behaviour to inquiring about the meanings of that behaviour, the ethnographer seeks to discover what meanings people have assigned to their thoughts (Jorgensen 1989). Individuals' behaviour is thus guided by thoughts that are predominately tied to the discourses of truths (or knowledge) within a given society (Foucault 1980a; Chapter Three, p. 93). In unearthing the discourses of truths, ethnography is a means by which the ethnographer can discern the explicit and tacit aspects of culture (Dewalt \& Dewalt 2002). The explicit dimensions of culture refer to what people know, their level of cultural knowledge and their ability to explain themselves (Dewalt \& Dewalt 2002). In contrast, a large part of cultural knowledge remains outside of our awareness (Dewalt \& Dewalt 2002). It is these two dimensions of cultural knowledge and meanings that regulate individuals' behaviours within their everyday relations of power-knowledge in their living places.

\section{'Multi-Sited' Ethnographies}

While inhabiting places frequented by everyday workers facilitated opportunities to gain insights into the lived experience of workers, their personal stories and opinions yielded little understanding of worker resistance and activism in Shenzhen during the first phase of data collection (2011-2012). The first phase of data collection was conducted in multiple locations. The first phase was conducted in Shenzhen City in Guangdong Province as well as in Hefei City in Anhui Province and Hangzhou City in Zhejiang Province (see Figure 7):

Figure 7: First Phase of Data Collection in China

First Phase: 2011 - 2012

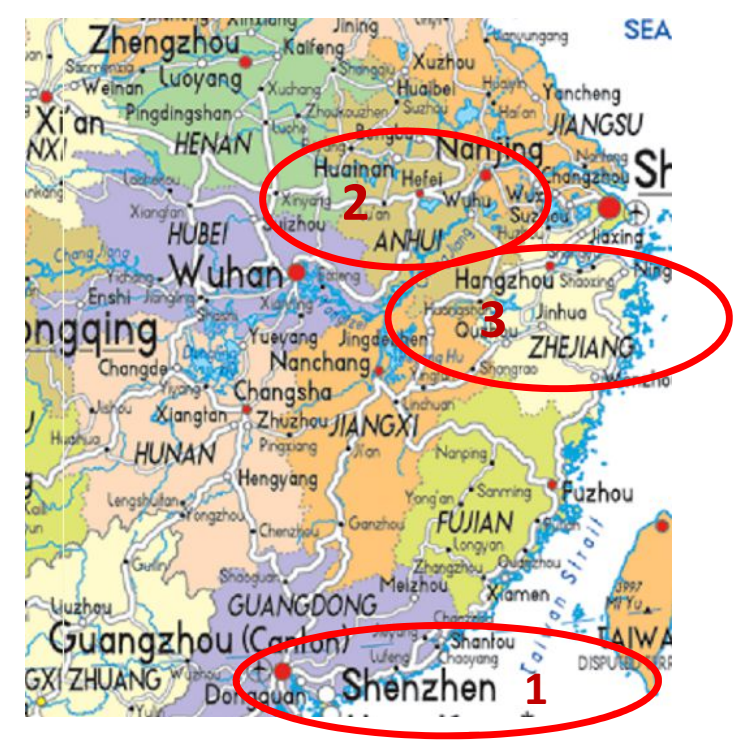


Shenzhen was chosen because of the prevalence of special economic zones (SEZs) which attract significant foreign investment (Harvey 2005). A 'flood' of peasant workers, nationwide have subsequently migrated here and provided cheap labour for the export factories (Harvey 2005). Resistance by these factory workers is a documented phenomenon in Shenzhen (Chan \& Pun 2009). Unlike Shenzhen, Hefei is an underdeveloped region with a large number of State-owned enterprises (SOEs) and largely local workers (National Bureau of Statistic's Database 2011). However, Hangzhou is one of the most developed regions with the largest number of domestic (or private) enterprises in China (National Bureau of Statistic's Database 2011) that have attracted a mixture of local and migrant peasant workers.

Given that the focus of this study was to understand how their living and working in post-Mao China has shaped their consciousness, and how this consciousness affects their activism, as well as their ability to develop into an organised labour movement to improve their living and working conditions for themselves and others, I decided to facilitate 'multi-sited' ethnographies (Croll 1987) to extend the research efforts from Shenzhen to other locations across the nation. By moving towards 'multi-sited' ethnographies, a researcher seeks to shift the focus of attention to other domains of cultural production of meanings to make comparisons between findings from different sites, and ultimately to challenge the assumptions and expectations that are privileged positioning in the 'true' (or universal) knowledge. Without attenuating the kinds of 'true' knowledge as the research evolves, 'multi-sited' ethnographies facilitate opportunities for the researcher to discover new paths of connection or association within the composition of relationships between fragmented and dispersed materials in different sites (Marcus 1995). This perspective thus recognises 'multi-sited' research as a product of knowledge bases of varying intensities and qualities through exploration along unexpected and even discordant fractures of social locations and spaces (Marcus 1995).

My selection of spaces and locations for investigation were inseparable from the logic of connection or association between the sites, which were defined by the research question (see Chapter One, p. 20) and propositions (see Chapter One, p. 29). While the three selected sites covered a spectrum of industry type, size and worker occupation, enabling exploration of the research focus with everyday workers, the findings suggested that workers in these sites were relatively quiescent and appeared to have consented themselves 'voluntarily' to their 
exploitative conditions at different sites. Given that the focus of this study was to understand how their consciousness affects their activism, as well as their ability to develop into organised labour movement to improve their living and working conditions for themselves and others, it was decided to interview two groups of everyday workers. Thus, the second phase of data collection was conducted in in Panyu, Foshan, and Haizhu districts in Guangdong Province between 2013 and 2014 (see Figure 8):

Figure 8: Second Phase of Data Collection in China

Second Phase: 2013 - 2014

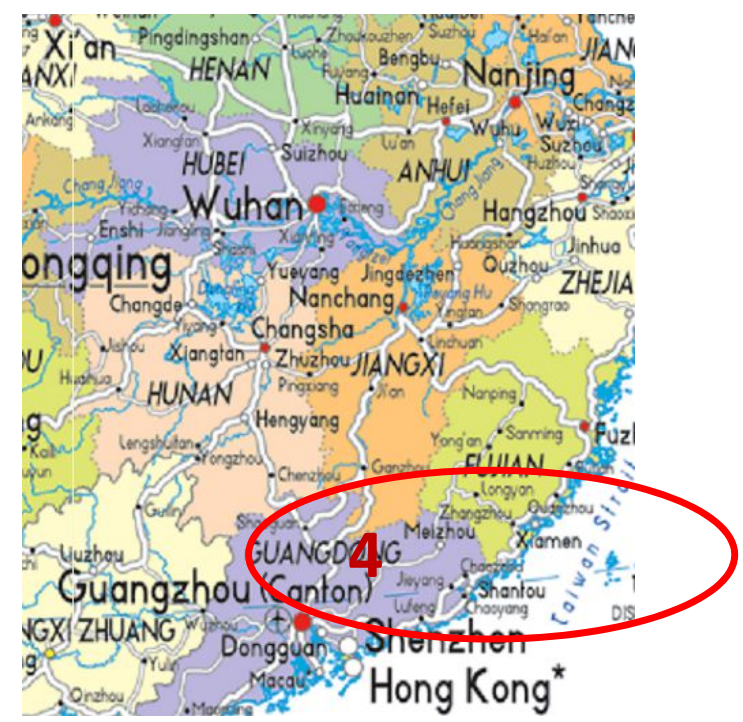

The second phase of data collection was conducted by deliberately contacting everyday workers who had engaged in protest activities, mainly through the non-government labour organisations (NGOs), such as the Asia Monitor Resource Centre (AMRC) ${ }^{70}$ and Labour Action China $(\mathrm{LAC})^{71}$, because these organisations were willing to assist me in contacting those who had engaged in protest activities.

\footnotetext{
${ }^{70}$ I came to know the director of the Asia Monitor Resource Centre (AMRC) through my supervisor prior to the commencement of the first phase of data collection in 2011. The discussions about my research topic with the director of the AMRC had led to the information about his contact of the Labour Law academic, who was in charge of two Labour NGOs, in Hefei, Anhui Province.

${ }^{71}$ Prior to my second phase of data collection in 2013, I participated in a number of events, including the seminars on the protection of labour rights for Chinese workers and also the campaigns for the protection of labour rights for Chinese workers, with the NGO workers of the AMRC and the Labour Action China (LAC) in Hong Kong. Throughout these activities, I established a working relationship with the NGO workers of the LAC through our numerous discussions about my research as well as their work. Because of our shared interests, the NGO workers
} 


\section{Participant Observation}

To understand the hidden knowledge (or truth) that shaped the consciousness of everyday workers in China, I adopted long-term participation observation as the primary method of data collection. Participant observation is rooted in ethnographic research, the aim of which is to connect the researcher to almost every aspect of living cultures (Vidich 1955). In so doing, the methodology of participant observation requires that the researcher becomes involved in the everyday events and interactions of the subjects, observing the rituals and activities of people at the research sites (Dewalt \& Dewalt 2002). This process enables the researcher to explore "what goes on, who or what is involved, when and where things happen, how they occur and why", by not only hearing people describing their reality in their own words, but also by interacting, observing, and experiencing the meanings of those people in another culture (Jorgensen 1989, p. 12).

In trying to understand the point of view of individuals of particular society, the researcher thus seeks to capture understandings of the subjective and interior aspects of human existence through intense research experience and participation in that particular cultural context (Hansen 2006). This view of participant observation conceptualises the researcher as being situated in a continuum; at one end there is the 'insider' and at the other an 'outsider' (Jorgensen 1989). This allows the researcher to identify and establish contacts with the people being studied. It also permits the researcher to maintain some sense of distance from the research participants throughout the processes of observation and data collection in the community of a particular culture (Brewer 2000).

By sharing in everyday community life by living with Chinese workers in the same community areas, I had the opportunity to experience, spend time with and participate in social activities while "consciously observing and recording what was observed" in the field (Dewalt \& Dewalt 2002, p. 261). Participant observation allowed me to observe cultural behaviour and study the discourses of the community as both an 'insider' and 'outsider'. This method thus exposed me

of the LAC had voluntarily introduced me to their colleagues in China to help organising interviews with those who had engaged in protest activities. During this research period, I lived with the NGO workers in different locations and I also helped to provide training and education on occupational health and safety as well as the compensation legislation for the workers who were injured or contracted with diseases such as asbestosis and silicosis as a result of their work activities across a number of hospitals in China. 
to other dimensions of personal experiences, such as fears and social meanings, and to reflect on what I had observed (Brewer 2000; Spradley 1980).

\section{Enculturation}

Enculturation becomes an inescapable aspect of the everyday life of a participant observer in a new cultural context (Dewalt \& Dewalt 2002; Spradley 1980). Moving from one culture to another is a complex process. 'Enculturation' is a learning process whereby a participant observer must employ different rules in a new cultural setting (Avery 1960). This suggests that living inside another culture requires the participant observer to learn to behave in culturally sanctioned ways that may be defined as being "good, honest, kind or polite" in that culture (Shimahrara et al. 1970, p. 149). When conducting participant observation in the field, this underpins the importance of learning the tacit aspects of a particular culture.

\section{Language in Context}

Given that the goal of a participant observer is to learn something meaningful about other people's lives, the linguistic competencies and capabilities of the participant observer are fundamental elements of this learning process (Crang \& Cook 2007). The participant observer must be familiar with the 'official' language(s) of the 'research community' in order to be able to listen and communicate effectively. These linguistic skills are also required to understand and join in formal and informal conversations in the local setting (Dewalt \& Dewalt 2002).

I grew up in Hong Kong, I am linguistically fluent in both Mandarin and Cantonese ${ }^{72}$. This enabled me to be involved in both formal and informal forms of social interaction in China. I also understand the broader "structure of communication and colloquial usage" (Devereux 1993, p. 45). Understanding the kinds of formal and informal expressions is important because the language might vary due to geographical factors (rural and urban areas), generational differences (old and young people) and interactional distance (the researcher and the 'researched') in different social situations (Crang \& Cook 2007; Devereux 1993). In this regard, my linguistic abilities permitted me to readjust, reconstruct and reinterpret the conservations to fit 'the talk' to the linguistic context. These are crucial to the discovery of cultural meanings and perspectives that Chinese workers bring to bear on their daily lives in China.

\footnotetext{
${ }^{72}$ Both of my parents were Chinese-Indonesians and Mandarin was their first language.
} 


\section{In-Depth Interviews}

The discovery of cultural meanings and perspectives is predominately facilitated by conversations in the form of informal and formal interviews (Spradley 1980). The former occurs as the researcher seeks opportunities to informally engage people in conversation. The latter occurs at an appointed, pre-arranged time which results from a specific request from the researcher (Spradley 1980). Both types of interviews involve a "verbal stimulus" (or question) to generate a "verbal response" (or answer) from the respondent (Brewer 2000, p. 63).

Guided by an interview schedule ${ }^{73}$ (see Appendix 2) that was constructed to explore the research focus after reviewing the literature (see Chapter Four), the stimulus of my interview came in the form of 'open-ended questions' (Brewer 2000). I prioritised open-ended questions because they allowed the natural conversation to be guided by the participant observer (Brewer 2000). The rationale behind this form of interview is that the absence of structure permits the participant observer to "prompt, probe and ask supplementary questions" while allowing the respondent freedom to "answer accurately and in depth" (Brewer 2000, p. 66). The interviews ranged from 2.5 to 5 hours, depending on how easy or difficult the interviewees found it to talk about their work and non-work-based experiences in their everyday lives. This form of in-depth interview enabled me to access "people's meaning-endowing capacities" to produce a rich, deep vein of data, which come in the form of "extracts of natural language" (Brewer 2000, p. 66).

\section{Initiating Access}

Gaining access to research participants in the field is critical to the research process (Brewer 2000). It is suggested that the participant observer establish and facilitate snowball contacts in order to access the 'research community' in the field (Brewer 2000; Crang \& Cook 2007). This implies that gaining access to the 'research community' is through an introduction by a community member (or a gatekeeper ${ }^{74}$ ), and the closer the ties the gatekeeper has with the community, the greater the potential for connecting to other community members (Brewer 2000). Moreover, where the participant observer has no intermediary, access to the 'research

\footnotetext{
${ }^{73}$ An interview schedule contains a set of questions to be posed to the interviewees in the course of informal and formal interviews. See Brewer, J 2000, 'Understanding Social Research: Ethnography', in Alan Bryman, Open University Press, Buckingham.

74 'Gatekeeper' refers to the individual who is in the position to grant access to the research field setting, such as a police chief or head of an organisation, ibid.
} 
community' can also be negotiated and achieved by engaging in non-threatening behaviour in the setting. This can include visiting local cafes and neighbourhood stores (Brewer 2000). Hence, access to the members of the 'research community' varies from case to case.

In my own case, I attempted to gain access to workers in China through labour $\mathrm{NGO}^{75}$ and academic connections ${ }^{76}$. This was because conducting research in China is subject to a number of unspecified political restrictions, such as workers engaging in labour activism (Thogersen $\&$ Heimer 2006), and thus it was difficult to predict whether my study would encounter these. Prior to the commencement of my two phases of field research, I therefore contacted several labour NGOs, such as LAC, and leading labour scholars, such as Pun Ngai, both in Hong Kong and in China. In so doing, I was able to discuss how my fieldwork could be conducted and what my research participants and I could safely talk about, and also seek advice from these experts about key informants (or primary sources) who could be contacted in order to set a snowball sampling process in motion through trusted sources in China.

\section{Establishing a Trust Relationship}

Access to the 'research community' requires positive relationships developed by gaining trust in order to gain people's cooperation (Harrington 2003). Without a bond of trust, people might be reluctant to cooperate with, or to talk to, the participant observer (Brewer 2000).

Noting that a bond of trust could not be built spontaneously, for the first field trip I decided to reside in the 'workers' communities' and organised to live with the NGO workers in China during the second field trip. By residing where everyday workers and NGO workers lived, I was able to develop familiarity with them, observe and engage in their behaviour patterns, such as dining at the same eateries and generally doing what they did in their natural setting (Brewer 2000). This is important, because a trust relationship is entirely regulated by a range of social norms, and therefore trust building requires a certain degree of sociability to develop an appropriate relationship.

\footnotetext{
${ }^{75}$ Labour NGO connection: See this Chapter, p. 144 (Footnote 101 and 102).

${ }^{76} \mathrm{I}$ had made contact with leading Chinese labour scholar - Pun Ngai - at the Hong Kong Polytechnic University prior to the commencement of the first phase of data collection in 2011. See also this Chapter, p. 148
} 


\section{Constraining Access}

Although developing a trust relationship with people is a way to secure access to the 'research community', there are unpredictable factors that might constrain access (Crang \& Cook 2007). Even after access has been successfully negotiated, the participant observer must remain uncontentious in the field setting (Crang \& Cook 2007). The major reason is that there are no secure, guaranteed outcomes of the findings. This is because the findings are dependent on people's willingness to answer questions, and the participant observer's capabilities to report or interpret the acquired findings (Sother 2006).

For example, some participant observers are trusted with extremely private or confidential information, which it would be inappropriate to report (Crang \& Cook 2007). In other situations, some participant observers have been known to be disgusted, shocked or threatened by conversations with community members; and at the same time, certain community members also fear being held responsible for their comments (Crang \& Cook 2007). In other cases, some participant observers have found that the community members were unable to fit lengthy indepth interviews into their busy schedules (Thogersen \& Heimer 2006).

Similarly, social polarisation and diversification in Chinese society constrains access to certain community members in that country (Thogersen \& Heimer 2006), which in the case of this research, created difficulties in initiating interviews and dialogue with workers. My initial experiences with Chinese workers took place in Shenzhen City, Guangdong Province, in 2011.

Before embarking on the fieldwork in Shenzhen, I had spent time with an internationally recognised labour NGO, the AMRC, as well as a leading Chinese labour academic Pun Ngai to discuss my research project. I had completed an extensive literature review of relevant scholarly material prior to the first field trip (Chan 2012a; Lee 2007a; Pun, Chan \& Chan 2009). This research argued that Chinese workers were becoming proactive in protecting and advancing their rights through collective action. In these circumstances, the AMRC and Chinese experts felt that Shenzhen would be an appropriate field site for my research. One of the reasons for this is that Shenzhen is a model of special economic zones (SEZs), and the city has been receiving significant foreign investments since China's economic reform in the 1980s (Chan 2001). This site has consequently attracted a 'flood' of peasant workers to provide cheap labour in the export-oriented zone (Harvey 2005). Thus, it is predicted that resistance activities 
by Chinese workers, particularly factory workers within the export sectors, will become a common phenomenon in Shenzhen.

When I arrived in Shenzhen in October 2011, I spent the first few days with one of the contacts - a doctorate candidature researching on Chinese workers' activism at the time - referred by the Chinese expert in Hong Kong. I spent time with her to become familiar with the 'community area' in which I lived (see Figure 9), and to discover how to begin data collection, which in my case meant interviews with factory workers in the Shenzhen Longhua industrial district.

Figure 9: 'Community Area'

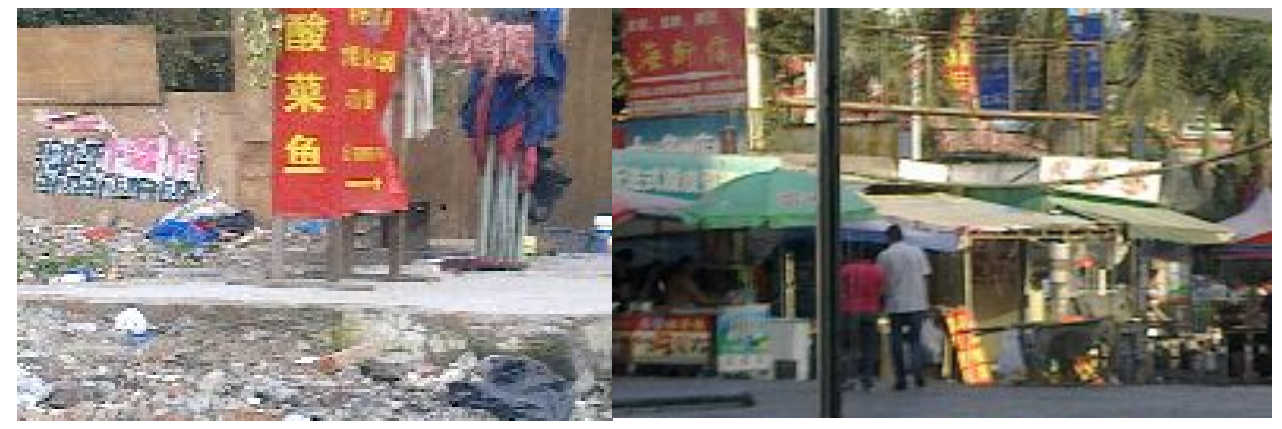

Source: Photo by author

This industrial district was supposedly an ideal location for my research because a number of factories, alongside one of the world's largest electronics manufacturer - Hon Hai Precision Industry Company (known as Foxconn) - were located in the area (Pun \& Chan 2010). China's Foxconn has come under the spotlight since 2010, when workers committed suicide to 'protest' against harsh labour control of the workforce. For this reason, a number of academics, research students (including my contact) and international labour NGOs have investigated the labour standards and experiences of workers at Foxconn (see Pun \& Chan 2010; SACOM 2014). Therefore, I chose to live in the 'workers' community' in this industrial district because I perceived that this site offered great possibilities for conducting fruitful fieldwork.

\section{Denied Access to the Public Places}

During my first two weeks in the Longhua district of Shenzhen, I noticed that the entire industrial area was filled with a multitude of workers on the streets. It was easy to identify factory workers, because they all wore factory uniforms in a sloppy way. They had messy hair 
and most had angry faces. These workers 'flooded' the streets, the restaurants, the internet cafes and the video game centres - day and night.

I started my fieldwork in a video game centre because I thought that the factory workers who were walking along the streets might be rushing to work and those at the restaurants might also be rushing to work after their quick meals. I presumed that factory workers who hung around at the video centre would not resume work so soon, and they might have time for a conversation; I also hoped to invite them for a research interview later on.

To enter the workers' daily lives, I spent a few days at the video game centre. My aim was to initially socialise with the factory workers, and then to conduct interviews with them later on, after an appropriate relationship had been established. During the process, I sought opportunities to stay close to the workers when they were focusing on the games at the game centre. I began my dialogue with them by asking general questions, such as 'how do I play this game?', although the answers were quite obvious. Despite receiving a brief explanation of how to play the games, I could not continue the dialogue with the workers, because they were too busy with their own games. I therefore moved on to the workers (waiters) at the game centre in order to practice my social skills. I spoke to two of them: the first one was scared of me after I posed questions about her work experiences in Shenzhen; the second one was more open to my work-related questions, albeit a little impatient with me. My conversations with both did not last longer than 10 minutes. Worse yet, spending every day speaking to people at a video game centre had attracted the attention of the owner of the game centre. The owner apprehended me and demanded an assurance that there would be no media or police attention on his business over the conversations I had had with the factory workers and the waiters before he would allow me to leave.

After 'retreating' from the video game centre, I found a more appropriate site. I eventually accessed workers in an open, public area at one of the factory dormitory sites. Before entering the open area of this particular factory dormitory, I could see a crowd of workers, mostly wearing factory uniforms, going in and out of the restaurants, internet cafes and the dormitory building. Some of them were going in and out of the dormitory area, while others were making use of their leisure time to meet or catch up with other factory workers, such as playing basketball and snooker together. I walked up to one of the snooker tables, because I had seen a 
few workers sitting and chatting around the table. I approached those workers by introducing myself with a 'consent sheet' that complied with Australian ethics and research procedure. Although I was exempted from requesting the workers to sign the 'consent sheet', I was required to verbally inform the workers about the scope of my research based on the information contained in the 'consent sheet'. Eventually, two workers were willing to be interviewed and shared their personal and work-related stories with me. While I was listening and talking to the workers, a security officer of the dormitory site had taken the 'consent sheet' from me and showed it to other security officers. Without giving a proper reason, the security officers stopped me from talking to their factory workers and ordered me to leave the public area of the dormitory site.

\section{Life on the Street: 'Guerrilla Street Interview' Technique}

The two attempts to access factory workers in the 'public' places had left me feeling that finding an appropriate research site was nearly impossible. I then decided to conduct 'street interviews' with workers. Street interviews, also known as 'guerrilla interviews', are defined by sociologist Thomas Gold (1989, p. 180) as "unchaperoned, spontaneous but structured participant observation and interviews as opportunities present themselves" on the streets. This suggests that a 'guerrilla street interview' involves observing people's daily behaviour and "picking persons for research interviews by spontaneously engaging in seemingly idle, friendly conversation [with] people [...] on the streets" (Gold 1989; Solinger 2006, p. 161).

To carry out a 'guerrilla street interview' in the public realm, I spent many hours walking on the streets in an attempt to speak to people I recognised as factory workers - either by their clothing or by their hairstyles. While it was easy to recognise factory workers in Longhua industrial area, I found it difficult to engage them in conversation. The workers I encountered were either afraid or unwilling to talk to a stranger, or they were in a rush to get to work or were on their way home. Therefore, I chose to conduct guerrilla street interviews in the evenings and at night, with those factory workers who looked less angry and walked slowly, in the hope that they were in a better mood and also had time to speak to a stranger. In Longhua industrial area, while many of them ignored me as they evidently did not want to spend time on me, there were a few factory workers who were willing to be interviewed. 
I extended the guerrilla street interview technique from Longhua industrial area to other industrial parks, and to the employment centres, known as Talent Markets (rencai shichang) (see Figure 10), in the industrial districts.

Figure 10: Talent Markets

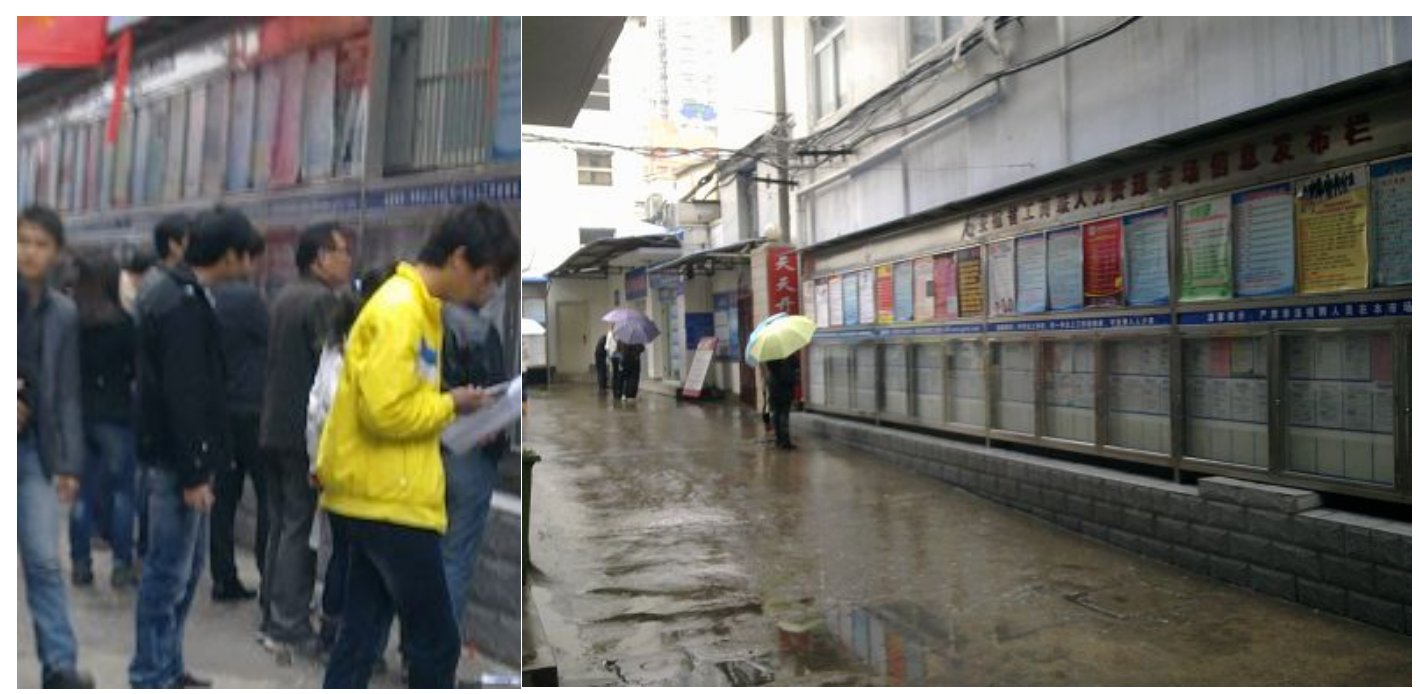

Source: Photo by author

At the latter sites, I found it easier to initiate conservations with job seekers, who were unemployed or underemployed. My practice was to walk through the job fairs and approach job seekers by reading the same postings that they were reading on the billboards, which listed job openings. I began conversations with job seekers with queries such as, 'What sort of job are you looking for?', 'Where are you from?' or 'How long have you been here?' I then explained my research interest to the job seekers and presented them with my name card as evidence that I was a research student. Following this form of trust establishment, it became possible for me to conduct guerrilla street interviews with them. My entry point into conversations with workers was different across the industrial parks. In some areas, I approached workers with a friendly greeting, such as 'How are you?' I would then immediately present the workers my name card, explain my research interest to them and ask them if they had time to talk before conducting a formal guerrilla street interview with them.

I also broadened the interviewees by approaching workers who were employed outside the factories, such as cleaners of the hotels, waiters at the small eateries or cafes, hawkers on the streets and masseuses of the massage centres. These are everyday workers from across different 
employment sectors selling their labour power for a wage (Croll 2006, p. 126). Taking up the opportunities offered by the guerrilla street interviews by randomly striking up conversations with workers, I was able to obtain rich ethnographic details and uncensored personal opinions and personal stories that structured interviews, news, and academic articles do not provide. It was through meeting with and talking to everyday workers across different places that I could observe how they spent their leisure time and how they thought about and lived their lives in China.

\section{Research Processes in Hefei}

Upon arriving Hefei in November 2011, I arranged my first meeting with a Chinese Labour Law academic whom I hoped would be able to provide me access to his two legal aid NGO networks and contacts. After a few discussions, I was granted permission to conduct observations and interviews at one of his NGO offices. I spent the first few days talking to the NGO workers while waiting for an opportunity to talk to the workers when they came to seek legal advice from the organisation. Barely anyone came into the office; during my time there; only one worker came in to enquire about workplace injury compensation. I was told that this was a 'normal situation', because the NGO office had opened only recently. Hence, instead of spending time waiting at the NGO office, I incorporated two coping methods to facilitate data collection in the field. One was to seek an opportunity to move the fieldwork to other NGO sites; and the other was to again conduct guerrilla street interviews at this new site.

I identified the locations of Hefei's industrial parks and noted them on my map. I chose to conduct 'guerrilla street interviews' in the industrial park near a place called Minzhu Plaza (or Minzhu shopping mall), because it was the only industrial area accessible by public transport. Once at the industrial park, I immediately noticed that conducting interviews in Hefei's industrial parks was impossible. Unlike the industrial districts in Shenzhen, the design of Hefei's industrial park was set up as a closed zone in which all the factories were behind secured front gates. The streets were also extremely quiet during working hours. There was no one walking in or out of the factories, even during the lunch breaks. A possible reason for this was that the entire industrial zone had no common meeting places, such as small eateries. By the evening, and after the working hours, some workers were picked up by the company transport at the factories and others squeezed themselves into the buses. 
I explained the difficulties I was having with collecting data in the industrial park and also within the NGO office to my academic contact in Hefei. My aim was to get permission to conduct research at other NGO sites. I had previously learnt that NGO workers at the two legal aid organisations had to promote their services in different places. For example, NGO workers took turns to provide free legal consultation for workers at the Talent Market and the Labour Bureau. I sought to work with the NGO workers at those sites in order to gather data.

In mid-November 2011, I began conducting observations during the legal advice sessions, both at the Labour Bureau and the Talent Market. At the Talent Market, the NGO workers and I were shared a working space with company representatives in the main hall of the building. In the main hall, company representatives or the job postings on the walls were the first point of contact for job seekers and workers. A few job seekers and workers approached us to see what company we were representing; others approached us to see what services we were providing. After discovering who we were and what we did, the job seekers and workers would walk off; very few would describe to us their work-related issues. However, those who enquired about their legal rights appeared to have no intention to further resolve the issues.

By contrast, workers who went to the Labour Bureau sought to resolve their work issues after being neglected by the Labour Bureau officials (see Figure 11). 
Figure 11: Labour Bureau Official

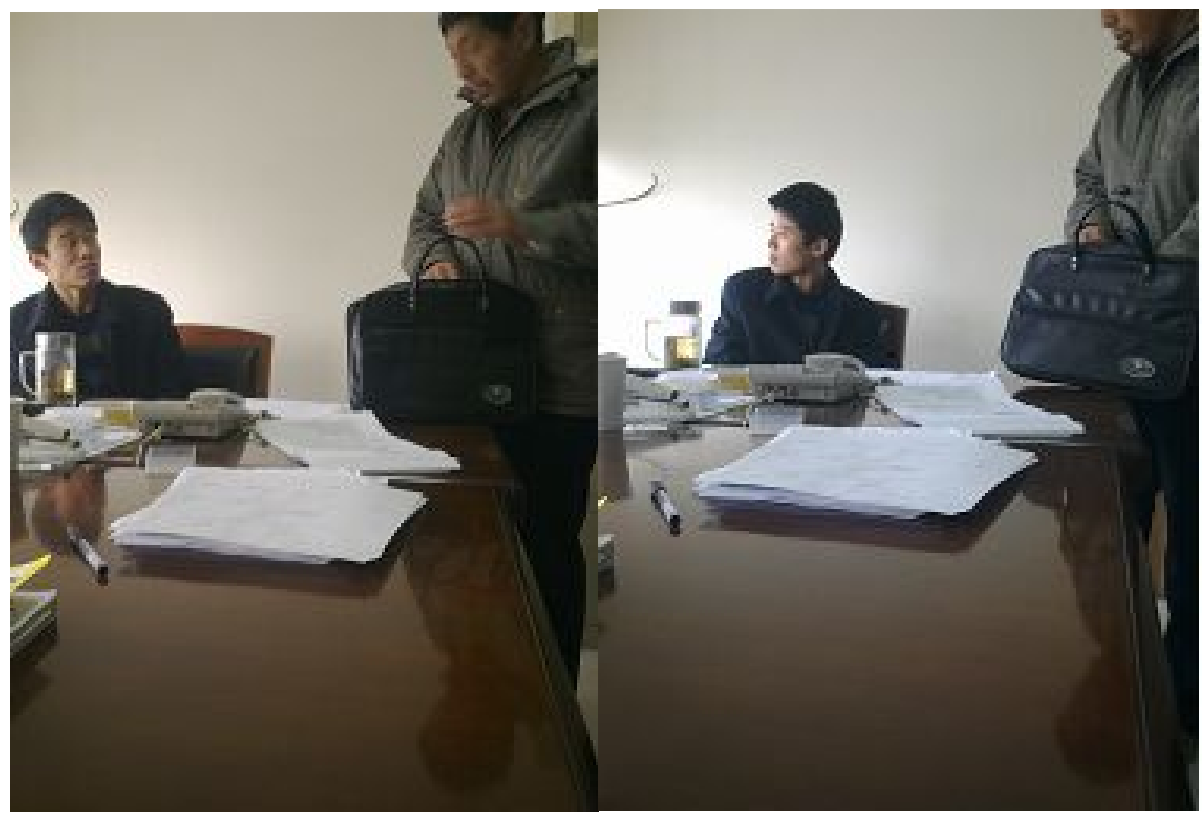

Source: Photo by author

At the Labour Bureau, the NGO workers and I shared an office with two officials. The Labour Bureau officials referred workers to us whenever they felt their cases were too complicated to handle. This included unpaid wages without an employment contract. In other cases, the officials demonstrated that they were not interested in dealing with the workers' issues. For example, one of the officials repeatedly ordered the worker to leave the office without even listening to his queries.

Being an unofficial NGO worker, I was not in a position to provide legal advice to workers when they enquired about their legal rights at the sites; however, I was able to engage in conversations with workers when they described their employment circumstances. For example, a local rural worker approached us to ask about how to be compensated for unpaid wages, and his entitlement to make a claim for work injury compensation. He said that his employer ordered a group of security officers to beat him up when he demanded his unpaid wages. I observed as the NGO worker gave him advice about what he could do to resolve these problems. After the worker's conversation with the NGO worker, I posed questions to him, such as the duration of his employment, his family background, his own daily life problems 
and experiences. Following this practice in other instances, I could occasionally conduct interviews with workers, although with some in more depth than others.

Besides conducting interviews with workers at the sites, I was able to organise interviews with workers through the contacts of NGO workers. By interacting with people at the NGO office and other NGO sites regularly, I was able to establish trust relationships with several NGO workers. Because of this positive relationship, NGO workers became enthusiastic about trying to connect me to their existing networks. Through these networks I was able to build snowball contacts and organise interviews with everyday workers in the field.

\section{Research Process in Hangzhou}

My commitment to exploring the research topic through 'multi-sited' opportunistic movement led me to travel further to Hangzhou. When I arrived in this field in December 2011, my first three days were spent locating research sites with Pun Ngai alongside a group of academics from both Hong Kong and China who were experts in Chinese labour studies. Their main purpose for visiting Hangzhou was to identify research sites for their postgraduate students. While the purpose of their visit was not to facilitate my research, I was convinced that I could conduct more interviews with workers by accompanying them to the research sites.

During the three-day intensive fieldtrip, we visited two places: an NGO in Jubao Zhen (or Jubao town) and a domestic-owned garment factory in Yuhang. The academics briefly introduced me to some of the NGO workers in Jubao Zhen and to the factory manager in Yuhang as an independent research student. This eventually made it possible for me to conduct research at these sites.

\section{Collecting Data in a Garment Factory}

In Yuhang I rented a hotel room with windows directly facing the shop floor of the garment factory (see Figure 12). 
Figure 12: Garment Factory Workers

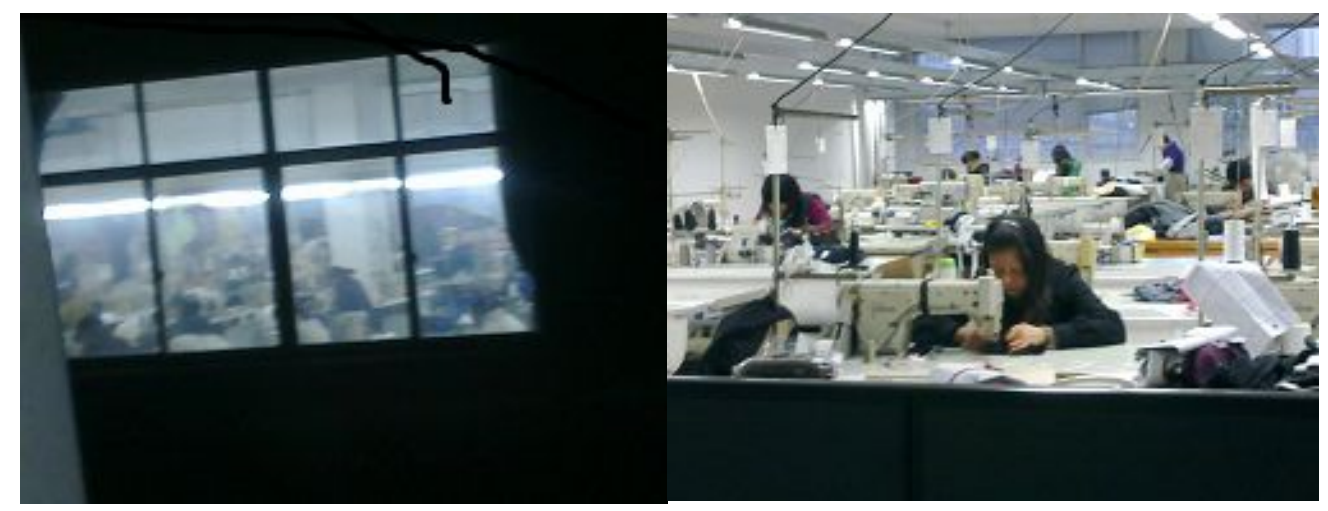

Source: Photo by author

When looking at the shop-floor through the window, I noticed that the factory workers started their daily work early in the morning and finished after midnight. I also noticed that there were two breaks between each working day; that was, an hour lunch break and a half an hour dinner break. There were two supervisors, who wore white blazers, and who made sure that the workers all left the shop-floor for the breaks before turning the light off.

I decided to choose a time to visit the factory by myself. I paid my first visit to the factory after the lunch break in the afternoon. After being allowed in by the security guard at the front gate due to being able to name the factory manager, I walked up to the second floor of the factory building where the shop-floor was located. When entering the shop-floor, I became aware that most of the workers were staring at me. To demonstrate to the workers that I had permission to be on the shop-floor, I initiated conversation with the factory manager on the production line. As soon as the manager acknowledged me, it became possible for me to conduct interviews with the workers, observe their work routine and work with them at the factory on a daily basis. I subsequently made 12 return visits to the factory.

\section{Collecting Data at an NGO}

I also collected data at the community-based NGO site in Jubao Zeng as I was introduced to the NGO workers by the academics. Unlike the NGOs in Hefei, this NGO had an established workers' service centre in the living area among the peasant workers. In the workers' services centre, there was a library that provided the workers with computer facilities and a book lending service. Free movies, interest-classes and recreational activities were also offered to the 
workers in separate rooms. Through these activities, the NGO also attempted to promote general knowledge about workers' rights.

Taking this opportunity, I stationed myself at the workers' services centre every night. I carried out the study at night, because that was the time when the workers had finished their shift and gathered at the services centre. At the time I was conducting fieldwork at the services centre, NGO and everyday workers were rehearsing a performance for the forthcoming cultural festival. By attending each rehearsal session, I was able to hold general conversations with NGO and everyday workers. At one of the rehearsal sessions, an NGO worker introduced me as an 'Australian research student' to a group of workers. After my official status as a research student had been obtained, I described my research study and my interest in learning from the group of workers. As the group of workers became interested in talking to me, it became easier for me to organise and carry out interviews with them at this site.

\section{Research Sample}

A total of 74 interviews with workers (detailed profile of respondents and occupations: see Appendix 3) were conducted across the two phases of data collection at multiple locations in China from 2011 to 2014. Table 3 contains a summary of the respondents' details:

Table 3: Respondents' Details

\begin{tabular}{|l|l|l|l|}
\hline & $\begin{array}{l}\text { Phase } \\
(\mathbf{2 0 1 1}-\mathbf{2 0 1 2})\end{array}$ & $\begin{array}{l}\text { Phase } \\
(\mathbf{2 0 1 3 - 2 0 1 4 )}\end{array}$ & Total \\
\hline Interviews & 53 & 21 & \multirow{2}{*}{74} \\
\cline { 1 - 3 } Gender & 26 Females & 10 Females & \\
\cline { 2 - 3 } & 27 Males & 11 Males & \\
\hline Age & $17-50$ & $17-40$ & \\
\hline
\end{tabular}

The findings are divided into two groups. Group One consists of 52 interviewees who had never participated in protest action, while 22 interviewees are in Group Two, that is, those who had engaged in protest activities, as summarised in Table 4: 
Table 4: Interviews Groupings

\begin{tabular}{|c|c|c|}
\hline & $\begin{array}{l}\text { Group } 1 \\
\text { Never Participated in } \\
\text { Protest Action }\end{array}$ & $\begin{array}{l}\text { Group } 2 \\
\text { Participated in Protest } \\
\text { Action }\end{array}$ \\
\hline Interviews & 52 & 22 \\
\hline Gender & $\begin{array}{l}26 \text { Females } \\
26 \text { Males }\end{array}$ & $\begin{array}{l}11 \text { Females } \\
11 \text { Males }\end{array}$ \\
\hline Locations & $\begin{array}{l}\text { Shenzhen } \\
\text { Hefei } \\
\text { Hangzhou }\end{array}$ & $\begin{array}{l}\text { Shenzhen } \\
\text { Hangzhou } \\
\text { Panyu } \\
\text { Haizhu } \\
\text { Foshan }\end{array}$ \\
\hline
\end{tabular}

\section{Documenting and Transcribing Data}

When conducting the interviews, I documented in note form some of the discussions while most were audio-recorded after receiving permission to do so from the research participants. The interviews recordings were transcribed and in keeping with established ethical protocols each audio file and transcription was stored on a password protected personal computer. While all the transcriptions contained the interview questions and interviewees' answers, pseudonyms were used to maintain the anonymity of my research participants.

When transcribing each research interview, building a rich body of work on the content from the field involves the documentation of values, feelings, attitudes and experiences of the local subjects, as well as including reflections on the experiences and insights of the ethnographer that arise from examining the subjects' everyday lives (Elliott 2005). Hence, ethnographic documentation is autobiographical, because it describes not only the research from the researcher's perspectives, but also captures detail such as the participants' appearances, body language and behaviours, as well as their knowledge (or 'truths) that are reflected in the dialogue (Brewer 2000). Described as "a conversation with a purpose" (Burgess 1984, p. 102), dialogue occurs in formal and informal conversational interviews initiated by the research participants who choose to take the researcher into their worlds and verbally relate what is in their minds (Rossman \& Rallis 2012). By interpreting other people's interpretations of their own and others' perspectives and experiences, the researcher thereby 'co-constructs' the 
meanings, together with the participants, of their particular cultural practice (Paulson 2011).The content of ethnographic notes is thereby 'thick' and 'descriptive' as the researcher writes in the first person to reflect his or her own account of experiences as an 'insider', and also writes in the third person as an 'outsider' to convey the words and actions of the participants in their cultural setting.

In keeping with the ethnographic traditions, I documented my personal insights, feelings, observations, and experiences in the ethnographic notes, as well as in each of the interview transcriptions. While time-consuming, my commitment to producing concrete descriptions in my field notes and transcriptions was determined by my interest in understanding the perspectives of the two groups of everyday Chinese workers in their cultural context. For this research, 'additional meaning' from the speech practices (see Table 5) of the workers, for example, their use of intonations, pauses and rhythms, were included in the transcriptions:

Table 5: Example of Speech Practices

[everyone started getting angry]

Yao (tone raised): We have to keep working...

Fang: ... We [paused] cannot just stop from what we are doing...

Ying: ... We have to keep picking up the rubbish and sweeping the floor non-stop - we cannot even stop

for a little rest for just a few seconds [tone raised] - we are not allowed to [screamed]

Although the speech, practices and characterisations of the workers were all documented in the transcriptions, pseudonyms were used to maintain the anonymity of the research participants. The documented verbal communications were translated from Chinese into English for analysis.

\section{Different Ways of Seeing: Narrative and Discourse Analysis}

In this study the narrative (or story) approach was used as an analytical device to explore the research topic by making sense of the discourses in their words and meanings, depending on how they were used, by whom and to whom - the daily experiences of the two groups of everyday workers in their socio-cultural context in China. Narratives in the social sciences are conceptualised as discourses that are organised by the sequences of historical events in ways 
that produce meaningful insights about peoples' experiences of another culture (Hinchman \& Hinchman 1997). The characterisation of narratives is thus chronological, meaningful and inherently social, and reflects the 'knowingness' of the individuals that leads to the shaping of their practices and experiences within their own histories (Foucualt 1997; 2001; 2006). Recollections of the past and evaluations of the present (or 'History of the Present') (Foucault $1980 \mathrm{~b} ; 1997$; 2014) and anticipations of the future through narratives offer possibilities for making sense of the various aspects of their lives.

Intimately connected with the historical qualities of narrative is the concept of plot in rearranging the narrative clauses, or the events, within a narrative that results in a change of meaning or situation (Elliott 2005). This is because a story presents itself as a jumble of unrelated sensations and events that generally appears to disrupt a state of equilibrium or representation of the chronological (or sequential) events in histories (Carr 1997). An example to illustrate this is E.M. Forster's (2005 [1927]) argument that 'The king died and then the queen died' is merely a 'chronicle' story, while 'The king died and then the queen died of grief is a plot that shows an explicit causal link between the two events in the sequence. Thus, a plot within a narrative is a connection of events with each other by linking a prior happening to the effects or causes of a subsequent event (Elliott 2005).

In establishing a causal relationship between specific events in the stories to inform techniques of narrative and discourse analysis, I used Nvivo 11 text analysis software to code the data by organising useful chunks of text (or content) into units for thematic analysis (Basit 2003). In this way, the volume of useable data decreases and thus I was able to 'make sense of the data' by continually revisiting the coded material and refining the interpretations through analysis (Basit 2003; Richards 2005).

In order to become familiar with my data, and to direct my analysis by using Nvivo 11, I facilitated two stages of coding for 'the content' of my ethnographic notes and interview transcriptions, that is, I focused the coding for subthemes and the identification of larger narrative themes. The coding (see Table 6) was a summary of each paragraph of ethnographic notes or interview transcripts that illustrated smaller stories of the lives of the two groups of workers. 
Table 6: Example of Coding 'On Work' from Interview Transcripts

\begin{tabular}{|l|}
\hline At the factory, I only obeyed and followed what I was told; brains were useless at a factory (G1 Xiaoyuan) \\
\hline We just won't do that because we won't want to go against our work leaders (G1 Xiaoxin) \\
\hline I can't talk to my boss because he hires me to do the job not to complain about the workload (G1 Yaxing) \\
\hline $\begin{array}{l}\text { Launching a strike is a risk for everybody because we might lose the job and we don't want to go against } \\
\text { the leaders at work (G2 Yi) }\end{array}$ \\
\hline $\begin{array}{l}\text { We are just the workers and we should obey to the leaders - we were paid to do our job and why should } \\
\text { we make it so difficult? (G2 Gong) }\end{array}$ \\
\hline
\end{tabular}

After grouping the coding into a list of smaller stories shared by the two groups of workers, the main narrative themes emerged from the data in a bottom-up fashion. To ensure the reliability of coding for subthemes and main narrative themes within categories, two independent raters ${ }^{77}$ had check-coded selected from portions (see Table 7 and Appendix 4) of the interview transcripts and had rated 100 percent accuracy of the codes.

Table 7: Examples of the Main Narrative Themes (highlighted in Red)

\section{Main Narrative Theme: The Practice of 'Voluntary' Submission}

\begin{tabular}{l}
\hline At the factory, I only obeyed and followed what I was told brains were useless at a factory (G1 Xiaoyuan) \\
\hline We just won't do that because we won't want to go against our work leaderp (G1 Xiaoxin) \\
\hline I can't talk to my boss because he hires me to do the job not to complain about the workload (G1 Yaxing) \\
\hline Launching a strike is a risk for everybody because we might lose the job and \\
the leaders at work (G2 Yi) \\
We are just the workers and we should obey to the leaders - we were paid to do our job and why should \\
we make it so difficult? (G2 Gong)
\end{tabular}

${ }^{77}$ Two independent raters are academic staff of the University of Western Australia (UWA) who attained appropriate research skill level but are not involved in this research study. 
Main Narrative Theme: A Sense of Self-Marginalisation

\begin{tabular}{l}
\hline At the factory, I only obeyed and followed what I was told:brains were useless at a factory (G1 Xiaoyuan) \\
\hline We just won't do that because we won't want to go against our work leaders (G1 Xiaoxin) \\
\hline I can't talk to my boss because he hires me to do the job not to complain about the workload (G1 Yaxing) \\
\hline $\begin{array}{l}\text { Launching a strike is a risk for everybody because we might lose the job and we don't want to go against } \\
\text { the leaders at work (G2 Yi) }\end{array}$ \\
\hline \hline We are just the workers and we should obey to the leaders - we were paid to do our job and why should \\
we make it so difficult? (G2 Gong)
\end{tabular}

\section{Main Narrative Theme: Self-Value and the Norm-based Moralities}

\begin{tabular}{|l|}
\hline At the factory, I only obeyed and followed what I was told; brains were useless at a factory (G1 Xiaoyuan) \\
\hline We just won't do that because we won't want to go against our work leaders (G1 Xiaoxin) \\
\hline \hline I can't talk to my boss because he hires me to do the job not to complain about the workload (G1 Yaxing) \\
Launching a strike is a risk for everybody because we might lose the job and we don't want to go against \\
\hline the leaders at work (G2 Yi) \\
\hline We are just the workers and we should obey to the leaders - we were paid to do our job and why should \\
\hline we make it so difficult? (G2 Gong) \\
\hline
\end{tabular}

These analytical processes partially resonate with the concept of grounded theory, which Barney Glaser and Anselm Strauss (2015) describe as generating new theory from data. This is because the theoretical conceptualisation that is used to analyse the data has emerged from the data itself. Albeit the theoretical framework for this study is not 'new', determining the main emergent narrative themes from the data as a technique of naturalistic enquiry for understanding Chinese cultural lives in a specific historical and societal context informed a 'quasi-grounded theory' (Terry 2009, p. 467) for this research.

\section{Reliability and Validity}

The immediate question about ethnonarrative research is the issue of the 'reliability' and 'validity' of the information obtained. Reliability is generally defined as the replicability (or stability) of the research findings, while validity refers to the capacity of the research to reflect the reality or to measure the notions of interest (Elliott 2005). Fred Kerlinger and Howard Lee 
(2000, p. 456) succinctly explain that "the commonest definition of validity is epitomised by the question 'are we measuring what we think we are measuring?"' This problematizes the capability of the research findings to be generalised and applied to a broader population (Elliott 2005). These thoughts originate in quantitative research methods, such as surveys and experiments, which are characterised as belonging within the positivist paradigm (Brewer 2000). The notion of 'measurement' is thereby less appropriate for evaluating research with a naturalistic emphasis because ethnographic studies aim to provide detailed descriptions of individuals' experiences and the meanings that construct those experiences (Elliott 2005).

By shifting the focus from measurement to description, researchers who use the ethnonarrative approach seek to provide objective data and analysis in the form of analytical induction advocated by grounded theory (2015). This bottom-up approach is underpinned by the recognition that there is no one fixed reality; thus one seeks to capture a multiplicity of perspectives, in line with Foucault (1977; 1980a; 1980b) assertion that individuals' behaviours are preconditioned by their power-knowledge relations within a particular historical and cultural time and space. Thus the research findings depend upon the use of unstructured, openended interviews to empower the participants to provide more concrete and specific details about the topics discussed and to use their own words and conceptual frameworks to describe their lived experiences (Elliott 2005). By enabling the participants to describe their thoughts, feelings and experiences, the researcher is able to learn about those aspects of their lives and then engage in the process of reflection in 'making sense' of the subjective experiences that make up a cultural society or community (Creswell 2003). It is the reflexive voice of the researcher that makes a significant distinction between a 'report' and a 'narrative' in those stories and produces 'reliable' and 'valid' evidence.

As with feminist ethnography (Brewer 2000), my study exploring the two worker groups for the potential of an organised labour movement was conducted from their personal stories as workers. Once a specific pattern of discourse and behaviour had become identified in a particular code and narrative theme, I was able to analyse the potential relationship between the discourses and analytical concepts drawing from Foucault's theoretical framework (see Chapters Three and Four). In working through the concepts and discourses, I compared the themes and narratives to other Chinese labour studies and in which I noted the inconsistencies between the findings of similar studies (see Chapter Four) and my research study (see Chapters 
Six, Seven and Eight). The differences and contradictions existed in ethnographic research as individuals are not automatons and are themselves exposed to different situations at various times of their everyday lives (Fife 2005). Thus, I acknowledged the multiplicity of perspectives as the complexities of social and cultural lives and the importance of reflexivity of that perspectives to provide a more accurate, reliable and valid analysis and description of the lived experiences of the two groups of Chinese everyday workers for ethical reasons.

\section{Ethical Considerations}

While it is recognised that the ethical risks inherent in social research might be less significant than in medical research, the social sciences have not been excused from allegations of unethical behaviour (Wiles 2013). In fact, the social sciences have been subject to increasing ethical regulation. Studies undertaken on vulnerable people are of particular concern - such as those conducted on prisoners and on homosexual behaviour (Wiles 2013). From an ethical perspective, concerns arise as researchers become immersed in the research process and involved in the lives of research participants (Bowen 2005). Hence, ethical frameworks for social research relate primarily to researchers' ethical responsibility to research participants in the conduct of research (Wiles 2013).

Throughout the first phase of the data collection between 2011 and 2012, one of my major concerns when conducting guerrilla street interviews was that most of the participants had high expectations on my role and ability to redress or resolve problems for them. This is because workers generally perceived me as a journalist even though I had made certain to clarify my role to those speaking with me, why they were targeted for an interview and how their work and non-work experiences in their daily lives were related to my research study. Despite their lacked of knowledge about academic research, their narratives concerning wages and hardships also generated the feelings of unease for me in sympathy with their efforts to live their everyday lives. My sympathetic responses to the concerns of participants had become a key factor in creating the dilemma of closeness and friendship leading to unrealistic expectations. To avoid high expectations and possible conflicts with participants, I detached myself from being too close to the workers by emphasising that my interest and responsibility as a research was only to understand and analyse their issues. Some workers felt disappointed and thus refused to be 
interviewed as they rather spend time with a journalist who could possibly redress the issues they were experiencing in their present struggles.

Although I was annoyed by the attitudes of some workers, my experience sensitised me to an important ethical concern, that is, the researcher owes loyalty and responsibility to actual and potential participants and thereby we must respect their choices. However, while my efforts to balance the research interest and my responsibility had discouraged some workers from talking to me, many of them were impressed by the fact that I was willing to take time to listen to their personal stories on the streets.

\section{Obtaining Informed Consent}

Gaining informed consent from those people involved in the research process is a core ethical research practice in the social sciences (Wiles 2013). Informed consent involves a procedure for ensuring that the research participants are aware of what the research entails, what their participation in the research will involve, how the data will be collected and how it will be used (Wiles 2013; Wilson 1993). Providing clear information to potential participants gives them an opportunity to make informed decisions about whether they want to be involved in the study (Wiles 2013). In the process of obtaining informed consent, a researcher is required to obtain evidence that the participants have consented to participating and understand the issues involved (Wiles 2013).

In thinking through the ethical issues in the context of my research, I concluded that signed consent was not in the interests of either the researcher or the researched in China. While I recognised that the practice of signed consent was aimed at ensuring that the research participants were aware of what the research entailed - and protecting the researcher from subsequent complaints from the research participants - I also understood that asking a study participant to sign a consent form might be problematic in China. Some of the reasons for this were that my intended study cohort of ordinary workers might have been illiterate; might not have fully comprehended the ethical procedures involved in social research, or might have feared that signed consent would reveal their identities and place them at risk (see Wiles 2013). Demanding signed consent could therefore have dissuaded potential participants from involvement in my research. For this reason, the University of Western Australia's (UWA's) Human Research Ethics Committee granted me an exemption from requiring signed consent 
from individuals prior to the commencement of my fieldtrip in China (see Appendix 4). However, I used an alternative method to obtain consent from the participants.

\section{An Alternative Method: Verbal Consent and Practical Issues}

As stated in previous sections, I relied on voluntary interviews to collect data at various locations in China. Throughout the study, I verbally informed the potential participants about what my research project entailed in accordance with a translated 'consent sheet' (see Appendix 5 [translated] and 6 [original]) in either Mandarin or Cantonese. In this way I could ensure that my potential participants understood the information in the consent sheet and that I had their verbal consent to participate. This approach was analogous to a situation in which a survey was being administered. The potential respondents could refuse to participate based on the verbal information provided.

A practical issue that arose was the challenge of obtaining consent from everyone involved in social research project. This was particularly the case when I was conducting research in public spaces, for example on the streets, in small eateries and at Talent Markets. In such instances, it was possible for me to gain verbal consent only from key informants; it was not feasible to gain verbal consent from everyone who contributed to the research in a public setting. Furthermore, obtaining consent in less public settings could be equally challenging. For example, during some of the interview sessions at people's homes, friends of research participants contributed to the discussions. It was not entirely clear whether or not people who contributed to the study in unexpected and minor ways should be classified as 'research participants'. In this respect, I continually obtained and re-negotiated consent from individuals, depending on their level of involvement in my research.

\section{Confidentiality and Anonymity}

Confidentiality and anonymity are another key ethical research concern in the social sciences (Wiles 2013). The management of both confidentiality and anonymity is closely associated with the management of consent. Clearly, potential participants must be informed about issues concerning confidentiality and anonymity before giving their (verbal) consent to be involved in the study (Wiles 2013). Specifically, potential participants must be made aware of how the data will be reported and how their identities will be protected. 
Thus I primarily sought to protect the research participants through the use of pseudonyms. Prior to the interview sessions, I made it clear to my participants that their personal details would not be revealed. In many instances, individuals trusted that they could talk without fear of being identified.

\section{Concluding Remarks}

This chapter comprised a description of how ethnonarrative tools (such as participant observation, in-depth and guerrilla street interviews, narrative and discourse analysis) assisted me to see beyond common (traditional or universal) understandings of Chinese activist culture through the discovery of hidden meanings (or discourses of truths) in the complex lived experiences of everyday Chinese workers in their daily lives. While the sample of this study was relatively small, the open format, with mixed research approaches and coping strategies empowered the research participants to tell stories (or narratives) about their unique experiences of their everyday lives. Narrative and discourse analysis of the collected data and theorising from that data in the ways described in this chapter were useful in terms of opening up possibilities to understand why certain thoughts and knowledge existed and how they impacted practices, as well as how they might be changed. In Chapters Six and Seven the meanings attached to everyday workers' experiences will be examined to explore living and working in post-Mao China has shaped the consciousness of everyday Chinese workers, and how this consciousness affects their activism, as well as their ability to develop themselves into organised labour movement to improve their living and working conditions for themselves and others. 


\section{Chapter Six: Automatic Docility in Market Socialism}

It is one of my targets to show people that a lot of things that are part of their landscape - that people think are universal - are the results of some very precise historical changes. All my analyses are against the idea of universal necessities in human existence. They show the arbitrariness of institutions and show which space of freedom we can still enjoy and how many changes can still be made.

(Foucault et al. 1988, p. 11)

The aim of this chapter is to present and discuss the two phases of original field data gathered from 52 workers in Group One - who had never engaged in any protest activities -across a range of industries and occupations at multiple locations in China between 2011 and 2014. Rather than class action, the workers in this group appeared to have submitted themselves 'voluntarily', both to their work superiors and exploitative conditions. From Foucault's viewpoint, this particular behaviour is an effect of particular types of knowledge (or truth) that reflect an effective operation of disciplinary power within the workers in their social relations. Foucault (1977) notes that these relations are reinforced through the carceral network (see Chapters Two, p. 47 and Three, p. 91) such as schools and workplaces which teaches the individuals to act in accordance with the truth of the normality of their given positions (or identities). For example, soldiers are trained to use the rifles in particular ways whereas school children are taught to hold a pen and sit at their school desks correctly in the public institutions (O'Farrell 2005). The new mass forms of these panoptic mechanisms (Magill 1997; see Chapter Three, p. 91; Oksala 2007, p. 57) aim at turning different 'classes' of people into units of automatic docility to think and behave in adherence with what is defined as normality for their given positions in their social spaces (Foucault 1977). The visibility of these public spaces subtly alters individuals' consciousness through their internalisation of the thought of the constant watchful gaze that guides them to self-regulate their own behaviours and that of others (or governmentality) in accordance with their social truth. 
This chapter examines how the truth discourses have continued to retain an 'older rule consciousness', that is, the status consciousness among the workers interviewed in this study and their behaviours. In so doing, the chapter begins with the narratives of workers' desires to escape poverty (tuopin 脫貧), which were influenced by the quality discourses (see Chapter Three, p. 90), before exploring how they marginalised themselves in the low-wage sectors within their social relationships. It will be shown that their sense of 'self-marginalisation' was linked to the Confucian 'truth' of 'destiny' (see Chapter Three, p. 92) and their responsibility for others (see Chapter Two, pp. 51-52) that had turned them to guide themselves to willingly submit to their work supervisors and any given conditions. It is subsequently argued that through their continuous submission to an imaginary 'truth' they became - consciously or subconsciously - the agents in constituting themselves as docile bodies and minds to serve the interests of their work supervisors, and ultimately the will of the CCP (Chinese Communist Party) leaders in China's market socialism. Finally, it is concluded while the Chinese mentality and their sense of responsibility for others had constrained workers' perceptions about themselves and hence their experiences, their self-care practices towards the matters that affected their lives (and families') opened up the possibilities for them to resist normalising disciplinary practices and shape their existence within Confucian-orthopraxy system.

\section{The Desire to Escape Poverty (tuopin 脫貧)}

I'm not happy with my living conditions [...] I'm so poor [...] I'm only allowed to think about ways to subsist in our society.

(Huage, Security Officer, Shenzhen, 2011)

Huage's perception of his life reflects the views of the everyday workers interviewed for this thesis $^{78}$ across different industrial sectors in multiple locations in China. I met Huage in the first week of my field trip in Shenzhen's Longhua industrial district in October 2011. He was then 30 years old, short, thin and dark skinned, with greasy and messy hair. Like many other

\footnotetext{
${ }^{78}$ Everyday Workers, see Research Background, pp. 26-27
} 
workers on the streets (see Figure 13) of Shenzhen, Huage wore a dirty, blue uniform with a red security badge on his left arm.

Figure 13: Everyday Workers in China

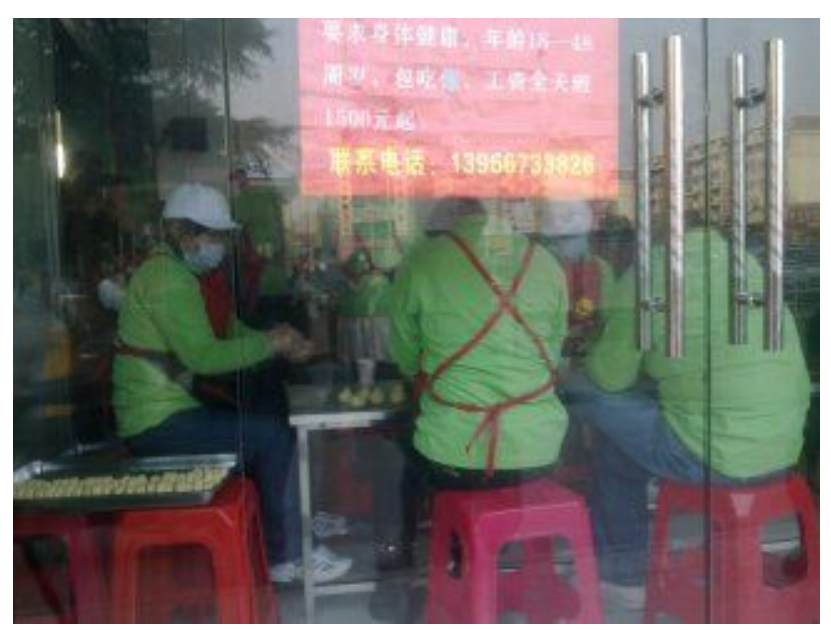

Source: Photo by author

He worked alone on the sidewalk, either standing or sitting in the middle of the walkway outside the massage centre he worked for - which was next to a small eatery I often passed by, or ate at, in the area in which I resided.

One afternoon Huage greeted me when I walked out of the eatery. We made small talk about the weather and where each of us came from. Then he told his story:

I am from a [...] poor village in Hunan Province [...] Our conditions were not good our lives were very bitter [...] we didn't have money; we barely had enough food in our bellies. I didn't like to live in the village and so when I grew up I [decided] to work in the city $[\ldots]$

(Huage, Security Officer, Shenzhen, 2011)

His choice to leave village life was not uncommon for local and migrant peasant workers. For instance, Xiaofong, a 20-year-old waitress, revealed that "I originally had two sisters [in the village in Guangxi Province], but my grandma gave one away because we were too poor [...] we had no money to raise her" (2011, Shenzhen). Daoqing, a 19-year-old former factory worker, said that "we were one of the poorest families in our village [in Sichuan Province] [...] we 
didn't have meat [to eat...] meat was very expensive [...] since I was young I wanted to [...] work in the cities" (NGO worker, 2013, Foshan). Similarly, Yaxing, a 26-year-old IT (or information technology) worker added that "in our village [in Hubei Province], the first thing that came to mind was to go out to the cities [...] this was the only choice we had $[\ldots]$ to make a bit of money to live" (2011, Shenzhen).

These narratives illustrate how precarious peasant life was. The desire to improve their living conditions by escaping poverty had driven approximately 253 million peasants to work in the cities in 2014 (National Bureau of Statistics of China 2015). This phenomenon is one of the dominant themes in Chinese labour studies (Chan \& Pun 2009; Friedman \& Lee 2010; Lee 1999a; Pun, Chan \& Chan 2009; see Chapters Three and Four), which have demonstrated that the prolonged exploitative working conditions experienced by millions of migrant workers has been a striking feature in fostering workers' class consciousness and action against their conditions of exploitation.

Guided by this theme which has dominated the Chinese labour studies (see Chapters One, pp. 16-19; Four, pp. 94-95 and Five, p. 123), working conditions were the focus of many of my discussions (see Appendix 2) with Group One workers. Despite their working lives, I was constantly told during the interviews of their hardships and struggle to access the necessities for daily life, and their dreams of entering the Chinese middle-class by escaping poverty (tuopin 脫貧) (Yan 2008; see Chapter Three, p. 88). While their capacity to pursue those dreams were predominately 'empowered' by household (hukou 戶口) registration mobility - the freedom to reside, visit and work in any area - under the discourse "to get rich is glorious" - since the 1980s (Mallee 2000; see Chapter Three, pp. 73-74), all the interviewees said that their employment opportunities were rather limited in the cities:

I don't have choices [...] it's impossible for me to get a better job. We work because we have to live, and there's no point thinking about whether we like our conditions or not $[\ldots]$ everywhere is the same for us [workers]. Even if I don't like my job [...] I have to do put up with it [...] uneducated people live like this [...]

(Bu, SOE Ready-Mix Concrete Worker, Hefei, 2011) 


\section{A Sense of Self-Marginalisation}

As a result of their lack of education (Chapter Three, pp. 86-87) as perceived by the workers themselves, they consequently marginalised themselves within the low-wage industries by consciously making 'necessary' adjustments and adaptations to any given conditions to maintain their basic livelihoods in the marketplace. Rather than being concerned about an improvement in their treatment and conditions at work, workers' self-perception of the 'lack' in themselves encourages a strong sense of fatalism:

My weekly roster is like nine hours work per day for two days, then one 24-hour shift followed by one day-off [...] I do 24-hour shifts seven times each month [...] literate gao sizhi 高素質 [ 'high-quality'] people are always the leaders above everyone [...] illiterate di suzhi 低素質 ['low-quality'] people are just like mud sitting on the ground for leaders to step on.

(Bing, Hotel Cleaner, Hangzhou, 2011)

Their 'self-knowledge' (Foucault 1966/2005; see Chapter Three, p. 47) of the 'heaven-andearth' difference between 'educated' and 'uneducated' classes of people that instilled in their mindset constituted a status consciousness (see Chapter One, p. 28) among these workers. This status consciousness was arguably the main determinant of disguising them to submit themselves to their poor treatment and working conditions (see Chapter Three, pp. 91-92). The qualifying statement that “illiterate di suzhi 低素質 ['low-quality'] people [...] are just like mud sitting on the ground for leaders to step on" indicated a self-recognition of a subservient status that was linked to their educational deficits:

I know my future - I'll be poor for the rest of my life. Once we're poor, we are always poor $[\ldots]$ Illiterate people like me $[\ldots]$ didn't even complete primary school $[\ldots]$ can only get low-wage jobs. Just like any other dagong [打工 work for the bosses] or gongren (工人 SOE workers) [...] we have to suffer because we have no 'culture' in us $[\ldots]$ that's why we do whatever our leaders want.

(Huage, Security Officer, Shenzhen, 2011)

While education is a primary criterion of stratification in capitalist societies generally, workers' understanding of the 'value' of education implies a strong sense of the Confucian doctrine of a 
'Mandate of Heaven' (tianming 天命) (Cheng 1979; see Chapter Three, pp. 59-61) by equating their low societal positions with the 'truth' of their 'low personal quality' within the high-low status hierarchy as discussed in Chapter Four (pp. 61-62). Thus workers' negative self-image about their 'low-quality' (Xu 2009) was one of the factors that steered them to obey the natural rule of their work leaders in the Chinese occupational hierarchy (see Chapter Three, pp. 8491).

\section{The Practice of 'Voluntary' Submission}

As a result of their hierarchical mindset, most of the interviewees submitted themselves 'voluntarily' to their work leaders by working in 'sweatshop-like conditions', where working hours varied between eight and 13 hours per day without a fixed rest day, despite Chinese labour laws (1995 and 2008) stipulating an eight-hour work day, six days a week, and only 36 hours overtime per month (see Chapter Three, p. 79 and Appendix 1):

We basically work 13 hours a day and we must work overtime every night. [...] Our overtime hour finishes at $9.30 \mathrm{pm}$ - some of us may finish our tasks before $9.30 \mathrm{pm}-$ but we must complete the required overtime hours and leave together.

(Qingjie, Garment Factory Worker, Hangzhou, 2011)

The phrase "we must complete the required overtime hours" used in the above description was one of many examples that exposed a hidden form of forced labour across all types of ownerships in China. Rather than criticising this situation as forms of social injustice or rights violations, interviewees regarded their long hours of exhausting work as 'normal' conditions for 'low-quality' workers to ensure their (and that of their family's) basic sustenance:

[...] workers are just workers - we don't have any rights - because power and rights all belong to the leaders [...] very normal [...] we dagong are so illiterate $[\ldots]$ we cannot do anything [...] 'low-quality' people are like that [...] don't know a thing [...] but to obey our leaders and do whatever we are told - so that we can get our wages and keep our 'rice bowl' [paid work] to live [...] this is what our destiny [ming] is.

(Bing, Hotel Cleaner, Hangzhou, 2011) 
As well as the internalisation of the negative self-images and consequences of being 'lowquality' by workers themselves, the findings suggest that their predefined 'destiny' (or ming 命) (Pankenier 1995; see Chapter Three, p. 90) that was aligned with their low societal status was further constructed by employers' capacity to exercise flexible wage (or floating wage) systems (Hsing 1998) across various industrial sectors in China.

\section{Forced Labour, Wage Flexibility and Overtime Work}

Since the 1980s, 'flexible wage adjustments' were advocated by Deng Xiaoping under his market principle of “distribution according to labour (anlao fenpei 按勞分配) is socialist and not capitalist", as a way to 'reward' workers' 'merits and contributions' (Wilson 2009, p. 129; see Chapter Three, pp. 72-76). Hence, to increase workers' output and performance, wage flexibility was based either on a component of basic wages with piece rates (sometimes hourly rates), subsidies, bonuses and overtime rates, or on subsidies and longer hours with positional wages, as a share of the total wage bill (Hsing 1998). These forms of wage practices give enterprises the capacity to set low base wages or positional wages to make workers work faster over longer hours:

I work about 15 hours a day from $7 \mathrm{am}$ to $11 \mathrm{pm}$ - I work from $7 \mathrm{am}$ to $11 \mathrm{pm}$, I want to work long hours $[\ldots]$ so I can produce more and also to get overtime payment $[\ldots]$ I don't know how I could live on my basic wage.

(Yue, Electronics factory worker, Hangzhou, 2011)

While overtime for most workers exceeded 120 hours per month as a result of wage flexibility, nearly none of the interviewees received adequate overtime payment in line with the legal rates $^{79}$ (Franceschini, Siu \& Chan 2016see Chapter Two, pp. 71-73):

We have to work at least 12 hours a day [...] our overtime hours start after eight hours of work [...] we're all on piece rates during the regular working hours and then we'll be on time rate during the overtime hours. [...] Our earnings are all dependent on the complexity of the styles [...] we earn from $\$ 2$ to $\$ 8$ for an item of clothing [...] but

\footnotetext{
${ }^{79}$ The legal overtime wage rate was set to be no less than $150 \%$ of the regular rates, while holiday overtime was set at no less than $200 \%$ of the regular rates. Hsing, Y-t 1998, Making Capitalism in China: The Taiwan Connection, Oxford University Press, Oxford.
} 
when the style is too complex or I have made it wrongly and I have to remove the stitches to then sew it back, then I might not even be able to make any money for the hour. [...] Sunday overtime work is not compulsory, but I'd better do it [...] and eight hours of work is a must if we work on Sunday so that we can get $\$ 20$ for our work.

(Yejie, Garment Factory Worker, Shenzhen, 2012)

Despite the pufa 普法 and weiquan 維權 campaigns (Benney 2013; see Chapter Four, pp. 99101) had said to exercise to propagate labour laws and legal knowledge to increase the legal rights consciousness (falu wequan yishi 法律維權意識) (Gallagher 2005; 2006; see Chapter Four, pp. 99-101) among the workers, all interviewees seemed to have little sense about their legal entitlement. In this context, all the interviewed workers appeared to have crafted an internal acceptance of the abusive labour practices from their work superiors and authority figures, that was seemingly guiding by a status consciousness among themselves, as in the Imperial and Mao's period (see Chapter Four, pp. 103-115):

"Education is the only thing that can change our destiny. [...] Dagong always have a tough life [...] all I learnt throughout my work experience was to obey the leaders so I can earn enough to subsist. [...] The life (or destiny) of 'low-quality' people like me is very bitter (mingku)."

(Fang, Garment Factory Worker, Hangzhou, 2011)

\section{The Destiny of 'Low-Quality' Workers}

The word mingku 命苦 (or bitter destiny) associated with the phrase “... all I learnt is to obey the leaders so I can earn enough to subsist..." indicates their frustration and everyday struggle over their lives under a 'common sense' notion of inferiority in 'low-quality' workers. However, their acceptance of this prearranged inferior destiny since the Imperial China was generated by the workers' self-degradation, which led them to behave 'properly' towards their work superiors by accepting any work conditions in the post-Mao period (see Chapter Three, pp. 56-91):

I work 12 hours a day from 8am to 8pm [...] I don't have a day-off [...] and I could 
earn up to $\$ 1,300$ a month ${ }^{80}[\ldots]$ not quite enough live on, but I only have to do the cleaning work and do whatever my boss wants me to and that's all [...] for someone who is so uneducated to have a job like this I feel very lucky.

(Yang, Motel Cleaner, Hangzhou, 2011)

Given the prevailing mentality regarding a status order of 'educated (high) - uneducated (low)' (see Chapter Three, pp. 84-92), social relations were perceived either as superordinated or subordinated to the extent to which the 'low-quality' of workers themselves was the key factor confining them to think that only certain types of jobs were available to them (Leung \& Caspersz 2016). This mentality guided workers to subject themselves to any given conditions in an occupational hierarchy:

I know all of us have to sign a contract [...] so our work leaders got us to sign on a piece of paper that we were not allowed to read. [...] When our work leaders were not looking at us then some of us looked at the contract but there was nothing written on the paper. We signed the paper anyway [...] we didn't have to know what we'd signed because we must do what our leaders want anyway.

(Shao, Garment Factory Worker, Hangzhou, 2011)

It is argued that workers' awareness of their submission to the 'rights' or the 'mandate' of those higher than them has further induced enterprises to continue to exercise exploitative and illegal labour practices as Chapters Three (pp. 73-76) and Four (pp. 101-112) have illustrated:

[...] when we renewed our contracts, we had to sign an additional clause in the 'mistake' section to indicate that we agreed to have our wages deducted when one or more team members was injured or contracted occupational diseases, because these sorts of abnormal things only occur when someone makes mistakes. [...] We all understood that we had to make no mistakes at work.

(Qing, SOE Car Factory Worker, Hefei, 2011)

Besides occupational injuries and illnesses, the findings suggest other types of mistakes,

${ }^{80}$ Legal Minimum Wage was set at 1,310 Yuan a month in Hangzhou in 2011 
ranging from refusing to work overtime to improper work postures, which were also defined as abnormal behaviour (Foucualt 2001) across numerous workplaces. In this context, all the respondents mentioned that they had to 'train' their bodily movements to fit into the prescribed destiny (ming) to perform 'normal' work behaviour (see Chapters Two, pp. 45-47 and Three, pp. 90-92) in order to avoid potential wage cuts:

My task is to wipe the screens of the mobile phones [...] I must follow our normal procedures [...] I must ensure that I only wipe once - horizontally from the left to the right of the screen - and the screen has to be clean. If I wipe it twice or do it vertically then it's a mistake and I would get a work fine because I wiped the wrong way and slowed down the production.

(Yanam, Foxconn Worker, Shenzhen, 2011)

Coupled with disciplinary wage cuts, humiliating measures were also used to control the behaviour of workers in order to maximise their efficiency at work:

Apart from paying our fines, we are also required to stand at the door and read out the company's rules and policies, such as the types of mistakes we shouldn't make at work, in front of the other workers.

(Ge, SOE Car Factory Worker, Hefei, 2011)

As a result of the disciplinary practices, all the interviewed workers reported that they had to perform their work tasks according to the 'prescribed' normal routines by moving in conformity to the correct, mechanised manners (Smart 1985). Despite the potential punishments, the findings suggest that their guilt feelings strongly directed their commitment towards the work routines:

I got a 100 yuan fine just a few days ago [...] I ordered the wrong materials [...] and our production was disrupted for half a day because of my mistake. We all have to bear the economic responsibility of the mistakes we make, because making mistakes means a profit loss for our company and so we should cover any financial loss we caused [...] I personally feel guilty when I make mistakes.

(Bu, SOE Ready-Mix Concrete Worker, Hefei, 2011) 
Rather than complaining about their work penalties, the workers' discourses indicated that their guilt feelings evolved from their failure to meet the 'prescribed' routines that made them accept the punishments 'voluntarily' and to maintain the 'mandate' of the work leaders to rule them in the occupational hierarchy (see Chapter Three, pp. 84-92). It is suggested that the ways in which workers' thought and felt about their 'wrongdoings' were generated by their concern over the fact that their behaviour deviated from the normal practices of their positioning - both self-positioning and being positioned:

[...] if we put the wrong accessories into the trolley then the production workers won't be able to find the correct items to build the cars. Last time I made such a mistake, causing a seven-minute disruption on the production line. Our company rule is that if any of the line is stopped for over 3.5 minutes then we'll get a penalty of $\$ 20$ for each minute. It's not the penalty that bothered me [...] I felt really bad about disrupting the entire production by making such a stupid mistake [...] so I stood up and apologised to everyone and the leaders for my disobedient act.

(Ge, SOE Car Factory Worker, Hefei, 2011)

Such self-directed confessional acts (Foucault 1978; see Chapter Two, p. 48) by workers demonstrate a high level of obedience (or docility) arising out of their truth (or knowledge) about the expected performance of their particular positions. This truth can occur only in conjunction with the social structures and norms through the internal relationships that the workers engage in (Evasdottir 2004; McKinlay \& Taylor 2014). As a result of these social relationships, the workers became cultivated bodily and spiritually as a self-directed means of alteration and betterment in upholding their shared normal standards of behaviour (Faison 2007) under the doctrine of similarity to judge and correct their actions and others' (see Chapter Three, pp. 61; 85-93) within their given positions.

\section{'Positive' Punishments and Doctrine of Similarity}

The findings support the discussion in Chapter Three (pp. 85-93) in illustrating that the notion of similarity among the workers in all the workplaces has effectively softened their negative view of the disciplinary and punitive measures. A Foxconn worker, for example, shared his thought about being forced to write confession letters concerning the mistake he made at work: 
I once dropped a cloth on the floor and my work leader made me write 'I'll never drop the cloth again' fifty times. It's in this way I will not - at least I'll try not - to make the same mistake again. This made me always remember not to make mistakes again.

(Yanam, Foxconn Worker, Shenzhen, 2011)

Similarly, workers in other enterprises also expressed a positive perception of the disciplinary measures, even when their work leaders abused them:

In most factories, workers are not allowed to chit-chat with one another $[\ldots]$ we should not chat anyway because we are there to work to earn more money $[\ldots]$ anyone of us who are slow on the production line deserve to be punished and yelled at because being slow is affecting our entire workflow.

(Xun, Lift Manufacturing Worker, Hangzhou, 2011)

While oppressive, the findings demonstrate that the workplace disciplinary systems functioned as a positive technique of normalisation (Foucault 1977; see Chapters Two, p. 47 and Three, pp. 84-86) that socialised the workers from within.

\section{The Disciplinary Techniques of Normalisation}

The disciplinary techniques of normalisation operated as a specific apparatus of knowledge (Foucault 1977; see Chapter Two, pp. 44-47) within the mindset of the workers thereby enabled them to examine and judge the immoral behaviour of themselves and others:

[...] it's teamwork; so if anyone of us is injured because of someone else's careless mistakes, then all of us in the team will get a wage deduction. We have to make sure no mistakes are made at work. Also, all of us in the team must be healthy and must contract no occupational diseases, like skin or eye problems, because these sorts of mistakes will also incur a penalty on all of us.

(Qing, SOE Car Factory Worker, Hefei, 2011)

The natural consequence of the normalising judgement thus provided a necessary condition that 'prohibited' workers from complaining about their work-related issues:

I used to operate a machine to cut short the edge of the snack food bag and then seal it 
[...] That day, a bag was dangling on the machine and so I grabbed the bag - it's at that moment the machine squashed two of my fingers [...] you know we are all uneducated and we don't know a thing [...] so occupational injuries are a very normal thing that happens to us when we made mistakes.

(Daoqing, Food Processing Worker, Foshan, 2013)

Their self-knowledge about themselves as uneducated, unknowing and mindless had profoundly stabilised the normative function of constituting a normal experience (Foucault 1977; see Chapter Two, pp. 46-47) and destiny (or ming) (see Chapter Three, pp. 84-92) for themselves as 'low-quality' workers in their social relationships:

My working environment was very smelly and dusty [...] sometimes the dust was yellow, sometimes it was grey, but most times it was black [...] A few workers at work were sick and then they never come back to work. I never wear a face mask [...] no one is wearing one at work and I don't want to look odd [...] Getting sick from work is a normal thing for most of us [...] our ming is bitter, isn't it?

(Rong, Tyre manufacturing worker, Hefei, 2011)

While recognising that their lives and health were potentially endangered by their working environments, most of the workers demonstrated an internal acceptance of these threatening conditions as part of their normal destiny (or ming) (see Chapter Three, pp. 90-92). Hence, despite it being their rights to enrol themselves in the social insurance scheme for medical needs and to refuse to work in the unsafe conditions under the Chinese Labour Laws (ACFTU 1997; Lehman 2008), most of the interviewees felt that these rights were not relevant to them:

[...] those are rubbish [...] how could I not work in unsafe working environments? All working environments are dirty and unsafe for 'low-quality' people [...] what do you think we are? You think we can choose where we want to work and can refuse to work in dirty, dangerous areas? [...] all of us working here don't have social insurance [...] we only earn $\$ 70$ a day and we have to budget our daily expenses [...] why would we want to pay for that insurance? [...] Low-quality is low quality - low-quality people live like this. 
Given their perception of their low societal status, the thought of themselves as 'low-quality' had become a foundational reason for all the interviewed workers to continue to behave properly to fit into their given positions. Most appeared to be willing to abandon any sense of reclaiming their legal rights with regard to matters such as long working hours, forced overtime, deductions from their subsistence wages, and even occupational health and safety:

...compared to others - mine was just a very small matter [...] it's not like I was dying or anything [...] some workers lost their whole arms or all their fingers at work, but I lost only two fingers so I was quite lucky. Imagine if I had lost my whole arm or leg. I wouldn't even have been able to find a job to earn a living. I feel that occupational accidents and illnesses are just some kind of normal things that are destined to happen to the low-quality people [...] it's just a matter of when.

(Daoqing, Food Processing Worker, Foshan, 2013)

\section{'Normalising' the 'True-Selves'}

By accepting the above conception of 'truth' about themselves, the thought of quality had become an essential construct in determining not only the identities (or positions) of the workers, but also in creating and manufacturing their 'true-selves' through their destiny. This was in turn associated with a view of socially accepted normal behaviour among those considered as 'low-quality'. These elements worked to shape workers' desires, health, lives, habits and moral worth to then guide them to move towards the norm:

I don't want a contract because I don't understand the content of the contract [...] I don't know what should be listed in the contract [...] just in case I am signing something that is harmful to me. [...] You know, illiterate 'low-quality' people don't know anything, so most of us don't care about things like contracts [...] we have no rights anyway.

(Min, Springs Manufacturing Worker, Hangzhou, 2011)

Rather than being forced or threatened into compliance with external (or capitalist) demands, the 'moral sense' of the workers as a community of 'low-quality' sub-individuals had become 
a major instrument in steering them to repeatedly perform in the prescribed 'proper' manner (Ransom 1997b) within their given positions. The cumulative effect of their repetitive behaviour thus approximated the normative and regulatory ideal among the workers and had essentially subjected them to vulnerable, exploitative and abusive conditions:

I didn't sign the contract [...] the leader promised to pay me 30 yuan for an eight-hour shift each day during the probation period. I worked with another six new workers for two days. On my second day of work yesterday, seven of us were called to get paid in our leader's office. We went in there, sitting in his office for about half an hour [...] we didn't get our pay so I went up to the leader and politely asked him for my wages [...] He beat me up straightaway and ordered the other security officers to smash me altogether $[. .$.$] and then I was ordered to leave.$

(Minge, Security Officer, Hefei, 2011)

Even though he had been denied his wages and even suffered physical abuse, the above respondent, like many other workers, demonstrated his commitment to the standardised conditions in accordance with his given position:

[...] my boss owed me $\$ 60$ altogether for my two days of work but I know I can’t get it back [...] I called the police officers after getting beaten up [...] they said they couldn't do anything about it but told me to have a medical check-up at my own expense if my wounds were too painful. I only had $\$ 500$ in my bank and I took $\$ 400$ for a checkup. When I got to the hospital I realised it would cost at least $\$ 700$ to check all my injured areas. I didn't have enough money so I skipped the medical examination of my face, neck, upper and lower back - I only got a check-up for my chest and stomach. I think security officer work isn't for everybody [...] I'm just an illiterate old man. I don't know a thing [...] I will try to find some small factory jobs and hopefully I won't have to experience the same thing again.

(Minge, Security Officer, Hefei, 2011)

Given the tremendous harassment, mistreatment and abuse that the workers experienced routinely in their daily lives, some subsequently adopted an orientation of 'exit', rather than attempting to improve their working conditions: 
I kept quiet while I was waiting and hoping that my boss would give me back the wages he owed me one day. You know my boss didn't pay me wages for around three months, from August [2011] until now [October]. I didn't say anything about it but just continued to complete my work tasks, because I didn't want to ruin my working relationship with my boss and maybe my leaders - I didn't want to get revenge at work or to lose my job [...] I decided that if I didn't get paid for a few more months, until no one else wants to lend me money to live, then I will have to quit the job and work somewhere else $[\ldots]$ we are very flexible [...] and our jobs are forever temporary; nothing permanent $[\ldots]$

(Yaxing, IT Worker, Shenzhen, 2011)

By defining their employment as a temporary phase in their lives resulting from the typical 'exit' orientation, most of them realised there was nothing much better waiting for them when they left their jobs:

I thought about quitting this job many times $[\ldots]$ but I have nowhere to go [...] I worked a few places previously [...] and to me all jobs are just about the same for any lowquality people like me - the working conditions, treatment and the earnings at all the jobs I could choose were quite similar to one another. Like this young migrant [pointing at a girl] in the sewing line, we didn't even complete junior high school - what sort of better jobs and opportunities do we have? What are our options? We have a huge population in China but the quality of most of us is really low. Low-quality people aren't even worth a cent [no value] and that's why we can't get better jobs with better pay and conditions.

(Qingjie, Garment Factory Worker, Hangzhou, 2011)

The evidence suggests that the self-degradation of the self-value among the 'low-quality' workers undermined their will to attempt to improve their treatment and conditions at work, as well as their positions as workers and their rights as human beings in general. This mindset further strengthened their sense of 'normality' as the workers confirmed their given identities through their 'norm' of performance: 
I have to put up with my own conditions like everybody else [...] I'll just do whatever my leaders want me to $[\ldots]$ it's even $[\ldots]$ say to clean the toilets. Work leaders have every right to ask the dagong to do anything because we're getting paid to work. We have to listen and obey our leaders and we also have to show them our ability to complete many tasks, even if those are extra work. You know, one of our co-workers got fired because she told the leader she didn't want to do extra work [...] who did she think she was? She's just a low-quality dagong but being so disobedient she deserved to lose her rice bowl [job].

(Xiaoqin, Cosmetic Sales Assistant, Shenzhen, 2011)

The emphasis of workers' punitive rationality and their conscious rejection of deviation from the 'norm' was attributed to the 'disobedient act' (or direct challenge) to the authority figures by those categorised as 'low-quality' within the superior (high) - inferior (low) relationships (Lai 1995; see Chapter Three, p. 60). This practice thus reflects a successful internalisation of the 'inferiority' (or status) consciousness within the workers, leading them to regulate their own behaviour and that of others to become the persons they ought to be within their social and historical setting. Workers thus became entangled in automated and disindividualised power relations, because their choices of action (or individualisation) were "proposed, suggested, imposed upon [them] by their culture, [their] society and [their] social groups" (Foucault 1997, p. 291).

\section{The 'Selves' and the Everyday 'Carceral Network'}

The mental acquiescence of most of the interviewees to their conditions further suggests that their experience and perception of their selves as 'low-quality' was maintained through their interaction with people, history and culture in the social relations in their everyday 'carceral network' (Schrift 2013; see Chapters Three, p. 93, and Four, p. 128). Institutions of normalisation are to be found within this 'carceral network', such as schools providing moral education and organisations offering assistance for moral improvement, to discipline the entire social body (Smart 1985):

We won't discuss our grievances with our work leaders [...] but Foxconn is very good because we have Wang Mama Hotline and so all of us can speak to the counsellors at 
the unions about anything we want. I rang up Wang Mama Hotline once because my work leader was either swearing at me or punishing me because I didn't stand or sit properly at work, so I was feeling a bit upset. The counsellor said I was very lucky that Foxconn hired me because my quality is better than most of the Chinese workers. She said that's why I earn a bit more than many other workers and that our leaders were a bit harsh on us because they wanted us to improve to become better workers. [...] She's right because the quality of the leaders is higher than us - that's why they're our leaders [...] I felt much better after talking to her.

(Xiaoyuan, Foxconn Worker, Shenzhen, 2011)

Within the everyday 'carceral network', the findings suggest that judgements, assessments and diagnoses of the Chinese institutions, organisations and the workers themselves were implicitly made up of the hierarchised 'high-low' quality discourses intended to achieve a restoration of the norm:

Last time my co-workers found out we earned 200 yuan less than other factory workers, so they went to talk to our trade union officials at work. Our union officials said that it was because the workers of other factories were of a higher quality than us and so they were able to earn a bit more. The officials also said that we could also earn that extra 200 yuan or more if we worked faster to exceed our work quota [...] They're right about this because this is how the 'low-quality' people earn a living in China - it's just the way it is.

(Ge, SOE Car Factory Worker, Hefei, 2011)

As well as the enterprises and the State-run trade unions in the workplaces, non-government labour organisations (or labour NGOs) also acted as educators to teach and correct workers' thoughts and behaviour to neutralise (or normalise) the technical power of discipline:

[...] workers only came to see us for their unpaid wages, and none of them came here to sort out their working conditions [...] I mean you might think that their conditions were horrible but the workers feel fine about it $[\ldots]$ we're all in the same boat and we all know that there is no way to improve our conditions for better treatment or better rights at work - we won't get what we want anyway so why would anyone bother to 
think about all this? We talk to the workers sometimes when they feel upset; you know, sometimes the work leaders are very difficult to please. I just told them to improve themselves to make their lives easier.

(Tai, NGO Worker, Hefei, 2011)

Thus, while labour NGOs played a significant role in filling the missing role of the State-run trade unions in protecting workers' rights as well as nurturing their labour rights' consciousness under weiquan discourses (see Chapter Four, pp. 99-101), daily work issues faced by everyday workers were often ignored by these organisations. This is because most of these organisations relied on international foundations for funding whereby these foundations tended to support the most vulnerable and exploited groups of workers, for example, occupationally injured or diseased workers:

Our centre is sponsored by one American foundation since 2007 [...] they fund our centre USD550.00 [approximately 3498 yuan] a month. This money covers the rent and equipment like the computers for the centre and our wages. We must run a number of legal seminars each month [...] and provide legal consultation so we explain to the injured workers how to assess grades of injuries and litigation procedures [...] Workers have to pay the litigation fee for themselves; it's very expensive [...] from 220 yuan to 3,800 yuan - the more they earn the more they have to pay. We decided to collect as many signatures as possible to try getting the Local People's Congress to cancel the fee. But no one wanted to get into this sort of trouble [...] I ended up spending a day in jail with another NGO worker [...] the police officers said that we were intensifying conflicts and disrupting social stability [...] we were on the news [...] Our sponsor had since decided to cancel all the projects with us next year [2013]. We may have to close down as we have no money to run the centre.

(Mr Zhang, NGO Worker, Shenzhen, 2012)

The withdrawal of the overseas funding from those labour NGOs that had their activities beyond the scope of the CCP rules illustrates that the State had successfully channelled international support for NGOs towards the practices of legal rights protection (weiquan) in the form of individual litigation: 
I think we are the only NGO that can represent the workers in court because we're lawyers [...] but we encouraged the workers to resolve their issues directly with their employers and we taught them the ways to deal with the employers. It is only when that didn't work then we would lodge legal claims [...] but we have to be very careful and we don't want to represent more than one or two workers who worked in the same company because we don't want to make it a collective case [...] Last time there were 5 injured workers from the same company - their boss refused to payout the injured compensation and they wanted to take the boss to court [...] Too many of them from the same company [...] this is something the government considered as threatening social stability [...] and so if we helped them, we might be in trouble [...] and our funder will not collaborate with us $[\ldots]$

(Li, Law Professor, Hefei, 2011)

The discourse above has implicitly showed that despite weiquan 維權, international funders were primarily committed to the CCP's project of maintenance of social stability (weiwen 維 穩) according to what they understood as the law-abiding activities in China (see Chapter Three, pp. 79-80). This commitment had thus profoundly influenced not only on the NGOs' day-today operations, but also on the NGOs' workers' attitudes and behaviours. One result of which had been that they made little or no effort to engage in any activities beyond the norm:

I don't care about the workers and I'm not interested in knowing how they live everyone lives this way. It's not my job to think about their conditions or their rights what sort of rights do the low-quality people expect to have? They have no rights; they won't have anything better unless they improve their quality if they want to make their lives easier - I really don't care. My job is only to provide legal advice to those who come to see us about their issues, such as unpaid wages or occupational injuries; but otherwise I don't care about their little things.

(Yu, NGO Worker, Hangzhou, 2011)

In line with this view, the interviewees revealed a preoccupation with and conformity to the implicit cultural norm that sought to control the manners of all their 'little things': 
We don't have employment contracts; only the leaders have the contracts - we don't have anything - so our work leaders can fire us anytime they don't want us and the factory doesn't have to pay social insurance for us. I know what they do is illegal and we can lodge a complaint with something like the labour bureau and I also called nonprofit organisations, but what's the point when everywhere is like that? Laws are something for rich people, not for poor people. We have to bear with the consequences of going against the leaders - we will lose our jobs and be black-listed forever from the labour market.

(Lei, SOE Ready-mix Concrete Worker, Hefei, 2011)

\section{Self-Control and Others at the Lowest Level}

The thoughts and behaviours of the workers about their societal positions represented an accumulation of a vast network of discourses on 'quality' to control themselves and others in a constructed hierarchy (see Chapter Three, pp. 90-92). The evidence highlights that this control method had been internalised as general practice among the workers and constructed a status consciousness within themselves at the lowest level of society:

I think the quality of China's education system might not be so good. That's why some rich parents send their children to somewhere else, like Hong Kong, to study. I don't know about the difference in terms of the quality between China and other countries [...] I feel that our grades are not equivalent to the effort we put in. It's about the behaviour that our teachers wanted to see. If we behaved properly, like respecting the teachers by greeting them each time we saw them, then we could get better grades [...] It's just like the way we have to treat our parents.

(Zhi, Foxconn Worker, Shenzhen, 2011)

While the control methods were seemingly different from the Imperial period (see Chapter Three, pp. 56-61), their knowledge about themselves had still emphasised on the proper behaviour of respect for superior and authority figures in their hierarchised social relations. Implicit in this practice is the fabrication and production of useful and docile workers through minute forms of correction, training and retraining the minds of children in their social lives: 
I grew up in a poor family in the village and we had to do farming work to maintain our living - we grew fruits and vegetables - and we had chickens and ducks too but we didn't usually eat them before Chinese New Year, because meat was very precious to us. Sometimes when I tried to avoid working on the farms or contradicted my parents they would beat me; when I did what they told me then I usually got to go out to play with the other kids and sometimes I got to eat meat. I was so naughty back then; we should always do what our parents want - it's just the rules in our culture that we all followed.

(Tai, NGO Worker, Hefei, 2011)

A prolonged training and retraining of a large group of people to perform various activities in repeated motions and movements in accordance with the particular rules had constituted specific mindsets within the workers:

[...] it's just a normal practice for us to do whatever our parents want because they're our seniors (superiors) [...] like I married because my parents had organised this for me - it really didn't matter if I liked it or not because all parents will have to organise marriage for their kids - we just have to obey their decisions. I wanted to divorce my wife because I found out she had an affair with someone else using my money. I told my parents but they didn't allow me to divorce because this is too abnormal for our family.

(Xun, Lift Manufacturing Worker, Hangzhou, 2011)

The hierarchical environment thus created a receptive psyche within family life to implant a sense of fatalism within the workers that was ultimately generated from their loyalty to their families in their original home villages:

[...] we must look after our parents when we grow up because they spent a lot of time and money on us when we were young, so it's our turn now. That's why I had to come to the city to work, and I can send them more money so they can have meat and also fix the roof of our house in the village. It's my turn to look after them and to maintain or, even better, to improve their living conditions [...] They're getting older and they can't do farm work anymore. 
The findings further suggest that commitment to their impoverished families had ensured their submissiveness and filial behaviour (Faison 2007; Javeline 2006) in their workplaces:

"I earn 1,450 yuan a month [...] I only allow myself to keep 200 yuan [...] I've got two kids in the village [...] I'm the only one to support my family, my parents [...] and also the family of my late husband [...] We dagong are like this [...] we have to look after ourselves and also our families [...] so most of us tolerate any conditions in the cities [...] we don't have any other choices."

(Chong, Motel Cleaner, Shenzhen, 2011)

\section{The Other as Self-Responsibility}

To support their suffering families, most of them sacrifice themselves by enduring the travails of work in the cities. The workers' sacrifice for their families thus underpins the link between their rightful positions and unique responsibilities (Foucault 1987; 1997; Smart 1998) in a close relationship that forms part of the condition of their constitution:

[...] my husband and I earn very little [...] only 2000 to 3000 yuan a month [...] very tough [...] have to be extra careful when we spend our money [...] we have to pay tuition fees for our boy and also give money to parents of both families [...] altogether they need around 20,000 yuan a year [...] we need to save up at least 1,500 yuan each month [...] no choice; taking care of the family is the normal responsibility for most of us in China [...] that's why we come out to dagong.

(Wang, Motel Cleaner, Shenzhen, 2011)

In order to 'maintain' their responsibility, most of the interviewed workers had become a hostage of their families by subjecting themselves to poor conditions in the cities:

I know this metal-shed dormitory is very small and so we have to keep our suitcases and other belongings on our beds. But we don't have a choice because we are only earning 70 yuan a day and we can't afford to rent a flat for ourselves elsewhere. Living in this dormitory is much cheaper - each of us has to pay only 100 yuan a month and all the utilities are included [...] although it's extremely dusty we don't have to spend 
additional money and time to travel to and from work [...] and we can save much more money for my wife, my kids and parents in my village.

(Cai, SOE Ready-mix Concrete Worker, Hefei, 2011)

Apart from reducing accommodation expenditures, a large proportion of interviewed workers revealed that they had to consume low-quality food to minimise their spending in order to support the financial needs of their families:

"I only have my daily lunch at the canteen when I am at work because their food is too expensive. I earn around 2000 yuan a month and I have to pay 300 yuan to our canteen at work, so that is about 10 yuan each time I eat at the canteen. I can only choose vegetable dishes because meat dishes are way too expensive [...] I have my dinner elsewhere because we're not allowed to cook in the dormitory [...] eating out is not cheap. It costs me 6 yuan for a bowl of plain noodles. But only in this way I can save a bit of money for my family - everyone does this in China

(Yanam, Foxconn Worker, Shenzhen, 2011)

All the interviewed workers appeared to maintain themselves by engaging in the socially accepted moral and ethical practices that constituted and were embedded in their social networks (or power-knowledge networks):

Being a worker is not good [...] we're just a bunch of uneducated people. We can't do any other things apart from working or staying in our dormitory because we don't have spare money. We must put up with whatever hardships we have; we don't have time and we don't have energy to think about any other things but our subsistence - this is our only right and our only concern. We only want to make enough to subsist and support our families.

(Yaxing, IT Worker, Shenzhen, 2011)

Their direct encounter with their constructed 'true selves' (or not selves) when they upheld the 'truth' about their status of 'degradation' and continued to take on responsibility for others had ingrained the attitudes of passivity and vulnerability in the core of their subjectivities (Foucault $1977 ; 1978 ; 1982)$. This subsequently became the 'true' characters and personalities of the 
workers, who worked to serve the interests of their employers and eventually the will of the Chinese State to maintain a docile labour force within the Confucian-orthopraxy system.

\section{Concluding Remarks}

Rather than reflecting the 'universal' view that resistance activity is undoubtedly motivated by their exploitative experience as a class, the workers' discourses reflected that the possibility of class action was undermined by their shared perception that 'subsistence' was all that they were entitled to in their daily lives and lived experiences as 'low-quality' workers. It is argued that these experiences were culturally constituted by the Confucian 'truth' about their social status through 'quality' discourses regarding the workers place in the hierarchy of relationships. As Chapter Four argues, the findings here show that their 'low-quality' due to their lack of education was their particular 'self-knowledge' that guided them to accept their given conditions because of the lower status that they occupied in the 'quality-based' occupational hierarchy. Their self-governance (or automatic docility) illustrated the effectiveness of the making of docile bodies and minds through their encounter with themselves and others as responsible in a relationship of proximity within the Confucian-orthopraxy system. The findings thus inform the research focus and propositions that workers' willingness to engage in activism to improve their conditions is constrained by a status consciousness within Chinese occupational hierarchy.

While the Chinese mentality and their sense of responsibility for others constrained the workers' perceptions and experiences, Chapter Seven explores how self-care practices (Foucault 1986) by these workers opened up possibilities for them to break out of the totality of their constituted experiences by engaging in critical thoughts to then improve their living and working conditions within their power-knowledge relations. 


\section{Chapter Seven: 'Beyond' the Selves and Reflective Docility}

I don't believe there can be a society without relations of power, if you understand them as means by which individuals try to conduct, to determine the behaviour of others. The problem is not of trying to dissolve them in the Utopia of a perfectly transparent communication, but to give one's self the rules of law, the techniques of management, and also the ethics, the ethos, the practice of self, which would allow these games of power to be played with the minimum of domination.

(Foucault 1987, p. 18)

The aim of this chapter is to present and discuss the two phases of empirical data elicited from 22 everyday workers in Group Two - those who had engaged in protest activities - that was deliberately collected at multiple locations, mainly through contact labour NGOs in Hong Kong and Guangzhou Province in China between 2011 and 2014. This body of data illustrates that, while protest activities by everyday workers open a space to transform the way they relate to themselves and to each other and to their conditions, these possibilities are conditioned by their cultural knowledge. This is because, according to Foucault (1982), 'being a subject' is possible only within the power-knowledge networks, and thus meaningful and effective resistant actions are always inherent in that particular context of concrete constraints traversing in society. While historically constituted, Foucault insists that the subjects can deconstruct a part of themselves by actively modifying their manner of action and mode of being through practices of the self (or care of the self) $(1986 ; 1987 ; 1997)$.

Drawing on 22 interviews from Group Two, in this chapter the cultural dimension of how 'care' or 'concern for oneself' becomes a particular goal that potentially modifies the behaviour and modes of living among the workers within the Confucian-orthopraxy system is examined. This chapter begins with a presentation of both the given conditions and oppression that the workers experienced in their daily lives. These experiences were inexorably intertwined subconsciously with the 'quality' discourses that guided workers to perceive themselves as 'low-quality sub- 
individuals' by accepting any given conditions, as with their Group One colleagues in the occupational hierarchy. The workers' accumulated feelings about their prolonged experiences of low status and poor conditions were a major determinant in shaping their oppositional thoughts towards their superiors and authority figures. These thoughts were further sharpened when the workers articulated their intense feelings about their daily experiences among themselves and they reinterpreted an alternative discourse and 'truth' about themselves through their participation in social and cultural activities. This chapter demonstrates that their involvement in these activities contributed to implanting a sense of 'togetherness' within them, which then acted to spark spontaneous embryonic trade union consciousness (Chan \& Siu 2012) and increased their solidarity to mobilise resistance activities. However, their actions were predominately guided by a status consciousness that was arguably preconditioned by their sense of deservingness with respect to subsistence and sustenance matters for themselves (and their families) within the limits of their perceptions of 'normality' within their given societal positions. Thus, while their emotions had spurred up their oppositional spirit, the effectiveness of their protest actions was undermined by their self-care practices within the 'normative' descriptions in China.

\section{The Tears of Yayi 壓抑}

One early morning in December 2013, I was invited to interview seven State-employed street cleaners (see Figure 14) at the labour NGO in Foshan, Guangdong Province.

Figure 14: State-employed Street Cleaners

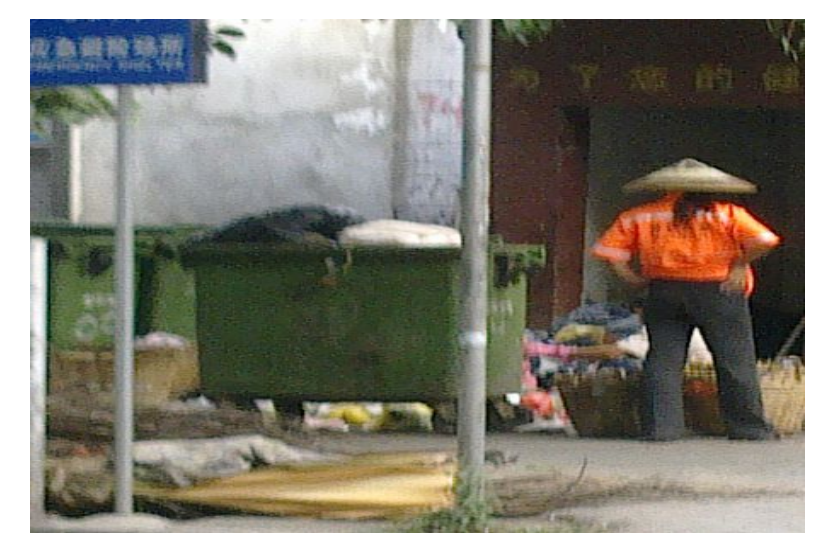

Source: Photo by author 
I was told that some of these cleaners had taken a few hours off from work to attend this interview because they were eager to discuss their thoughts about their second attempt to protest against their working conditions. When I arrived at the NGO office and was waiting for the rest of the cleaners, one cleaner with strong body odour suddenly burst into tears while debriefing me about their situation:

I've been working for this danwei 單位 [work unit] for 10 years but the money I earned over those years wasn't even enough to buy a toilet bowl. Everyone who decided to come here today has been trying to spend money carefully because we have no money to waste. I came out to work in the city because I pictured myself being able to save up a bit of money so that I don't have to worry about my living when I get older. This was just a dream - a dream is a dream - it will never happen [...] because di zuzhi 低素 質 [low-quality people”] are destined to do low-pay dirty work but we should be allowed to make enough to eat rice [feed themselves]; we feel very yayi [repressed 涯 抑] deep inside [...]

(Yao, SOE Street Cleaner, Foshan, 2013)

A recurring theme that emerged when this group explained their motivation for engaging in the resistant activity was their collective concern about their minimal subsistence and sustenance levels (see Chapter Four, pp. 96-119). Like their colleagues in Group One (see Chapter Six), their self-knowledge about themselves as low-quality ( $d i$ zuzhi 低素質) people was a determining factor in accepting any given work conditions as their destiny (ming 命) in exchange for subsistence (see Chapters Three, pp. 90-91; and Four, p. 119). Their daily experiences of deep frustration, resentment, anger and sorrow over the continual struggle against the difficulties to maintain their 'right to subsistence' (shengcun quan 生存權) (Chen 2000; see Chapter Four, pp. 102-104) - the only deservingness as being low-quality workers were described as yayi (repressed 壓抑) by all the interviewed workers. Thus, yayi is a concept of long-accumulated emotional feelings of contradictions, involving both their passive acceptance of their given situation as their destiny (ming) (see Chapter Three, pp. 84-91) and a desire to overcome or to work against that situation. 
The mixture of these intense feelings of yayi was frequently verbalised by the workers to interpret their anger, frustration and resentment (Pun \& Lu 2010; see Chapter Three, pp. 110111) about their everyday lives. Min, for example, a 36-year-old worker, revealed the treatment he experienced at work: "I know as a worker I don't have any rights and so it is up to work leaders to muck me around whenever they like. I worked very long hours and they paid me so little that I could barely survive - you know I feel so yayi when I go to work and then I have to repeatedly think about my next bills when I am home" (Springs Manufacturing Worker, Hangzhou, 2011). Shen, a 24-year-old worker, spoke about his yayi about not having received more education: "I'm so illiterate that I can't have a better job to marry anyone [...] my life is already yayi [...] my earnings are so low and it'll be really hard for me to look after a family [...] I can't even look after myself" (Lighting Factory Worker, Shenzhen, 2011). Xiaoling, a 30 -year-old masseuse, interpreted her deeply felt yayi that she shared with her fellow workers over the constant deductions from their subsistence wages:

[...] our team leaders deduct money from our wages for nearly everything [...] like when we are doing overtime with the client(s) in the room; or whenever a client puts in a complaint about us; or if we eat the food that the clients offer us. You know each mistake is going to cost us between 300 and 500 yuan - our monthly earnings are already so low - one work fine is equivalent to at least two weeks of our wages! We are so yayi when we have or even don't have clients; we are so yayi for trying not to make mistakes; we are so yayi when our wages are deducted; we are so yayi to earn our living when we actually have a job to do and we worked for so many years!

(Xiaoling, Masseuse, Shenzhen, 2011)

Despite emotional feelings towards the inhuman treatment they faced at work in exchange of minimal subsistence wages for survival, they also used the word yayi to describe their nonwork personal lives under the weight of their daily hardships. A 33-year-old jewellery worker who was suffering from leukaemia elaborated this:

I was diagnosed with leukaemia [...] not long after our first strike [...] in 2007 [...] My wife left me as well as our [twin] boys [...] since then because she didn't want to 
waste her time a sick person [...] My boys live with my parents in the village [...] I only saw them a few times since they were born [...] I'm so sick I can't travel a long way to get back home to see them and yet I also can't look after them in the city. I have to go to the hospital nearly every day [...] The boys are 7-year-old; I could only speak to them on the phone over the past years. I always feel yayi when the boys talked to me like they are talking to a stranger rather than to their father, though I also have nothing much to talk to my boys. It feels like I have no family and no one [...] I feel so yayi my life is all about going to work and to the hospital [...] I feel so yayi to live [...] I sometimes feel like to put an end to it [...]

(Fa, Jewellery Worker, Haizhu, 2013)

The comments made by the interviewed workers about their frustration and resentment over their work and non-work lives have illustrated how the cultural concept and expression of yayi has played a significant role in shaping their daily experiences. While the concept of yayi as expressed by these workers did not indicate an awareness of inequality of their social status (or position) or a realisation of their common interest as being the workers, it is a moral language that may work to heighten their sense of injustice as well as their spirit of resistance to the oppression of their work superior and authority figures within the hierarchical occupational structure:

Our work leaders were very mean and nasty - they subcontracted our work to other factories to low down the production cost and keep the excess in their own pockets. I can give you an example: our factory had to pay us 0.2 yuan for each stone we inserted but the subcontractor charged only 0.15 yuan per stone inserted and so the work leaders saved 0.05 yuan each stone and they kept this money for themselves and yet we didn't have sufficient work to earn enough money. You know working and putting up with our nasty work leaders were already a very yayi thing for us; having us working but not letting us to make enough [money] to live had increased [the level of] our yayi [...] even though they were work leaders they shouldn't be so mean and unfair [...] because of this we must get rid of our work leaders [...] 
(Jinhua, Jewellery Worker, Panyu, 2013)

\section{Yayi-Based Protest Actions}

Henceforth, beneath the expression of yayi lies a perception of egalitarian and spiritual resistance to the hierarchical social order that is disguised by workers' long-suppressed resentment and anger over their work superiors and by their own interpretation of the idea of injustice in their lived experiences:

My life started off here [Hangzhou] by working in a very small factory - my boss was my work leader and I was the only worker he employed. In the beginning I thought he was very nice as he bought me a television, microwave, a pillow and a blanket and he let me live inside the factory - so the machines were operated downstairs and I lived upstairs. But after a few days I found that I had to work at least 10 hours a day and in the peak season I had to work 24 hours a day - I had to bring my blanket and pillow to sleep with the machines [...] I worked and lived in this way for a long period of time but he didn't even increase my wages [...] I felt so yayi about that so I asked him for a pay-rise, but he yelled at me as usual [...] I felt more yayi as he kept barking [yelling] at me like he has every right to look down on me just because he's a rich man. It's so unfair because I was his tool helping him to make money and he yelled at me but didn't even give me a bit of pay-rise [...] You know I had to pay for my food and I had to send money home; I was extremely yayi so I punched him [...]

(Min, Spring Manufacturing Worker, Hangzhou, 2011)

Workers' spontaneous, violent reaction towards the constant labour abuses exercised by their work superiors suggest that yayi played a crucial role in promoting a growth of consciousness of injustice among the workers. This consciousness concealed an explosive potential for workers' oppositional and resistant attitudes to flare up as strong feelings of affinity occurred when the deep-seated yayi matters had touched the minds of those who shared similar experiences: 
Our strikes occurred all of a sudden usually - no one organised the strikes but we just told each other to stop working when we felt too yayi to live and to feed our families as our wages were way too low, so that we couldn't even earn our basic living. We got very angry and yayi when our leaders refused to discuss the pay-rise with us; that's why we stopped working.

(Gong, Batteries Manufacturing Worker, Haizhu, 2013)

Rather than class opposition or antagonism (Walder 1991) as suggested by scholars such as Leung Pak Nang and Pun Ngai (2009) as illustrate in Chapter Four (pp. 108-109), yayi-based protests had insinuated a sense of injustice towards what Feng Chen (2003, p. 242) has referred to as the 'subsistence crisis'. Thus, it is when the abuses reached an extreme level to the extent that threatened their minimal subsistence level, the accumulated pain and anger of the workers burst into acts of resistant activities in defence of their only deservingness as being the lowquality workers. Yi, 22-year-old - who was categorised in the group of well-educated second generation of peasant workers in academic literature (Chan \& Hui 2012; 2016; Chan \& Pun 2009; Gray \& Jang 2015; Smith \& Chan 2015) - revealed how the yayi feelings had spontaneously turned workers into a group of emotional protesters to engage in one of the resistant activities that was frequently described as an organised, interest-based action (Chan \& Hui 2012; 2016; Gray \& Jang 2015) at Honda's transmission and engine parts factory in Foshan:

[...] I started working at Honda since 2007 [...] it's a very yayi thing to work on the production line $[\ldots]$ we were not allowed to talk; we had to repeat the same task over and over at a fast pace without making mistakes; we earned very little money. We also felt yayi even when we were not at work [...] we stayed in the flat because we didn't have much money to go out $[\ldots]$ we lived on a tight budget because we had to save money to send home. By 2010, doing a living became impossible because our wages were extremely low and we were unable to catch up with the inflation [...] I realised that everyone became so grumpy [...] It's very easy for us being rude to other people not only because we are low-educated, but also because we cared only about ourselves and so we couldn't be bothered about other people [...] One day, we started to text 
each other on our QQ group chat [online forum in China] using our phones when we were having lunch or dinner [...] We talked about our income; our money and our family [...] The more we talked about it, the more yayi we felt; and as our yayi feeling increased we felt like we were all in the same boat that we had to stick to each other [...] We decided that we couldn't live any longer with the little money so we turned off [pushed a stop button] the production line and so all of us had to stop working [...]

(Yi, Honda Worker, Foshan, 2013)

Thus, intensified emotional feelings within the workers had stimulated a rather embryonic trade union consciousness among themselves which laid the foundation for motivating them to struggle against their given conditions. Their sense of solidarity (or coalescence) appeared to become stronger when their yayi feelings of injustice were being translated into emotional words and content in their ordinary conversations:

We whinged about our yayi every time we met each other at work [...] Can you imagine, I earned only 1,170 yuan each month for three years and our leaders keep deducting money from our already low wages, from 0.01 to $\$ 8$ yuan, whenever they found rubbish in the areas we handled? [...] we all tried to save our money and we only go to the market to buy the 'ready-to-throw-away' food at night - we never buy meat, we never buy fresh food, because they're all too expensive. We tried so hard to save our money but our leaders just took our money away when they saw a chance [...] Each time when we talked about this we felt angry [...] we felt very yayi to work and to live [...] we feel our yayi deep inside cannot be shifang 釋放 (released) [...] so we talked to one another $[\ldots]$ we know we must stick together and do something about it $[\ldots]$

(Ying \& Yao, SOE Street Cleaners, Foshan, 2013)

The forms of releasing (shifang 釋放) yayi among the interviewed workers were either symbolically, through conversation or dance, or practically, through actions and/or through a combination of both: 
We stopped working because our leaders deducted another 100 yuan a month from our wages for our meal money at the canteen - but the food was really bad - you know the food we ate for each of our meals had some funny smell. We only had one hour lunch break and it was really far for us to walk to any other eateries outside. We worked very hard and every dollar we earned was through our blood and sweat [...] but our leaders fed us with some pig food and we all felt very yayi about this [...] so we stopped working. I felt that it was fun to stop working because we didn't have to work - we laughed and talked; some slept or danced on the shopfloor - we just did whatever we liked. It felt like we could eventually shifang our yayi, particularly when we looked at how angry the leaders were.

(Shen, Lighting Factory Worker, Shenzhen, 2011)

Many of the protest actions that accompanied the workers' sit-in demonstrations (or work stoppages) were manifested in forms of shifang yayi. Across private or State-owned enterprises (SOEs), large and small, some interviewed workers appeared to vent their long-suppressed anger and resentment on their work leaders by 'humiliating' them in the protest actions:

The days before we stopped working we had tried to discuss our issues with the leaders so many times but they refused to talk to us. I wrote a list of our issues on a piece of paper and handed to the leader (manager) - I also told him 'we are going to stop working if the leaders are not going to redress our issues'. This leader rang up the higher leader (Chinese director) and told him what was happening but no leaders talked to us; so we stopped working. Then the higher leader came to tell us how wrong we were and that he didn't even know why we'd stopped working. We were so yayi when he said that; we were very angry with him; but you know we couldn't do anything too disrespectful to our leaders, so we ignored him - he basically talked and shouted by himself for three hours [...] I felt my yayi shifang a bit when I saw his face turning angry red - it was so funny to look at.

(Feng, Plastic Board Factory Worker, Foshan, 2013) 
While the significance of self-directed status oppression (or status consciousness) (Yang 1978) was demonstrated in workers' collective responses, their actions indicated that their desire to shifang their compressed feelings was their motivating force to spark a yayi-based solidarity among those who suffered the same experiences.

\section{Cultural Activities and Yayi-based Solidarity}

The evidence suggests that yayi-based solidarity sharpens further when workers shifang their intense feelings by engaging in cultural activities organised by the non-government labour organisations (or labour NGOs). While these organisations did not engage in any workers' protest activities, they provided the workers with an interactive platform through learning and entertaining activities, for example small group discussions (see Figure 15) on labour rights, readings, movie sharing, singing and dancing, to release their emotional feelings:

Figure 15: Small Group Discussions at the NGO

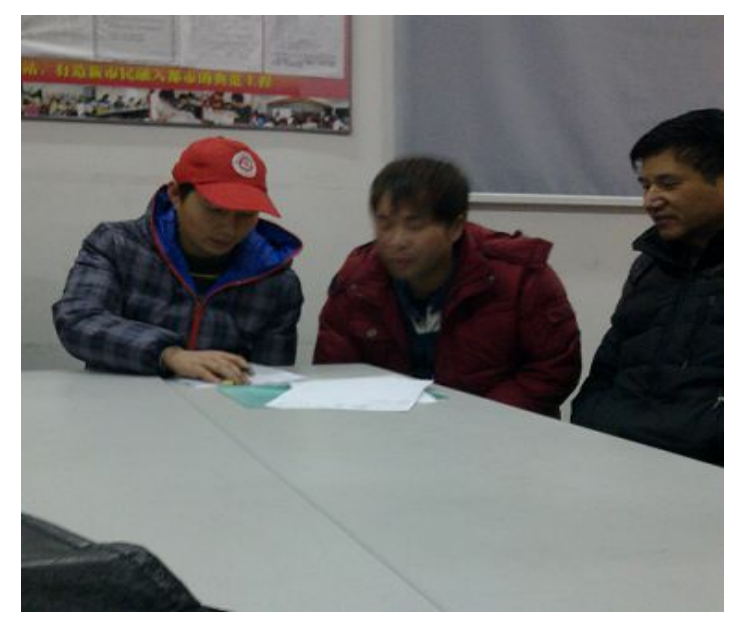

Source: Photo by author

Many reported that their initial motivation to participate in these forms of activities was just to have fun, but they slowly established close ties with other fellow workers across enterprises and geographical areas:

I lived around this area [...] I was a bit curious about this centre as I saw that it organised many different activities. [...] One night I just walked into the centre after work. [...] Since then I have come here to 'play' every night. [...] You know we are very yayi at work and we all come here to shifang ourselves [...] we work in different factories and 
places and we all came from different regions. [...] It feels like we are all in a big family [...] it's a close feeling of being together - we are all together.

(Min, Springs Manufacturing Worker, Hangzhou, 2011)

The feeling of 'togetherness' implanted within the circles of workers thus reflected their 'belongingness' to the NGO cultural centre(s). The 'togetherness' and 'belongingness' among the interviewed workers appeared to be deepened by the content of the NGO's cultural activities, which were oriented to forging a more inclusive and positive sense of the workers' positions as well as promoting a critical consciousness among the workers as a class. This intention was expressed in the lyrics of the labour song in a singing session:

We workers have power

Hey! We workers have power

We're busy at work every day

Hey! We're busy at work every day

We changed the world

We built houses

We built railways

We turned on the machines,

to make hammers for farming production;

to make guns and weapons for our soldiers!

Our faces glowed

Our sweats dropped

Why? We wanted to be released

Why? We wanted to be released

We wanted our entire country to be released!

This labour song, titled 'We workers have power', was produced in 1947 to construct a positive working-class identity in Mao's socialist period. The lyrics of the song were crafted to mobilise workers for physical and manual labour using nationalistic ideology. In this context, nationalism was combined with military rhetoric, equating industrial workers with soldiers fighting for national defence (Koo 2001). Workers' dedication to China's market economy is now advocated as a patriotic act that a working class should be proud of as in the Mao's period (see Chapter Three, pp. 63-64) in post-socialist China. 


\section{Nationalistic Sentiments and the 'Truth' of Yayi Lives}

While the nationalistic (or Maoist) rhetoric had little effect on the workers' consciousness, enthusiastic singing of the labour songs had worked to heighten their emotions about their experiences as a class. A garment factory worker used Maoist language (see Chapter Four, pp. 103-105) to describe their daily work life:

Mao Zedong was a great leader - without him there's no China. Back in Mao's time everyone was treated equally - no one was particularly rich or poor. [...] But Deng Xiaoping opened up China for economic development [...] he said some of us must get rich first [...] we jiceng 基層 (grassroots), dagong 打工 and gongren 工人 worked hard [...] laboured day and night for those leaders to get rich first [...] but what about us? [...] Why, we can't even earn enough to live [...] we have to live our yayi lives every day for the rich people.

(Shao, Garment Factory Worker, Hangzhou, 2011)

By using nationalistic sentiment to interpret the yayi feeling experienced in their daily work lives, some workers began to criticise the social 'truth' (Foucault 1980b; see Chapters Two, pp. 43-46 and Three, pp. 83-91) about their conditions within the given occupational status hierarchy:

I felt like I was a machine myself...

Like a robot repeating the same tasks and motions...

Repeating the same tasks and motions was boring and tiring...

We didn't need brains to do work...

...Just like a robot repeating the same things over and over...

It felt like the Japanese turned us into their machines...

and made a lot of money by selling a lot of cars we made...

I was one of their robots...

(Di, Honda Worker, Foshan, 2013)

By relating the personal feelings of despair about the alienation and exploitation that caused them to question the status quo, the workers appeared to attain a new level of understanding of themselves. The consequent revised knowledge (or truth) about themselves (see Chapter Two, pp. 48-51) created possibilities for reshaping workers' consciousness to one that can encourage 
them to engage in a sequence of exercises to facilitate self-modification (or resubjectivication of the self) (Foucault 1987; 1997; see Chapter Two, pp. 48-51)

\section{Counter-Hegemonic Discourse and Alternative 'Truth'}

Opportunities for workers' self-modification were presented in the working-class materials produced by the NGOs, such as poems, songs and short stories, which were assessable in the workers' newspapers, newsletters, and magazines, as well as in the online forums, such as QQ and Weibo. These media channels also provided alternative information about current labour protests and informative educational columns on labour laws and workers' rights that were not normally covered in the regular, State-controlled daily newspapers (see Chapter Three, pp. 8390). Hence, it is suggested that the objective of the NGOs was to counter the 'official' reality by establishing the counter-hegemony of a Chinese working-class culture.

Given the 'official' cultural environment and material conditions of the everyday Chinese workers, new counter-hegemonic discourse (Gramsci 1988/2000) was an alternative 'truth' (or reverse discourse) (Foucault 1997; see Chapter Two, pp. 48-50) that worked to empower the workers:

We qingjie gongren 清潔工人 (street cleaners) are human too. [...] We had enough! We must nao 閙 [create trouble] and make it big to get our justice back [...] we must stick together in our work strike until we get what we want $[\ldots]$

(Fang, SOE Street Cleaner, Foshan, 2013)

Their assertive sense of their positions through the revelation of an alternative truth about themselves consequently contributed to turning their normal practices (Foucault 1977; see Chapter Two, p. 47) of adaptation or 'exit' orientation to their given conditions into 'voice':

We must stand up for ourselves and fight for our own things - things that belonged to us. [...] If we don't fight for ourselves [...] who will? And if we don't fight for ourselves [...] employers will take advantage of all of us!

(Hung, Jewellery worker, Panyu, 2013) 


\section{'Automatic' Self-Devaluation}

While the alternative 'truth' was a critical ingredient for increasing their consciousness to one that posed oppositional attitude towards their superiors and authority figures, the findings suggest that workers' 'automatic' self-devaluation that was guided by their status consciousness had still severely prevented them from obtaining a sense of power vis-à-vis their superiors in the resistance activities (see Chapter Three, pp. 58-62):

We [...] street cleaners (qingjie gongren) do not have 'culture' in us - we are extremely illiterate, extremely grassroots, extremely dirty. [...] Our work leaders wouldn't want to talk to us [...] wouldn't want to look at us. [...] We know we shouldn't expect much $[\ldots]$ because our quality is extremely low. [...] We are always at the bottom of society.

(Yao, SOE Street Cleaner, Foshan, 2013)

The workers' recognition of the truth about their devalued societal status, which was associated with their educational deficiency (see Chapter Three, pp. 84-91) that sprang from their cultural reactions and experiences played a critical role in defining their 'collective demands':

We only want to get a raise to earn our basic living - we didn't ask for that much - and that's because we're just a bunch of low-quality people. But even if we're uneducated, illiterate and at the bottom of society, our work leaders should at least allow us to have 'full bellies'.

(Ying, SOE Street Cleaner, Foshan, 2013)

The threats to their entitlement and deservingness of a 'subsistence wage' within their given positions had angered the 'low-quality' workers (see Chapter Three, pp. 84-91), which triggered protest actions within the hierarchical system. The outbursts of these protests were therefore predominantly motivated by a cultural reflection of the workers' desperate economic situations in relation to their everyday sustenance. Rather than being concerned with a more humane treatment or better conditions at work, the workers' demands were still centred on their immediate economic conditions relating to their moral sense of a right to basic subsistence (see Chapter Four, p. 102) in the protest activities: 
We're not being greedy - we just want to get a raise so all of us will be able to live [...] Our leaders are so mean to us $[\ldots]$ keep deducting our wages $[\ldots]$ they come to check on us to see if there's any rubbish in the streets. Sometimes when the weather was too hot [...] I stood there to rest a little bit [...] the leaders would just come out from nowhere to swear and yell at me [...] I don't mind the leaders yelling at me or insulting me as long as I can earn enough to live [...] because they are our work leaders.

(Ying, SOE Street Cleaner, Foshan, 2013)

As with Group One workers, their internal acceptance of the 'rights' or 'mandate' of their work superiors to treat them badly in return for a liveable income indicates that the truth about different destinies for the perceived superiority (the high) and the perceived inferiority (the low) (Cheng 1979; see Chapter Three, pp. 59-60) had been internalised by the workers within their relations of power-knowledge (Foucault 1977; 1980a; 1980b; see Chapters Two, pp. 4347). It is the status consciousness among the interviewed workers that had become forms of subtle power which exercised by themselves in their daily lives had undermined the potential for effective protest activities.

\section{The Struggle for a United 'Voice'}

During their protest actions, all the interviewed workers reported that they were asked by their work leaders to 'voice' their problems (or demands) and their proposed solutions to redress their issues:

Our strike broke out suddenly [...] during the work stoppage [...] we hadn't really thought about what we wanted and no one was able to represent anyone to speak. [...] Our leaders asked many times what we wanted but none of us said anything. [...] The leaders started to get pissed off with us [...] they slammed the tables and yelled at us [...] we were feeling very yayi as the leaders were angry at us so we started saying different things on our own at the same time for about two hours [...] we didn't know how much money we needed [...] we didn't know how much we should say $[\ldots]$ we only knew we were all very yayi about our basic living with our little incomes.

(Yuan, Plastic Board Manufacturing Worker, Foshan, 2013) 
The highly spontaneous and defensive yayi-based protests illustrate the workers' failure to articulate their needs in their particular situations. The difficulty with such a self-assessment was caused by their silent habits (Cooke, Xie \& Duan 2016; Foucault 1978; see Chapters Two, p. 47; Three, pp. 64-68 and Four, p. 117) associated with their inferior status and hence their status consciousness:

On the $2^{\text {nd }}$ or the $3^{\text {rd }}$ day of our strike, our work leaders did ask about our demands. We all had our heads down immediately - we tried not to look at our leaders [...] we just kept our heads down - didn't say a word - we were too scared to speak to the leaders because they were normally on top of us. [...] And after I don't know how long some workers told the leaders that our wages were extremely low so we didn't have enough to live on. [...] Other than that, none of us dared to speak to our work leaders [...] we just stood there listening to what our leaders had to say to us with our heads down.

(Di, Honda Worker, Foshan, 2013)

Despite a vague emphasis on a 'subsistence wage', it becomes evident that the workers' demanding attitude was weakened by their knowledge (or truth) about themselves as inferior (or low) on normative grounds (see Chapter Two, p. 47) in the context of their quality-based hierarchical power relations (see Chapter Three, pp. 85-90). Without a doubt, being born and shaped in certain ways to interact with the historical mode of 'high-low' hierarchy, their unthinking and uncritical engagement with the norm-based moralities (Chapter Three, p. 47) had further legitimised the 'prescribed' values of their given positions by themselves:

We didn't know what we wanted [...] we wrote 117 items on our demand list but at least 70 of them were repeating each other. It was like we wanted many things to be improved, but we didn't know what exactly needed improving. The only thing we knew was a pay rise [...] but we didn't know how much exactly we needed to live on. [...] Honestly, it's very hard for us to tell the leaders what we want $[\ldots]$ because we're just dagong $[\ldots]$

(Yi, Honda Worker, Foshan, 2013)

Like their colleagues in Group One, their low level of legal rights consciousness (falu wequan yishi 法律維權意識) (Gallagher 2005; 2006; Chapter Four, p. 100) along with their unchanged 
perception of themselves as 'unknowing' low-quality subjects together with the sense of inferiority had been a crucial factor to maintain their status consciousness. It is in such a way that the workers had disempowered themselves and had thus diminished the possibility of mobilising an effective resistance to improve the working as well as living conditions for themselves and others:

I had to join the work stoppage anyway [...] because our production line had stopped already [...] and I also wanted to get a pay rise. [...] But dagong is just dagong. We are just some uneducated 'low-quality' people - we know nothing - so we didn't ask for a particular amount because we didn't think and didn't know how much [money] was reasonable to sustain our basic living [...] some of us wanted (a raise of) 300 yuan; some wanted 500 yuan; some wanted 600 yuan [...] so on and so forth [...] it was like a chaotic market $[\ldots]$ our leaders were so confused and angry as everybody was saying different things at the same time.

(Yuan, Plastic Board Manufacturing Worker, Foshan, 2013)

Thus, despite their main concern had been hovering on their personal and immediate economic issues as with those in Group One (Chapter Six), their lack of a united voice was by and large inherent in the absence of any form of leadership in their resistance activities:

No one organised the work strike $[\ldots]$ we didn't have a strike leader $[\ldots]$ but there were two I think so-called leaders who already resigned before the strike and later on I found out they were the ones who pushed the button to stop the production lines and so there was no work to do. [...] We just stopped working all of a sudden [...] I think all of us supported it because we're very yayi at work [...] we couldn't live any longer with that little money $[\ldots]$

(Yi, Honda Worker, Foshan, 2013)

It is even with the Honda strike (see Chapter Four, pp. 111-112), which had been articulated by scholars (Chan \& Hui 2012; 2016) as a breakthrough of class consciousness development among workers, the above discourse illustrates that the workers had no long-term plan or solid core of workers to lead or continue the protest activity. This spontaneous and unorganised 
resistant activity, like those preceded it, remained isolated as workers' consciousness had not increased beyond reacting to immediate economic circumstances.

\section{The Attacks on Workers'}

While spontaneous and unorganised, the workers' actions during most of the protest actions were predominantly developed by seeking the right moment and right excuse to shifang (release) their long-suppressed yayi feelings:

Our first strike happened in July (2013) - we picked July because it's school holidays and it's also the hottest month. [...] Can you imagine how much rubbish would be accumulated and how smelly the streets would be when we stopped cleaning for only an hour? We had about 400 to 500 cleaners not cleaning the streets and we were all sitting outside the local government building. [...] We wanted to tell the local government how yayi our lives were and how hungry we were - no food, no energy to work $[\ldots]$

(Yao and Ying, SOE Street Cleaners, Foshan, 2013)

Despite enjoying a sense of 'freedom' to shifang yayi without immediate fear of the consequence of their actions, most of these spontaneous and unorganised protests hardly ever brought any gains for the workers:

We sat out at the local government building all day from $12 \mathrm{pm}$ but no one bothered coming to speak to us [...] but we wanted to speak to the government - we wanted to get a raise to be able to live. [...] We tried to draw the government's attention by going out onto the main road to block the traffic three times, but the security officers blocked us and they put barriers between the pedestrian path and the main road. [...] They also beat up some of our cleaners. [...] We got called into the leaders' office the day after the strike - we were forced to take a 30 yuan wage increase or resign.

(Ying, SOE Street Cleaners, Foshan, 2013)

Not only had the forms of unorganised protests brought few positive outcomes for the workers, but also led to dismissal for some of those who participated in the strikes: 
The leaders had warned us that if we did not resume work straightaway then we would be dismissed without compensation. We resumed our work along with all the other workers without getting a wage increase. The five of us in the same team were not happy with the outcome so we refused to work overtime $[\ldots]$ and then we were fired. Our leader told the five of us that, according to the Labour Law - Clause 39, companies can dismiss any disobedient workers without compensation.

(Xiaohuang, Carton Box Manufacturing Worker, Panyu, 2013)

Besides dismissal, enterprises were able to remove 'impure and disobedient elements' by blacklisting the activist workers from gainful employment:

People like me causing troubles [nao] for the companies are all blacklisted by the business council. Joining work stoppages is just like stealing things from the companies, causing financial damage to the enterprises; and so I am blacklisted by the business council [...] There's no way for me to get a regular job at a large factory anymore because these factories are members of the business council [...] I can only do some temporary or casual work in small factories.

(Heng, Jewellery Worker, Panyu, 2013)

While these fierce attacks on resistance activities had forced the majority of workers into silence and submission again, some angry workers took their grievances to the streets:

Our leaders deducted a large part of our wages anytime they liked [...] and there was this one time they declined my application for exemption from overtime work [...] but I really couldn't work that night and so I didn't [...] the next day they deducted 350 yuan from my earnings because I didn't work overtime. [...] We were very angry that our hard-earned wages got deducted all the time so the six of us stopped working. [...] Our leaders threatened to fire us if we continued to not work [...] four of them resumed work and two of us were sacked. I was very yayi and upset [...] so I went out onto the 
street and handed out some flyers to tell people what happened to me at work [...] I wrote on the flyers: 'My leaders are thieves - they took away my money'.

(Qiang, Jewellery Worker, Panyu, 2013)

\section{Externalising the Worker Struggle in the 'Carceral Network'}

Some of these street demonstrations were significant for developing closer interconnections between the labour NGOs and activist workers who were unwilling to bear the consequences of joining the work strikes:

On the third day of handing out flyers on the street [...] three NGO workers came and talked to me [...] I couldn't stop telling them how yayi I was as the leaders fired me without giving me compensation [...] because I joined the strike to try to get back my hard-earned money [...] I was invited to meet with some workers of other firms and also to have a discussion with other NGO workers in their office to work out a better solution.

(Qiang, Jewellery Worker, Panyu, 2013)

Apart from promoting social ties and communication among different groups of workers across enterprises, the interviewed workers revealed that they received minimal support from the NGOs to continue their resistance actions:

The NGO workers told me that I should not engage in the work stoppage, because we wouldn't be able to get anything out of these actions. [...] They said our action caused financial loss for the factory [...] and that we were given a chance to get back to work [...] they said because we didn't apply for exemption from doing overtime work the leaders had the right to fire us for breaching the factory rules $[. .$.$] we were an example,$ showing other workers the consequence of being disobedient. [...] The NGO workers said if they had known us earlier they could have helped us to organise a 'negotiation team' among ourselves and teach us the way to discuss issues with our leaders. 
(Xiaohuang, Carton Box Manufacturing Worker, Panyu, 2013)

As with other institutions such as the trade unions in China (see Chapters Four, pp. 78-79), the NGOs are enmeshed in the historical and cultural structure of the everyday 'carceral network' (Foucault 1980a; see Chapters Two, pp. 44-46 and Three, p. 81) that engages in activities in the way defined by the CCP. The NGOs, although could be viewed as independent, are just one of the 'branches' among many in the governmental bureaucracy that are subject to the 'norms' and 'discipline' constructed by the CCP:

[...] the NGO workers said that we should resolve our unpaid social insurance issues through the 'proper' channels. [...] Before we lodged our complaint with the Labour Bureau, the NGO appointed some of us as the worker representatives and told us to hold a meeting to discuss our issues with our leaders [...] The NGO workers had arranged a lawyer to help us to bargain with our leaders. [...] Our leaders were furious and they raised their voices at us - particularly at the lawyer - and they said to the NGO workers and the lawyer if they insisted on being that nosy then they would give them some trouble. The NGO workers and lawyer said that we should all have a break before we continued the discussion [...] but after the break the NGO workers and lawyer just disappeared from the meeting.

(Meilin, Jewellery Worker, Panyu, 2013)

Thus, while some NGOs had been somewhat more daring to provide workers with guidance, if not leadership, established worker committees and engaged themselves with the workers in confrontational struggles or negotiations with management in the workplaces, their role as 'rights protectors' and scope of activities remained limited or readjusted to what they know of proper within the Chinese legal framework. The reactions of the NGO along with the legal workers (or lawyer) towards the threats or harassment of the workplace management revealed not only their subservient status in the bureaucratic structure, but also reflected a hierarchical obedience of subordinates to the 'perceived' superior and authority figures. These 'high-low' hierarchical practices by the everyday workers (see Chapter Three, pp. 57-61) within the 
'carceral network' (Foucault 1980a; see Chapters Two, pp. 45-47) had secured the capability of the employers and the CCP to 'override the law' (Chapter Three, pp. 71-76):

[...] the NGO workers said that we were already given a chance to get back to work after the strike action and it's our fault because we didn't get approval from the leaders to be exempt from doing overtime work [...] They said if we really believed it was an unlawful dismissal they could help prepare the paperwork to sue the factory. [...] We lost the lawsuit $[\ldots]$ the court didn't consider the evidence that we provided $[\ldots]$ the court didn't take the side of the workers [...] the court ruled that the factory did not dismiss us unlawfully $[\ldots]$

(Xiaohuang, Carton Box Manufacturing Worker, Panyu, 2013)

The decision of the court indicates that the legal rights protection (weiquan 維權) practices (Chapter Four, pp. 99-100) in China are substantially influenced by behavioural norms and are entirely subject to the CCP discipline to ensure the maintenance of a cheap, docile labour market and 'social harmony' (hexie 和諧) (see Chapter Three, pp. 79-82) to uphold the orthopraxy system in the hierarchical socialist market. The lack of either procedural equality or an impartial and independent tribunal subsequently guaranteed that the legal rights of the workers were not upheld:

We didn't hear anything from the court for at least five months [...] so we went to the court to harass the judge. [...] The judge told us that he was just waiting for a response from our former employer to see if they were able to compensate us. [...] The judge was trying to drag on the case for as long as possible so that we might have to give up the court case $[\ldots]$

(Qiang, Jewellery Worker, Panyu, 2013)

\section{Strengthening Worker Passivity}

The joint control exercised by the State and by the employers thus strengthened worker 
passivity within their given positions in the labour market as a result of the governmental discourses of 'personal quality' in their everyday 'carceral network' (see Chapters Two, pp. 45-46 and Three, pp. 90-91):

Workers are always powerless [...] because we're 'low-quality' and we're always at the bottom of society. [...] Employers can always bully us and our government doesn't care about us. [...] Even though a work strike can be an effective method to push for better pay, it doesn't have any support from the government so it can also be a means to damage our benefits easily. [...] We never know when the government and particularly our work leaders want to exact revenge on us [...] it is very difficult for us to organise many of us to strike [...] because none of us want to go against our work leaders. [...] Strikes only happen when the subsistence level of the whole lot of us is under threat.

(Di, Honda Worker, Foshan, 2013)

The day-to-day status experiences among the workers as influenced by China's governmental discourse within its thought management system thus continued to guide them to remain silence over their grievances (Cooke, Xie \& Duan 2016; Chapter Four, p. 117) and act only when a ‘subsistence crisis' (see Chapter Four, pp. 102-103) was commonly perceived:

[...] after the unpaid social insurance issues [...] our leaders subcontracted at least half of our production work to other factories. [...] Those orders being left for us were all complicated and time-consuming items that we couldn't make money from at all to earn our living. Our situation was getting worse, with our leaders constantly picking on us and getting us to make corrections to the same items over and over so that we were unable to move on to the next items. [...] You know a large part of our income relied on piece rates and so we kept losing money by making constant corrections to each item [...] then how were we going to make enough to have a basic living? Subsistence is our only right but our leaders didn't allow us to live. [...] We didn't know what to do to live so we stopped working. 
(Meilin, Jewellery Worker, Panyu, 2013)

Their defensive act towards their only deservingness, namely the 'right to subsistence' (see Chapter Four, pp. 102-103), had made their base of solidarity easy to break through individual incentives:

Our leaders told us how wrong we were to nao (create troubles) for the factory and we were told to correct our wrongdoings by getting back to work immediately. [...] They said that they were willing to increase our piece-rate by 0.01 yuan as a reward if we got back to work. [...] One of my co-workers took that 'reward' straight away. [...] Our leaders then invited us to dinner $[\ldots]$ and the next day straight after that dinner my coworkers started working again.

(Qiang, Jewellery Worker, Panyu, 2013)

Even when some respondents demonstrated stronger determination and resistance than the others, their lack of interest in the long-term improvement of their conditions had caused the protest actions to become insignificant:

We were trying to get a raise of 500 or 600 yuan a month in our strike [...] we said we were not going to back off until we got a raise of at least 500 yuan [...] but you know our action lasted less than half a day with an increase of only 200 yuan [...] Our leaders said they would fire all of us if we continued our action; but at the same time, they gave us a supper and promised us an increase of 200 yuan if we returned to work. You see all of us were worried about losing our jobs [...] and you know our attitudes changed so quickly as we were having our supper - like the way we talked - we dropped our angry tone to a pretty gentle soft tone when speaking to our leaders while we were eating together. The workers then began to accept the 200 yuan increase and so the rest of us had to follow.

(Yuan, Plastic Board Manufacturing Worker, Foshan, 2013) 
The ineffective, short-lived protests staged by these workers highlighted not only their disunity about their goals and collective interests, but also reflected a 'filial culture' that was linked to the Confucian ideologies (see Chapter Three, pp. 56-61) within their predefined 'true-selves':

Most of us supported our work strike in 2010 because everything was so expensive and our wages didn't allow us to live in Foshan. But after the strike we all got a pay-rise $[\ldots]$ and from then on, we had an increase of $3 \%$ each year [...] though it was still very low [...] we already had enough money to survive. We shouldn't keep on asking for more and more [...] our factory doesn't have the money to give us a raise all the time. [...] That's why we didn't support the second strike this year [2013] [...] he stopped the production line suddenly just because he wanted to get a raise when we already got enough [money] to live on [...] the strike lasted about two hours [...] we didn't get a raise out of this $[\ldots]$ he put us at risk as if we also wanted to go against our work leaders - that's just not right.

(Zhi, Honda Worker, Foshan, 2013)

\section{Self-Value and the Norm-based Moralities}

The value judgement between 'right' and 'wrong' acts (Foucault 1980a) for the 'worker selves' reflects the effective operation of the norm-based moralities (Chapter Three, pp. 61-90) in relation to one another within the mindsets of the workers. This acceptance was arguably tied to their knowledge of the 'truth' about themselves as inferior, which caused them to self-direct themselves to regulate themselves and others in accordance with their given positions in the hierarchical structure:

[...] many of our strikes in China are all about the threat to our subsistence [...] organising a strike is a very difficult task [...] because we cannot afford to be angry $[\ldots]$ most of us hesitated to nao [...] as we wanted to keep our jobs $[\ldots]$ that's the reason we tried not to nao. Previously we nao as we could barely subsist [...] but we were not very determined in the $2^{\text {nd }}$ strike [2009] because we had already got enough [money] to live on [...] Though our first strike [2006] did give us a wage increase, I still think my 
act was really thoughtless and irresponsible - no leaders like disobedient workers - I could easily have lost my job over that $[\ldots]$ and yet I have a family to look after [...] my old parents, my wife and my child [...]

(Yuan, Plastic Board Manufacturing Worker, Foshan, 2013)

Such confessions (Foucault 1978; see Chapter Two, p. 48) about 'incorrect' behaviour that was contrary to their social status, associated with the 'truth' about their responsibility for others, thus worked together to maintain their status consciousness as the low-quality workers and hence restricted the area of their acts:

If I could start it all over again I wouldn't want to go against my work leaders [...] I don't think striking is an appropriate strategy - I don't think anyone should join a work strike at all. It's a very tiring process and it's very difficult to get everyone to stay on the same boat because everyone is selfish - we only care about ourselves.

(Meilin, Jewellery Worker, Panyu, 2013)

These 'care' practices (Foucault 1986; 1987; 1997; see Chapter Two, pp. 49-52) in the form of 'selfishness' exercised by these workers made them 'voluntarily' subject themselves to a strict set of self-regulations that they imposed on themselves. Rather than improving their living and working conditions, their self-care practices at defending their minimal subsistence level were grounded in the cultural understanding of 'proper' behaviour within the social hierarchy thus maintained their level of 'docility' to support the orthopraxy system within their powerknowledge relations (see Chapter Three, pp. 90-91):

I wasn't angry about losing my fingers at work, though I couldn't work anymore and it's very difficult for me to find work again. [...] A lot of beggars on the streets are handicapped [...] I considered myself lucky because it's not like I lost my two hands and legs. [...] You know we can't afford to be angry - we can't stand up for ourselves [...] as long as we have food in our bellies. I wouldn't do anything to go against our leaders as long as I live. You know I didn't have meat to eat in the village but now I 
have. This is our mentality - we only believe in money and power - that all belongs to the leaders above us and that's why they are like kings (emperors). Workers are just workers; we have to obey the leaders. [...] Power and rights just belong to the leaders.

(Feng, Plastic Board Manufacturing Worker, Foshan, 2013)

\section{Concluding Remarks}

The findings discussed in this chapter show that while the lived experiences of this group of workers incited them to engage in resistance activities as other scholars predict (Pun \& $\mathrm{Lu}$ 2010; Pun \& Lu 2010b; Chan \& Hui 2012), their protest behaviours were constrained by a high-level of status consciousness that is linked with the truth about their devalued societal status as low quality workers and the truth about their normative and abnormal practices within the social hierarchy in China (see Chapter Three, pp. 88-89). Thus, as Chapter Four (pp. 89788) shows, their practices reflect the internalised 'truth' about themselves and their internal acceptance of their given destiny (or ming) and conditions within their 'prescribed' routines in the 'high-low' hierarchical relationships. This is because, while the experiences of these workers had provoked them to engage in protest activities, their yayi-based actions were grounded in their immediate economic needs in accordance with their prescribed conditions within their given positions. Their lack of interest in changing their destiny in terms of their status and conditions in the long term was a major factor that made their protest actions ineffectual. Hence, their actions were generally 'once-only' events, even when they reaped only partial or little gain. This reflects that these workers, like their Group One colleagues continued to exercise their 'prescribed' routines and thus they also became the agents of maintaining the power-knowledge framework - consciously and subconsciously - and hence continued to maintain a high-level of internal 'docility' or acquiescence to their given status within the Confucian-orthopraxy system. Thus, even while this group of workers had engaged in protest activities, their actions appeared to be influenced by an 'older rules consciousness' that affected their willingness to continue their struggles to improve their conditions for themselves and others, rather than their work-based experiences. 
This cultural compliance thereby acts to endorse a natural self-regulation by the workers to internally accept the legitimacy of labour practices that - ultimately - works to serve the will of their work leaders and ultimately the 'mandate' of the Chinese State to rule by maintaining an abundant docile labour force in the socialist market economy within the Confucianorthopraxy system. The question of whether everyday workers can overcome the centuries-old cultivation of docile bodies and minds to engage in activism that will lead to the formation of an active working class will be discussed in Chapter Eight. 


\section{Chapter Eight: Conclusions}

I take care not to dictate how thing[s] should be. I try instead to pose problems, to make them active, to display them in such [...] complexity that they can silence the prophets and lawgivers, all those who speak for others or to others. In this way, it will be possible for the complexity of the problem to appear in its connection with people's lives.

(Foucualt 2001, p. 288)

The aim of this chapter is to discuss how the genealogy of Chinese workers as presented in Chapter Four and original findings in Chapters Six and Seven help to understand how living and working in post-Mao China has shaped the consciousness of the everyday Chinese workers studies in this research project. The chapter further discusses how this consciousness affects their activism, as well as their ability to develop into an organised labour movement to improve their living and working conditions for themselves and others. The chapter begins by providing a summary of the historical events that have shaped the development of the Chinese society and the making (and remaking) of working class politics in China. This chapter then summarises the debates about class and class consciousness development by scholars in Chinese labour studies. The discussion of similarities between the two groups of findings is presented by addressing the research questions (see Chapter One, pp. 19-20) and propositions (see Chapter One, p. 29) posed in this study. The chapter then concludes with considering the implications of the findings for the future of Chinese workers and the organised labour movement in China, before discussing the limitations of the study and the future research directions.

\section{Making and Remaking a Chinese Working Class over the Past Decades}

In Chapters Three and Four, the key events that shaped the development of the Chinese society and the changing of working class politics were discussed. In Mao Zedong's China after 1949, the Chinese expression of the 'iron rice bowl'(tie fanwan 鐵飯碗) - a system in which the peasants and workers (masses or proletariats) were administratively allocated to the Stateowned village communes and work units (danwei 單位) (see Chapter Three, p. 66) - had 
symbolically engendered a socio-political status wherein the State and personalities such as Mao became the 'masters' of the 'masses' (or the Chinese working class) (Chapter Four, p. 103). As illustrated in Chapter Three (p. 68), this privileged status was constituted by the idea that lifetime employment and the livelihood of the masses were guaranteed and enforced by the State as long as they demonstrated their loyalty and compliance to key personalities; at that time this was Chairman Mao. This 'docility' was further maintained by the internalisation of the correct Maoist truth (see Chapter Three, p. 64) among the masses about their revolutionary duties as a Chinese working class through numerous thought control programmes such as zhengfeng 整風( or 'Rectification Campaign') and compulsory study groups (see Chapter Three, p. 63). Drawing on Foucault's concept of 'problematisation' (Bacchi 2012; Foucault 1976; Rabinow \& Rose 2003; see Chapter Two, pp. 37-40) this study has sought to contextualise (see Chapter One) and subsequently untangle (see Chapter Three) how as a result of the approach to governmentality (see Chapter Three), Mao and the Maoist State was able to create a working class of hundreds of millions of docile bodies and minds to automatically respond to Mao's goals of revolutionising the already poor China (see Chapter Three, pp. 65-69).

Following the death of Mao in the late 1970s, and drawing on Foucault's (1977) tool of genealogy, Chapter Three (pp. 71-83) shows how the creation of the docile bodies and minds among the working class has remained fundamental to the success of the post-Mao leaders' goal of transforming China from a rural economy into an urbanised, industrialised economy. Nonetheless, the changes introduced by the post Maoist State overturned Mao's revolutionary ideologies and practices along with the restructuring of the Chinese economy from State ownership towards one driven by market competition and multiple forms of ownerships through the open market reforms programmes after 1978 (Girdner 2004). Driven by economic and political forces within and beyond China, Chapter Three (pp. 71-79) shows that these reforms were supported by two parallel transformations of China's labour market, that is, the conversion of millions of peasants into urban industrial and service workers and, secondly, dismantling the iron rice bowl lifetime employment for millions of State workers. These historical processes essentially reflected a neo-liberal model of economic development (Harvey 2005). However, in China, the implementation of this model was dependent upon high rates of exploitation and State control of labour standards to construct the world's largest cheap labour force of 996.8 million workers (Li, Sheldon \& Sun 2011, p. 111; see Chapter One, p. 17). Their 
labour has supported the repositioning of China as a 'world factory' and a world export leader (Leung \& Pun 2009) over the past three decades (see Chapter One, pp. 17).

\section{Studies on Labour Activism in China}

Chapter Two illustrates how the mainstream studies have posited the debates of Chinese labour activism. A major assumption in the mainstream studies is that the failure of the Chinese State to prioritise labour protections triggered increased protest activities by workers over the subsequent decades of economic reforms (see Chapter Four, pp. 71-76). Influenced by class theories (see Chapter One, pp. 20-21), nearly all studies that were conducted prior to the 2000s analyse worker protests by focusing on the changing workplace conditions in the State sector after the policies by post-Mao CCP (Chinese Communist Party) leaders called for a massive lay-off (off-duty or xiagang 下崗) (see Chapter Three, p. 74) alongside a restructuring of the State-owned enterprises (SOEs) (see Chapter Three, pp. 74-76).

With the mushrooming of private and foreign-invested enterprises (FIEs) since the mid-1990s (Chen 1997; see Chapter Three, p. 71-76), analyses conducted after 2000s seek to understand the formation of a Chinese class-for-itself by expanding analysis to include peasant workers in the non-State sector. Studies by Pun Ngai and Jenny Chan (2012) and Chris Chan and Elaine Hui $(2012 ; 2016)$ among others (see Chapter Four, pp. 111-112) argue that while peasants were not historically organised into a specific working class, their development of class and class consciousness is sponsored by their work-based lived experiences as peasant workers in the past decades.

Despite the view that an increase volume of protest actions represents a new stage of class consciousness among workers in China, scholars such as Ivan Franceschini, Kaxton Siu and Anita Chan (2016), Yanhua Deng and Jonathan Benney (2017), Fang Lee Cooke, Yuhua Xie and Huimin Duan (2016) and others are skeptical about the ability of Chinese workers to form into a class-for-itself by analysing their resistance patterns.

After reviewing the literature about how workers' consciousness and activism are influenced by their work-based lived experiences in China, the following research questions emerged to guide the empirical exploration of the study (see Chapter One, pp. 19-20):

1. How has worker consciousness been shaped in China? 
2. How does the shaping of worker consciousness affect labour activism by Chinese workers?

3. How does the shaping of worker consciousness affect their ability to form themselves into an organised labour movement to improve living and working conditions for themselves and others?

When considering the latter body of literature, the following research propositions subsequently emerged (see Chapter One, p. 29):

1. Worker activism in China is influenced by a status consciousness (or older rules consciousness)

2. This 'older rules consciousness' has affected their willingness to engage in acts that are perceived as contradictory to their cultural (or social) practices in China

3. Workers' consciousness and their resistant activities are influenced by 'older rule consciousness', rather than work-based experiences alone

\section{Discussing Research Propositions}

The findings presented in Chapter Six (Group One workers - who have never engaged in any protest activities) and Chapter Seven (Group Two workers - who have engaged in protest activities) illustrate that class formation in China departs from the Western idea that class "happens" when workers "feel and articulate the identity of interests [...]" through their lived experiences (Thompson 1966, p. 9). Thus, as presented in Chapter Four (pp. 101-108), workbased experiences have been stressed in the mainstream studies as a key factor that forged a collective class identity and consciousness among workers to struggle against their decades of exploitative conditions in post-Mao China (Li 2006; Silver \& Zhang 2009; Pringle 2011). Despite experiencing forms of repressive conditions, discourse of the workers studied in this research project, that is "[...] we do whatever our leaders want" (Group One) and "I don't mind the leaders [...] insulting me [...] because they are our work leaders" (Group Two) suggest that the mentalities (Foucault 1980a) and everyday practices of workers have effectively them in governing themselves (Foucault 2014) and subordinating their own interests to that of their authority figures. In view of this contrasting picture with the mainstream literature, the theoretical propositions that guided this study should be revisited: 
Proposition 1: Worker activism in China is influenced by a status consciousness (or 'older rules consciousness').

Chapter Three discusses Foucault's $(2001 ; 2014)$ analytical tools to explore the operation of power-knowledge relations that facilitates governmentality (government of mentalities or conduct of conduct) to guide individuals in behaving towards the desired end of a society (Ransom 1997b; Chapter Two, p. 36). Despite its philosophical framing, governmentality also has a conceptual-empirical orientation (Fanoulis 2017, p. 10) entrenched in historicity, which facilitates the interpretation of the current research, that is, the 'history of the present' (Gutting 2003, p. 10). Foucault notes that doing a 'history of the present' is based on genealogical method to grasp the unnoticed details of governance in order to analyse the effects of the powerknowledge relations in a particular society (Hook 2005; see Chapter Two, pp. 41-43). Chapter Three (see pp. 56-90) therefore charts the historical development and the conceptual underpinnings of the social practices and knowledge that have historically shaped the status consciousness (Koo 2001) (or 'older rules consciousness') (Perry 2009) among workers, the way they live their lives and relate to others through reinterpretation of historical events in China. The selected historical events present in Chapter Three (see pp. 56-91) illustrate how the Confucian rules, which emphasise hierarchical status and respect for authority, was internalised in the minds of 'the Chinese':

[...] workers are just workers - we don't have any rights - because power and rights all belong to the leaders [...] we cannot do anything [...] but to obey our leaders and do whatever we are told.

(Group One, Bing, Hotel Cleaner, Hangzhou, 2011)

Workers are always powerless [...] and we're always at the bottom of society [...] Employers can always bully us [...] none of us want to go against our work leaders [...]

(Group Two, Di, Honda Worker, Foshan, 2013)

In summary, the effect of the Confucian 'older rules consciousness' had shaped and reshaped their thoughts and behaviours in their work and non-work lived experiences to fulfil the interests of Chinese rulers in different historical periods. It is therefore suggested that the findings of Group One and Group Two provide support for Proposition 1. 
The findings of Group One and Group Two further indicate that the inclination of the workers to be subservient to the Confucian hierarchical rules have thus support proposition 2:

Proposition 2: This 'older rules consciousness' affects their willingness to engage in acts that are perceived as contradictory to their cultural (or social) practices in China.

It is suggested that this 'older rules consciousness' is strengthened by workers' understanding about their societal status (identity or position) and that they reinforce that status among themselves:

[...] Dagong 打工 [workers] always have a tough life [...] all I learnt throughout my work experience was to obey the leaders so I can earn enough to subsist [...]

(Group One, Fang, Garment Factory Worker, Hangzhou, 2011)

[...] we can't afford to be angry - we can't stand up for ourselves [...] as long as we have food in our bellies [...] Workers are just workers; we have to obey the leaders [...]

(Group Two, Feng, Plastic Board Manufacturing Worker, Foshan, 2013)

The comments reflect that workers' sociocultural knowledge about their status (in relation to themselves and worker supervisors and their authority figures) make it disgraceful for them to engage in open and direct confrontation with superiors and authorities (Fouts \& Chan 1995; see Chapters Six and Seven) and that they must adapt to any conditions in order to live:

Being a worker is not good [...] We must put up with whatever hardships we have; we don't have time and we don't have energy to think about any other things but our subsistence [...] We only want to make enough to subsist [...]

(Group One, Yaxing, IT Worker, Shenzhen, 2011)

We [...] street cleaners (qingjie gongren 清潔工人) do not have 'culture' in us - we are extremely illiterate, extremely grassroots, extremely dirty [...] We know we shouldn't expect much $[\ldots]$ We are always at the bottom of society

(Group Two, Yao, SOE Street Cleaner, Foshan, 2013) 
In summary, the findings suggest that workers' internal acceptance of the 'rights' or 'mandate' of the State and their work superiors to subject them to any kind of treatment is compounded by their own self-perception of their lower societal position (or status consciousness). This status consciousness thus relates to their 'older rules consciousness' that mitigates their willingness to engage in struggles to improve their conditions as that they perceived those acts as contradictory to their social and cultural practices.

The findings that the mindset of Group One and Group Two workers hence exerts a significant influence in ensuring that their actions matched their given positions within the social hierarchy in China that supports proposition 3:

Proposition 3: Workers' consciousness and their resistant activities are influenced by 'older rules consciousness', rather than work-based experiences alone.

Evidence from Group One and Group Two underlines that societal positions in China are constituted by the value of 'personal quality' that is linked to the 'truth' of educational qualification as discussed in Chapter Three (see pp. 89-92). Although education is a primary criterion of stratification in most capitalist societies, the findings suggest that the workers' selfperception about their lack of education has been the main determinant of their poor treatment and working conditions:

[...] literate gao suzhi 高素質 ['high-quality'] people are always the leaders above everyone [...] illiterate $d i$ suzhi 低素質 ['low-quality'] people are just like mud sitting on the ground for leaders to step on.

(Group One, Bing, Hotel Cleaner, Hangzhou, 2011)

We only want to get a raise to earn our basic living - we didn't ask for that much - and that's because we're just a bunch of low-quality people. But even if we're uneducated, illiterate and at the bottom of society, our work leaders should at least allow us to have 'full bellies'.

(Group Two, Ying, SOE Street Cleaner, Foshan, 2013)

The above workers' discourses from Group One and Group Two indicate that their negative self-image about their low-quality is linked to their educational deficits. Their self-recognition 
of a subservient status has been a major factor that constituted a strong 'sense of fatalism' (or filial piety) among themselves which steered them to submit themselves to any employment conditions. Thus, even poor working conditions have at odds triggered protest activities by Group Two workers, their actions are still tied to a 'filial culture':

Most of us supported our work strike in 2010 [...] we all got a pay rise [...] from then on $[\ldots]$ though it was still very low $[\ldots]$ we already had enough money to survive. We shouldn't keep on asking for more and more $[\ldots]$ as if we [...] wanted to go against our work leaders - that's just not right.

(Group Two, Zhi, Honda Worker, Foshan, 2013)

It is thus suggested that the practices and behaviours in terms of the self-control among workers in Group One and Group Two is guided by their status consciousness that is constituted through their work and non-work lived experiences within the social hierarchy in China, thus providing support for proposition 3 .

\section{Discussing Research Questions}

The above picture contradicts that presented in the mainstream studies (see Chapter Three, pp. 106-112) that leads to considering the first research question:

\section{Research Question 1: How has worker consciousness been shaped in China?}

In exploring how worker consciousness is shaped, the thesis has drawn on Foucault's (1991a) genealogical method (see Chapter Two, pp. 40-43) to analyse how key events in Chinese history have shaped worker (or status) consciousness and practices through their lived experiences to the present day (see Chapter Three, pp. 84-93). The analysis shows that the links between their status consciousness (or awareness of their own social status) (Koo 2001) and their current knowledge about the 'truth' of their social status can be traced to events in the pre-Confucian epoch whereby the $l i$ 禮 hierarchical ideology (or knowledge) was internalised in the minds of Chinese workers today (Head \& Wang 2005). Beginning with the Zhou dynasty in the $13^{\text {th }}$ century B.C.E. (Melton 2014, p. 87) the $l i$ and later Confucian constitutive element emphasised the concept of filial piety (xiao 孝) within the hierarchical order of superior (the high) to inferior (the low) relationships, to regulate how those categorised 
as inferiors (such as children) should behave towards their superiors and authorities (such as parents) (Whyte 1988a; see Chapter Three, pp. 56-62). This 'proper' conduct, referred to as orthopraxy (seeChapter One, p. 30 and Chapter Four, p. 119; and Four, pp. 108-109), is the effect from the exercise of power-knowledge relations (or social relationships) (see Chapters Two, p. 46 and Four, pp. 59-61) by individuals within the hierarchy or status ranking of Confucian society (Fouts \& Chan 1995).

While the Confucian status system was supposedly dismantled during the events of post-1949 socialist China (see Chapter Three, pp. 62-63), it is suggested that generations of the CCP leadership - such as Mao Zedong, Deng Xiaoping, Hu Jintao and the current Chinese Premier Jinping -retained this traditional status hierarchy as a framework to regulate Chinese society into different status and identity categories (see Chapter Three, pp. 71-84). Contrary to the previous system of control of the imperial and Mao periods that forced the community to act in certain ways, post-Mao leaders have exercised soft control of the inferiors by revising Confucian status values into the CCP's thought management (sixiang guanli 思想管理) approach (Brady 2008, p. 120). As Chapter Three shows (pp. 85-91), Confucian status values within the thought management system are now backed by the notion of educational qualifications through 'quality' (suzhi 素質) discourses, to refocus proper behaviour in inferiors by redefining workers' identities. The identities of gongren (SOE workers 工人 or government slaves 宮人); nonmingong 農民工 (peasant workers); mangliu 盲流 (blind floats); wailaigong 外 來工 (outside workers); and dagong 打工 (those working for bosses) (see Chapter Four, p. 107), all of which carried a negative status, are used not only to push workers to work in certain occupations, but to also make them think and hence behave as the 'low-quality' (see Chapter Three, pp. 90-92) in order to fit into China's occupational hierarchy.

The evidence as presented in Chapter Three (see pp. 71-92) and the resulting influences as illustrated in Chapters Six (see pp. 156-158) and Seven (see pp. 179-181) further suggest that the continuous efforts of the post-Mao leaders to internalise the Confucian concept of social status through use of the quality discourses effectively guided Group One and Group Two workers to co-construct a destiny (or ming 命) for themselves to fit into their given position within the hierarchy. Thus, as Chapters Six and Seven show, both groups of workers appear to have crafted an internal willingness to accept their condition as 'given': 
I felt that occupational accidents and illnesses are just some of the normal things that are destined to happen to low-quality people [...]

(Group One, Daoqing, Food Processing Worker, Foshan, 2013)

$[\ldots]$ low-quality people are destined to do low-paid dirty work $[\ldots]$ "

(Group Two, Yao, SOE Street Cleaner, Foshan, 2013).

The discourses above illustrate that not only have the workers' internal acceptance of their destiny lead them to abandon any desire to improve working conditions, but their destiny further defined the performance standards and goals they have for life as 'low-quality' workers:

All working environments are dirty and unsafe for 'low-quality people [...] what do you think we are? You think we can choose where we want to work and can refuse to work in dirty, dangerous areas? [...] Low-quality is low quality - low quality people live like this.

(Group One, Ding, SOE Ready-mix Concrete Worker, Hefei, 2011)

I've been working for this danwei 單位 [work unit] for 10 years but the money I earned over those years wasn't even enough to buy a toilet bowl! [...] low-quality people are destined to do low-pay dirty work [...]

(Group Two, Yao, SOE Street Cleaner, Foshan, 2013)

The concepts of behavioural standards and destiny thus emerged as the 'truth' to normalise judgment (see Chapter Two, p. 47) between 'right' and 'wrong' acts among the 'low-quality' workers to maintain the orthopraxy (or proper behaviour according to their social status) system (Evasdottir 2004; Watson 1988; see Chapter Three, p. 61):

[...] she told the leader she didn't want to do extra work... Who did she think she is? She's just a low-quality dagong, but being so disobedient [...]

(Group One, Xiaoqin, Cosmetic Sales Assistant, Shenzhen, 2011) 
[...] he stopped the production line suddenly just because he wanted to get a raise when we already have enough [money] to live on [...]; he put us all at risk as if we also wanted to go against our work leaders - that's just not right"

(Group Two, Zhi, Honda Worker, Foshan, 2013)

Contrary to the mainstream assumption (see Chapter Four and this Chapter) that their brutal work-based experiences have fostered a rising consciousness among Chinese workers to become a class-for-itself, the evidence presented in this study suggests that workers' lived experiences of being 'the low' guided them to engage in a strict set of self-regulatory (governance or control) rules that they impose on themselves to continue to think and live properly by accepting their poor working and living conditions voluntarily according to their low status.

Thus, the findings instead support the alternative thesis in the literature about Chinese worker consciousness (see Chapter Two and this Chapter) and shows that the factors constraining class and class consciousness development among both groups of workers are grounded in their sociocultural understanding and commitment to behave properly to uphold the orthopraxy system (Evasdottir 2004; Watson 1988; see Chapter Three, p. 61). Henceforth, the section turns to the second research question:

Research Question 2: How does the shaping of worker consciousness affect labour activism by Chinese workers?

Evidence from both groups suggests that workers desire to act according to the 'truth' of their orthopraxy was reaffirmed by their willingness to correct their own behaviours in accordance with the commonly held standards of their particular position:

I felt really bad about disrupting the entire production by making such a stupid mistake [...], so I stood up and apologised to everyone and the leaders for my disobedient act.

(Group One, Ge, SOE Car Factory Worker, Hefei, 2011)

Though our first strike [2006] did give us a wage increase, I still think my action was really thoughtless and irresponsible - no leaders like disobedient workers. 
(Group Two, Yuan, Plastic Board Manufacturing Worker, Foshan, 2013)

Workers' own commitment and persistence in regulating the actions both of themselves and others to continue to live properly is further guided by their sense of similarity about themselves as receiving low educational qualifications and that being 'low-quality' workers in China have to live and behave in the same way under the orthopraxy system (Evasdottir 2004; Watson 1988; see Chapter Three, p. 61). Thus, it is the shared common understanding among workers that all 'the low' are being the 'same' and hence they interpret and evaluate their own and each other's actions in the same way under the doctrine of similarity to others (see Chapters , p. 61 and Four, p. 119). Thus, what they can or cannot do, and what they can expect from society regarding their working conditions in accordance with their lower societal position, is guided by that doctrine.

The findings thus illustrate that the doctrine of similarity to others created what Foucault (1980b; 1997) calls social truth (see Chapters Two, p. 43 and Four, p. 119), in that it appears to have reinforced a mindset within workers that the 'rights to subsistence' (shengcun quan 生 存權) (Chen 2000, p. 44; see Chapter Four, p. 102) was 'all that they were entitled to'. In much the same way as Foucault's work on sexuality (1976; 1986), subjectivity (1980b; 1982), and madness and criminality $(1977 ; 2001 ; 2006)$, the practices of everyday workers in this study are also found to be subject to what they have come to know as the truth about themselves.

Truth, as Foucault explains (see Chapter Two, pp. 43-46), emerged as specific forms of knowledge around the needs of particular disciplines (or practices) by defining what is 'normal' or 'abnormal' (see Chapter Two, pp. 46-47), in order to naturalise the behaviours of individuals according to different categories or identities, for example, the sick and the healthy, and the criminal and the good (1982). Behaviours in these classifications are arguably tied to cumulative meanings to identify the signs of normality and abnormality (McKinlay \& Taylor 2014, p. 1). This subtle method of control enabled a continuous measurement of individual performance, subject to a person's identity (position or status), which was interpreted and perceived by others as well as by themselves according to the dominant discourses in their everyday social relationships (Smart 1985, pp. 104-107). As Chapter Three explains, Foucault describes these social relationships as power-knowledge relations that consist of a network, such as schools, hospitals, workplaces, and families, in which they together produce and 
reproduce the discourses of truth, in order to regulate the behaviours of self and others (1997, pp. 299-301; see Chapter Two, pp. 45-46). Foucault terms such individual engagement in selfregulation (or self-governance) in conforming to these discourses of 'truth', as the 'effects of governmentality' (or the 'conduct or conduct'), which describes the effective operations of both direct (the State or institutions per se) and indirect (the social network) forms of disciplinary power in guiding people's behaviours to the desired end of others (2008, pp. 4042; see Chapter Two, p. 36). In the case of Chinese workers, Chapter Four and Chapters Six and Seven show that the desired end has been to meet the aims of the State and management to maintain an abundant docile labour force in the market economy.

The evidence as presented in Chapter Four and then in Chapters Six and Seven about the governmentalisation of everyday Chinese workers in this study shows that the social operations of a disciplinary power includes self-regulation among workers in achieving the CCP's desire to sustain China's docile labour force under the discourses of quality (see Chapters Three, pp. 83-92; Six, pp. 156-159; Seven, pp. 201-202). This assertion is further supported by workers' self-recognisation and acceptance of their devalued and subservient status through which they believed that their employment opportunities are minimised by their lack of education. It is this mindset (or mentality) among workers that steers them to internally accept any conditions that are prescribed for their status, causing them to obey the 'natural' rules of their work leaders in return for a liveable income.

With the embracing of the truth about their personal quality in social relationships, these workers defined and reinforced practices and norms for themselves, under which their existence as 'low-quality' workers is reflected in their 'rights to subsistence' (Chen 2000, p. 44; see Chapter Four, p. 102). This idea appears to preoccupy their minds, even while they are conscious of and protested against economic issues at work. Consequently, as Chapter Seven shows (see pp. 201-202) protest actions by Group Two workers spring neither from a rational effort at improving their treatment at work, nor a push for better working conditions, but simply from the 'norm-based moral sense' of their deservingness of minimal subsistence levels within the 'quality-based' status structure.

The findings suggest that - as Foucault (1987, see Chapter Two, pp. 47-48) argues - the 'normbased moralities' of the two groups of workers are further reinforced by their self-care (or care 
of the self) practices that is associated with a sense of duty (or responsibility) in order to secure the lives for themselves and others (Foucault 1987; see Chapter Two, pp. 50-53). This effort is mostly directed at looking after others which has been repeatedly emphasised in workers' discourses (see Chapters Six and Seven). Beyond the flow of normative behaviours, care ethics are defined by the workers in terms of the areas of meanings and purposes for their existence which is opposite to the 'me first' ethics:

[...] taking care of the family is the normal responsibility for most of us in China [...] that's why we come out to dagong.

(Group One, Wang, Motel Cleaner, Shenzhen, 2011)

I could easily have lost my job over that [protest] and yet I have a family to look after $[\ldots]$ my old parents, my wife and my child [...]

(Group Two, Yuan, Plastic Board Manufacturing Worker, Foshan, 2013)

It is argued that, as Chapters Three, Six and Seven show - this double responsibility - towards others and towards the selves - along with the internalised rules (or norms) among the workers - worked together to constitute a basis for them to become docile bodies and minds in the Chinese labour markets.

Although threats to workers' deservingness of minimal subsistence triggered collective actions, these protest activities were weighed down by their care practices to retain their job so as to be able to look after 'others'. The matters of self-care practices which influenced their moral judgment about the rightness or wrongness of work practices, thus rarely resulted in protest activities being triggered by a strong sense of solidarity as illustrated in Chapter Seven.

In summary, while the work-based experiences have incited Group Two workers to engage in protest activities their actions are grounded in their immediate day-to-day survival needs, which is limited to 'prescribed' conditions in accordance with their given positions.

Thus, the lack of interest among both groups of workers to engage in the long-term improvement of their conditions leads to the consideration of the third research question posed to this thesis: 
Research Question 3: How does the shaping of worker consciousness affect their ability to develop themselves into an organised labour movement to improve living and working conditions for themselves and others?

The findings suggest that protest activities are frequently sparked by deep-seated economic issues among the workers; their protest behaviours appear to be driven by their deservingness of the 'rights to subsistence' (Chen 2000, p. 44; see Chapter Four, p. 102) on an individual level. However, as Chapter Seven shows, their lack of a united voice in the protests, as characterised by different individualistic demands, hardly ever brought about positive outcomes for the workers. The findings presented in Chapter Seven (see pp. 200-202) further suggest that the effectiveness of the protest actions by Group Two workers is undermined by their collective recognition of the truth about their positions within the quality-based hierarchy. Thus, even while they engaged in protest actions, the quiescent habits of workers are constituted by their unchanged perception of themselves as ignorant subjects, which is linked to the sense of their inferior (or 'low') position (or identity).

Much like the relation between a true sex and gender identity (Foucault 1986; see Chapter Two, pp. 48-49), the idea of true quality determined these workers' identities and their subsequent behaviour in the marketplace. While it can be argued that their daily experiences, as well as the efforts of NGOs (non-government organisations), created opportunities for workers to protect their legal rights (weiquan 維權) as well as to question the status quo through alternative truths (or counter-hegemonic discourse), their true selves are still upheld by their ongoing proper performance, in line with the expectations associated with their identities. Implicitly, this mentality guided workers to 'feel' a certain way about themselves.

Rather than class as claimed by mainstream scholars (see Chapter Four, pp. 101-112), the findings illustrate that the workers in this study sample are subject to a strict set of self-imposed regulations, grounded in a cultural understanding of proper behaviour towards their superiors and those in authority. This subsequently minimises their opportunities to permanently change their everyday working conditions.

In summary, this study has illustrated how a centuries-long tradition of Confucian ideologies internalised a power-knowledge regime, with the result of a constructed 'truth' for both groups 
of workers about their status, and what they could expect from society regarding their working conditions as a result of that status.

Hence, rather than take class action, both groups of workers exhibited an internal willingness to live and behave in adherence to the given 'truth' about their 'prescribed' routines. The study therefore argues that by 'exercising' these routines, workers become agents in maintaining the power-knowledge framework - consciously and subconsciously - and thus assume a level of internal 'docility' (or acquiescence) in maintaining their status.

In contrast to the mainstream assumption that resistance activity is necessarily triggered from their exploitative experience as a class (see Chapter Four, pp. 101-112), the findings suggest that there is a high-level of 'obedience' (or docility) among the workers studied, whereby they appeared to 'voluntarily' submit themselves to their repressive circumstances in an uncritical manner. This cultural compliance on the part of the workers is exercised by their self-care practices towards their day-to-day survival needs in order to be able to look after themselves and hence their family members.

In summary, the practices by workers are fundamental to guide them to submit themselves to a 'natural' self-regulation by internally accepting the legitimacy of labour practices that, ultimately, works to the benefit and the will of the State, rather than themselves. It is this aspect of workers' lived experiences that, this study suggests, significantly limits their capacity to exercise agency beyond their power-knowledge networks, and thus constraining classconsciousness and class-for-itself development among everyday workers in China.

\section{Worker Activism and Governmentality in China's Thought Management System}

By engaging with Foucault's theoretical framework, this study contributes to an understanding of the relation between worker activism and politics in China, through the investigation of historical events that have fostered the production and reproduction of docile bodies and minds of workers (see Chapters Four, Six, and Seven) in post-Mao China. The study shows that the (re-) production of docile bodies and mind among Chinese workers is tied to the subtle forms of the replication of power-knowledge - that is, the centuries-long Confucian ideology (or 
knowledge) of 'superior-inferior relationships' (see Chapter Three, pp. 56-61) - which has been embedded through forms of governmentality (Foucault 2014) in the everyday lives of workers throughout the historical development of China. Hence, rather than deploying coercive political rules to control individuals, China's approach to governmentality has drawn on a diversity of approaches to construct a knowledge about workers that regulates their lives with the aim that they serve as an instrument of the State with regards to economic development (see Chapter Three, pp. 79-84).

While Chinese scholars (Chan \& Hui 2016; Pun \& Lu 2010; Smith \& Chan 2015) have emphasised work-based lived experience to argue that there is a development of a rising consciousness and the forming of a class-for-itself by analysing the waves of protest actions, this study instead shows how workers' self-practices that are grounded in both their work and non-work' lived experience to stage resistance have been constrained by the approach to governmentality (the culture and normative dimension), that draws on China's thought management system under the governmental discourses of quality (suzhi 素質), stability maintenance (weiwen 維穩), well-off (xiaokang 小康) and harmonious society (hexie shehui 和 諧社會) (Brady 2012a, p. 2; Benney 2016, p. 390; Xu 2009, p. 38; see Chapter Four, pp. 117119).

However, Chinese workers cannot exercise their agency outside their power-knowledge relations, it is suggested that they can still adjust their thoughts and behaviour (Foucault 1997; Chapter Two, pp. 49-50). For example, the CCP leaders exercised tight control over flows of information following the 1989 crackdown of the Tiananmen movement and the successful democratic revolutions in the Middle Eastern countries in order to sustain its 'mandate' (Cheng 1979; Tan 2009; see Chapter Three, pp. 56-61) to dominate the Chinese population (Buckley 2011; Florcruz 2014). This particular form of domination was facilitated by prolonged censorship of the mass media, such as newspapers and the internet, which were prohibited from reporting potentially disruptive knowledge, such as information on the Western concept of democratic political participation (Zang 2011). The practice of censorship as a form of control in China had had a long history. It dates the Qin dynasty (221 B.C.E - 206 B.C.E), for example, the emperor burned all disapproved books (Ching, Jarzombek \& Prakash 2007). Similar practices continued throughout the history of Imperial China, right up to the last emperors of the Qing dynasty (1644-1912), under which literary inquisitions were held and disobedient 
authors persecuted (Yutang 1936). Similarly, in 1966, during the Cultural Revolution in Mao period, Confucian and capitalistic materials were also destroyed as a form of censorship (Grasso, Corrin \& Kort 2009; Weatherley 2006).

Given the long historical experience of censorship, the Chinese masses "understand well that they cannot openly ask for democracy and will not get it even if they ask for it” (Zang 2011, p. 179). Rather than confronting the CCP leaders openly, approximately one percent of Chinese 'netizens', for example, began using anti-censorship products, such as Astrill, to bypass the CCP internet filter 'Great Firewalls' to gain access to 'outside' knowledge and to make ironic and satirical comments (Benney 2015; MacKinnon 2008; 2012, p. 35). A few shared sarcastic comments with each other, saying things such as "socialism is good" and "I have been represented by my local officials" ( $\mathrm{Ng} 2013$, p. xxi) as a way to criticise the performance of government officials in terms of their wrongdoings on the internet forum. It is suggested that by changing the way they interacted with each other, this small percentage of 'netizens' showed an extension of the ethics of the self through caring for others in such muted forms of 'resistance'. This creative form of 'resistance' and existence lays a foundation for the 'lowquality' Chinese workers to ethically exercise practices of freedom and to resist the normalising power in order to improve their working and living conditions within the power-knowledge relations.

However, the research sample discussed in Chapter Seven shows that while work-based experiences have sparked workers' triggered Group Two workers to engage in protest actions, their discourses reflect little willingness to improve their working and living conditions wherein their resistance activities reveal that at times they retreated from the protest actions without any redress of their grievances such as low-wage issues. Furthermore, their gains remained minimal and did not change their living and working conditions to any great degree. From Foucault's (1980b; 1982; Chapter Two, pp. 36-37) perspective, workers' protest behaviours and attitudes as examined in this study were underlined by the productive functions of governmentality in China's thought management system, which compelled and remained them to be workers appropriate to the aims of the Chinese State, by producing and internalising the truth about themselves. Thus, as Chapters Six and Seven show, the nature of the truth (Foucault 1980b) particularised workers' identities to organise the sense of their selves, which in turn constrained their agency and capacity to respond to certain circumstances in certain 
ways. As a result, workers' identities and their subjective capacities - their choices, desires, skills, thoughts, behaviours, and lifestyles - are all assured by the fact their activities are conducted within the deliberate setting of specific norms and prescribed routines (see Chapters Two, pp. 40-47; Three, pp. 79-92; Four, pp. 103-107; Six, pp. 165-168; Seven, pp. 198-202). This context reflects that workers are not only the products of power, but also agents in exercising a 'micro-physics of disciplinary power' (Foucault 1977, p. 26; see Chapter Two, p. 37), thus controlling their own thoughts and behaviours among themselves through their lived experience. Because of this, it is argued that it is debatable whether everyday workers in China can overcome the centuries-old cultivation of docile bodies and minds among themselves to engage in activism that will lead to the formation of an active working class to improve their living and working conditions for themselves and others in China.

To conclude, this chapter has discussed how the study contributes to understanding the research questions and propositions that were stated for the study. It has been argued that the 'truth' of status, linked with centuries-long Confucian ideology, has historically produced (see Chapter Four) and reproduced (see Chapters Six and Seven) docile bodies and minds among Chinese workers in working for the will of the CCP. As Chapter Seven shows, while work-based experiences provoked Group Two workers to engage in protest actions, the findings show that their psyches have not moved away from acquiescence to the authority of the Chinese State, regardless of their experience at, and of, work. This strength of 'older rules consciousness' in the everyday practices of Chinese workers as shown in this thesis has thus illustrated how the linkage between past knowledge and present social practices that have constituted Chinese workers as a specific kind of subject, that is, docile bodies and minds, which have severely constrained their possibility to become a class-for-itself to act collectively to improve their conditions beyond their power-knowledge relations. Thus, this study proposes that understanding worker consciousness in China is not simply a matter of workers coalescing to act, but one that is indelibly influenced by matters of culture and history. Developing detailed accounts of these influences is important to then do as Foucault (1980a, p. 83) tasks us: “...establish[ing] a historical knowledge of struggles and to make use of this knowledge tactically today". 


\section{Major Contribution}

The unique contribution of this thesis lies in the ethnographic data collection in multiple locations across various industrial sectors in China to understanding how living and working in post-Mao China has shaped the consciousness of everyday Chinese workers, and how this consciousness affects their activism, as well as their ability to develop themselves into an organised labour movement to improve their living and working conditions for themselves and others using Foucault's analytical tools (see Chapter Two). Drawing on Foucault's (1991a) concepts and methods, the study analyses historical events and original empirical research to highlight the problem of how China's thought management (sixiang guanli) is exercised through the governmental discourses of quality (suzhi), stability maintenance (weiwen), welloff (xiaokang) and harmonious society (hexie shehui) (Brady 2012a, p. 2; Benney 2016, p. 390; Xu 2009, p. 38; see Chapters Three, pp. 79-85). Chapter Three has illustrated how China operated its governmental discourses around the management of the lives of workers wherein Chapters Six and Seven have discussed the resulting trends of shaping or influencing worker consciousness to achieve its will in the present time.

\section{Limitations}

However, the findings in this thesis were obtained from a relatively small sample of workers when compared to the numbers of workers in China, and samples used by other research in China; hence generalisability of the data is not claimed. Rather, the study contextualises the findings to allow better elaboration about the lived experiences of everyday workers, using Foucault's lenses. While this does not undermine the value of this research, it is important to note this limitation.

Some of the challenges encountered by the researcher within the $\mathrm{PhD}$ process included those of time and funding limitations throughout the four-year period of data collection in China. These limitations represented a major difficulty for the researcher in terms of accessing participants in China. During the first phase of data collection (2011-2012), the researcher aimed to collect data on worker activism in China (see Chapter Five) based on the background assumptions (see Chapters One and Four). However, during the time spent in the first field site, the researcher realised that it was impossible to solely collect this one data set (see Chapter 
Five). Thus, the researcher had to adjust the research methodology (see Chapter Five) to recruit participants within the sampling timeframe.

Although 53 participants were recruited in the first phase of data collection, most of them appeared to be relatively quiescent and submissive (see Chapters Five and Six). Given that the focus of this study was to examine how everyday workers' lived experiences had influenced them to campaign and improve their working and hence living conditions, the researcher deliberately contacted those who had participated in protest actions, through a number of NGOs, in the second phase of data collection (2013-2014) (see Chapter Five). Making this arrangement was difficult and time-consuming, as the researcher had to approach, and establish a working relationship with NGO workers in Hong Kong and China. While the NGO workers were able to introduce the researcher to workers who had participated in protest actions in order to conduct the interviews, in many cases the researcher did not know the workers long enough to be able to conduct follow-up interviews with them, due to restrictions of time and funding.

The lack of a voice from government officials, for example, from the Ministry of Labour, in the exploring of the impacts of labour rights violations and worker protests, is another limitation of this study. The perspectives of Chinese government officials on worker protests and labour rights violations are seemingly unexplored in the existing literature. Including these perspectives would undoubtedly have offered a greater understanding of mutual perceptions, and better insight into the social interactions and relationships embedded between various parties in China.

Finally, the use of Foucault's governmentality approaches to explore the Chinese activist culture may lead to a pessimistic view of the development of worker consciousness and activism for this study. This hopelessness is grounded in the limited agency (or action) imbued with Foucault's manners in analysing the subjects, thoughts and behaviours through the evaluation of the discourses, such as 'madmen' (Foucault 2006) and 'prisoners' (Foucault 1977). This aspect of Foucault's work has been criticised by writers such as Anthony Giddens (1993); Tim Newston (1998) and Mike Reed (2000) for undermining the possibilities of human agency, choices, change and hence resistance in the social world. Such possibilities, however, are found in Foucault's (1990) works, particularly in his final works $(1986 ; 1987)$, that manifestations of power are innately defined by various patterns of resistance against the 
specific normalising disciplinary practices (or 'counter conducts') (Dean 2010, p. 9) through ethical practices (care of the self or aesthetics of existence) (Foucault 1997) in particular cultures (see Chapter Two, pp. 49-51). Following Foucault's work, this study illustrates an example of Chinese 'netizens' to explore how everyday workers may be able to adjust their thoughts and behaviours to engage in creative forms and long-term resistant activities to improve their working and living conditions within the power-knowledge relations as discussed in this thesis.

\section{Future Research}

Conducting research in authoritarian countries is a difficult task, particularly in this context, given the subject's complexity and sensitivity. While this study has generated important findings, further research is still required in order to fully understand how China's governmentality has shaped a consciousness and influenced the lived experiences of 'the Chinese' beyond the geography of China. An important implication that emerges from this research study is how the Chinese State continues to influence and manage its subjects who reside outside of China (or overseas Chinese) to serve the interests of the CCP (Chinese Communist Party). The CCP's transnational governmental programmes 'overseas Chinese work' (qiaowu 僑務) ${ }^{81}$ by using discourses such as 'falling leaves return to their roots' (luoye guigen 落葉歸根) in mobilising overseas Chinese to support the Chinese State (Liu \& vanDongen 2016). Positive effect of qiaowu programmes, for example, was evident as the overseas Chinese reacted negatively to the 2008 Tibetan unrest ${ }^{82}$ and the pro-Tibetan independence with comments damaging China's reputation as an Olympic host aired on the Western media, such as CNN and BBC (LaFleur 2010). The acts of Tibetans and Western media had sparked outrage among overseas Chinese all around the world to protest against the Tibet independence and anti-China media coverage to voice support for the Beijing Olympics (Callahan 2010). In Germany, thousands of overseas Chinese participated in the march and sang patriotic songs and chanted 'Go Beijing!' with the slogans such as 'Tibet was, is and will be a part of China' and 'Boycotting Olympics = New Berlin Wall' (Xinhua 2008). The

\footnotetext{
${ }^{81}$ Qiaowu 僑務 ('overseas Chinese work') programmes are facilitated through the networks of foreign legion of diplomats, agents and cadres to influence the thoughts and behaviours of overseas Chinese. See Liu, H \& vanDongen, E 2016, 'China's Diaspora Policies as a New Mode of Transnational Governance', Journal of Contemporary China, vol. 25, no. 102, pp. 805-821.

82 The 2008 Tibetan unrest was a series of riots, protests, and demonstrations that attempted to overthrow the Chinese rules and occupation of Tibet. See LaFleur, R 2010, Asia in Focus: China, ABC CLIO, Oxford.
} 
Guardian also reported that in the U.S. as well as Britain, thousands of overseas Chinese gathered outside CNN's offices in California and the BBC in Manchester to protest against distorted Western reporting (Chinese Nationalists Hit at Carrefour over Tibet 2008). These worldwide protests were a complete reversal of the anti-CCP sentiment of the 1989 Tiananmen movement. These phenomena thereby lead to a question of how is this level of widespread support for China and the CCP leaders achieved among the overseas Chinese through qiaowu efforts?

It is suggested that the considerably efforts of the CCP's qiaowu programmes to secure the loyalty of the overseas Chinese is becoming an essential part for China's economic development initiatives abroad (Barabantseva 2011). The continuation of the overseas and local Chinese workers in engaging in the practice of docile bodies and minds thus suggests the spreading of China's governmentality beyond its geo-political environment. This is a matter for serious consideration in light of the growing industrial power of China and the spread of its industrial activities, population and power worldwide, and for conducting future research.

\section{Concluding Remarks}

In conclusion, the study holds a number of implications for the future of not only workers in China, but also workers elsewhere, as the influence of Chinese thought spreads through strategies such as these, as well as of course through China's investment power. Future research could thus build on the research undertaken here to explore these implications further. 


\section{Appendix}

\section{Appendix 1: Labour Law (1995) and The Labour Contract Law (2008)}

The Labour Contract Law (2008) is an addition to the Labour Law (1995) with an emphasis on the use of employment contracts in order to improve workers' rights. The following clauses cover the legal rights of workers as outlined in the introductory chapter:

\section{Labour Law (1995)}

Article 3: Labourers have the right to be employed on an equal basis, choose occupations, obtain remunerations for labour, take rests, have holidays and leaves, receive labour safety and sanitation protection, get training in professional skills, enjoy social insurance and welfare treatment, and submit applications for settlement of labour disputes, and other labour rights stipulated by law.

Article 36: The State shall practise a working hour system wherein labourers shall work for no more than eight hours a day and no more than 44 hours a week on the average.

Article 41: The employer can prolong work hours due to needs of production or businesses after consultation with its trade union and labourers. The work hours to be prolonged, in general, shall be no longer than one hour a day, or no more than three hours a day if such prolonging is called for due to special reasons and under the condition that the physical health of labourers is guaranteed. The work time to be prolonged shall not exceed, however, 36 hours a month.

Article 70: The State shall promote the development of the cause of social insurance, establish a social insurance system, and set up social insurance funds so that labourers can receive help and compensation when they become old, suffer diseases or work-related injuries, lose their jobs, and give birth.

Article 72: The sources of social insurance funds shall be determined according to the categories of insurance, and the practice of unified accumulation of insurance funds shall be introduced. The employer and individual labourers shall participate in social insurance in accordance with law and pay social insurance costs.

Article 44: The employer shall pay labourers more wage remunerations than those for normal work according to the following standards in any one of the following cases:

(1) Wage payments to labourers no less than 150 per cent of their wages if the labourers are asked to work longer hours; (2) Wage payments to labourers no less than 200 per cent of their wages if no rest can be arranged afterwards for the labourers asked to work on days of rest; (3) Wage payments to labourers no less than 300 per cent of their wages if the labourers are asked to work on legal holidays. 


\section{Labour Contract Law (2008)}

Article 10: A written labour contract shall be concluded in the establishment of an employment

Article 6: The labour union shall assist and direct the employees when they conclude with the employers and fulfil labour contracts and establish a collective negotiation mechanism with the employers so as to maintain the lawful rights and interests of the employees.

Article 78: A labour union shall protect the employees' legitimate rights and interests and supervise the employer's fulfilment of the labour contracts and collective contracts. If the employer violates any law or regulation or breaches any labour contract or collective contract, the labour union may put forward its opinions and require the employer to make ratification. If the employee applies for arbitration or lodges a lawsuit, the labour union shall support and help him in pursuance of law.

\section{Appendix 2: Interview Schedule}

The study was guided by the following interview schedule when conducting the two phases of data collection in China:

1. Background of the participants - (such as their location of residence, family members, age, education and livelihood)

2. Ask the participant to describe the employment issues they have.

3. How old are they?

4. Do they have siblings and where are they?

5. Why do they migrate to the chosen cities, and why migration is the option?

6. What do they do for a living? What did they do previously? And why did they resign from the previous jobs?

7. Where do they live in the cities? In a dormitory or a share flat with other workers?

8. How much do they pay to rent the place?

9. How much do they earn each month? What is the base-wage like?

10. In general (regardless the locations of the jobs), did/do their employers or work leaders treat them well?

11. How do they like their current jobs?

12. What and where do they usually have their meals? How much do they spend on their meals each week?

13. Do they have to send money to their parents or family members? How much do they usually send home?

14. Did/do they have employment contracts?

15. Did/do they have annual leave?

16. Were/are they entitled for sick leave when you were/are unwell?

17. Did/does the factory compliance with the codes of occupational safety and health?

18. Did/do they have the pension and social insurance benefits? 
19. On average, how many hours did/do they work each day?

20. Did/do they receive overtime payment if you were/are required to work overtime?

21. Are they allowed to refuse doing overtime work?

22. Do they have to achieve any work quotas? If so, what happens if they failed to achieve the set quotas?

23. Do they get penalised if they make mistakes at work?

24. Did/do they receive year-end bonus?

25. Ask the participants to describe the work flows and organisational structure

26. What do they think of their current and previous living and working environments?

27. Have they ever sought assistance from their local unions, worker representatives, or other organisations when the employers mistreated them?

28. If so, were the unions helping?

29. If the unions were helping, were they happy with the result?

30. If the unions were not providing assistance, what did they do to defence their rights?

31. As a worker and a social member, do they know anything about their labour rights, both before and after the new labour law came into effect?

32. In 2008, the government had introduced a new labour law to protect workers, have they heard of it? If so, did the new law make a positive impact for the majority workers?

33. Have they ever participated in protest actions? Why and why not?

34. Who organised the protest actions? What were their strike demands?

35. How long did the strike actions last?

36. Did they achieve what they aim throughout the strike actions?

37. Were there any difficulties in organising and coalescing the co-workers to strike for the same goals?

38. Do they think protest actions are an effective means to resolve their work-related issues?

Do they think they will engage in protest action again? 


\section{Appendix 3: Respondents' Profile}

Group One - who had never engaged in any protest activities

\begin{tabular}{|c|c|c|c|c|c|}
\hline Names & Gender & Age & Occupation & Hometown & Current City \\
\hline Xiao Fong & $\mathrm{F}$ & 17 & $\begin{array}{l}\text { Waitperson (Video } \\
\text { Game Centre) }\end{array}$ & Guangxi & Shenzhen \\
\hline Xiao Lin & $\mathrm{F}$ & 18 & $\begin{array}{l}\text { Waitperson (Video } \\
\text { Game Centre) }\end{array}$ & Guangxi & Shenzhen \\
\hline Xiao Yin & M & 17 & $\begin{array}{c}\text { Waitperson (Video } \\
\text { Game Centre) }\end{array}$ & Chongqing & Shenzhen \\
\hline Huage & M & 35 & $\begin{array}{l}\text { Security Officer } \\
\text { (Massage Centre) }\end{array}$ & Hunan & Shenzhen \\
\hline $\begin{array}{c}\text { Mrs Qin/Mr } \\
\text { Qin }\end{array}$ & $\mathrm{F} / \mathrm{M}$ & $35 / 38$ & Small Eatery & Hunan & Shenzhen \\
\hline Zhi & M & 22 & Foxconn Worker & Chongqing & Shenzhen \\
\hline Yanam & $\mathrm{M}$ & 22 & Foxconn Worker & Guangxi & Shenzhen \\
\hline Qui & $\mathrm{M}$ & 23 & Unemployed & Guangxi & Shenzhen \\
\hline Xiaomei & $\mathrm{F}$ & 17 & $\begin{array}{c}\text { Electronics } \\
\text { Factory Worker }\end{array}$ & Hubei & Shenzhen \\
\hline Yachai & M & 35 & $\begin{array}{l}\text { Security Officer } \\
\text { (Factory) }\end{array}$ & Hubei & Shenzhen \\
\hline Xiaoyan & $\mathrm{F}$ & 19 & $\begin{array}{c}\text { Electronics } \\
\text { Factory Worker }\end{array}$ & Hunan & Shenzhen \\
\hline Xiaoyuan & $\mathrm{F}$ & 19 & Foxconn Worker & Jiangxi & Shenzhen \\
\hline Xiaoqin & F & 24 & $\begin{array}{c}\text { Cosmestic Sales } \\
\text { Assistant }\end{array}$ & Hubei & Shenzhen \\
\hline Yaxing & $\mathrm{M}$ & 26 & IT Worker & Hubei & Shenzhen \\
\hline $\mathrm{Li}$ & $\mathrm{M}$ & 50 & Professor & Anhui & Hefei \\
\hline Xiaofang & $\mathrm{F}$ & 22 & NGO Worker & Anhui & Hefei \\
\hline Tai & $\mathrm{M}$ & 22 & NGO Worker & Shandong & Hefei \\
\hline Huang & $\mathrm{F}$ & 24 & $\begin{array}{l}\text { Clerk in Chemistry } \\
\text { factory }\end{array}$ & Anhui & Hefei \\
\hline Minge & M & 50 & $\begin{array}{l}\text { Security Officer } \\
\text { (Factory) }\end{array}$ & Anhui & Hefei \\
\hline Хiaoyu & $\mathrm{F}$ & 25 & $\begin{array}{c}\text { Electronics } \\
\text { Factory Worker }\end{array}$ & Anhui & Hefei \\
\hline Ge & M & 23 & $\begin{array}{c}\text { SOE Car Factory } \\
\text { Worker }\end{array}$ & Ningxia & Hefei \\
\hline Rong & $\mathrm{M}$ & 26 & $\begin{array}{c}\text { Tyre } \\
\text { Manufacturing } \\
\text { Worker } \\
\end{array}$ & Anhui & Hefei \\
\hline Qing & $\mathrm{F}$ & 20 & $\begin{array}{c}\text { SOE Car Factory } \\
\text { Worker }\end{array}$ & Anhui & Hefei \\
\hline Lei & M & 50 & $\begin{array}{l}\text { SOE Ready-mix } \\
\text { Concrete Worker }\end{array}$ & Anhui & Hefei \\
\hline Cai & M & 40 & $\begin{array}{l}\text { SOE Ready-mix } \\
\text { Concrete Worker }\end{array}$ & Anhui & Hefei \\
\hline Ding & M & 30 & $\begin{array}{l}\text { SOE Ready-mix } \\
\text { Concrete Worker }\end{array}$ & Anhui & Hefei \\
\hline
\end{tabular}




\begin{tabular}{|c|c|c|c|c|c|}
\hline $\mathrm{Bu}$ & $\mathrm{M}$ & 33 & $\begin{array}{l}\text { SOE Ready-mix } \\
\text { Concrete Worker }\end{array}$ & Anhui & Hefei \\
\hline Lai & $\mathrm{F}$ & 50 & $\begin{array}{c}\text { Garment Factory } \\
\text { Worker }\end{array}$ & Hangzhou & Hangzhou \\
\hline Qingjie & $\mathrm{F}$ & 46 & $\begin{array}{c}\text { Garment Factory } \\
\text { Worker }\end{array}$ & Hangzhou & Hangzhou \\
\hline Fang & $\mathrm{F}$ & 46 & $\begin{array}{c}\text { Garment Factory } \\
\text { Worker }\end{array}$ & Hangzhou & Hangzhou \\
\hline Bing & $\mathrm{F}$ & 30 & Hotel Cleaner & Hangzhou & Hangzhou \\
\hline Xun & $\mathrm{M}$ & 30 & $\begin{array}{l}\text { Lift Manufacturing } \\
\text { Worker }\end{array}$ & Henan & Hangzhou \\
\hline Pin & $\mathrm{F}$ & 45 & Hawker & Sichuan & Hangzhou \\
\hline Yue & $\mathrm{F}$ & 45 & $\begin{array}{c}\text { Electronics } \\
\text { Factory Worker }\end{array}$ & Anhui & Hangzhou \\
\hline Yun & $\mathrm{M}$ & 24 & Construction Work & Anhui & Hangzhou \\
\hline Yang & $\mathrm{F}$ & 41 & Motel Cleaner & Shaanxi & Hangzhou \\
\hline Min & $\mathrm{M}$ & 29 & $\begin{array}{c}\text { Springs } \\
\text { Manufacturing } \\
\text { Worker }\end{array}$ & Henan & Hangzhou \\
\hline Xing & $\mathrm{F}$ & 24 & $\begin{array}{c}\text { Garment Factory } \\
\text { Worker }\end{array}$ & Anhui & Hangzhou \\
\hline Yong & $\mathrm{M}$ & 37 & Cooker & Hangzhou & Hangzhou \\
\hline $\mathrm{Ju}$ & $\mathrm{F}$ & 22 & Boutique Owner & Hangzhou & Hangzhou \\
\hline Xiaohai & $\mathrm{F}$ & 24 & $\begin{array}{c}\text { Electronics } \\
\text { Factory Worker }\end{array}$ & Sichuan & Shenzhen \\
\hline Tianjie & $\mathrm{F}$ & 38 & $\begin{array}{c}\text { Lighting Factory } \\
\text { Worker }\end{array}$ & Hunan & Shenzhen \\
\hline Shunjie & $\mathrm{F}$ & 28 & $\begin{array}{c}\text { Lighting Factory } \\
\text { Worker }\end{array}$ & Guangdong & Shenzhen \\
\hline Yejie & $\mathrm{F}$ & 33 & $\begin{array}{c}\text { Garment Factory } \\
\text { Worker }\end{array}$ & Hunan & Shenzhen \\
\hline Mrs Zhang & $\mathrm{F}$ & 35 & NGO Worker & Hunan & Shenzhen \\
\hline Mr Zhang & $\mathrm{M}$ & 35 & NGO Worker & Hunan & Shenzhen \\
\hline Xiaoshun & $\mathrm{F}$ & 25 & $\begin{array}{c}\text { Electronics } \\
\text { Factory Worker }\end{array}$ & Henan & Shenzhen \\
\hline Chong & $\mathrm{F}$ & 47 & Motel Cleaner & Shanxxi & Shenzhen \\
\hline Wang & $\mathrm{F}$ & 43 & Motel Cleaner & Guangxi & Shenzhen \\
\hline Daoqing & $\mathrm{F}$ & 19 & $\begin{array}{c}\text { Food Processing } \\
\text { Worker }\end{array}$ & Sichuan & Guangzhou \\
\hline Xiao Hua & $\mathrm{F}$ & 26 & NGO Worker & Guangxi & Guangzhou \\
\hline
\end{tabular}

Group Two - who had engaged in protest activities

\begin{tabular}{|c|c|c|c|c|c|}
\hline Names & Gender & Age & Occupation & Hometown & Current City \\
\hline Shen & M & 24 & $\begin{array}{c}\text { Lightening } \\
\text { Factory Worker }\end{array}$ & Guangxi & Shenzhen, Guangzhou \\
\hline Xiaoling & F & 30 & Masseuse & Unknown & Shenzhen, Guangzhou \\
\hline
\end{tabular}




\begin{tabular}{|c|c|c|c|c|c|}
\hline Xiaqing & $\mathrm{F}$ & 36 & Masseuse & Unknown & Shenzhen, Guangzhou \\
\hline Gong & $\mathrm{M}$ & 45 & $\begin{array}{c}\text { Batteries } \\
\text { Manufacturing } \\
\text { Worker }\end{array}$ & Sichuan & Guangzhou \\
\hline Feng & M & 33 & $\begin{array}{l}\text { Plastic Board } \\
\text { Factory Worker }\end{array}$ & Guangxi & Guangzhou \\
\hline Yuan & $\mathrm{M}$ & 30 & $\begin{array}{c}\text { Plastic Board } \\
\text { Factory Worker }\end{array}$ & Guangxi & Guangzhou \\
\hline Liu & $\mathrm{M}$ & 44 & $\begin{array}{c}\text { Porcelin } \\
\text { Manufacturing } \\
\text { Worker }\end{array}$ & Sichuan & Guangzhou \\
\hline Heng & $\mathrm{M}$ & 26 & $\begin{array}{l}\text { Jewellery } \\
\text { Worker }\end{array}$ & Unknown & Guangzhou \\
\hline $\mathrm{Fa}$ & $\mathrm{M}$ & 33 & $\begin{array}{l}\text { Jewellery } \\
\text { Worker }\end{array}$ & Hunan & Guangzhou \\
\hline Xiaohuang & $\mathrm{M}$ & 27 & $\begin{array}{c}\text { Carton Box } \\
\text { Manufacturing } \\
\text { Worker }\end{array}$ & Jiangxi & Guangzhou \\
\hline Mei Lin & $\mathrm{F}$ & 30 & $\begin{array}{l}\text { Jewellery } \\
\text { Worker }\end{array}$ & Guangxi & Guangzhou \\
\hline Jin Hua & $\mathrm{F}$ & 33 & $\begin{array}{l}\text { Jewellery } \\
\text { Worker }\end{array}$ & Guangxi & Guangzhou \\
\hline Qiang & $\mathrm{M}$ & 23 & $\begin{array}{l}\text { Jewellery } \\
\text { Worker }\end{array}$ & Gui Zhou & Guangzhou \\
\hline Hong & $\mathrm{F}$ & 31 & $\begin{array}{l}\text { Jewellery } \\
\text { Worker }\end{array}$ & Henan & Guangzhou \\
\hline Di & $\mathrm{F}$ & 23 & Honda Worker & Guangxi & Guangzhou \\
\hline Zhi & $\mathrm{M}$ & 26 & Honda Worker & Unknown & Guangzhou \\
\hline Yi & $\mathrm{M}$ & 22 & Honda Worker & Unknown & Guangzhou \\
\hline Fang & $\mathrm{F}$ & 35 & Street Cleaner & Unknown & Guangzhou \\
\hline Shan & $\mathrm{F}$ & 37 & Street Cleaner & Unknown & Guangzhou \\
\hline Yao & $\mathrm{F}$ & 41 & Street Cleaner & Unknown & Guangzhou \\
\hline Ying & $\mathrm{F}$ & 40 & Street Cleaner & Unknown & Guangzhou \\
\hline
\end{tabular}




\begin{tabular}{|c|c|c|c|c|c|}
\hline Shao & M & 24 & Farment & & \\
Factory Worker & Anhui & Hangzhou \\
\hline
\end{tabular}




\title{
Appendix 4: Exception from Requiring Signed Consent Form from the Research Participants
}

\author{
Dr Donella Craparuz \\ UTWA Buinen School \\ MBDP: M261
}

Dear Doctor Caspersz

HUMAN RESEARCH ETHICS APPROVAL - THE UNIVERSITY OF WESTERN AUSTRALIA

The Employment and Lived Experience at Work and in Socieny of Textile and Garment Workers Engaging in Domestic Production in Ceniral and Western China

\section{Smadend(s): Elly Lewng}

Ethics approval for the above projoct has bean ganted from 05 Angust 2011 to 01 Angust 2012 in accordance with the requirements of the National Statement on Frhical Conduct in Fuman Resecurch (Nutional Statement) and the policien and procedures of The University of Westem Australia.

You are reminded of the following requirements:

1. The applicaticn and all supporting documantation form the basis of the ochies approral and you mast not depart from the resesrch protocol that has bean approved.

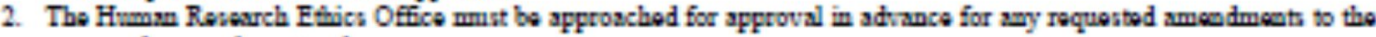
spprowod revasrch protocol.

3. The Chief Invostigator is required to roport immediately to the Humen Research Ethics Offee any adverne or unerpected vrent or any otber ervat that may impset on the othich ryproval for the project.

4. The Chiof Imvestigator must inform the Human Research Ethics Office as voon as practicable if a research project is discontimued before the expected dete of completion, providing ressoms.

Any conditions of othies approval that han boen imposed are listed below:

\section{Special Conditions}

\section{None specified}

The Univority of Westorn Austalis is bound by the Nationsl Satement to monitor the progren of all approved projects untl



Plesa note that the maximnm period of ethics approval for this project is five (5) yaus from the date of this nocification.

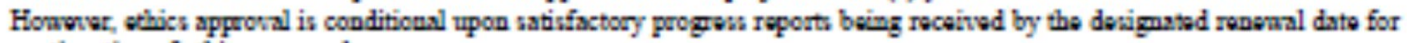
contimation of othics approvsl.

The Hruman Research Ethics Office will forward a requent for a Progrens Report rpproximately 60 drys before the dae date. A further raminder will be forwarded approximately 30 days before the due date.

If your progens report is not receinvd by the due date for renewal of ethics approval, penr ethice approval will expirs requiring that all resesch activitios involving humen participonth cesse immodiately.

If you have any quarios ploase do not besiate to contact the Human Research Ethics Offee (HREO) at hreo- 


\section{Appendix 5: Translated Consent Sheet}

\section{口頭同意書}

\section{研究細節 :}

\section{類型：口頭同意書}

參與者 $: 18$ 歲以上

\section{研究項目 :}

了解中國勞工的生活狀況

調查員 : Donella Caspersz 博士及梁雅莉 (Elly Leung)

背景及目的 :閣下已被邀請參與西澳洲大學商學院的一份博士論文調查計劃. 本研究計 劃的目的是了解中國勞工的生活狀況,此研究將探討中國近代在社會及經濟的改革情況.

正因閣下現於中國居住及工作, 現已被邀請提供閣下於生活及工作的體驗及意見. 如時 間許可, 誠意希望閣下能與研究員梁雅莉進行相關討論.

程序 : 是次討論將以小組或個人形式進行, 討論時間約四十五分鐘至一個半小時. 在閣 下同意下, 討論内容將被記錄, 目的只是更作準確記錄該次討論内容. 記錄資料將會安全 地存放於西澳洲大學商學院, 並會於論文完成後毀掉.

機密及風險 : 是次研究不存在任何危害, 風險或構成不便. 不會記名及以任何形式透露 閣下身份以保障閣下個人私隱. 而在討論中, 閣下亦有權選擇是否需要回答或討論某些 會引致不安的問題.

退出參與 : 閣下的參與屬義務性質, 可在任何討論時間内退出參與, 不會受責.

參與權益 : 是次討論不涉及任何費用及利益, 將以義務形式於工作時間外, 閣下認為合 適及方便的時間及地點進行, 因此不會對閣下騰出的時間作任何保贘. 


\section{投訴 :}

如閤下對是次研究有任何投訴, 可致電 5108585 聯絡安徽大學本地勞動法學系李坤剛教 授, 或電郵至 Donella.Caspersz@uwa.edu.au 聯絡西澳洲大學商學院 Donella Caspersz 博 士.

藉此機會多謝閣下閲讀此份口頭同意書, 無論是否參與, 本人謹致謝意.

Donella Caspersz 博士

西澳洲大學商學院管理及組織學系

研究員梁雅莉 


\section{Appendix 6: Original Consent Sheet}

\section{VERBAL CONSENT FORM}

\section{STUDY DETAILS:}

Type: Verbal Consent Sheet

Participants: Over 18

\section{Study Title: Understanding the Lived Experiences of Everyday Workers in China}

Researcher: Dr Donella Caspersz \& Elly Leung

BACKGROUND AND PURPOSES: You are being asked to take part in a research project for a doctoral thesis for the UWA Business School in Australia. The aim of this research is to understand the lived experience of ordinary workers in China. The research is contributing to an assessment of the social and economic transformation in China. As someone who lives and works in China, you are invited to provide insights about your experience at work and in society, and we appreciate it if the researcher, Elly Leung, could hold a discussion with you at your convenience.

PROCEDURES: The format of this discussion will either be a group discussion or private discussion. It will take at least forty-five minutes to a maximum of one and a half hours. With your permission this discussion will be transcribed. This is solely for the purpose of accurately recording the conversation. These transcriptions will be stored securely at the UWA Business School and will be destroyed once the thesis is completed.

CONFIDENTIALITY AND RISKS: This research imposes no harms, risks or inconveniences. There will be no names or other forms of identification are used to protect your personal security. Please know though that you do not have to answer any questions or discuss any issues that make you feel uncomfortable. 
WITHDRAWAL OF PARTICIPATION: Participatory is voluntary. Should you decide at any time during the discussion that you no longer wish to participate, you may withdraw your consent without prejudice.

COSTS BENEFITS TO YOU: There are no costs involved with the participation of the discussion. There are also no direct benefits to you as such a voluntary-based discussion will be held after your working hours, any time, any where, at your convenience, and therefore your time will not be compensated.

COMPLAINTS: Should you have any complaints about the research, you can contact local Labour Law Professor Li Kungang at Anhui University on 5108585 or Donella Caspersz, at UWA Business School: Donella.Caspersz@uwa.edu.au

I would like to take this opportunity to thank you for taking the time to listen to this consent sheet and, whether or not you decide to take part in the research, to thank you for considering it.

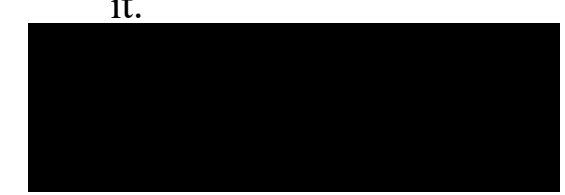

Dr Donella Caspersz

Management and Organisation

UWA Business School

Elly Leung

Research Candidate 


\section{Bibliography}

ACFTU 1997, Labour Law of the People's Republic of China. Available from:

$<$ http://www.acftu.org.cn/template/10002/file.jsp?cid=56\&aid=31 >. [10 September 2012].

Ahn, B-J 1975, 'The Political Economy of the People's Commune in China: Changes and Continuities', The Journal of Asian Studies, vol. 34, no. 3, pp. 631-658.

Althusser, L 1965/2005, For Marx, trans. B Brewster, Verso, New York.

Avery, R 1960, 'Enculturation in Industrial Research', IRE Transcations on Engineering Management, vol. 7, no. 1, pp. 20-24.

Bacchi, C 2012, 'Why Study Problematizations? Making Politics Visible', Open Journal of Political Science, vol. 2, no. 1, pp. 1-8.

Baek, SW 2000, 'The Changing Trade Unions in China', Journal of Contemporary Asia, vol. 30, no. 1, pp. 46-66.

Ball, S \& Olmedo, A 2013, 'Care of the Self, Resistance and Subjectivity under Neoliberal Governmentalities', Critical Studies in Education, vol. 54, no. 1, pp. 85-96.

Bao, S, Chang, GH, Sachs, J \& Woo, WT 2002, 'Geographic Factors and China's Regional Development under Market Reforms, 1978-1998', China Eocnomic Review, vol. 13, pp. 89-111.

Barabantseva, E 2011, Overseas Chinese, Ethnic Minorities and Nationalism: De-Centering China, Routledge, New York.

Barcelos, C 2013, 'Producing (potentially) Pregnant Teen Bodies: Biopower and Adolescent Pregnancy in the USA', Critical Public Health, vol. 24, no. 4, pp. 476-488.

Barlow, J 1981, 'Mass Line Leadership and Thought Reform in China', American Psychologist, vol. 36, no. 3, pp. 300-309.

Basit, T 2003, 'Manual or Electronic? The Role of Coding in Qualitative Data Analysis', Educational Reseach, vol. 45, no. 2, pp. 143-154.

Bell, D 2008, China's New Confucianism: Politics and Everyday Life in a Changing Society, Princeton University Press, New Jersey.

Benney, J 2013, Defending Rights in Contemporary China: Reserving the Right, Routledge, New York.

Benney, J 2015, "'The Corpses were Emotionally Stable": Agency and Passivity on the Chinese Internet', in China Online: Locating Society in Online Spaces, eds P Marolt \& DK Herold, Routledge, New York, pp. 33-48.

Benney, J 2016, 'Weiwen at the Grassroots: China's Stability Maintenance Apparatus as a Means of Conflict Resolution', Journal of Contemporary China, vol. 25, no. 99, pp. 389-405.

Benney, J \& Marolt, P 2015, 'Modes of Activism and Engagement in the Chinese Public Sphere', Asian Studies Review, vol. 39, no. 1, pp. 88-89.

Bentham, J 1843, The Works of Jeremy Bentham, William Tait, Edinburgh.

Besley, T \& Peters, MA 2007, Subjectivity \& Truth: Foucault, Education, and the Culture of Self, Peter Lang, New York.

Biddulph, S 2015, The Stability Imperative: Human Rights and Law in China, UBC Press, Toronto.

Blecher, M 2002, 'Hegemony and Workers' Politics in China', The China Quarterly, no. 170, pp. 283-303. 
Bowen, G 2005, 'Preparing a Qualitative Research-Based Dissertation: Lessons Learned', The Qualitative Report, vol. 10, no. 2, pp. 208-222.

Brady, A-M 2008, Marketing Dictatorship: Propaganda and Thought Work in Contempory China, Rowman \& Littlefield Publishers, Maryland.

Brady, A-M 2012a, 'Introduction: Market-Friendly, Scientific, High Tech, And Politics-lite: China's New Approach to Propoganda ', in China's Thought Management, ed. A-M Brady, Routledge, New York, pp. 1-10.

Brady, A-M 2012b, 'State Confucianism, Chineseness, and tradition in CCP Propaganda', in China's Thought Management, ed. A-M Brady, Routledge, New York, pp. 57-75.

Bray, D 2005, Social Space and Governance in Urban China: The Danwei System from Origins to Reform, Stanford University Press, Stanford.

Bray, D 2009, 'Building 'Community': New Strategies of Governance in Urban China', in China's Governmentalities: Governing Change, Changing Government, ed. E Jeffreys, Routledge, New York, pp. 88-106.

Breslin, S 2014, Mao: Profiles in Power, Routledge, New York.

Brewer, J 2000, 'Understanding Social Research: Ethnography', in Alan Bryman, Open University Press, Buckingham.

Bridgham, P 1968, 'Mao's Cultural Revolution in 1967: The Struggle to Seize Power', The China Quarterly, vol. 34, pp. 6-37.

Brook, T, Bourgon, J \& Blue, G 2008, Death by a Thousand Cuts, Harvard University Press, London.

Brown, M 2007, 'Ethnic Identity, Cultural Variation, and Processes of Change: Rethinking the Insights of Standardization and Orthopraxy', Modern China, vol. 33, no. 1, pp. 91124.

Buckley, C 2011, China President Calls for More Internet Oversight, Reuters.

Burgess, R 1984, In the Field: An Introduction to Field Research, Allen \& Unwin, London.

Cai, Y 2002, 'The Resistance of Chinese Laid-Off Workers in the Reform Period', The China Quarterly, vol. 170, pp. 327-344.

Cai, Y 2006, State and Laid-off Workers in Reform China: The Silence and Collective Action of the Retrenched, Routledge, New York.

Callahan, W 2010, China: The Pessoptimist Nation, Oxford University Press, Oxford.

Carr, D 1997, 'Narrative and the Real World: An Argument for Continuity ', in Memory, Identity, Community: The Idea of Narrative in the Human Sciences, eds L Hinchman \& S Hinchman, State University of New York, New York, pp. 7-25.

Cartier, C 2016, 'Governmentality and the Urban Economy: Consumption, Excess, and the 'Civilised City' in China', in New Mentalities of Government in China, eds D Bray \& E Jeffreys, Routledge, New York.

Castel, R 1994, "'Problematization" as a Mode of Reading History', in Foucault and the Writing of History, ed. J Goldstein, Blackwell Publishers, Massachusetts, pp. 237 252.

Chaline, ER 2010, 'Sexual Identities: A Preliminary Description of Gay SM Sexual Identity Practices', Sexualities, vol. 13, no. 3, pp. 338-356.

Chan, A 1993, 'Revolution or Corporatism? Workers and Trade Unions in Post-Mao China', Chicago Journals, vol. 29, pp. 31-36.

Chan, A 2000, 'Globalization, China's Free (Read Bonded) Labour Market, and the Chinese Trade Unions', Asia Pacific Business Review vol. 6, no. 3-4, pp. 260-281. 
Chan, A 2001, China's Workers Under Assault: The Expoitation of Labour in a Globalizing Economy, An East Gate Book, New York.

Chan, A 2011, 'Strikes in China's Export Industries in Comparative Perspective ', The China journal, vol. 65, pp. 27-51.

Chan, A \& Siu, K 2012, 'Chinese Migrant Workers: Factors Constraining the Emergence of Class Consciousness', in China's Peasants and Workers: Changing Class Identities, eds B Carrillo \& D Goodman, Edward Elgar Publishing Ltd, Massachusetts, pp. 79101.

Chan, C 2010a, The Challenge of Labour in China: Strikes and the Changing Labour Regime in Global Factories, Routledge, New York.

Chan, C 2010b, 'Class Struggle in China: Case Studies of Migrant Worker Strikes in the Pearl River Delta', South African Review of Sociology, vol. 41, no. 3, pp. 61-80.

Chan, C 2012a, 'Community-based Organizations for Migrant Workers' Rights: The Emergence of Labour NGOs in China', Community Development Journal, vol. 10, pp. $1-17$.

Chan, C 2012b, 'Labour Policies under Hu-Wen's Regime: Transformation and Challenges', in China: A New Stage of Development for an Emerging Superpower, ed. J Cheng, City University of Hong Kong Press, Hong Kong, pp. 357-388.

Chan, C \& Hui, E 2012, 'The Dynamics and Dilemma of Workplace Trade Union Reform in China: The Case of the Honda Workers' Strike', Journal of Industrial Relations, vol. 54, no. 5, pp. 653-668.

Chan, C \& Hui, E 2016, 'Bringing Class Struggles Back: A Marxian Analysis of the State and Class Relations in China', Globalizations, pp. 1-13.

Chan, C \& Pun, N 2009, 'The Making of a New Working Class? A Study of Collectvie Actions of Migrant Workers in South China', The China Quarterly, vol. 198, pp. 287303.

Chan, J 2013, 'A Suicide Survivor: the Life of a Chinese Worker', New Technology, Work and Employment, vol. 28, no. 2, pp. 84-99.

Chan, J, Pun, N \& Selden, M 2013, 'The Politics of Global Production: Apple, Foxconn and China's New Working Class', New Technologies, Work and Employment, vol. 28, no. 2, pp. 100-115.

Chan, J \& Selden, M 2016, 'The Labour Politics of China's Rural Migrant', Globalizations, pp. 1-13.

Chan, KW 2010, 'The Global Financial Crisis and Migrant Workers in China: 'There is No Future as a Labourer; Returning to the Village has No Meaning", Internaltional Journal of Urban and Regional Research, vol. 34, no. 3, pp. 659-677.

Chan, KW \& Li, Z 1999, 'The Hukou System and Rural-Urban Migration in China: Processes and Changes', The China Journal, vol. 160, pp. 818-855.

Chang, CM 1951, 'Mao's Stratagem of Land Reform', Foreign Affairs, vol. 29, no. 4, pp. 550563.

Chen, C 1997, Foreign Direct Investment and Trade: An Empirical Investigation of the Evidence from China. Available from:

$<$ http://www.economics.adelaide.edu.au/research/papers/cerc/cercwp1997-11.pdf $>$. [18 December 2012].

Chen, F 2000, 'Subsistence Crises, Managerial Corruption and Labour Protests in China', The China Journal, vol. 44, pp. 41-63. 
Chen, F 2003, 'Industrial Restructuring and Workers' Resistance in China', Modern China, vol. 29 , no. 2 , pp. 237-262.

Chen, F 2006, 'Privatization and its Discontents in Chinese Factories', The China Quarterly, vol. 185, pp. 42-60.

Chen, F 2009, 'Union Power in China Source, Operation, and Constraints', Modern China, vol. 35, pp. 662-689.

Chen, F 2010, 'Trade Unions and the Quadripartite Interactions in Strke Settlement in China', The China Quarterly, vol. 201, pp. 104-124.

Chen, J 2009, 'Growing Social Unrest in China: Rising Social Discontents and Popular Protests', in Socialist China, Capitalist China: Social Tension and Political Adaptation under Economic Globalization, eds G Wu \& H Lansdowne, Routledge, New York, pp. 10-28.

Chen, J 2013, A Middle Class without Democracy: Economic Growth and the Prospects for Democratization in China, Oxford University Press, Oxford.

Chen, K 2011, Labour Law in China, Kluwer Law International BV, The Netherlands.

Chen, M 2015, 'From Economic Elites to Political Elites: Private Entrepreneurs in the People's Political Consultative Conference', Journal of Contemporary China, vol. 24, no. 94, pp. 613-627.

Chen, M \& Goodman, D 2012, 'The Asia Pacific, Regionalism and the Global System', in The Asia-Pacific, Regionalism and the Global System, eds C Dent \& J Dosch, Edward Elgar Publishing Limited, Massachusetts, pp. 185-200.

Chen, M \& Goodman, D 2013, 'Introduction: Middle Class China - Discourse, Structure and Practice', in Middle Class China: Identity and Behaviour, eds M Chen \& D Goodman, Edward Elgar, Cheltenham, pp. 1-11.

Chen, X 2002, 'Social Control in China: Applications of the Labeling Theory and the Reintegrative Shaming Theory', International Journal of Offender Therapy and Comparative Criminology, vol. 46, no. 45, pp. 45-62.

Chen, X 2016, 'Elitism and Exclusion in Mass Protest: Privatization, Resistance, and State Domination in China', Comparative Political Studies, pp. 1-27.

Chen, Y 2016, The Chinese Christology of T. C. Chao, Brill Publishers, Netherlands.

Cheng, C-Y 1979, 'Human Rights in Chinese History and Chinese Philosophy', Comparative Civilisations Review, vol. 1, pp. 1-20.

Cheung, T \& Selden, M 1994, 'The Origins and Social Consequences of China's Hukou System', The China Quarterly, no. 139, pp. 644-668.

China Statistical Yearbook, 2015, China Statistics Press. Available from: $<$ http://www.stats.gov.cn/tjsj/ndsj/2013/indexeh.htm>. [11 August 2016].

China: Strike by 3,000 women workers, 2009, China Worker. Available from: $<$ http://old.chinaworker.info/en/content/news/900/>. [4 July 2016].

Chinese Nationalists Hit at Carrefour over Tibet 2008, ed.^eds 21 April, 2008.

Chinese Workers are Beaten and Hospitalized, 2005, Institute for Global Labour and Human Rights. Available from: <http://www.globallabourrights.org/reports/chinese-workersare-beaten-and-hospitalized $>$. [July 11 2016].

Ching, F, Jarzombek, M \& Prakash, V 2007, A Global History of Architecture, John Wiley \& Sons, New Jersey.

CLB 2017, Strike Map, China Labour Bulletin. Available from: $<$ http://maps.clb.org.hk/strikes/en>. [6 April 2017].

Clegg, S 1989, The Theory of Power and Organization, Routledge, London. 
Clifford, M 2001, Political Genealogy After Foucault: Savage Identities, Routledge, New York.

Confucius 2010, The Analects of Confucius, trans. J Legge, The Floating Press, Auckland.

Cooke, F-L, Xie, Y \& Duan, H 2016, 'Workers' Grievances and Resolution Mechanisms in Chinese Manufacturing Firms: Key Characteristics and the Influence of Contextual Factors', The International Journal of Human Resource Management, vol. 27, no. 18, pp. 2119-2141.

Cooke, S 2009, "Religious Work': Governing Religion in Reform-era China ', in China's Governmentalities: Governing Change, Changing Government, ed. E Jeffreys, Routledge, New York, pp. 125-150.

Cooney, S 2006-2007, 'Making Chinese Labor Law Work: The Prospects for Regulatiory Innovation in the People's Republic of China', Fordham International Labour Journal, vol. 30, pp. 1053-1097.

Cooney, S, Biddulph, S \& Zhu, Y 2013, Law and Fair Work in China, Routledge, New York. Corbin, J \& Strauss, A 2015, Basics of Qualitative Research: Techniques and Procedures for Developing Grounded Theory, Fourth edn, Sage Publications, California.

Crang, M \& Cook, I 2007, Doing Ethnographies Sage Publication Ltd, California.

Creswell, J 2003, Research Design: Qualitative and Quantitative Approaches Sage, California.

Croll, E 1987, 'Short-Term Field Investigation in China: A Personal View', China INformation, vol. 2, pp. 17-26.

Croll, E 2006, China's New Consumers: Social Development and Domestic Demand, Routledge, New York.

Crowther, D \& Green, M 2004, Organisational Theory, Chartered Institute of Personnel and Development, London.

Daily, C 2014, 'Editorial: Tourists, Behave Yourselves', China Daily, 15 December, 2014[23 July, 2016].

Database 2011, Main Indicatior of Private Industrial Enterprises (by Region). Available from:

$<$ http://219.235.129.58/reportView.do?Url=/xmlFiles/en/42e506eeaea24621bec9bcb5 89ec0a4d.xml\&id=0dc9400055324e318b7cf88637af6548\&bgqDm=20110000\&i18n Lang=en AU>. [31 January 2013].

Davidson, A 1994, 'Ethics as Ascetics: Foucault, the History of Ethics, and Ancient Thought', in Foucault and the Writing of History, ed. J Goldstein, Blackwell Publishers, Cambridge, pp. 63-80.

Davidson, A 2003, 'Ethics as Ascetics: Foucault, the History of Ethics, and Ancient Thought', in The Cambridge Companion to Foucault, Second edn, ed. G Gutting, Cambridge University Press, New York, pp. 123-148.

Dean, M 1994, Critical and Effective Histories: Foucault's Methods and Historical Sociology, Routledge, London.

Dean, M 2010, Governmentality: Power and Rule in Modern Society, 2nd edn, Sage, Los Angeles.

Dean, M 2012, 'Rethinking Neoliberalism', Journal of Sociology, vol. 50, no. 2, pp. 150-163.

Deng, Y \& Benney, J 2017, 'Selective Use of Political Opportunity: A Case of Environmental Protest in Rural China', Journal of Chinese Governance, vol. 2, no. 1, pp. 91-105. 
Devereux, S 1993, "Observers are worried': Leanring the Language and Counting the People in Northeast Ghana', in Fieldwork in Developing Countries, eds S Devereux \& J Hoddinott, Lynne Rienner Publishers, Colorado.

Dewalt, K \& Dewalt, B 2002, Participant Observation: A Guild for Fieldworkers, Altramira Press, Walnut Creek.

Dikotter, F 2010, Mao's Great Famine: The History of China's Most Devasting Catastrophe, 1958 - 1962, Walker Publishing Company, New York.

Dillon, M 2015, Deng Xiaoping: The Man who Made Modern China, I.B. Tauris \& Co. Ltd, London.

Ding, D, Goodall, K \& Warner, M 2002, 'The Impact of Eocnomic Reform on the Role of Trade Unions in Chinese Enterprises', The International Journal of Human Resource Management, vol. 13, no. 3, pp. 431-449.

Dittmer, L 1973, 'Mass Line and "Mass Criticism" in China: An analysis of the Fall of Liu Shao-Ch'i', Asian Survey, vol. 13, no. 8, pp. 772-792.

Dittmer, L 1981, 'China in 1980: Modernization and its Discontents', Asian Survey, vol. 21, no. 1 , pp. 31-50.

Downing, L 2008, The Cambridge Introduction to Michel Foucault, Cambridge University Press, Cambridge.

Dreyer, J 1993, China's Political System: Modernization and Tradition, Paragon House Publishers, New York.

Dudbridge, G 2013, A Portrait of Five Dynasties China: From the Memoirs of Wang Renyu (880-956), Oxford University Press, Oxford.

Dutton, M 1992, Policing and Punishment in China: From Patriarchy to 'the People', Cambridge University Press, Cambridge.

Efthymiou-Egleton, I 2016, Do We Really Know China?: An Outsiders View, Xlibris Corporation, Bloomington.

Elliott, J 2005, Using Narrative in Social Research: Qualitative and Quantitative Approaches, Sage Publications, Thousand Oaks.

Estlund, C 2017, A New Deal for China's Workers?, Harvard University Press, Massachusetts.

Evasdottir, E 2004, Obedient Autonomy: Chinese Intellectuals and the Acheivement of Orderly Life, The University of British Columbia, Vancouver.

Fairbank, J \& Goldman, M 2006, China: A New History, 2nd edn, The Belknap Press of Harvard University Press, Massachusetts.

Faison, E 2007, Managing Women: Disciplining Labor in Modern Japan, University of California Press, Berkeley.

Fan, C 2003, 'Rural-Urban Migration and Gender Division of Labor in Transitional China', International JOurnal of Urban and Regional Research, vol. 27, no. 1, pp. 24-47.

Fan, C 2004, 'The State, the Migrant Labor Regime, and Maiden Workers in China', Political Geograpy, vol. 23, pp. 283-305.

Fanoulis, E 2017, The Democratic Quality of European Security and Defence Policy: Between Practices of Governance and Practices of Freedom, Routledge, New York.

Feng, C 2011, 'The Chinese Liberal Camp in Post-4 June China', in The Impact of China's 1989 Tiananmen Massacre, ed. J-P Béja, Routledge, New York, pp. 66-85.

Fife, W 2005, Doing Fieldwork: Ethnographic Methods for Research in Developing Countries and Beyond, Palgrave Macmillan, New York. 
Fillion, R 1998, 'Foucault on History and the Self', Laval Theologique et Philosophique, vol. 54, no. 1, pp. 143-162.

Florcruz, M 2014, 25 Years After 1989 Tiananmen Square Protests: For China's Young, Economic Concerns Overshadow Political Past, International Business Times.

Flynn, T 2005, 'Foucault's Mapping of History', in The Cambridge Companion to Foucault, ed. G Gutting, Cambridge University Press, Cambridge, pp. 29-48.

Forster, EM 2005 [1927], Aspects of the Novels, Penguin Classics, Harmondsworth.

Foucault, M 1966/2005, The Order of Things: An archaeology of the Human Sciences, trans. Routledge, Routledge, New York.

Foucault, M 1976, The History of Sexuality Penguin Books, New York.

Foucault, M 1977, Discipline and Punish: The Birth of the Prison, trans. A Sheridan, Vintage Books, New York.

Foucault, M 1978, The History of Sexuality, Volume 1: An Introduction, trans. R Hurley, Pantheon Books, New York.

Foucault, M 1980a, Power/Knowledge: Selected Interviews and Other Writings 1972-1977, trans. C Gordon, L Marshall, J Mepham \& K Soper, Vintage Books, New York.

Foucault, M 1980b, Truth and Subjectivity University of California, Berkely.

Foucault, M 1982, 'The Subject and Power', in Michel Foucault: Beyond structuralism and hermeneutics, eds H Dreyfus \& P Rabinow, University of Chicago Press, Chicago, pp. 208-226.

Foucault, M 1986, The Care of the Self, trans. R Hurley, Pantheon Books, New York.

Foucault, M 1987, 'The Ethic of Care for the Self as a Practice of Freedom: An Interview with Michel Foucault on January 20, 1984', Philosophy \& Social Critisim, vol. 12, pp. 112-131.

Foucault, M 1989/2002, Foucault: Archaeology of Knowledge, trans. S Smith, Routledge, New York.

Foucault, M 1990, The Use of Pleasure, trans. R Hurley, Vintage Books, New York.

Foucault, M 1991a, The Foucault Reader: An Introduction to Foucault's Thought, Penguin, Harmondsworth.

Foucault, M 1991b, 'Politics and the Study of Discourse', in The Foucault Effect: Studies in Governmentality: with Two Lectures by and an Interview with Michel Foucault, eds G Burchell, C Gordon \& P Miller, The University of Chicago Press, Chicago, pp. 53-72.

Foucault, M 1991c, Remarks on Marx, trans. J Goldstein \& J Cascaito, Semiotexte, New York.

Foucault, M 1997, Ethics, Subjectiivity and Truth: The Essential Works of Foucault 19541984, trans. R Hurley, The New Press, New York.

Foucault, M 1999, 'Who are you, Professor Foucault? (1967)', in Religion and Culture, ed. J Carretta, Routledge, New York, pp. 87-103.

Foucault, M 2001, Madness and Civilization: A History of Insantity in the Age of Reason, Vintage Books, New York.

Foucault, M 2002, The Order of Things: An Archaeology of the Human Sciences, trans. Tavistock/Routledge, Routledge, New York.

Foucault, M 2003, The Birth of the Clinic: An Archaeology of Medical Perception, trans. A Sheridan, Psychology Press, East Sussex.

Foucault, M 2006, History of Madness, trans. J Murphy \& J Khalfa, Routledge, New York.

Foucault, M 2008, The Birth of Biopolitics: Lectures at the Collège de France, 1978-1979, trans. G Burchell, Palgrave Macmillan, New York. 
Foucault, M 2014, On The Government of the Living: Lectures at the College De France 1979-1980, trans. G Burchell, Palgrave Macmillan, New York.

Foucault, M \& Kritzman, L 1988, Politics, Philosophy, Culture : Interviews and Other writings, 1977-1984, Routledge, New York.

Foucault, M, Martin, L, Gutman, H \& Hutton, P 1988, Technologies of the Self: A Seminar with Michel Foucault, University of Massachusetts Press, Massachusetts.

Foucualt, M 1997, The Politics of Truth, Semiotext(e), New York.

Foucualt, M 2001, Power: The Essential Works of Foucault 1954-1984 trans. R Hurley, Penguin Books, London.

Fouts, J \& Chan, J 1995, 'Confucius, Mao and Modernization: Social Studies Education in the People's Republic of China', Journal of Curriculum Studies, vol. 27, no. 5, pp. 523-543.

Franceschini, I, Siu, K \& Chan, A 2016, 'The "Rights Awakening" of Chinese Migrant Workers: Beyond the Generational Perspective', Critical Asian Studies, vol. 48, no. 3, pp. 422-442.

Freire, P 2016, Pedagogy in Process: The Letters to Guinea-Bissau, trans. J Hunter, Bloomsbury Publishing New York.

Friedman, E \& Lee, CK 2010, 'Remaking the World of Chinese Labour: A 30-Year Retrospective', British Journal of Industrial Relations, vol. 48, no. 3, pp. 507-533.

Fu, C 1974, 'Confucianism, Marxism-Leninism and Mao: A Critical Study', Journal of Chinese Philosophy, vol. 1, pp. 339-371.

Fujita, M \& Hu, D 2001, 'Regional Disparity in China 1985 - 1994: The Effects of Globalization and Economic Liber', The Annals of Regional Science, vol. 35, pp. 337.

Fung, H-1 2001, 'The Making and Melting of the "Iron Rice Bowl" in China 1949 to 1995', Social Policy \& Administration, vol. 35, no. 3, pp. 258-273.

Gabriel, S 2006, Chinese Capitalism and the Modernist Vision, Routledge, New York.

Gabriel, S \& Todorova, E 2003, 'Racism and Capitalist Accumulation: An Overdetermined Nexus', Critical Sociology, vol. 29, pp. 29-46.

Gallagher, M 2005, "'Use the Law as Your Weapon!": institutional Change and Legal Mobilization in China', in Engaging the Law in China: State, Society, and Possibilities for Justice, eds N Diamant, S Lubman \& K O'Brien, Stanford University Press, Stanford, pp. 54-83.

Gallagher, M 2006, 'Mobilizing the Law in China: "Informed Disenchantment" and the Development of Legal Consciousness', Law \& Society Review, vol. 40, no. 4, pp. 783816.

Gallagher, M 2007, Contagious Capitalism: Globalization and the Politics of Labor in China, Princeton University Press, New Jersey.

Gallagher, M, Giles, J, Park, A \& Wang, M 2013, China's 2008 Labor Contract Law: Implementation and Implications for China's Workers, WPS6542, The World Bank.

Giddens, A 1993, The Giddens Reader, Macmillan, London.

Giddens, A \& Dallmayr, F 1982, Profiles and Critiques in Social Theory, University of California Press, Los Angeles.

Girdner, E 2004, 'China as a Capitalist State: From "Primitive Socialist Accumulation" to Neoliberal Capitalism', The Turkish Yearbook, vol. XXXV, pp. 121-144. 
Gold, T 1989, 'Guerrilla Interviewing Among the Getihu', in Unofficial China: Popular Culture and Thought in the People's Republic, eds P Link, R Madsen \& P Pickowicz, Westview Press, London, pp. 175-192.

Goldman, M 2000, 'The Potential for Instability Among Intellectuals and Students in PostMao China', in Is China Unstable?: Assessing the Factors: Assessing the Factors, ed. D Shambaugh, M.E. Sharpe Inc, New York, pp. 112-124.

Gordon, C 1991, 'Introduction', in The Foucault Effect: Studies in Governmentality: with Two Lectures by and an Interview with Michel Foucault, eds G Burchell, C Gordon \& P Miller, The University of Chicago Press, Chicago, pp. 1-52.

Gov.cn 2001, Trade Union Law of the People's Republic of China. Available from: $<$ http://english.gov.cn/laws/2005-10/11/content 75948.htm>. [16 September 2012].

Gramsci, A 1988/2000, The Gramsci Reader: Selected Writings, 1916-1935, New York University Press, New York.

Grasso, J, Corrin, J \& Kort, M 2009, Modernization and Revolution: From the Opium Wars to the Olympics, 4th edn, M.E. Sharpe, Inc, New York.

Gray, K \& Jang, Y 2015, 'Labour Unrest in the Global Political Economy: The Case of China's 2010 Strike Wave', New Political Economy, vol. 20, no. 4, pp. 594-613.

Greenhalgh, S 2010, Cultivating Global Citizens: Population in the Rise of China, Harvard University Press, Massachusetts.

Guo, S 2013, Chinese Politics and Government: Power, Ideology and Organization, Routledge, New York.

Gutting, G 2003, 'Michel Foucault: A User's Manual ', in The Cambridge Companion, Second edn, ed. G Gutting, Cambridge University Press, Cambridge, pp. 1-28.

Guy, J-S 2016, 'Beyond Global Modernity, Global Consciousness and Global Governmentality: The Symmetrical Anthropology of Globalization', European Journal of Social Theory, vol. 19, no. 4, pp. 451-467.

Hansen, H 2006, 'The Ethnonarrative Approach', Human Relations, vol. 59, no. 8, pp. 10491075.

Harding, N 2009, Lenin's Political Thought: Theory and Practice in the Democratic and Socialist Revolutions, Haymarket Books, Chicago.

Harrington, B 2003, 'The Social Psychology of Access in Ethnographic Research', Journal of Contemporary Ethnography, vol. 32, no. 5, pp. 592-625.

Harvey, D 2005, A Brief History of Neoliberalism, Oxford University Press, New York.

Hassard, J, Sheehan, J, Zhou, M, Terpstra-Tong, J \& Morris, J 2007, China's State Enterprise Reform: From Marx to the Market, Routledge, New York.

Haugaard, M 1997, The Constitution of Power: A Theoretical Analysis of Power, Knowledge and Structure, Manchester University Press, Manchester.

Hays, J 2012, Major Protests, Riots and Demonstrations in China. Available from: $<$ http://factsanddetails.com/china/cat8/4sub2/item1645.html $>$. [1 December 2016].

Head, J \& Wang, Y 2005, Law codes in dynastic China : a synopsis of Chinese legal history in the thirty centuries from Zhou to Qing, Carolina Academic Press, Durham.

Hess, S 2013, Authoritarian Landscapes: Popular Mobilization and the Institutional Sources of Resilience in Nondemocracies, Sprinkler, New York.

Hinchman, L \& Hinchman, S 1997, 'Introduction', in Memory, Identity, Community: The Idea of Narrative in the Human Sciences, eds L Hinchman \& S Hinchman, State University of New York, New York, pp. xiii-xxxii. 
Ho, P 2007, 'Embedded Activism and Political Change in a Semiauthoritarian Context', China Information, vol. 21, no. 2, pp. 187-209.

Hook, D 2005, 'Genealogy, Discourse, 'Effective History': Foucault and the Work of Critique ', Qualitative Research in Psychology, vol. 2, no. 1, pp. 3-31.

Howell, J 1993, China Opens its Doors: The Politics of Eocnomic Tranistion, Lynne Rienner Publishers, Boulder.

Howell, J 1998, 'An Unholy Trinity? Civil Society, Economic Liberalization and Democratization in post-Mao China', Government and Opposition, vol. 33, no. 1, pp. 56-80.

Howell, J 2008, 'All-China Federation of Trades Unions Beyond Reform? The Slow March of Direct Elections', The China Quarterly, vol. 196, pp. 845-863.

Hsing, Y-t 1998, Making Capitalism in China: The Taiwan Connection, Oxford University Press, Oxford.

Huan, G 1986, 'China's Open Door Policy, 1978-1984', China in Transition, vol. 39, no. 2, pp. 1-18.

Hunter, C, Lam, L \& Lin, K 2008, Employment Law in China, CCH Hong Kong Limited, Hong Kong.

Hurst, W 2008, 'Mass Frames and Worker Protest', in Popular Protest in China, ed. K O'Brien, Harvard University Press, Massachusetts, pp. 71-87.

Hurst, W 2009, The Chinese Worker After Socialism, Cambridge University Press, Cambridge.

Hurst, W \& O'Brien, K 2002, 'China's Contentious Pensioners', The China Quarterly, vol. 170, pp. 345-360.

Hutchings, K 1997, 'Foucault and International Relations Theory', in The Impact of Michel Foucault on the Social Sciences and Humanities eds M Lloyd \& A Thacker, Macmillan Press Ltd, London, pp. 102-127.

ITUC 2010, Internationally Recognised Core Labour Standards in the People's Republic of China: Report for teh WTO General Council Review of the Trade Policies of the People's Republic of China. Available from: $<$ http://www.ituccsi.org/IMG/pdf/Chinal_Final-2.pdf>. [2 November 2012].

Jantz, J 2010, 'Soft Approaches to Social and Labor Standards in Adverse Environments: The case of Sector Wide Self Regulation in the post-ATC Textile and Clothing Industry', in, University of Potsdam, pp. 1-16.

Javeline, DL 2006, Protest and the Politics of Blame: The Russian Response to Unpaid Wages, The University of Michigan Press, Ann Arbor.

Jeffreys, E 2004, China, Sex and Prostitution, Routledge, New York.

Jeffreys, E \& Sigley, G 2009, 'Governmentality, Governance and China', in China's Governmentalities: Governing Change, Changing Government, ed. E Jeffreys, Routledge, New York, pp. 1-23.

Jeffreys, E \& Su, X 2016, 'Governing through Lei Feng: A Mao-era Role Model in Reformera China', in New Mentalities of Government in China, eds D Bray \& E Jeffreys, Routledge, New York.

Jessop, B 2012, 'Marxist Appraoches to Power', in The Wiley-Blackwell Companion to Political Sociology, eds E Amenta, K Nask \& A Scott, Blackwell Publishing Ltd, Oxford, pp. 3-14.

Jorgensen, D 1989, Participation Observation: A Methodology for Human Studies, Sage Publications, London. 
Jorgensen, K 2006, 'Writing History and Relations of Power', Managment and Philosophy, no. 5, pp. 1-35.

Joseph, J 2009, 'Governmentality of What? Populations, States and International Organisations', Global Society, vol. 23, no. 4, pp. 413-427.

Keith, R \& Lin, Z 2003, 'The "Falun Gong Problem": Politics and the Struggle for the Rule of Law in China', The China Quarterly, vol. 175, pp. 623-642.

Kent, A 1997-1998, 'China, International Organizations and Regimes: The ILO as a Case Study in Organizational Learning', Pacific Affairs, vol. 70, no. 4, pp. 517-532.

Kent, A 1999, China, The United Nations, and Human Rights: The Limits of Compliance, University of Pennsylvania Press, Philadelphia.

Kent, A 2007, Beyond Compliance: China, International Prganizations, and Global Security, Standford University Press, Califonia.

Kerlinger, F \& Lee, H 2000, Foundations of Behavioral Research, Harcourt College Publishers, New York.

Koo, H 2001, Korean Workers: The Culture and Politics of Class Formation, Cornell University Press, Londo.

Korsch, K 1938/2016, Karl Marx, trans. M Buckmiller, Brill, Boston.

Kuhn, R 2011, How China's Leaders Think: The Inside Story of China's Past, Current and Future Leaders, John Wiley \& Sons, Singapore.

Kunz, R 2011, The Political Economy of Global Remittances: Gender, Governmentality and Neoliberalism, Routledge, New York.

LaFleur, R 2010, Asia in Focus: China, ABC CLIO, Oxford.

Lai, H 2010, The Domestic Sources of China's Foreign Policy: Regimes, Leadership, Priorities and Process Routledge, New York.

Lai, K 1995, 'Confucian Moral Thinking', Comparative and Asian Philosophy in Australia and New Zealand, vol. 45, no. 2, pp. 249-272.

Landsberger, S 2002, 'The Deification of Mao: Religious Imagery and Practices during the Cultural Revolution and Beyond', in China's Great Proletarian Cultural Revolution, ed. WL Chong, Rowman \& Littlefield Publishers, Oxford, pp. 139-184.

Larner, W \& Walters, W 2004, 'Globalization as Governmentality ', Alternatives: Global, Local, Political, vol. 29, no. 5, pp. 495-514.

Lee, CK 1999a, 'From Organized Dependence to Disorganized Despotism: Changing Laboru Regimes in Chinese Factories', The China Quarterly, vol. 45, pp. 44-71.

Lee, CK 1999b, 'From Organized Dependence to Disorganized Despotism: Changing Labour Regimes in Chinese Factories', The China Quarterly, vol. 45, pp. 44-71.

Lee, CK 2000a, 'Pathways of Labour Insurgency', in Chinese Society, 2nd Edition: Change, Conflict and Resistance, 2nd edn, eds E Perry \& M Selden, Routledge, New York, pp. 71-92.

Lee, CK 2000b, 'The 'Revenge of History': Collective Memories and Labor Protests in NorthEastern China', Ethnography, vol. 1, no. 2, pp. 217-237.

Lee, CK 2002a, 'From the Specter of Mao to the Spirit of the Law: Labor Insurgency in China', Theory and SOciety, vol. 31, pp. 189-228.

Lee, CK 2002b, 'Revisiting the South China Miracle', Lador Studies Journal, vol. 27, no. 2, pp. 61-64.

Lee, CK 2007a, Against the Law: Labor Protests in China's Rustbelt and Sunbelt, University of California Press, Berkeley. 
Lee, CK 2007b, Against the Law: Labor Protests in China's Rustbelth and Sunbelt, University of California Press, Califonia.

Lee, H-Y 2000, 'Xiagang, the Chinese Style of Laying Off Workers', Asian Survey vol. 40, no. 6 , pp. 914-937.

Lehman 2008, Labour Contract Law of the People's Republic of China. Available from: $<$ http://www.lehmanlaw.com/fileadmin/lehmanlaw com/laws regulations/Labor Contract Law of the PRC LLX 06292007 .pdf $>$. [12 October 2010].

Lenin, V 1918/1992, The State and Revolution, trans. R Service, Penguin Books, London.

Leung, E 2016, 'Docile Bodies and Minds: A Genealogy of Chinese Workers in China', in TASA 2016 Conference, ed. M Chou, The Australian Catholic University, Fitzroy, Melbourne, pp. 215-221.

Leung, E \& Caspersz, D 2016, 'Exploring worker consciousness in China', Labour \& Industry: A Journal of The Social And Economic Relations of Work vol. 26, no. 3, pp. 237-250.

Leung, J \& Xu, A 2010, 'The Emergence of Social Assistance in China: Challenges and Issues', in Social Policy and Poverty in East Asia: The Role of Social Security, eds J Midgley \& K-L Tang, Routledge, New York, pp. 47-65.

Leung, L 2017, Contemporary Chinese Fiction Writers: Biography, Bibliography, and Critical Assessment, Routledge, New York.

Leung, P \& Pun, N 2009, 'The Radicalisation of the New Chinese Working Class: A Case Study of Collective Action in the Gemstone Industry', Third World Quarterly, vol. 30, no. 3, pp. 551-565.

Leung, W-Y 1988, Smashing the Iron Rice Pot: Workers and Unions in China's Market Socialism, Asia Labour Monitor, Hong Kong.

Li, H 2015, Political Thought and China's Transformation: Ideas Shaping Reform in PostMao China, Palgrave Macmillan, London.

Li, L \& O'Brien, K 1996, 'Villagers and Popular Resistance in Contemporary China', Modern China, vol. 22, no. 1, pp. 28-61.

Li, S 2006, 'Low Wage and Low Labor Standards in China: A Substitute Explanation of 'The Race-to-the-Bottom", in The Chinese Economy after WTO Accession, eds S Bao, C Zhao \& S Lin, Ashgate Publishing Limited, Hampshire, pp. 291-306.

Li, W \& Yang, DT 2005, 'The Great Leap Forward: Anatomy of a Central Planning Disaster', Journal of Political Economy, vol. 113, no. 4, pp. 840-877.

Li, X 2012, China at War: An Encyclopedia, ABC-CLIO, LLC, California.

Li, Y, Sheldon, P \& Sun, J-M 2011, 'Education, Training and Skills', in China's Changing Workplace: Dynamism, Diversity and Disparity, eds P Sheldon, S Kim, Y Li \& M Warner, Routledge, New York, pp. 111-128.

Liew, L 2005, 'China's Engagement with Neo-liberalism: Path Dependency, Geography and Party Self-Reinvention', The Journal of Development Studies, vol. 41, no. 2, pp. 331352.

Lin, J, Cai, F \& Li, Z 1996, The China Miracle: Development Strategy and Economic Reform, The Chinese University of Hong Kong, Hong Kong.

Lin, K 2015, 'Recomposing Chinese Migrant and State-Sector Workers', in Chinese Workers in Comparative Perspective, ed. A Chan, Cornell University Press, Ithaca.

Lippit, V 1982, 'China's Socialist Development ', in The Transition to Socilaism in China, eds M Selden \& V Lippit, M.E. Sharpe New York. 
Lipschutz, R \& Rowe, JK 2005, Globalization, Governmentality and Global Politics: Regulation for the Rest of Us, Routledge, New York.

Littlejohn, R 2011, Confucianism: An Introduction, I.B. Tauris \& Co Ltd, New York.

Liu, C 2011, 'Contested Ground: Community and Neighbourhood', in Understanding Chinese Society, ed. X Zang, Routledge, New York, pp. 63-74.

Liu, H \& van-Dongen, E 2016, 'China's Diaspora Policies as a New Mode of Transnational Governance', Journal of Contemporary China, vol. 25, no. 102, pp. 805-821.

Lorimer, D 2004, The Class Nature of the People's Republic of China, Resistance Books, Newtown.

Lovell, J 2007, The Great Wall: China Against the World, 1000 BC - AD 2000, Grove Press, New York.

Lu, L 2011, 'Socialism in the Developing World', in 21st Century Political Science: A Reference Handbook, eds J Ishiyama \& M Breuning, Sage Publications, California, pp. 673-684.

Lu, X 1998, Rhetoric in Ancient China, Fifth to Third Century B.C.E.: A Comparison with Classical Greek Rhetoric, University of South Carolina Press, South Carolina.

Lu, X 2004, Rhetoric of the Chinese Cultural Revolution: The Impact on Chinese Thought, Culture, and Communication, University of South Carolina Press, Columbia.

Lu, Y 2009, Non-Governmental Organizations in China: The Rise of Dependent Autonomy, Routledge, New York.

Lukacs, G 1968, History and Class Consciousness: Studies in Marxist Dialectics, trans. R Livingstone, The MIT Press, Massachusetts.

Lum, T 2006, Social Unrest in China, Congressional Research Service (CRS) Report for Congress, [11 August, 2016 ].

Ma, X 2013, '14 Suì Shàonŭ Zhăo Gōngzuò Shàngdàng Bèi Bī Màiyín 20 tiān jiēkè 200 Cì (14-year-old Girl Forced into Prostitution)', Sina, 27 September, 2013 [4 Auguest, 2016].

MacFarquhar, R 1997, 'Introduction', in The Politics of China: The Eras of Mao and Deng, ed. R MacFarquhar, Cambridge University Press, Cambridge, pp. 1-4.

MacFarquhar, R \& Schoenhals, M 2006, Mao's Last Revolution, Harvard University Press, Cambridge.

MacKinnon, R 2008, 'Flatter World and Thicker Walls? Blogs, Censorship and Civic Discourse in China', Public Choice, vol. 134, no. 1-2, pp. 31-46.

MacKinnon, R 2012, Consent of the Networked: The World-Wide Struggle for Internet Freedom, Basic Books, Philadelphia.

Madsen, R 2008, 'Confucian Conceptions of Civil Society ', in Confucian Political Ethics, ed. D Bell, Princeton University Press, New Jersey.

Magill, K 1997, 'Surveillance-Free-Subjects ', in The Impact of Michel Foucault on the SOcial Sciences and Humanities, eds M Lloyd \& A Thacker, Macmillan Press Ltd, London.

Mah, B 2011, China and the World: Global Crisis of Capitalism, iUniverse, Bloomington. Mak, M \& So, A 2011, Scientific Feng Shui for the Built Environment: Fundamentals and Case Studies, City University of Hong Kong Press, Hong Kong.

Mallee, H 2000, 'Migration, Hukou, Resistance in Reform China', in Chinese Society, 2nd Edition: Change, Conflict and Resistance, eds E Perry \& M Selden, Routledge, New York. 
Mao, X 2004, 'China: Views of a Medical Geneticist', in Genetics and Ethics in Global Perspective, eds D Wertz \& J Fletcher, Kluwer Academic Publishers, London, pp. 208-222.

Marcus, G 1995, 'Ethnography in/of the World System: The Emergence of Multi-Sited Ethnography', Annual Review of Anthropology, vol. 24, pp. 95-117.

Marx, K 1844/2007, Economic and Philosophic Manuscripts of 1844, trans. M Milligan, Dover Publications, New York.

Marx, K 1894/1992, Capital, trans. D Fernbach, Penguin Books, London.

Marx, K \& Engels, F 1848/2010, The Communist Manifesto, Penguin Books, London.

McCormick, J 2010, Comparative Politics in Transition Cengage Learning, Boston.

McKinlay, A \& Taylor, P 2014, Foucault, Governmentality, and Organization: Inside the Factory of the Future, Routledge, New York.

MDGIF 2011, Shenghuo Jineng Shouce (Life Skill Manual), MDG Acheivement Fund in China.

Meadmore, D, Hatcher, C \& McWilliam, E 2000, 'Getting Tense about Genealogy', International Journal of Qualitative Studies in Education, vol. 13, no. 5, pp. 463-476.

Melton, G 2014, Faiths Across Time: 5,000 Years of Religious History ABC-CLIO, Oxford.

Merchant, T 2004, 'Recognizing ILO Rights to Organize and Bargain Collectively; Grease in China's Transition to a Socialist Market Economy', Case Western Reserve Journal of International Law, vol. 36, no. 223, pp. 223-253.

Miao, X 1992, 'China', in International Handbook of Reading Education, eds J Hladczuk \& W Eller, Greenwood Press, London, pp. 77-92.

Miethe, TD \& Lu, H 2005, Punishment: A Comparative Historical Perspective, Cambridge University Press, Cambridge.

Mitchell, K 2006, 'Neoliberal Governmentality in the European Union: Education, Training, and Technologies of Citizenship ', Environment and Planning D: Society and Space, vol. 24, no. 3, pp. 389-407.

Mitter, R 2004, A Bitter Revolution: China's Struggle with the Modern World, Oxford University Press, New York.

Munck, R 2004, 'Introduction: Globalisation and Labour Transnationalism', in Labour and Globalisation: Results and Prospects, ed. R Munck, Liverpool University Press, Liverpool, pp. 1-18.

Musto, M 2012, 'Revisiting Marx's Concept of Alienation', in Marx for Today, ed. M Musto, Routledge, New York, pp. 92-116.

Nadesan, MH 2008, Governmentality, Biopower, and Everyday Life, Routledge, New York.

NBSC 2015, Statistical Communiqué of the People's Republic of China on the 2014 National Economic and Social Development, National Bureau of Statistics of China. [15 December 2016].

Newton, T 1998, 'Theorizing Subjectivity in Organizations: The Failure of Foucauldian Studies', Journal of Organization Studies, no. 19, pp. 415-447.

Ng, J 2013, Blocked on Weibo: What Gets Suppressed on China's Version of Twitter (and Why). The New Press, New York.

Ngok, K 2008, 'The Changes of Chinese Labor Policy and Labor Legislation in the Context of Market Transition', International Labor and Working-Class History, no. 73, pp. 4564.

Nicholls, D 2009, 'Putting Foucault to Work: An Approach to the Practical Application of Foucault's Methodological Imperatives', Aporia, vol. 1, no. 1, pp. 30-40. 
Noon, M, Blyton, P \& Morrell, K 2013, The Realies of Work: Experiencing Work and Employment in Contemporary Society 4th edn, Palgrave Macmillian, New York.

O'Brien, K 1988, Michel Foucault's Genealogy of the Subject, thesis, Katholieke Universiteit Leuven.

O'Brien, K 1996, 'Rightful Resistance', World Politics, vol. 49, pp. 31-55.

O'Farrell, C 1989, Foucault: Historian or Philosopher?, The MacMillan Press Ltd, London.

O'Farrell, C 2005, Michel Foucault, Sage, California.

O'Reilly, K 2012, Ethnographic Methods, Routledge, New York.

Oi, J 1995, 'The Role of the Local State in China's Transitional Economy', The China

Quarterly, no. 144, pp. 1132-1149.

Oksala, J 2005, Foucault on Freedom, Cambridge University Press, Cambridge.

Oksala, J 2007, How to Read Foucault, Granta Books, London

Olssen, M 1999, Michel Foucault: Materialism and Education, Greenwood Publishing Group, Westport.

Ong, A \& Zhang, L 2008, 'Introduction: Privatizing China: Powers of the Self, Socialism from Afar', in Privarizing China: Socialism from Afar, eds L Zhang \& A Ong, Cornell University, New York, pp. 1-20.

Orser, C 2014, Encyclopedia of Historical Archaeology, Routledge, New York.

Orts, E 2001, 'The Rule of Law in China', Vanderbilt Journal of Transnational Law, vol. 34, no. 43, pp. 43-115.

Pankenier, D 1995, 'Astrological Origins of Chinese Dynastic Ideology', Vistas in Astronomy, vol. 39, pp. 503-516.

Parameswaran, P 2008, AFP: Labor unrest growing in China: activist. Available from: $<$ http://www.clb.org.hk/content/afp-labor-unrest-growing-china-activist $>$. [23 November 2016].

Paulson, S 2011, 'The Use of Ethnography and Narrative Interviews in a Study of 'Cultures of Dance", Journal of Health Psychology, vol. 16, no. 1, pp. 148-157.

Pearce, S 2001, 'Form and Matter: Archaizing Reform in Sixth-Century China', in Culture and Power in the Reconstitution of the Chinese Realm, 200-600, eds S Pearce, A Spiro \& P Ebrey, Harvard University Asia Center, London, pp. 149-180.

Penttinen, E 2008, Globalization, Prostitution and Sex Trafficking: Corporeal Politics, Routledge, New York.

Perry, E 1993, Shanghai on Strike: The Politics of Chinese Labor, Standford University Press, California.

Perry, E 1996, 'Introduction: Putting Class in its Place: Bases of Worker Identity', in Putting Class in its Place: Worker Identities in East Asia, ed. E Perry, University of California, California, pp. 1-10.

Perry, E 2002, 'Moving the Masses: Emotion Work in the Chinese Revolution', Mobilization: An International Quarterly, vol. 7, no. 2, pp. 111-128.

Perry, E 2008, 'Permanant Rebellion? Continuities and Discontinuities in Chinese Protest', in Popular Protest in China, ed. K O'Brien, Harvard University Press, Massachusetts, pp. 205-216.

Perry, E 2009, 'A New Rights Consciouness?', Journal of Democracy, vol. 20, no. 3, pp. 1720.

Poster, M 1982, 'Foucault and HIstory ', Social Research, vol. 49, no. 1, pp. 116-142.

Postiglione, G 2011, 'Education', in Understanding Chinese Society, ed. X Zang, Routledge, New York, pp. 80-95. 
Potter, P 2001, The Chinese Legal System: Globalization and Local Legal Culture, Routledge, New York.

Pringle, T 2011, Trade Unions in China: The Challenge of Labour Unrest, Routledge, New York.

Pringle, T \& Clarke, S 2011, The Challenge of Transition: Trade Unions in Russia, China and Vietnam, Palgrave Macmillan, New York.

Pun, N 2005, Made in China: Women Factory Workers in a Global Workplace, Duke University Press, Durham.

Pun, N 2007, 'Gendering the Dormitory Labor System: Production, Reproduction, and Migrant Labor in South China', Feminist Economics, vol. 13, no. 3-4, pp. 239-258.

Pun, N, Chan, C \& Chan, J 2009, 'The Role of the State, Labour Policy and Migrant Workers' Struggles in Globalized China', Global Labour Journal, vol. 1, no. 1, pp. 132-151.

Pun, N \& Chan, J 2010, 'Suicide as Protest for the New Generation of Chinese Migrant Workers: Foxconn, Global Capital, and the State', The Asia-Pacific Journal, vol. 37, no. 2, pp. 1-50.

Pun, N \& Chan, J 2012, 'Global Capital, the State, and Chinese Workers: The Foxconn Experience', Modern China, vol. 38, no. 4, pp. 383-410.

Pun, N, Chan, J \& Selden, M Forthcoming, Separate Dreams: Apple, Foxconn, and a New Generation of Chinese Workers, Rowman and Littlefield, Lanham.

Pun, N \& Lu, H 2010, 'Unfinished Proletarianization: Self, Anger, and Class Action among the Second Generation of Peasant-Workers in Present-Day China', Modern China, vol. 36, no. 5, pp. 493-519.

Pun, N \& Lu, H 2010b, 'A Culture of Violence: The Labor Subcontracting System and Collective Action by Construction Workers in Post-Socialist China', The China Journal, vol. 64, pp. 143-158.

Pun, N, Shen, Y, Guo, Y, Lu, H, Chan, J \& Selden, M 2016, 'Apple, Foxconn, and Chinese Workers' Struggles from a Global Labor Perspective', Inter-Asia Cultural Studies, vol. 17 , no. 2, pp. 166-185.

Pye, L 1986, 'Reassessing the Cultural Revolution', The China Quarterly, vol. 108, pp. 597612.

Pye, L 1999, 'An Overview of 50 Years of the People's Republic of China: Some Progress, but Big Problems Remain', The China Quarterly, vol. 159, pp. 569-579.

Qi, D 2010, 'Chinese Working Class and Trade Unions in the Post-Mao Era: Progress and Predicament', International Journal of China Studies, vol. 1, no. 2, pp. 413-433.

Rabinow, P \& Rose, N 2003, 'Introduction: Foucault Today', in The Essential Foucault, eds P Rabinow \& N Rose, New Press, New York, pp. 1-30.

Rainey, L 2010, Confucius and Confucianism: The Essentials, Wiley-Blackwell Malaysia.

Ransom, J 1997a, Foucault's Discipline, Duke University Press, London.

Ransom, J 1997b, Foucault's Discipline: The Politics of Subjectivity, Duke University Press, London.

Reed, M 2000, 'The Limits of Discourse Analysis in Organizational Analysis', Journal of Organization, vol. 7, no. 3, pp. 520-530.

Richards, L 2005, Handling Qualitative Data: A Practical Guide, Sage Publications, Thousand Oaks.

Richardson, F \& Woolfolk, R 2013, 'Subjectivity and Strong Relationality', in Subjectivity in the Twenty-First Century, ed. R Tafarodi, Cambridge University Press, New York, pp. 11-40. 
Roberts, JAG 1999, A Concise History of China, Harvard University Press, Massachusetts.

Rojek, D 1989, 'Social Control in the People's Republic of China', Criminal Justice Review, vol. 14, pp. 141-153.

Rong, X \& Shi, T 2001, 'Inequality in Chinese Education', Journal of Contemporary China, vol. 10, no. 26, pp. 107-124.

Rossman, G \& Rallis, S 2012, Learning in the Field: An Introduction to Qualitative Research, Sage Publications, London.

Roth, M 1981, 'Foucault's "History of the Present"', History and Theory vol. 20, no. 1, pp. 3246.

SACOM 2014, Supporting "Let's Tackle Apple Action" of May of Solidarity in Europe. Available from: $<\underline{\text { http: } / / \text { sacom.hk/statement-supporting- }}$ $\% \mathrm{E} 2 \% 80 \% 9 \mathrm{Clet} \% \mathrm{E} 2 \% 80 \% 99$ s-tackle-apple-action $\% \mathrm{E} 2 \% 80 \% 9 \mathrm{D}$-of-may-ofsolidarity-in-europe/>. [15 May 2014].

Schram, S 1969, 'The Party in Chinese Communist Ideology', The China Quarterly, vol. 38, pp. $1-28$.

Schrift, A 2013, 'Discipline and Punish', in A Companion to Foucault, eds C Falzon, T O'Leary \& J Sawicki, John Wiley \& Sons, Ltd, pp. 137-153[11 August, 2016].

Schucher, G 2011, 'The Constricted Evolution of China's Rural Labor Market', in Politics and Markets in Rural China, ed. B Alpermann, Routledge, New York, pp. 30-47.

Scott, J 1999, Gender and the Politics of History, Revised Edition edn, Columbia University Press, New York.

Semple, J 2003, Bentham's Prison : A Study of the Panopticon Penitentiary: A Study of the Panopticon Penitentiary, Oxford University Press, Oxford.

Shankman, S \& Durrant, SW 2000, The Siren and the Sage: Knowledge and Wisdom in Ancient Greece and China, Cassell, New York.

Shepley, N 2013, Russia's Struggle With Modernity 1815-1929, Andrews UK Limited, Bedfordshire.

Shimahrara, N, Basso, K, Brown, IC, Fischer, JL, Gjessing, G, Horner, G \& Wallace, AFG 1970, 'Enculturation-A Reconsideration', Chicago Journals, vol. 11, no. 2, pp. 143 154.

Sigley, G 1996, 'Governing Chinese Bodies: The Significance of Studies in the Concept of Governmentality for the Analysis of Government in China', Economy and Society, vol. 25, no. 4, pp. 457-482.

Sigley, G 2016, 'From Socilaism to Social Work: Social Workers, Professionalism, and Community Governance in Contemporary Urban China', in New Mentalities of Government in China, eds D Bray \& E Jeffreys, Routledge, New York, pp. 97-117.

Silver, B \& Zhang, L 2009, 'China as an Emerging Epicenter of World Labor Unrest', in China and the Transformation of Global Capitalism, ed. H-f Hung, The Johns Hopkins University Press, Maryland, pp. 174-187.

Skålén, P, Fougère, M \& Fellesson, M 2008, Marketing Discourse: A Critical Perspective, Routledge, New York.

Skeldon, R 1997, 'Hong Kong and Coastal China Growth Linkages', in Regionalization and Labour Market Interdependence in East and Southeast Asia, eds D Campbell, A Lateef, A Parisotto \& A Verma, MacMillan Press, London, pp. 151-173.

Smart, B 1985, Michel Foucault, Tavistock Publications Limited, London.

Smart, B 1998, 'Foucault, Levinas and the Subject of Responsibility', in The Later Foucault: Politics and Philosophy, ed. J Moss, Sage Publications Ltd, California, pp. 78-92. 
Smith, C \& Chan, J 2015, 'Working for Two Bosses: Student Interns as Constrained Labour in China', Journal of Human Relations, vol. 68, no. 2, pp. 305-326.

Smith, C \& Pun, N 2006, 'The Dormitory Labour Regime in China as a Site for Control and Resistance', The International Journal of Human Resource Management, vol. 17, no. 8, pp. 1456-1470.

So, A 2003, 'The Changing Pattern of Classes and Class Conflict in China', Journal of Contemporary Asia, vol. 33, no. 3, pp. 363-376.

So, A 2006, 'Beyond the Logic of Capital and the Polarization Model', Critical Asian Studies, vol. 37, no. 3, pp. 481-494.

Solinger, D 2002, 'Labour Market Reform and the Plight of the Laid-off Proletariat ', The China Quarterly, no. 170, pp. 304-326.

Solinger, D 2006, 'Interviewing Chinese People: From High-Level Officials to the Unemployed', in Doing Fieldwork in China, eds M Heimer \& S Thogersen, University of Hawai'i Press, Honolulu, pp. 153-167.

Sother, E 2006, 'Fieldwork as Coping and Learning', in Doing Fieldwork in China, eds M Heimer \& S Thogersen, NIAS Press, Hawaii, pp. 42-57.

Spradley, J 1980, Participant Observation, Harcourt Brace College Publishers, London.

Su, Y \& He, X 2010, 'Street as Courtroom: State Accomodation of Labor Protest in South China', Law \& Society Review, vol. 44, no. 1, pp. 157-184.

Sutton, D 2007, 'Ritual, Cultural Standardization, and Orthopraxy in China: Reconsidering James L. Watson's Ideas ', Modern China, vol. 33, no. 3, pp. 3-21.

System 2011, Quanguo Wenming Chengshi Ceping Tixi (Spiritual Civilisation Commission), National Civilised City Evaluation System.

Szalay, L \& Mir-Djalali, E, 'Image of the Enemy: Critical Parameters, Cultural Variations', in The Psychology of War and Peace: The Image of the Enemy, ed. R Rieber, Plenum Press, New York, pp. 213-250.

Tan, T-S 2009, Cheng Ho and Islam in Southeast Asia, Insitutue of Southeast Asian Studies, Pasir Panjang.

Teiwes, F 1997, 'The Establishment and Consolidation of the New Regime, 1949 - 57', in The Politics of China: The Eras of Mao and Deng, 2nd edn, ed. R MacFarquhar, Cambridge University Press, Cambridge, pp. 5-86.

Teiwes, F 2000, 'The Chinese State during the Maoist Era', in The Modern Chinese State, ed. D Shambaugh, Cambridge University Press, Cambridge, pp. 105-160.

Terry, W 2009, 'Working on the Water: On Legal Space and Seafarer Protection in the Cruise Industry', Economic Geography, vol. 85, no. 4, pp. 463-482.

Thacker, A 1997, 'Foucault and the Writing of History', in Michel Foucault on the Social ciences and Humanities, eds M Lloyd \& A Thacker, Macmillan Press Ltd, London, pp. 29-53.

Thogersen, S \& Heimer, M 2006, 'Introduction', in Doing Fieldwork in China, eds M Heimer \& S Thogersen, NIAS Press, Hawaii, pp. 1-26.

Thompson, E 1971, 'The Moral Economy of the English Crowd in the Eighteenth Century', The Past and Present Society, vol. 50, pp. 76-136.

Thompson, EP 1966, The Making of the English Working Class, Vintage Books, New York. Thompson, EP 1978, 'Eighteenth-Century English Society: Class Struggle without Class?', Social History, vol. 3, no. 2, pp. 133-165.

Tong, Y \& Lei, S 2010, 'Large-Scale Mass Incidents and Government Responses in China', International Journal of China Studies, vol. 1, no. 2, pp. 487-508. 
Tsou, T 1969a, 'The Cultural Revolution and teh Chinese Political System', The China Quarterly, vol. 38, pp. 63-91.

Tsou, T 1969b, 'The Cultural Revolution and the Chinese Political System', The China Quarterly, vol. 38, pp. 63-91.

UNHCR 1989, Law of the People's Republic of China on Assemblies, Processions and Demonstrations, National Legislative Bodies. Available from: $<$ http://www.unhcr.org/refworld/docid/3ae6b592e.html >. [22 October 2012].

UNHRC 1997, Criminal Law of the People's Republic of China, National Legislative Bodies. Available from: $<$ http://www.unhcr.org/cgibin/texis/vtx/refworld/rwmain?docid=3ae6b5cd2\&page=search $>$. [31 October 2012].

Vidich, A 1955, 'Participant Observation and the Collection and Interpretation of Data', Chicago Journals, vol. 60, no. 4, pp. 354-360.

Vouros, D 2013, 'Poulantzas on Social Class and Class Struggle', Historical Materialism Australasia Conference 2013.

Wagner, D 1998, A Classical Chinese Reader: The Han Shu biography of Huo Guang, Routledge, New York.

Walder, A 1991, 'Workers, Managers and the State: The Reform Era and the Political Crisis of 1989', The China Quarterly, vol. 127, pp. 467-492.

Walder, A \& Gong, X 1993, 'Workers in the Tiananmen Protests: The Politics of the Beijing Workers' Autonomous', The Australian Journal of Chinese Affairs, vol. 29, pp. 1-29.

Wănbào 2016, 'Bèi Piàn 8000 Yuán Nóngmíngōng Shàngdiào Zìshā (8000 Yuan Cheated, Migrant Workers Hanged Himself)', Zhèngzhōu Wănbào, 3 Feburary, 2016[4 August, 2016].

Wang, H, Appelbaum, R, Degiuli, F \& Lichtenstein, N 2009, 'China's New Labour Contract Law: Is China Moving Towards Increased Power for Workers?', Third World Quarterly, vol. 30, no. 3, pp. 485-501.

Wang, L 2008, 'The Marginality of Migrant Children in the Urban Chinese Educational System', British Journal of Socialogy of Education, vol. 29, no. 6, pp. 691-703.

Wang, T \& Cooke, F-L 2016, 'Striking the balance in industrial relations in China? An analysis of court decisions of 897 strike cases (2008-2015)', Journal of Industral Relations, vol. 59, no. 1, pp. 22-43.

Warner, M 1991, 'Labour-Management Relations in the People's Republic of China: The Role of the Trade Unions', The International Journal of Human Resource Management, vol. 2, no. 2, pp. 205-220.

Warner, M \& Zhu, Y 2010, 'Labour and Management in the People's Republic of China: Seeking the 'Harmonious Society", Asia Pacific Business Review, vol. 16, no. 3, pp. 285-298.

Watson, J 1988, 'The Structure of Chinese Funerary Rites: Elementary Forms, Ritual Sequence, and the Primacy of Performance', in Death Ritual in Later Imperial and Modern China, eds J Watson \& E Rawski, University of California Press, California, pp. 3-19.

Watson, J 1993, 'Rites or Beliefs? The Construction of a Unified Culture in Late Imperial China', in China's Quest for National Identity, eds L Dittmer \& S Kim, Cornell University Press, Ithaca, pp. 80-103.

Weatherley, R 2006, Politics in China since 1949: Legitimizing Authoritarian Rule, Routledge, New York. 
Wei, YD 2001, 'Decentralization, Marketization, and Globalization: The Triple Processes

Underlying Regional Development in China', Asian Geographer, vol. 20, no. 1-2, pp. 7-23.

Wen, M \& Zhang, L 2014, Imperial Criminal Law (Huángquán xínglü), Second edn, China Environmental Science Publishing House (Zhōngguó huánjìng kēxué chūbăn shè chūbăn), Beijing.

White, G 1989, 'Restructuring the Working Class: Labor Reform in Post Mao China', in In Marxism and the Chinese Experience, eds A Dirlik \& M Meisner, M.E. Sharpe, New York, pp. 152-168.

White, M \& Epston, D 1990, Narrative Means to Therapeutic Ends, W.W. Norton \& Company, New York.

Whyte, M 1988a, 'Evolutionary Changes in Chinese Culture', Transformations: Comparative Study of Social Transformations, pp. 1-22.

Whyte, M 1988b, 'Evolutionary Changes in Chinese Culture', Transformations: Comparative Study of Social Transformations, vol. 14, pp. 1-22.

Wiles, R 2013, What are Qualitative Research Ethics, Bloomsbury Academic, Cornwall.

Wilson, K 1993, 'Thinking about the Ethics of Fieldwork', in Fieldwork in Developing Countries, eds S Devereux \& J Hoddinott, Lynne Rienner Publishers, Colorado.

Wilson, M 2003, 'Thoughts on the History of Sexuality', William and Mary Quarterly, vol. 60, no. 1, pp. 193-196.

Wilson, S 2009, Remade in China: Foreign Investors and Institutional Change in China, Oxford University Press, Oxford.

Withington, J 2008, A Disastrous History of the World: Chronicles of War, Earthquake, Plague and Famine, Hachette Digital, London.

Wong, J \& Ding, L 2002, China's Economy into the New Century: Structural Issues and Problems, Singapore University Press, Singapore.

Wong, L 2011, 'Chinese Migrant Workers: Rights Attainment Deficits, Rights Consciousness and Personal Strategies', The China Quarterly, vol. 208, pp. 870-892.

The World Bank, 2017. Available from: $<$ http://www.worldbank.org/en/country/china/overview>. [20 April 2017].

Woronov, TE 2016, "Model Consumers': Beauty Bloggers, Everyday Experts, and Governmentality in Urban China', in New Mentalities of Government in China, eds D Bray \& E Jeffreys, Routledge, New York, pp. 204-222.

Wu, B 2011, Improving Socialist Legal System with Chinese Characteristics on a New Starting Point, The People's Congress Journal, Beijing

Wu, C 2016, 'Introduction', in Mapping China: Peasants, Migrant Workers and Informal Labor, ed. C Wu, Koninklijke Brill, The Netherlands, pp. 1-6.

Wu, X 2011, The Household Registration System and Rural-Urban Education Inequality in Contemporary China, II - 735, Population Studies Center, University of Michigan.

Wu, X \& Treiman, D 2004, 'The Household Registration System and Social Stratification in China: 1955 - 1996', Demography, vol. 41, no. 2, pp. 363-384.

Xiaogang 2016, 'It's a Worry: Chinese Doesn't Read', Philippine World News, 18 March, 2016[23 July, 2016].

Xiaoyong 1999, 'Burang Tigao Suzhi (Not Allowing to Improve Quality)', Nanfang Zhoumo (Southern Weekend).

Xinhua 2008, Overseas Chinese in Germany protest against biased media coverage in Xinhua, ed.^eds 20 April, 2008. 
Xu, F 2009, 'Governing China's Peasant Migrants: Building Xiaokang Socialism and Harmonious Society', in China's Governmentalities: Governing Change, Changing Government, ed. E Jeffreys, Routledge, New York, pp. 38-62.

$\mathrm{Xu}, \mathrm{Y}$ 2013, 'Labor Non-Governmental Organizations in China: Mobilizing Rural Migrant Workers', Journal of Industral Relations, vol. 55, no. 2, pp. 243-259.

Yan, H 2003, 'Neoliberal Governmentality and Neohumanism: Organizing Suzhi/Value Flow through Labor Recruitment Networks', Cultural Anthropology, vol. 18, no. 4, pp. 493523.

Yan, H 2008, New Masters, New Servants: Migration, Development, and Women Workers in China, Duke University Press, London.

Yang, M 1978, Chinese Social Structure: A Historical Study, 2nd edn, The National Book Company, Taipei.

Yao, X \& Zhao, Y 2010, Chinese Religion: A Contextual Approach, Continuum International Publishing Group, New York.

Yip, B 2006, 'Privatisation', in Critical Issues in Contemporary China, ed. C Tubilewicz, Routledge, New York, pp. 49-78.

Yuan, L \& Wen, H 2014, 'Confucius (551-479 BC)', in The Oxford Handbook of Process Philosophy and Organization Studies, eds J Helin, T Hernes, D Hjorth \& R Holt, Oxford University Press, Oxford, pp. 48-63.

Yueh, L 2011, Enterprising China: Business, Economic, and Legal Developments Since 1979, Oxford University Press, Oxford.

Yutang, L 1936, A History of the Press and Public Opinion in China, University of Chicago Press, Chicago.

Zang, X 2011, 'Government and Changing State-Society Relations', in Understanding Chinese Society, ed. X Zang, Routledge, New York, pp. 170-182.

Zeng, M 1989, 'Guangxi Renkou De Wenhua Suzhi Yu Shangpin Shengchan De Guanxi (The Relationship between the Cultural Quality of Guangxi's Population and Commodity Production)', in Zhongguo Xinnanbu Renkou Xianzhuan Yanjiu (Studies of the Present Situation of China's Southwestern Population), ed. YPCOaYPRCfPD Strategies, Yunnan Renmin Chubanshe, Kunming, pp. 165-172.

Zhang, D, Li, X \& Xue, J 2015, 'Education Inequality between Rural and Urban Areas of the People's Republic of China, Migrants' Children Education, and Some Implications', Asian Development Review, vol. 32, no. 1, pp. 196-224.

Zhang, J 2014, The Tradition and Modern Transition of Chinese Law, Springer.

Zhang, Q 2015, An Introduction to Chinese History and Culture, Springer, New York.

Zhang, Y 2014, 'The Idea of Order in Ancient Chinese Political Thought: A Wightian Exploration ', International Affairs, vol. 90, no. 1, pp. 167-183.

Zhongguo zhigong zhangkuang diaocha (China personnel executive survey) 1996, Xiyuan Chuanshe, Beijing.

Zhou, Y 2001, 21 Shìjì zhōngguó liăng dà zhīzhù: Kējì jiàoyù huà yǔ jiàoyù kējì huà (China's Two Pillars in the Twenty-First Century : Science and Technological Education), Fújiàn jiàoyù chūbăn shè (Fujian Education Press), Fuzhou.

Zhu, Y, Warner, M \& Feng, T 2011, 'Employment Relations "with Chinese Characteristics": The Role of Trade Unions in China', International Labour Review, vol. 150, no. 1-2, pp. 127-143. 